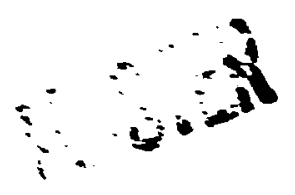

\title{
Pressure Vessel Fracture Studies Pertaining to a PWR LOCA-ECC Thermal Shock: Experiments TSE-3 and TSE -4 and Update of TSE-1 and TSE-2 Analysis
}

\author{
R. D. Cheverton \\ S. E. Bolt
}


ORNL 'TTREG-2:

Dist. Categor: IRC-5

Coatract No. $5-7405-e n g-26$

Engineering Technolog: Division

PRESSLRE IESSEL FRACTLRE STLDIES PERTAINING, TO A PSR LOCA-ECC THERYHL SHOCR: EXPERIYENTS TSE-3 AND TSE-4 AND LPDATE OF TSE-1 AND TSE-2 ALILYSIS

R. D. Cheverton S. F. Bolt

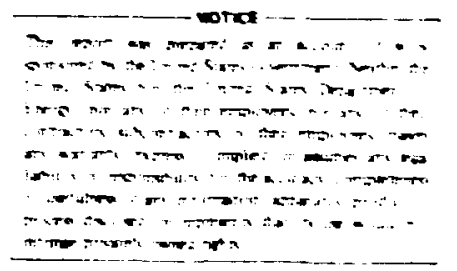

Yanuscript Completed - Noveaber 4, 1977 Date Published - Deceriber 1977

Prepared for the

I.S. Tuclear Regulatory Cownission

office of Nuclear Regulacory Research

rinder Interageacy Agreements ERDA 40-550-75 and 40-551-75

Prepared by the

PAK RIDGE NATIONAL LABRRATORY

nak Ridge, Tennessee 37839

operated by

INION CARBIDE CORPORATION

Sor the

DEPARTMENT OF ENERGY 
ForduRd $\ldots \ldots \ldots \ldots \ldots \ldots \ldots \ldots \ldots \ldots \ldots \ldots \ldots \ldots \ldots \ldots \ldots \ldots \ldots \ldots \ldots \ldots$, v

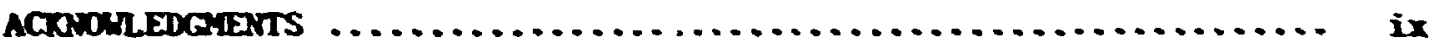

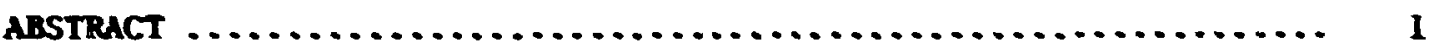

1. ENTRODLCTION AND SLARTY $\ldots \ldots \ldots \ldots \ldots \ldots \ldots \ldots \ldots \ldots \ldots \ldots \ldots \ldots$ I

2. ANALYSIS OF THE PUR AND ITS INFLLENCE ON TRE EXPERIGANAL

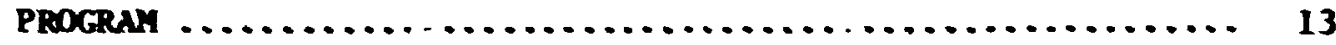

3. SYNOPSIS OF EXPER IMENTAL TECFNIQUES AND PFOCEXRES $\ldots \ldots \ldots \ldots .22$

4. THERYAL SHOCK EXPERTIENT TSE-1 $\ldots \ldots \ldots \ldots \ldots \ldots \ldots \ldots \ldots \ldots \ldots \ldots$ 27

5. THERMLL SHOCR EXPERIMEAT TSE-2 $\ldots \ldots \ldots \ldots \ldots \ldots \ldots \ldots \ldots \ldots \ldots \ldots, 28$

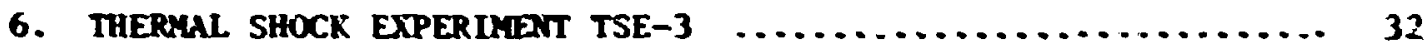

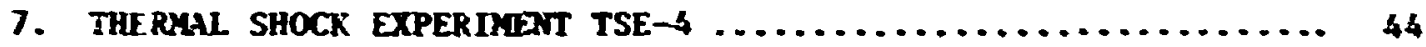

8. FRACTOGRAPHIC EXAMMUTION OF THE FRACTURE SURFACES DEVELOPED DLRIXE TSE-1, TSE-3, and TSE-4 ............ 56

8.1 Thermal Shock Experiments TSE-1 and TSE-3 ........... 59

8.2 Thermal Shock Experiment TSE-4 $\ldots \ldots \ldots \ldots \ldots \ldots \ldots \ldots \ldots \ldots \ldots, 60$

8.3 Discussion and Sumary $\ldots \ldots \ldots \ldots \ldots \ldots \ldots \ldots \ldots \ldots \ldots \ldots . \ldots 9$

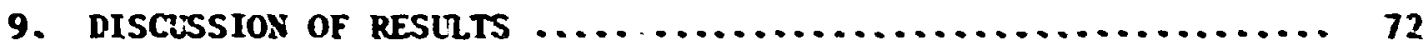

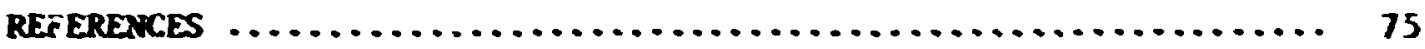

APPEXDIX A. THERALL-HYDRALLIC EXPERIYLATS YOR IXVESTIGATING DEGREE OF SMMLTRY IN OCEENCHIXG THE 533-an-OD

THERMAL SHOCX TEST SPECIIENS $\ldots \ldots \ldots \ldots \ldots \ldots \ldots \ldots \ldots$ 77

APPENDIX B. INSTRUAEMTATION FOR DETECTING CRACK PROPAGATION .... 79

APPENDIX C. THERYAL AND FRACTURE MECHANICS DÁTA PERTAINING

TO TSE-3 AND TSE $-4 \ldots \ldots \ldots \ldots \ldots \ldots \ldots \ldots \ldots \ldots \ldots \ldots \ldots 121$ 


\section{FORETORD}

The work reported here was performed at Oak Ridge National Laborator; (ORIL) under sponsorship of the U.S. Nuclear Regulatory Comission"s (NRC) Heavy-Section Steei Techerlogy (HSST) Progran, which is direcred br ORth. The program is conducted as part of the ORNL. Pressure Vessel Tecianology Progran, of which G. D. inituan is manager. The manager for the WiC is E. K. Lyan.

This report is de:isjated Heavy-Section Steel Techaology Program

Technical Report No. 46. Prior reports in this series are listed below.

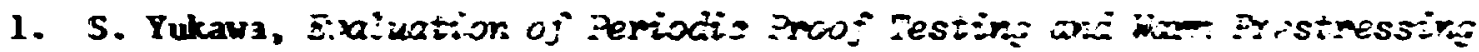
Procecionss for the $\therefore$ ear Pecetor iesse is, HSSTP-TR-1, General Electric Company, Schenectad;, A.S. (July 1, 1959).

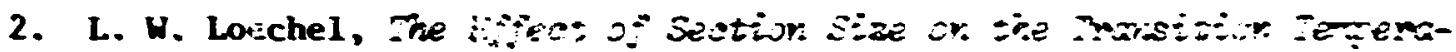
ine in Biee?, MCR-o $\$-139$, Martin Marietca Corporation, Lanver, Colo. (Xov. 20, 1969).

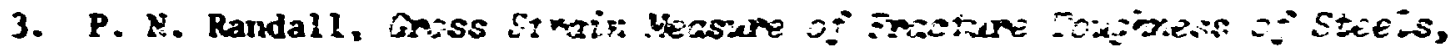
HSSTP-TR-3, TRU Systeas Grouf, Redondo Beach, Calif. (ANk. 1, 1969).

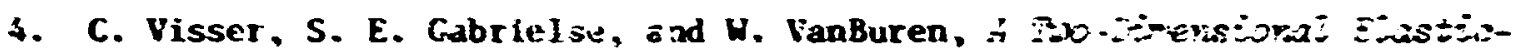

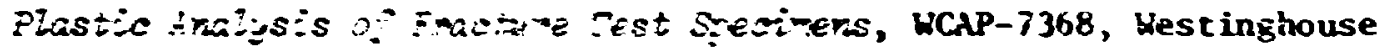
Electric Corporation, PNF Systeas Division, Pittsburgh. Pa. (October 1969).

5. T. R. Mager, F. "1. Thirass, and $i$. S. Hazelton, Exaidition 3; Zirean

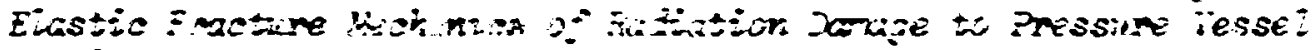
Stcels, d AP-7328 (Ro:.), Westinghouse Electric Corporation, PWR Systems Division, Paisbur, Pa. (Jctober 1969).

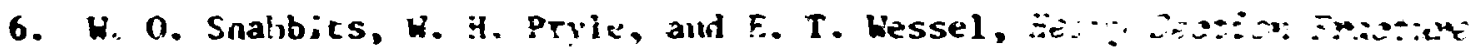

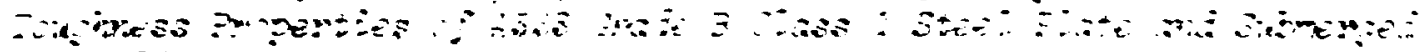

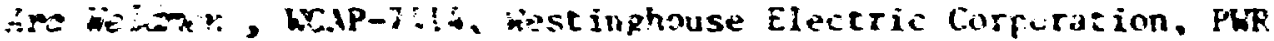
System Division, Pix: :iur \&

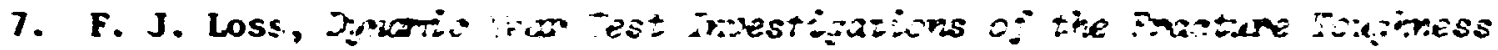

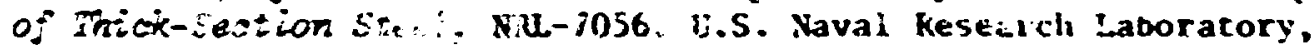
Hashington, D.C. $(4,3,34,1970)$.

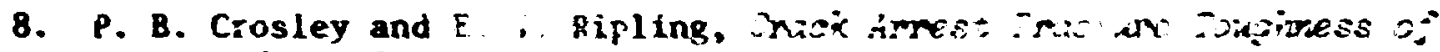

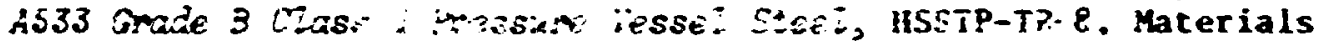
Research Loborator, Inc., Gidemrood, ill. (March 19:0?.

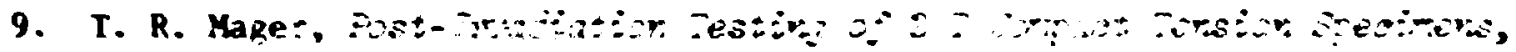
WCPP-756i, Werting wure Electric Corporation, ThR Systerri Division. Pittsburgh. Pa. (A igus: 137i.).

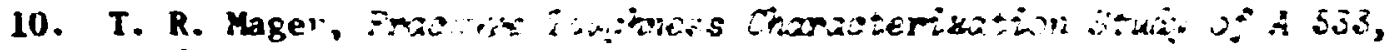

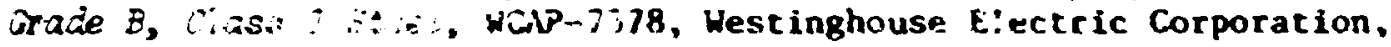
PUR Systems Divisici, Pi:tsburgh, Pa. (October 19:0). 
11. T. R. Kager, Dotch Preparcioion in Capact Fension Specimens, Ucap7579, Eestinghouse Electric Corporation, PR Systes Division. Pittsburgh, Pa. (Novenber 1970).

12. N. Levy and P. V. Marcal, Three Dimensional Elastic-PLastio Stress and Struin Analysis for Fracture Meiraries, Phase I: Simole Flawei Syecimens, uSSTP-TR-12, Rrown Daiversity, Providence, R.I. (Dece-ber 1970).

13. H. C. Shabbits, Dynamic Fractare Foughness Properties of Hexvy Section A533 Crade 3, Class 1 Steel Piate, WCAP-7623, Westinghouse Electric Corporation, PWR Systems Division, Pittsburgh, Pa. (December 1970).

14. P. I Randall, Gross Strain Track Tolerance of A533-B Steel, HSSTPTR-14, Trd Systems Group, Redondo Beach, Calif. (Hay 1, 1971).

15. H. T. Corten and R. H. Sailors, Relationship Setween Anterial Fracture

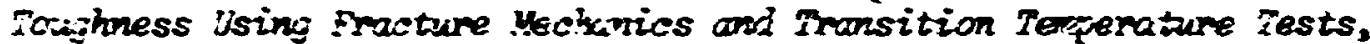
TSNM Report 346, Iniversity of I11inois, Urbana, Ill. (Aug. 1, 1971).

16. T. R. Mager and V. J. Mcloughlin, The Effect of an Bwiroment of wigh Temperature Primary Made puctecr Reactor later and the Fatigue rack orowti Characteristics of $\mathrm{A} 533$ wrade $B$ C?ass 1 Plate and ieidnent Haterial, WCAP-7776, Westinghouse Electric Corporaticn, PWR Systens Division, Pittsburgh, Pa. (October 1971).

17. N. Levy and P. V. Marcal, Three-Iingnsional Elastic-Plastic Stress and Strain Anaiysis for Fracture Mecracicics, Phase II: improved Modeting, HSSTP-TR-17, Brown Eniversity, Providence, R.I. (November 1971).

18. S. C. Grigory, Six-Inch-Thich Fined Tensile Tests, First Techrical Sumar, Report, Longitudinal Specinens 7 through 7, HSSTP-TR-18, Southwest Research Institute, San Antonio, Tex. (June 1972).

19. P. N. Randall, Efjects of Strain Gratients on tine Arass Strain Crack Folerance of A 533-B Stee $i$, HSSTP-TR-19. TRH Systens Group, Redondo Beach, Cal if. (Hay 1, 1972).

20. S. C. Grigory, Tests of Six-Inch-Thick Flawed Tensile Shecimens, Secind Technical Simmari Report, Transverse Specinens humbers 8 through 10, Weided Specinems mmbers 11 through 13, HSSTP-TR-20, Southwest Research Instituce, San Antonio, Tex. (June 1972).

21. L. A. James and J. A. Williams, Beary, Section Steel TechnoLogy Propram Techrical Report No. 21, The Effect of Tempe: uture and Meutron Irradiation ufon the Fatigue-Crack Propagation Behavior of ASTY A533, Grade B, Class i Steel, HEDL-TME-72-132, Hanford Engineering Dev . opwent Laboratery, Richland, Wash. (Septewber 1972).

22. S. C. Grigory, Tests of Six-Inch-Thick Flaved Tensile Srecinens, Thind Tochiosal Sumary Ruport, Longit:dinal Specinens Hubers 14 througin 16, inflimed Specimen mober 17, HSSTP-TR-22, Southwest Research Institute, San Antonio, Tex. (October 1972).

23. S. C. Grigory, Tests of Six-Inch-Thick Flawed Tensile Specinens, Fourth Technical Sumary Report, Tests of One-Inch-Thick Flowed Tensile Specimens for Sise Effect Zualuation, HSSTP-TR-23, Southwest Research Institute, San Antonio, Tex. (June 1973). 
24. S. P. Ying and i. C. Grigory, Fests of Six-Inch-Thick Tewile Specimens, Fifth Technicai Sumeny Report, Acoustic Bnission Monitoring of One-inch and Six-In-h-Thick Tensile Specinens, HSSTP-TR-24, Southwest Research Institute, San Antonio, Tex. (Kovenber 1972).

25. R. W. Dexby et al., Test of 6-írcin-thicik Pnessire VesseIs, Semies 1: Intemediate Fest Vesse is $\mathrm{V}-1$ ard $\mathrm{V}-2$, ORKL-4895, Oak Ridge National Laboratory, Dak Ridge, Tenn. (February 1974).

26. W. J. Stelman and R. G. Bergrren, Radiation Strughthening and Bnorittiement in Neavy Section Piates and Weids, ORML-4871 (June 1973).

27. P. B. Crosley and E. J. Ripling, Crack Arrest in an increasing $K-$ Field, HSSTP-TR-27, Macerials Research Laboratory, Glemood, I11. (January 1973).

28. P. V. Marcal, P. M. Stuart, and R. S. Bertes, Elastic-Flastic Behavior of a Longitudinal and Seani-Elliptical Track in a Thick Pressure Vessel, Brown University, Providence, R.I. (June 1973).

29. H. J. Stelman, Characterization of HSST Plate 02 (in preparation).

30. D. A. Canonico, Characterization of Heavy Section Weldaents in Pressure Vessel Steels (in preparation).

31. J. A. Willians, The Imadiation and Tenperature iepenaience of Terisile and Frovture Properties of ASTY A533, Grade B, Class 1 Steel Plate cancieidient, HEDL-TIE 73-75, Hanford Englneering Developent Laboratory, Richland, Hash. (August 1973).

32. J. M. Steichen and J. A. Willians, High Strain Rate Tensile Pracertive of I'madiatei ASTM A533 Graie B Class 1 Pressure Vessel Steel, Hanford Engincering Development Laboratory, Richland, Wash. (July 1973).

33. P. C. Riccardella and J. L. Swedlow, A Cambinea sinaiyticai-Experimenta: Irasture Study, WCAP-8224, Mestinghouse Electric Corporation, PUR Systens Division, Pitesburgh, Pa. (October 1973).

34. R. J. Podlasek and R. J. Elber, Final Report on Irvestigation of Mode III i rack Extension in Reactor Pipirg, Batcelle Columbus Laboratories. Columbus, Ohio (Kay 1974).

35. i. R. Hager et al., Intsrin Report on the Effect of Lou Frequencies in tice fatione Crack orowth Characteristics of A533 Grade B Class I

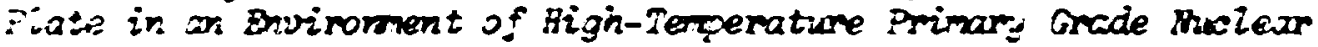
Feactor water, WCAP-8256, West inghouse Electric Corporation, Pittsburgh, Pa. (December 1973).

36. I. A. HIllians, The Irraciiated Fracture 7oughness of ASTM AS33, Grade $\because$ Cass 1 Stee $I$ Measured vith a Pour Inch Thick Compact Tension $\because$ :-3-7er, HEDL-TME 75-10, Hanford Engineering Development Laboratory, Richland. Wash. (January 1975).

37. K. H. Bryan et al., Test of 6-Incin-Fhick Pressicre iesseis, Series 2: Nat ional Laboratory, Oak Ridge, Tenn. (November 1975). 
38. T. K. Mager, S. E. Yanichko, and L. R. Singer, Jajigien Fodiriess

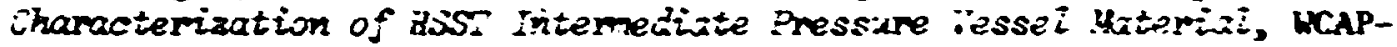
8456, Westinghouse Electric Corporation, Pittsburgh, Pa. (Decenber 1974).

39. J. G. Merkle, G. D. Whitman, and R. H. Bryan, An Evaluation of the HSST Program Intemediate Pressume Vessel Tests in Tems of LightHater Reactor Pressure Vessel Safety, ORM/TH-5090, Oak Ridge Wational Laboratory, Oak kidge, Tean. (November 1975).

40. J. G. Merkle et al., Test of 6-Inch-Mhicix Pressure Vessels. Series 3: Intemediate Test Vessel $V-7$, ORen/NUREG-1, Oak Ridge National Laboratory, Oak Ridge, Tenn. (August 1976).

41. J. A. Davidson, L. J. Ceschini, R. P. Shogan, and G. V. Rao, the Irracizated Dynutic Fracture Toughness of ASTX A533, Grade B, Fass 1 Steel Plate and Suimerged are Weldment, WCAP-8775, Westinghouse Electric Corporation, Pittsburgh, Pa. (October 1976).

42. R. D. Theverton, Pressure Vesse? Practure Studies Pertaining to a PiVR iNh-Ei: Thermai Shock: Experiments $75 E-1$ and $75 E-E$, ORN/NLTEC/TH-3i. Dak Ridge Kational Laboratory, Oak Ridge, Tenn. (September 1976).

43. J. G. Merkle, P. P. Holz, G. C. Robinson, and J. E. Snith, Fest of :-

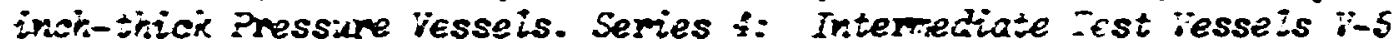
coni $\because-9$ ith Inside . Hoaz'e Eracks, ORR/MuREG-7, Oak Ridge National Laboratory, Oak Ridge, Tenn. (August 1977).

44. J. A. Williams, The Ductiie Fracture Toughness of Heavy Section Steel Plate, Hanford Engineering Development Laboratory, Richland, Wash. (in preparation).

45. R. H. Bryan, J. G. Merkle, and G. C. Snith, Test of 6-in.-thick Pressure Vessels. Series 3: Internediate Test Vessel V-7A under Sustained Loading, Oak Ridge National Laboracory, Oak Ridge, Tenn. (in preparation).

Copies of these reports ay be obtained from Laboratory Records Department, Oak Ridge National Laboratory, P.0. Box X, Oak Ridge, TN 37830. 


\section{ACKTOHLEDQIENTS}

The authors wish to acknowledge contributions made to the Thermal Shock Program by J. E. Smith and T. Y. Cate (test specimen instrumentation and data retrieval); T. A. King and R. Ssith, Jr. (installation of test specimen instrumentation); and P. P. Holz (flau development). D. A. Canonico and $W$. J. Stelzean vere responsible for obtaining materials propercy data, and Canonico and R. S. Crouse conducted the fractographic exapinations. Shafik Iskander and his associates were responsible for development of computational techniques and for performing the many required achine computations.

kany helpful suggestions were contributed by the Thermal Shock Review Comittee (E. R. Lynn, Chairman) and its consultants; by R. H. Bryan, J. G. Kerkle, G. C. Robinson, and G. C. Snith, all wembers of the HSST Progran; and by G. D. Whicman, HSST Progran Manager. 
PRESSURE VESSEL FRACTURE STUDIES PERTAINING TO A PUR LOCA-ECC IAEReUL SHOCR: EXPERIMENTS TSE-3 AVD TSE-4 AND UPOATE OF TSE-1 AND TSE-2 ARALYSIS

R. D. Cheverton S. E. Bolt

\section{ABSTRACT}

The LCCA-ECC Thernal Shock Progran was established to investigate the potential for flaw propagation in pressurizedvater reactor (PWR) vessels during injection of energency core coolant following a loss-of-coolant accilant Studies thus far have included fracture mechinics analyses of typical PWRs, the design and construction of a thermal shock test facilicy, deternination of material properties for test specinens, and four thermal shock experimeats with 0.53-a-0D (21-in.) by 0.15-m-wall (6-ia.) cylindrical test specinens.

The PWR calculations indicated that, under some circumstances, crack propagation could be expected and that, in the absence of warm prestressing, long flaus aight propagate wore than halfway through the wall. However, if warn prestressing is assuwed to be eifective, flaws with a fractional depth greater than 0.2 could not initiate. If it is further assued that the arrest toughness is equal to $K_{I R}$, the maximum penetration would be 0.35 . In view of these results, the Thermal Shock Progran was oriented toward determining the validity of linear elastic fracture mechanics for shallow cracks under LOCA-ECC thermal shock conditions, with a subsequent effort on demonstrating warm prestressing under basically the sane conditions.

In the first experiment, initiation was noi expected and did not occur, although there was a small arount of subcritical crack growth. In the second experiment, initiation of a semicircular flaw took place as expected; the final length Aloug the surface was about four times the initial length, but there was no radial growth. The third and fourth experiments were similar, and the long axial flaw initiated in good agreezent vith predictions.

\section{INTRODUCTION AND SUMAYRY}

In the event of a loss-of-coolant accident (LOCA) in a light-water reactor, an ewergency core-cooling system (ECCS) is ackivated that injects cold sacer into the reactor vessel to maintain coolant for the core. As shown schematically in Fig. 1, the ECCS coolant enters the vessel chrough the main coolant lines and passes over the inner surface of the 


\section{BLANK PAGE}




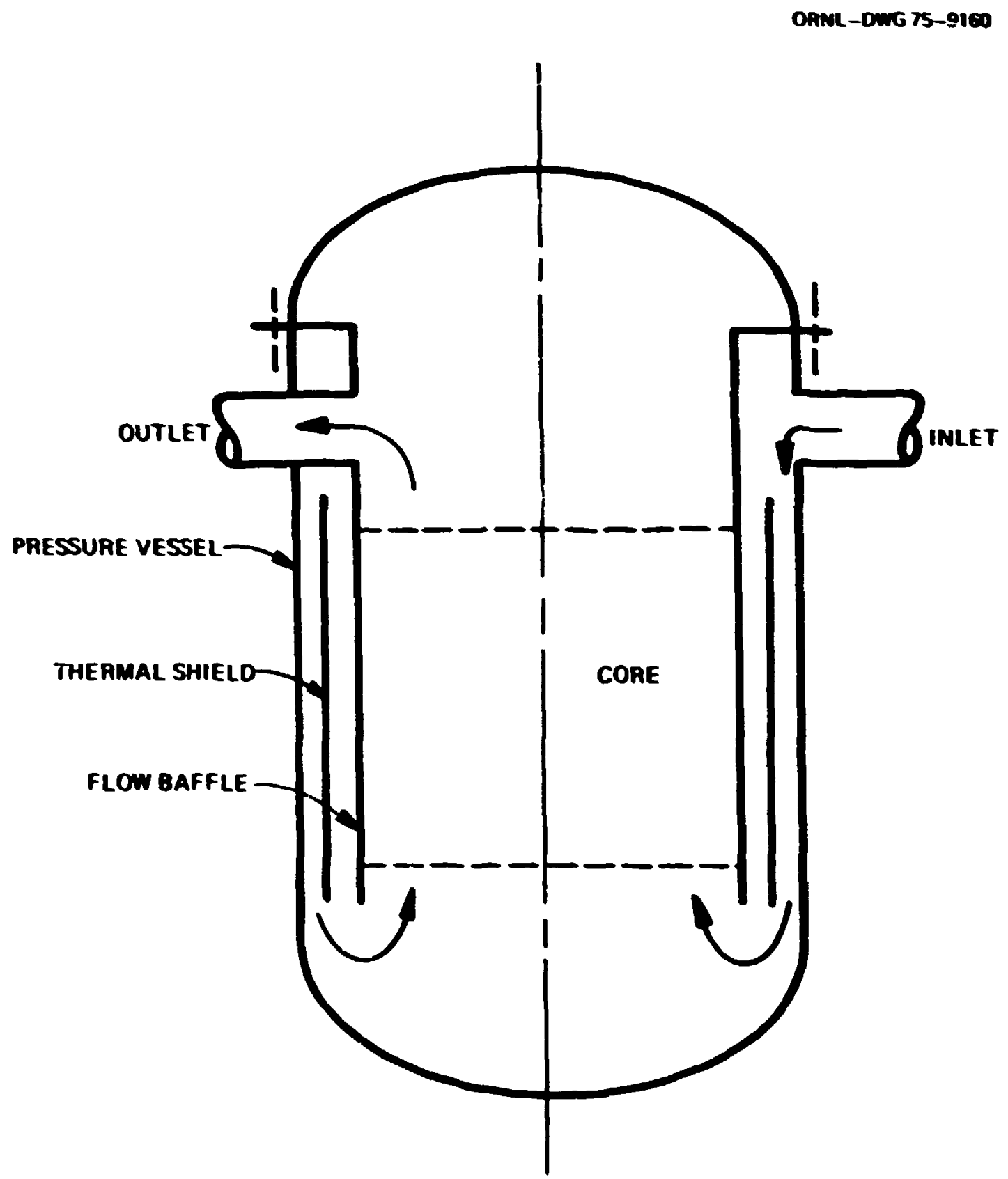

Fig. 1. Schematic of typical PWR showing flow path for emergency core coolant. 
vessel wall prior to reaching the core. Thus, a portion of the initially hot vessel is quenched by the emergency core coolant. As shown in Fig. 2 , this quenching action, or thermal shock, results in rather steep positive temperature gradients through the wall and thus high tensile stresses in the inner portion of the vessel wall.

The reduction in temperature ard the high fast-neutron fluence that accumulates over many years of reactor oferation tend to reduce the fracture toughness $\left(K_{I c}\right)$ of the vessel material. Because of the sensitivity of fracture toughness to temperature and fluence, as shown in fig. 3, and the positive gradient in temperature and the attenuation or the fluence, as show in Fig. 2, there is a net positive gradient in toughness in the vessel rall, as shown in Fig. 4.

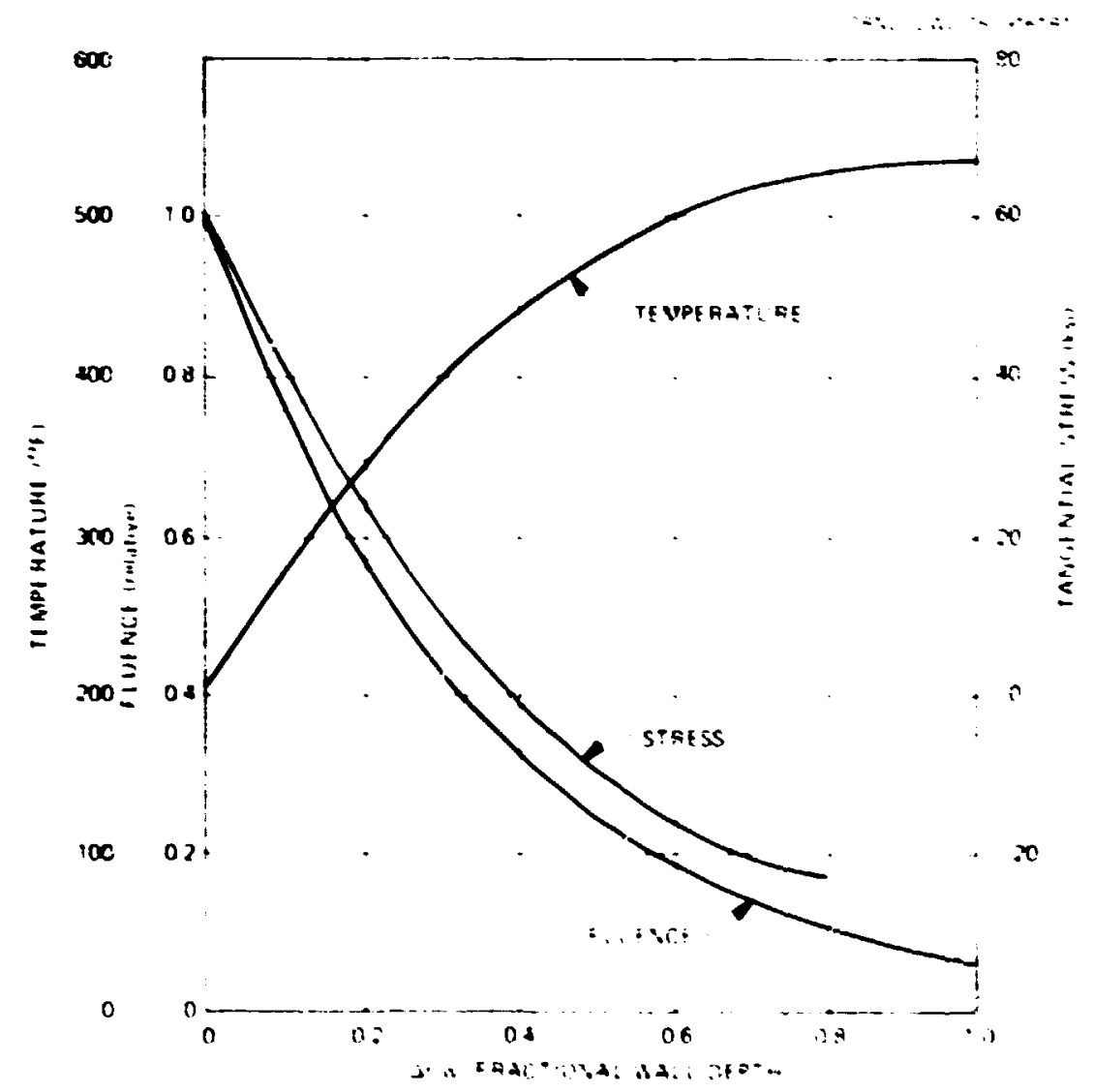

FiB. 2. Typical fast-neutron fluence attentuation and LOCA-ECC thermal shock temperature and stress distributions in a PWR ( 1 ksi = $6.805 \mathrm{MPa}$ ). 


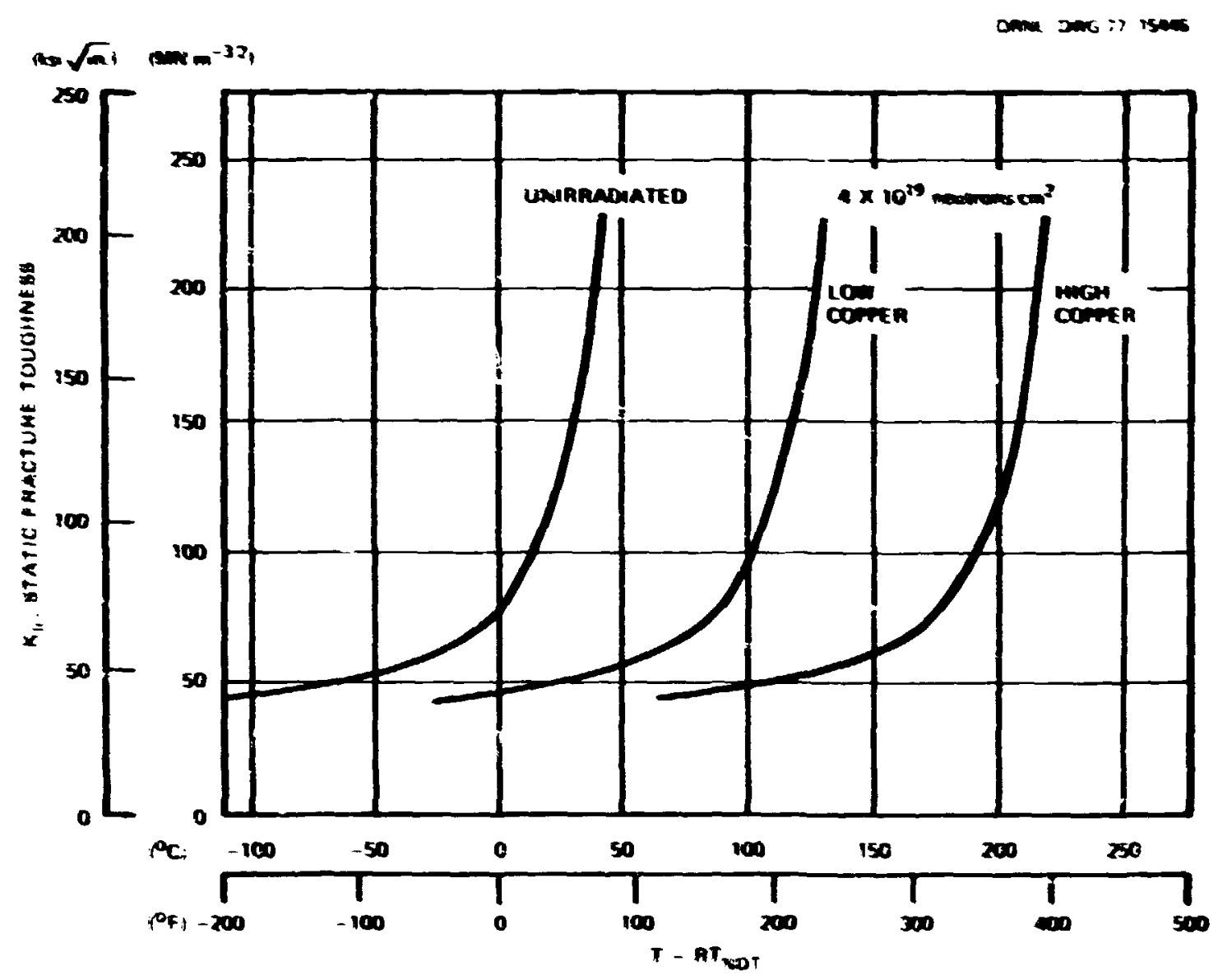

Fig- 3. Static fracture coughness vs $T-R_{\mathbf{X p T}}$ for no fluence and a finence of $4 \times 10^{13}$ neuicons/ca' considering high and lou copper concentrations. Data used in LOCA-ECC thermal shock studies for PwR analysis (Refs. 4, 6, 7).

If there is a flaw (crack) on the inner surface (below the cladding) of the vessel wall, the high, thermally induced tensile stress will result in an appreciable stress-intensity factor $\left(R_{1}\right)$ at the tip of the flaw. This is illustrated in Fig. I for long axial and continuous circunferential cracks. The combined effect of high stress-intensity factor and low fracture toughness ay result in propagation of the preeristing flaw. However, the steep positive gradient in toughness, as show in Fig. 4, teads to provide a mechanisa for arresting the crack.

The tendency for fracture to occur also depends on the inpurity content (prinarily copper) of the vessel aterial because of the effect that inpurities have on the reduction in toughness due to neutron irradiation. 


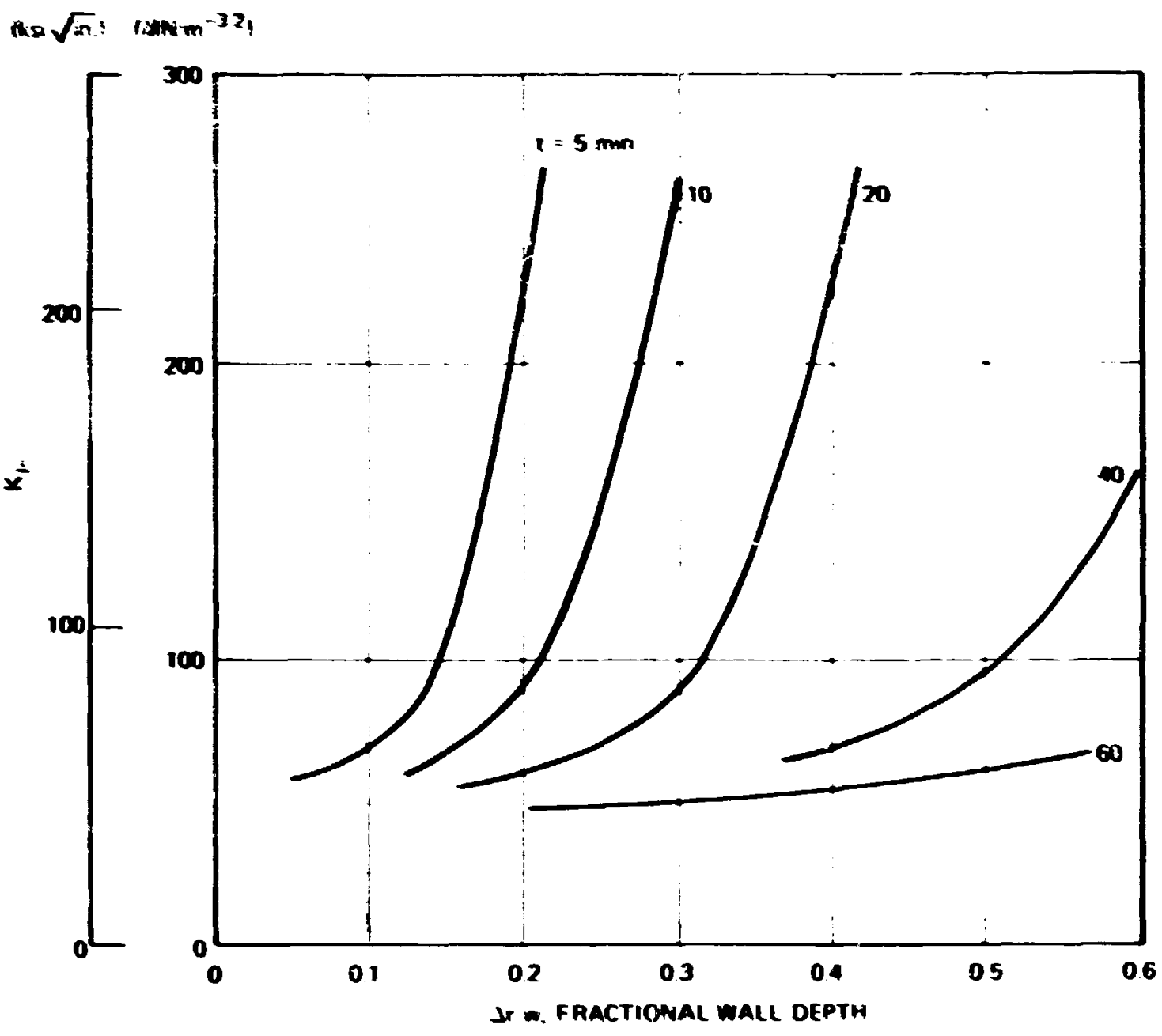

Fig. 4. RIc vs fractional wall depth $(\Delta \mathrm{r} / \mathrm{v})$ for the reference calculational wodel with high coppor concentraion.

This effect is illustrated in Fig. 3 by showing the fracture toughness vs temperacure curves for low and high-copper materials with a waxim expected Inner-surface fluence of $4 \times 10^{39}$ neutrons $/ \mathrm{cm}^{2}$.

Another factor that influences crack propagation is wara prestressing, a phenomenon that may prove to be very important in limiting the extent of crack propagation.

The need to investigate crack propagation and arrest in connection with an ECC theral shock depends upon the 1 ijelihood of crack propagation and the state of the art of calculational cechniques for predicting crack 


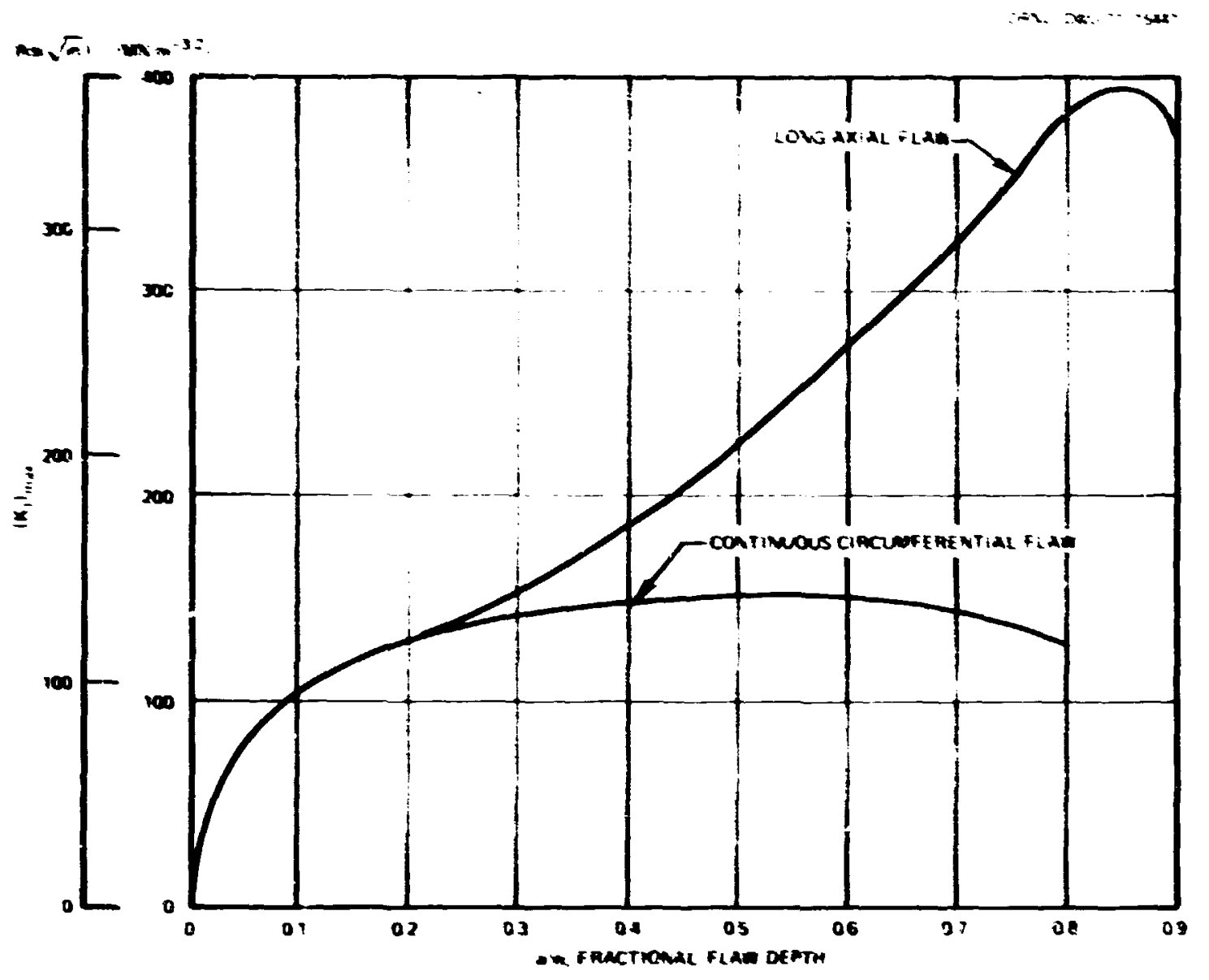

Fi8. 5. ( $\left.R_{I}\right)_{\max }$ (aximin with respect to tine) us a/v for $l_{\text {ong }}$ axial and continuous circunferential flaws in the reference calculational model.

behavior. There was concern regarding the accuracy of linear elastic fracture mechanics in a thermal shock situation - not because thermal stresses per se are unique, but because the stress field (nearly equal biaxial stresses) and the very steep gradients in temperature and stress comprise a unique situation that ay influence fracture behavior. Also, preliniary calculations indicated that, under some circunstances, the probability of crack propagation in PWRs during a LCCA-ECC incident was high. For these reasons, the LOCA-ECC Theraal Shock Program was established, and it was deened advisable to conduct experinents that would reveal the behavior of PWR vessels under specific thermal shock conditions. The particular LOCAbOC event being considered at this tine is the double-ended pipe break, for 
whic! the primry-syste pressure is essentially zero by the tine the thermal shock is under way.

An initial step is the thermal shock studies at Qak Ridge National Laboratory (ORRI) was to estabiish a calculational nodel for PuRs, considering both thermal and fracture mechanics aspects, and to explore the possibility of scaling from actual PUR conditions to practical experinental models. The results of this exploration indicated that dirert scaling could not be achieved because of geometric and netallurgical problems. Therefore, the objective of the studies being performed at ORML is to determine the accuracy of the calculatinal techniques for predicting crack initiation and arrest. PMR conditions are bing simulated as closely as possible in order to mininize the degree of extrapolation required in applying the techniques to actual PWRs.

Results of calculations ${ }^{\prime}$ for the PWR reference calculational wodel (RCA) indicate that PWR vessels containing a low concentration of copper impurity will not experience significant crack propagation under ECC therwal shock conditions. However, near the end of its service life, a vessel with a high concentration of copper and either a long axial crack or a continuous circunferential crack ay experience crack extension. If propagation of the crack is not liaited by warm-prestressing effects, the crack could penetrate through at least half the vessel wall thickness. Thus, a saall-scale experinent in wich a crack, in the absence of wara prestressing, would run about halfway into the wall was proposed. Considering theraal shock and =tallurgical capabilities, the test specinen required to achieve such penetration had to have an outside dianeter of 1 - (40 $\mathrm{in.}$ ) or larger. An outside dianeter of 0.99 a (39 in.) was specified, but procurement time was longer than desired. In crder to expedite the progran, it was decided to conduct experiments with two saller specirus $[0.53$ a $00(21 \mathrm{in.})]$ that would be adequate for the study of shallow cracks and that could be achined from existing forgings.

The possibility that wara prestressing aight have a significant effect in limiting crack propagation was not considered until the theral shock studies were well under way. Since that time, it has been reasoned that, If warm prestressing is as effective as presently indicated, there wili not be as ach incentive for studying propagation and arrest of deep cracks, 
which require the use of the larger test specimens. Instead, a dewonstration of warm-prestressing effects under appropriate conditions would be sufficient. It is wot clear at this time just how this aight be done. A. an initial step, vare-prestressing effects are being studied by Loss ${ }^{2}, 3$ using a three-point-loaded bean.

In order to simlate the FWR fracture echanics paraneters as closely as possible in the ORil thermal shock experiments, the test specinens were fabricated from FuR pressure vessel encerial, were given a quench-only heat treatment to reduce the toughness and increase the yield strength (simlating irradiation effects to some extent), and were subjected to thermal shocks more severe than those imposed on PWR vessels in order to further reduce the toughness and to eahance $R_{1}$; these latter two neasures vere necessary because the test specimen mterial, even in the quench-only condition, was tougher than the irradiated material.

An important aspect of the experimental progran was the deternination of fracture toughness for the test specimen aterial. Figure 6 shows the $K_{\text {Ic }}$ vs temperature curve based on measurenents of $K_{\text {Ic }}$ for the test specinen prolongations. Additional measurements are being ade for the cest specicens themselves.

Four thermal shock experimeats have been conducted with the $0.53-00$ (21-in.) specimens. The first (TSE-1) is referred to as the noninitiation experiment, because the calculated maximu $R$ ratio $\left(K_{I} / R_{I c}\right)$ was less than unity (initiation takes place when $K_{I} / K_{I c}=1$ ). The flw was a long axial crack of optim depth, and the specific aximas $K$ racio selected was the sane as that calculated for the PWR reference calculacional codel, assuning a low concentration of copper. In the second experiment (TSE-2), it was intended that sone crack extension take place, and the full thermal shock capability of the test facility was used. The fluy was an axially oriented senicircular crack with a 38-m (1.5-in.) dianeter. A sumary of cest conditions for these first two thermal shock experinents is presented in Table 1.

Acoustic-enission (AE) and crack-opening-displacenent (COD) instrurentation indicated that unstable crack growth did not take place during TSE-1. Hetallographic exanination showed sone extension, but it has been Identfled as subcritical crack grourb. 


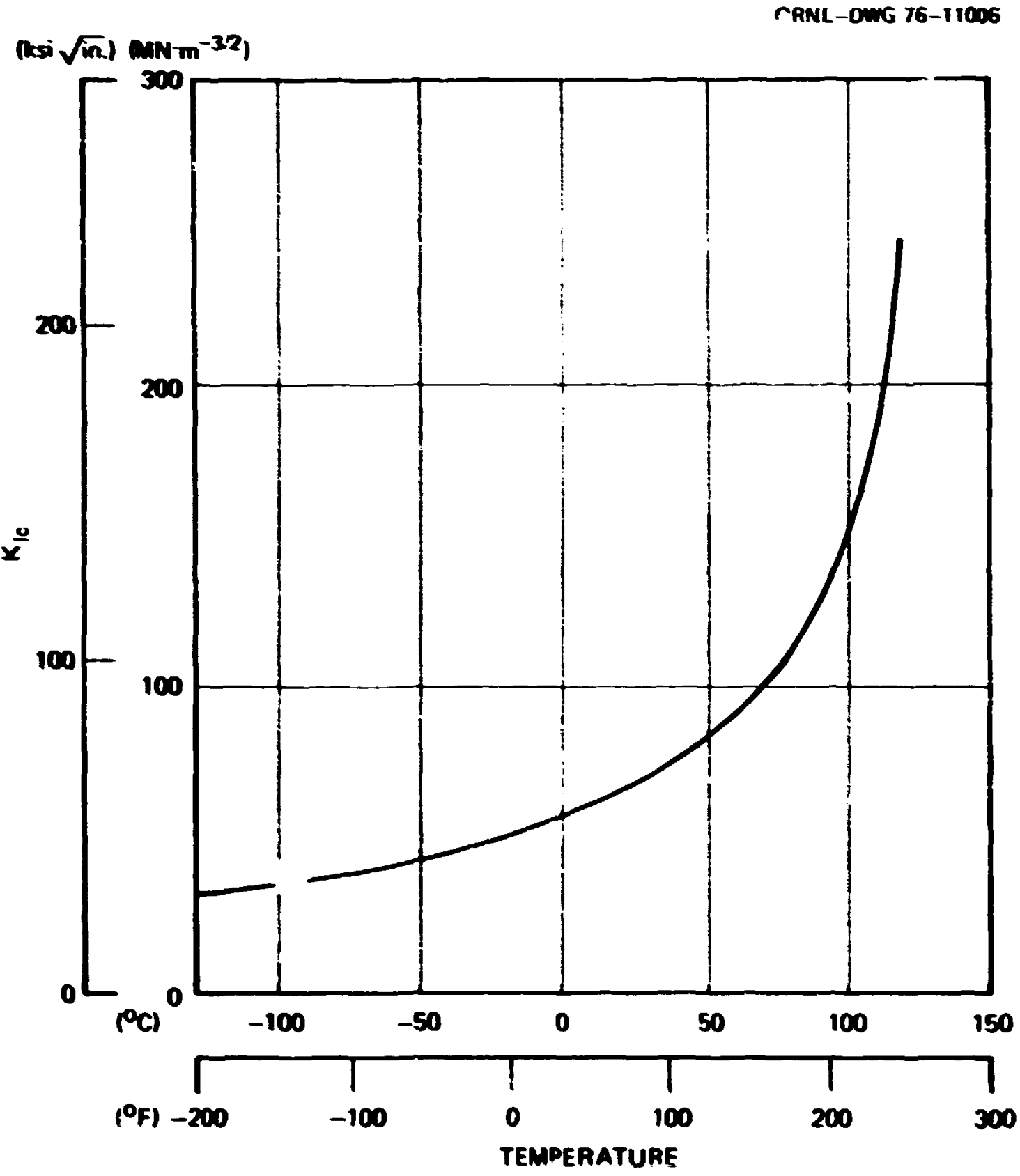

Fig. 6. Static fracture coughness curve used in analysis of theral shock experiments TSE-1, $-2,-3$, and -4 . The curve is based on data from AS33 and A508 (V-1, TSV-1, and TSV-2 prolongations) in the as-quenched condicion [quenched in water from $87 !^{\circ} \mathrm{C}\left(1600^{\circ} \mathrm{F}\right)$ ]. (See Ref. 1 for additional information.) 
Table 1. Test conditzons for TSE-1 and TSE-:

\begin{tabular}{|c|c|c|}
\hline Test conditions & TSE-1 & TSE-? \\
\hline Test specien & $T S K-1$ & TST-2 \\
\hline \multicolumn{3}{|l|}{ Test specisen diecasions, a (ir.) } \\
\hline$\infty$ & $0.53(21)$ & $0.53(21)$ \\
\hline in & $0.2+(9.5)$ & $0.2+(9.5)$ \\
\hline Leng:h & $0.91(36)$ & $0.91(36)$ \\
\hline Test sptized miterial & Ance, class ? & tios, ilass : \\
\hline Heat 1 reatarat & $\begin{array}{l}\text { luenith only from } \\
\text { a:1'C (1620\%) }\end{array}$ & 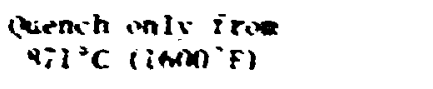 \\
\hline flat & $\begin{array}{l}\text { iune axial erack. } \\
a=11 \text { a in.s? } \\
\text { in.? }\end{array}$ & $\begin{array}{l}\text { Sequircular axial itaik. } \\
x=19-(0.25 \text { in. })\end{array}$ \\
\hline \multicolumn{3}{|l|}{ Texperarures. $=\left(C{ }^{\circ} \mathrm{F}\right)$} \\
\hline $\begin{array}{l}\text { Gall (initial) } \\
\text { jink (initial) } \\
\text { Sinix (final) }\end{array}$ & $\begin{array}{l}=88(j 50) \\
+(+0) \\
=(+5)\end{array}$ & $\begin{array}{l}-89(55: 1 \\
: 310.31 \\
19.451\end{array}$ \\
\hline cowlane & bister & 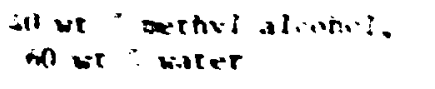 \\
\hline Coolant flow rate. ${ }^{3}$ ihr (kpa) & i9 $(260)$ & $11+(\mathrm{im})$ \\
\hline $\begin{array}{l}\text { Cowlant pressure in test section, } \\
k P a \text { (psi) }\end{array}$ & $13: n(2: 2 n)$ & $912(133)$ \\
\hline $\begin{array}{l}\text { Back-pressure orifice diameter, } \\
=0 \text { (in.) }\end{array}$ & $25.43(1.001)$ & $\$ 3.28(1.3(m)$ \\
\hline 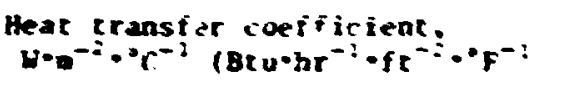 & $\because 800(-i m)$ & $\therefore 37001.10 \%$ \\
\hline$\left(K_{1} / R_{1 c}\right)_{\max }$ & n. 23 & $1.33\left(\therefore=75^{\circ}\right)$ \\
\hline $\begin{array}{l}\text { Time of occurrence of } \\
\left(\mathrm{K}_{\mathbf{I}} / \mathrm{K}_{\mathrm{Ic}}\right)_{\text {max }} \text { ain }\end{array}$ & s & 3 \\
\hline Duration of experiment, win & 30 & $3 n$ \\
\hline
\end{tabular}

In the second experinent, the $A E$ and COD instrumentation indicated axin extension of the senicircular flav in two events: first at the downstre 2 end and then at the upstrean end. The sequence of events and the varlous flaw shapes and sizes are depicted in Fig. 7. There are indications that warm prestressing restricted the axial extension and that the running-crack dymanic coughness, and thus the arrest toughness, was significantly less than the static fracture toughness.

The third experinent (TSE-3) constituted a second and wore severe theral shock to the test specimen and flaw used in TSE-1. Crack initiation 


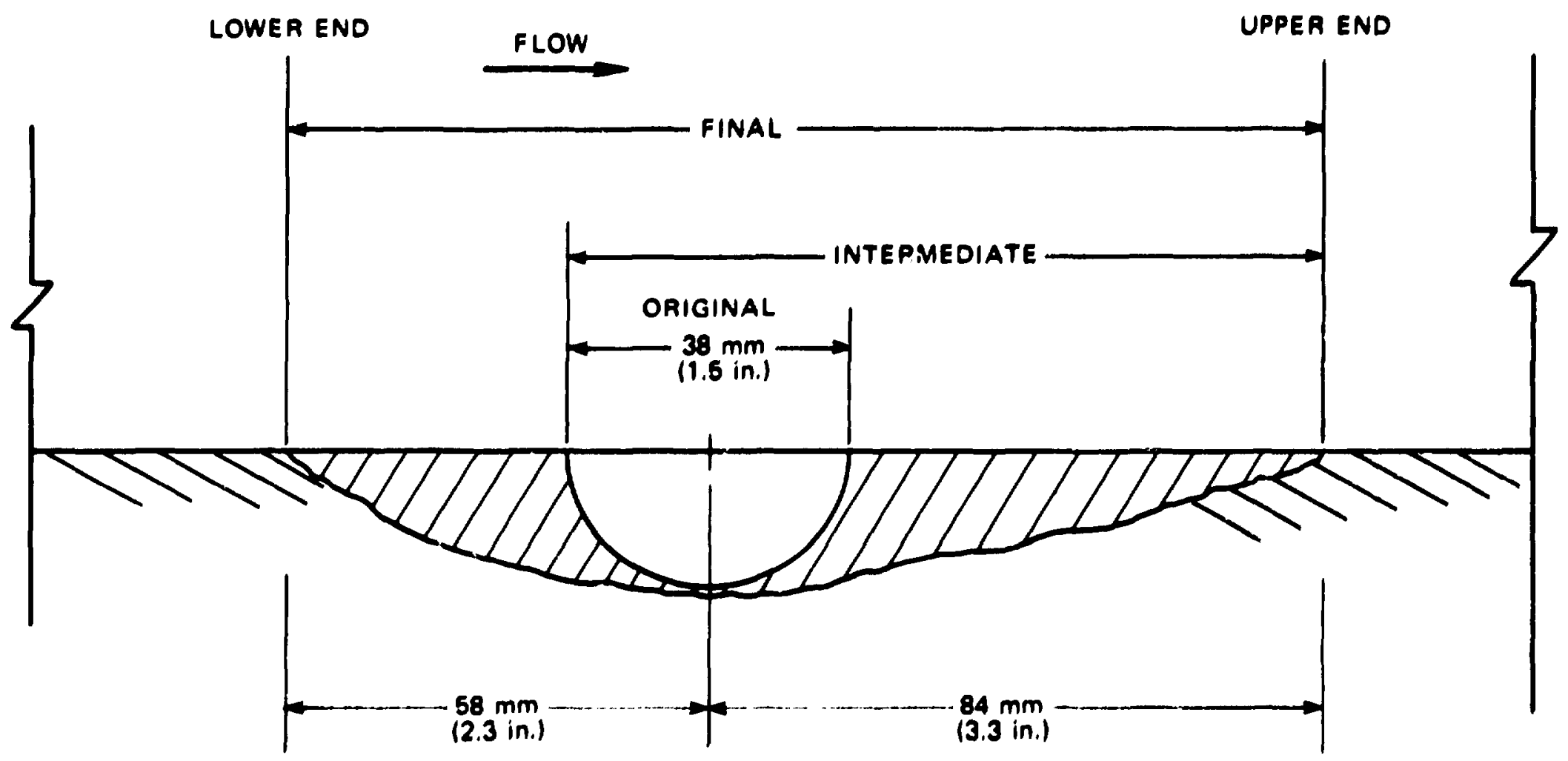

F1g. 7. Sketch of or 1ginal memicircular flaw and llaw extension in TSV-2 (TSE-2). 
ws expected and occurred; however, there were unforeseen conplications that ade interpretation of the results difficult. The fourth experinent (TSE-6) ws a repeat of TSE-3, using another test specimer (TSV-2) and a virgin flaw. Results of this experiment agree reasomably well with predictions. Test conditions for TSE-3 and TSE-4 are sumarized in Table 2.

Detailed information relating to results froe TSE-1 and TSE-2, the methods of analysis, the PUR analysis, the theraal shock test facility. test spectmen acerial properties, and data retrieval is included in Ref. 1. Experineats TSE-3 and TSE-4 are discussed in this report, along with further interpretive coments regarding TSE-1 and TSE-2. Also included in this report is additional information on the PWR analysis, particularly with regard to warn prestressing.

Toble 2. Test conditions for TSE-3 and TSE-

\begin{tabular}{|c|c|c|}
\hline Test cenditions & TSE-3 & TSE-: \\
\hline Test specinen & IST-1 & TSr-2 \\
\hline \multicolumn{3}{|l|}{ Test specined dineastoas. = (la.) } \\
\hline $\begin{array}{l}\infty \\
\text { I0 } \\
\text { Lengeh }\end{array}$ & $\begin{array}{ll}0.53(21) \\
0.21(9.5) \\
0.91(36)\end{array}$ & $\begin{array}{l}0.53(21) \\
0.2+(9.5) \\
0.91(36)\end{array}$ \\
\hline Test specilen material & Asoa, class : & A508, class: \\
\hline Beat creationt & $\begin{array}{l}\text { Quench only from } 871^{\prime} \mathrm{C} \\
\left(1600^{\circ} \mathrm{F}\right)\end{array}$ & $\begin{array}{l}\text { Wench only from } 871^{\circ} \mathrm{C} \\
\left(1600^{\circ} \mathrm{F}\right)\end{array}$ \\
\hline Fle & $\begin{array}{l}\text { Lonk axisl crack, } \\
a=11=0 .+1 \text { in })\end{array}$ & $\begin{array}{l}\text { Lomp axial crach } \\
d=I 1=10.21 \text { in. }\end{array}$ \\
\hline \multicolumn{3}{|l|}{ Iemperatures, "C $\left({ }^{\circ} \mathrm{F}\right)$} \\
\hline $\begin{array}{l}\text { Uall (Initial) } \\
\text { Sink (Initial) } \\
\text { Sink (final) }\end{array}$ & $\begin{array}{l}291(555) \\
-23(--1) \\
-15(2.5)\end{array}$ & $\begin{array}{ll}=91 & (555) \\
-25 & (-13) \\
-19 & (-2)\end{array}$ \\
\hline Coolant & $\begin{array}{l}60 \mathrm{wt} \text { : Sethwl alcohol } \\
60 \mathrm{wt} \text { : Eater }\end{array}$ & $\begin{array}{l}40 \mathrm{wt} \text { : Wethyl alcohol } \\
60 \mathrm{wt} \text { : mater }\end{array}$ \\
\hline Coolawt flow rate. "'/hr (wo) & $-11+(500)$ & $\because 11+(300)$ \\
\hline coolent pressure in test section, kPa (psi) & $917(1+0)$ & $1000(2+3)$ \\
\hline Eack-pressure oriflce dimerer, $=($ in.) & $43.28(1.700)$ & $+3.28(1.700)$ \\
\hline $\begin{array}{l}\text { Reat eraasfer coefficient. } H=a^{-2} \cdot k^{-1} \\
\left(\text { ecu } h r^{-1} \cdot f t^{-3} \cdot-f^{-2}\right)\end{array}$ & $25200\left(210^{\prime}\right)$ & $\because 3500(210 \%)$ \\
\hline$\left(K_{1} / K_{I c}\right)_{\max }$ & 1.13 & 1.29 \\
\hline Tine of occurreace of $\left(k_{t} / k_{I c}\right)=1$, aid & 23 & 2.7 \\
\hline Tine of occurreace of $\left(k_{I} / k_{I c}\right)^{\prime \max }$, ain & 6 & 5 \\
\hline Durstion of experient, ain & 30 & 30 \\
\hline
\end{tabular}

acolculated ines deed on easured temperature distributions. For TSE-J, the effect of core noles is not lacluded. 


\section{AKALYSIS OF THE PUR AND ITS INFLUENCE ON THE EXPERTIENTAL PROGRAM}

An appareatly practical appraach to the aaalysis of the PWR LOCA-ECC thermal shock problen was to consider a two-dinensional linear elastic fracture wechanics wolel with long axial and continuous circunferential flaus, the reasons being that, in nost respects, this odel represented conservative worst-possible conditions and accurate methods of analysis (two-dimensional finite-elenent) vere available. If the PWRs could survive this approach, the LOCA-ECC theral shock problem would be solved, and a reasonable wethod of analysis would have been established.

is a part of the Ther ul Shock Progran, OPal defined a reference calculational welel (BCA) that was intended to represent typical PWR conditions (see Table 3), and then perforaed the rype of analysis described above. The results indicated that, in the absence of warm prestressing (a phenomenon that was not considered until rather late in the progran), a long axial crack would penetrate about 902 of the wall and a continuous circurferential crack abouc 70x. Initially, there had been a desire to limit crack propagation to $250 \%$; thus, the results of the analysis created some concern over the porsibly excessive degree of conservatisn in the calculational codel.

Several approaches to a wore realistic wodel were consiútereo arid are sumarized as follows:

1. Include the three-dimensional aspects of the long-axial-crack problew. There are axial gradients in temperature and fluence, and thus in stress and toughness, that will tend to linit crack propagation. Restraint afforded by the vessel heads will also tend to linit propagation relative to the two-dimensional wodel. Unfortunately, a three-dimensional model of this type is probably out of the question because of present computer limitations.

2. The two-dimensional linear elastic model analysis indicates that the long axial crack will not $g 0$ all the way through the wall. The error in applying linear elastic fracture mechanics to such a deep crack is not known. However, a siople plastic analesis performed by Merkle for a very deep flaw resulted in about the same $K_{1}$ values, thus indicating that the crack will not penetrate the outer surface. 
Table 3. Reference calculational wodel for Thernal Shock Progran studies

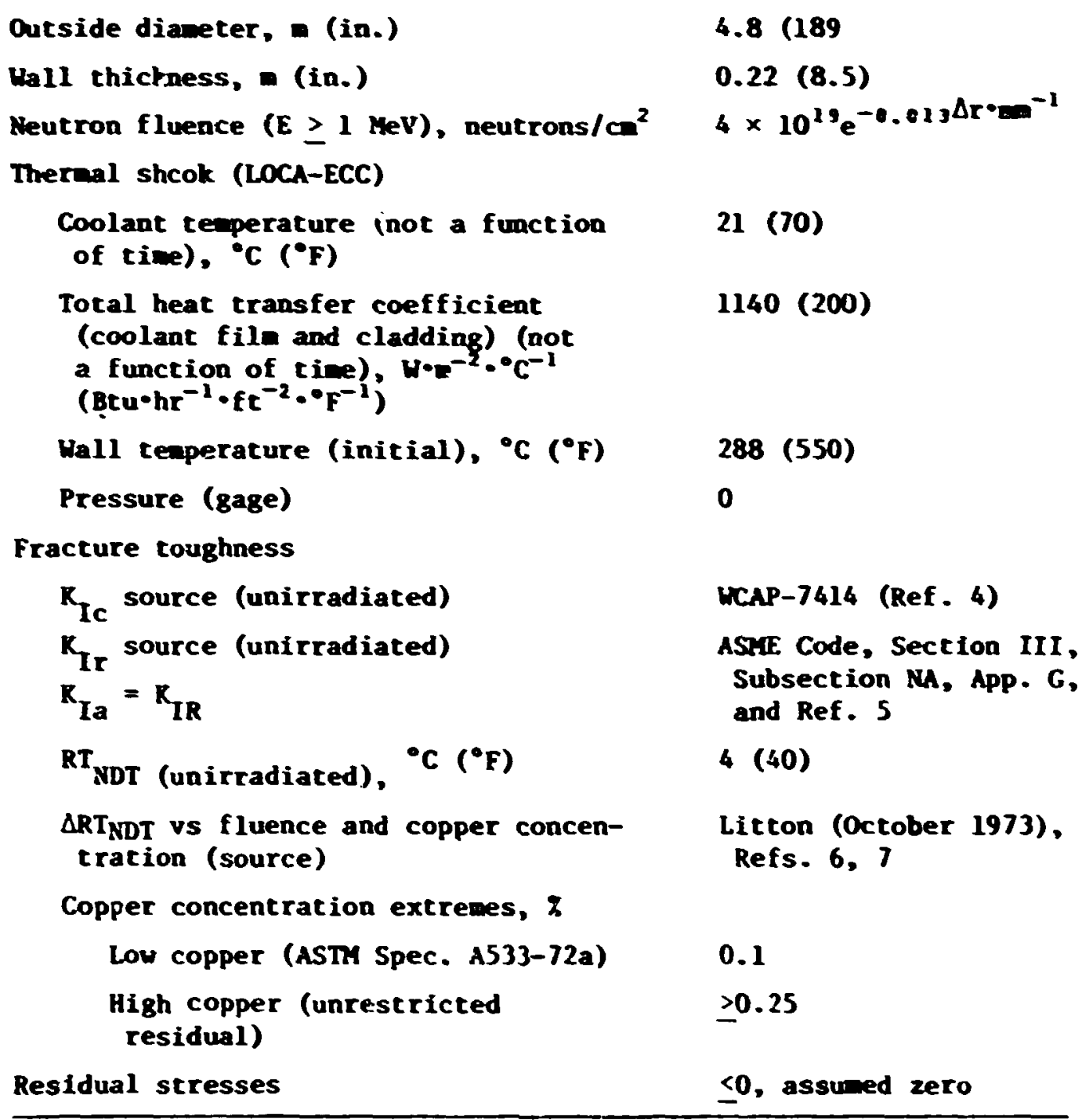

Under exergency core-cooling corditions, it way be that a very deep axially oriented crack that does not leak would be acceptable, since in wost respects the vessel would be structurally sound and would contain the emergency core coolant. If this approach were adopted, it would be necessary to dewonstrate further that, indeed, the crack would not penetrate the outer surface. It is not likely that a more sophisticated analysis (finite-element, elastic-plastic fracture mechanics analysis) would provide 
the necessary assurance, and thermal stock experiments of the type considered for this program would not suffice.

Another type of experiment proposed was based on the notion that rotation of the crack faces, as shown in Fig. 8, is limited by the net theral went and the stiffness of the wall. Under these conditions, there must be some uncracked ligament that can withstand the limiting angle. This was suggested sone tine ago, and Loss" conducted beam experinents in wich angles up to $4^{\circ}$ were used. The bean cross section was $38 \times 76=(1.5 \times$ $3.0 \mathrm{in.}$ ), and $a / w=0.42$. The material was tempered 1533 (plate 02), ar.d the test temperatures were on the upper shelf $\left[82-121^{\circ} \mathrm{C}\left(180-250^{\circ} \mathrm{F}\right)\right]$.

OANU-Dug 75-4133A

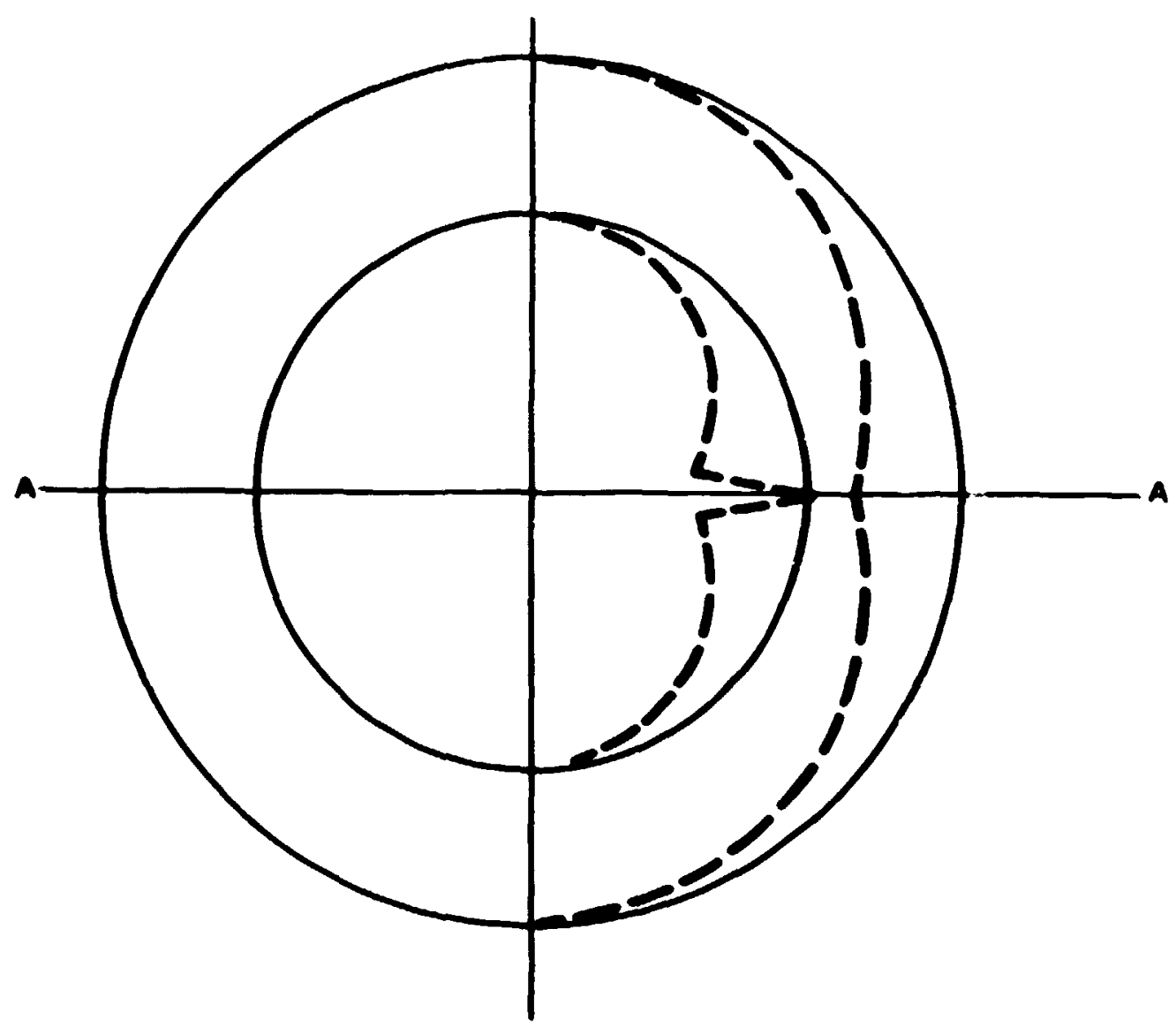

Fig. 8. Bending which occurs in long cylinder containing a long axial crack when it is subjected to a thermal quench on the inner surface. 
Crack extension was no greater than $5=(0.2 \mathrm{in.})$. At ORNL, two $150 \times 150$ w $(6 \times 6 \mathrm{in.})$ beans ade from 1533 in the quench-only condition and with a crack depth of $51=(2 \mathrm{in.})$ vere loaded at room temperature $\left[R_{I_{c}}=55\right.$ $\left.\mathrm{Ny}=\mathrm{E}^{-3 / 2}(50 \mathrm{ksi} \sqrt{\mathrm{in.}})\right]$ through a liniting angle of $4^{\circ}$. Fracture took place, but the crack did not penetrate the back surface.

For $a / w=0.90$, the maximan angle of rotation calculated for the RCA is $2.6^{\circ}$. Thus, there is sone experimental evidence that a two-dinensional, long axial crack in a PWR could not penetrate the outer surface.

There is at least one reservation with regard to interpretation of the above data. When the thermal woment is being applied and the crack is opening, the uncracked ligament is subjected to a rather large compressive load. This tends to result in plastic deformation as the ligameat grows thinner. When the theraal gradient is gone, the crack will be closed, ard a residual tensile stress will exist in the uncracked liganent that ay be large enough to crack the ligament.

3. Perhaps an axially ortented through crack would be acceptable, since in most respects the vessel would still be sound, and the crack would be tight encugh during and after the transient to limit leakage of the coolant.

4. Even if complete penetration of an axial crack were acceptable, very deep penetration of a continuous circumferential creck could not be tolerated, since it could result in detachment of the lower portion of the vessel. A sensitivity analysis, including the uncertainties in $K_{I c}$ and $K_{I_{a}}$, would have to be conducted to deteraine the maximu likely depth of penetration. Unfortunately, $K_{I a}$ data for irradiated naterial are not too abundant at this time.

5. Another possible approach is to relegate long cracks to a very improbable category and concentrate on finite-length cracks. Although calculations ${ }^{\prime}$ indicate that, in the absence of warm prestressing, finite cracks aight grow to becowe long cracks and then propagate radially, the results from TSE-2 seen to indicate othenwise or chat warm prestressing was effective in liniting propagation. At ORN,, a three-dimensional, finite-element fracture mechanics method of analysis for wore accurately interpreting the results of TSE-2 is being developed. 
6. The final approach is to demonstrate that warm prestressing will be effective in substantially limiting crack propagation. Recent experiments by $\operatorname{Loss}^{2}, 3$ and earlier ones by Brothers and Yukava ${ }^{10}$ and Harrison and Fearnehough" demonstrated how warm prestressing ay effectively increase the static fracture toughness of a pressure vessel under thermal shock conditions. The process is illustrated in Fig-9. If a flawed specian is loaded at an elevated temperature to a load greater than the fracture load corresponding to a lower temperature and then is loaded at the lower tenperature, the fracture load will be greater than that obtained without applying the preload. Furthermore, for certain loading and teraperature conditions, the fracture load will be greater than the preload. Loss $^{3}$ reports that these latter conditions exist during the PWR LOCA-ECC thermal shock. Thus, if a $k$ ratio of unity is not achieved until after $k_{1}$ has passed through its maximu value, crack propagation cannot occur. If

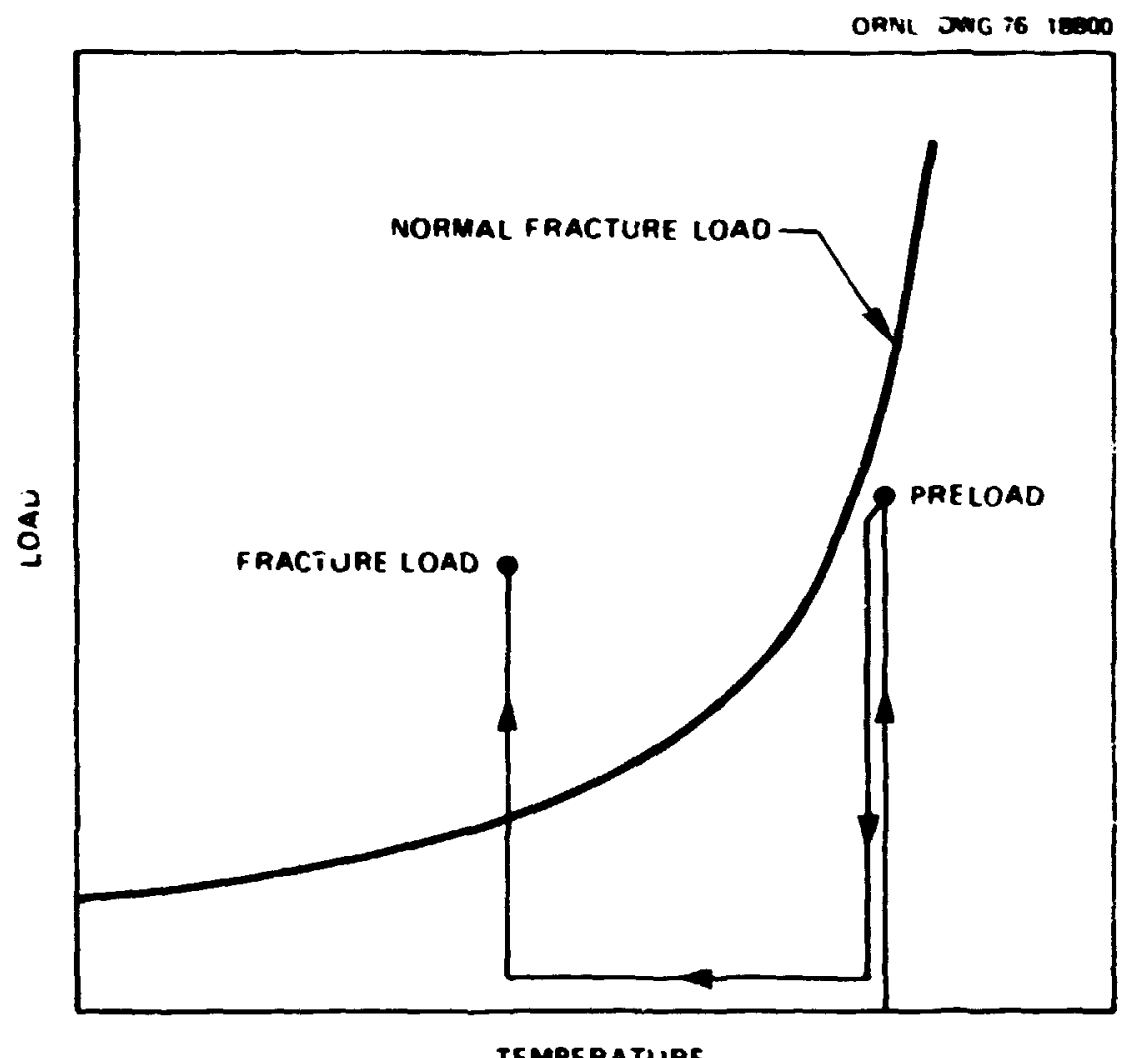

Fig. 9. Graphical illustration of warm prestressing for a simple test specimen. 
it were possible to denonstrate that varm prestressing would be this ef fective under the conditions assuned for the ROA, then perhaps noce of the five aiternative approaches to achieving a core realistic analytical nodel would have to be pursued.

The first task in assessing the possible benefits of wam prestressing vas to calculate the locus of points for $K_{1} / K_{I c}=1$ on a plot of $R_{I}$ vs tine with crack depth as a paraneter. Such a graph for the high-copper Rar with a loag axial flaw is shown in Fig. 10. It is observed that, for fractional crack depths greater than $\mathbf{0 . 2}$, a $R$ ratio of unity is achieved only after $K_{1}$ has reached a maximn value. Thus, if it is assuned that Loss's data are applicable to a vessel under thermal shock loading, lang axial and continuous circunferential cracks with fractional depths greater than $\mathbf{2 0 . 2}$ will not initiace.

The extent to which propagation might cake place (final arrest depth) is evaluated with the critical-crack-depth set of curves as illustrated in Figs. 11 and 12 for the long axial and continuous circunferential cracks in the high-copper Rar. In these fizures, $a_{c}\{w$ is the fractional crack depth for which $R_{I} / R_{I c}$ and $R_{I} / R_{I a}$ are equal to unity for specific times in the thermal transient. Selecting a time provides a crack depth for initiation and the correspoading arrest depth. Maximu depths are nct shown for the long axial flaw because the nethod of analysis breaks down for very deep rracks, but it is clear that, in the absence of varm prestressing, the penetration is greater than S0x. For the circunferential flaw, the maximu depch for initiation is just under $50 \mathrm{x}$ and the corresponding arrest depth is $270 \%$. On the other hand, if warm prestressing linits the maxim crack depth for initiation to 20\%, then, as illustrated by Figs. 11 and 12 , the maximu penetration (arrest depth) will be linited to $235 \%$.

If warm prestressing is as effective as indicated above, and if the actual arrest toughness is sinilar to that assuned for the RCA analysis, then the LOCA-FCC thermal siock problea ceases to exist, and it should not be necessary co experimentally investigate the arrest behavior of deep cracks $(a / w \geq 0.5)$. It will be necessary, hovever, to adequately demonstrace wara prestressing under appropriate conditions; to obtain $\mathrm{K}_{\mathrm{Ia}}$ data 


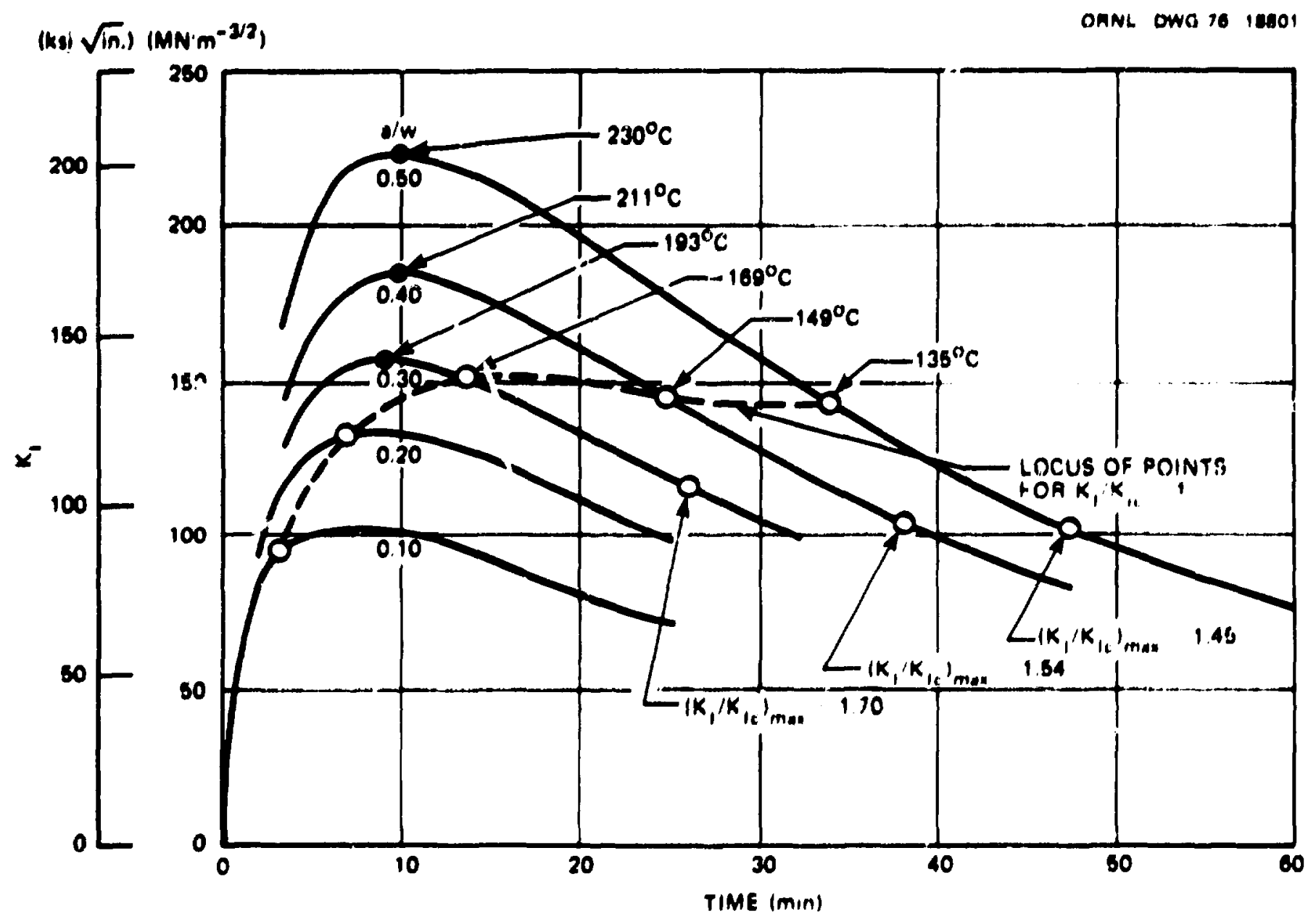

F18. 10. Stress-1ntensity factor ve time in transient and fractonal flaw depth $(a / w)$ for a long axlal flaw in the reference calculationnl model. Thr locus of polnt for $K_{I} / K_{I C}-1$ is allown for the case of highcopper materlal. Polnts to rlght of peak in $K_{1}$ curvo indlcate warm prestreesing. 


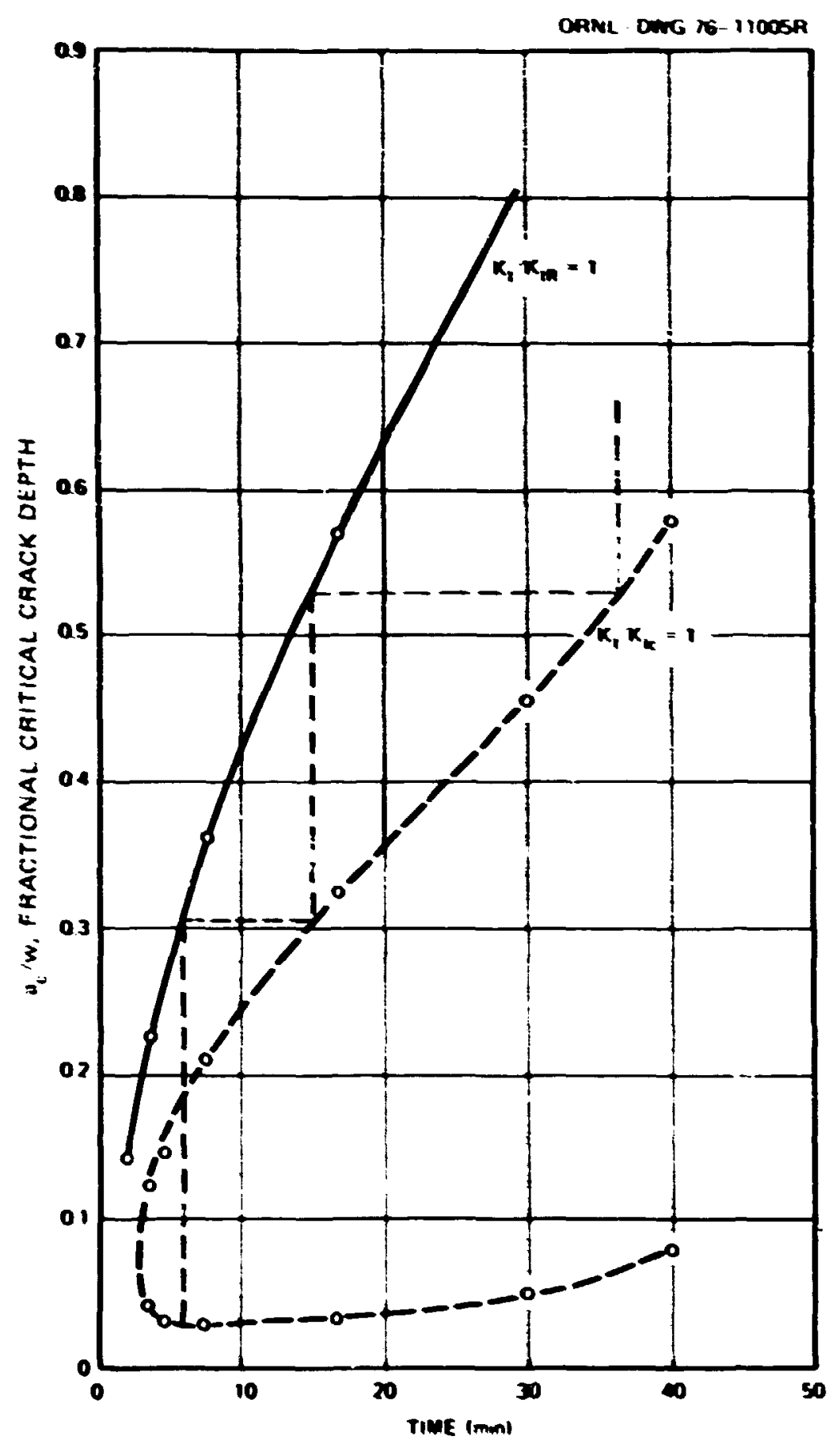

Fig. 11. Fractional critical crack depth $\left(a_{c} / w\right)$ us time in transient for long axial flaws in the high-copper reference calculational wodel, illustrating stepwise crack propagation in the absence of warm prestressing. 


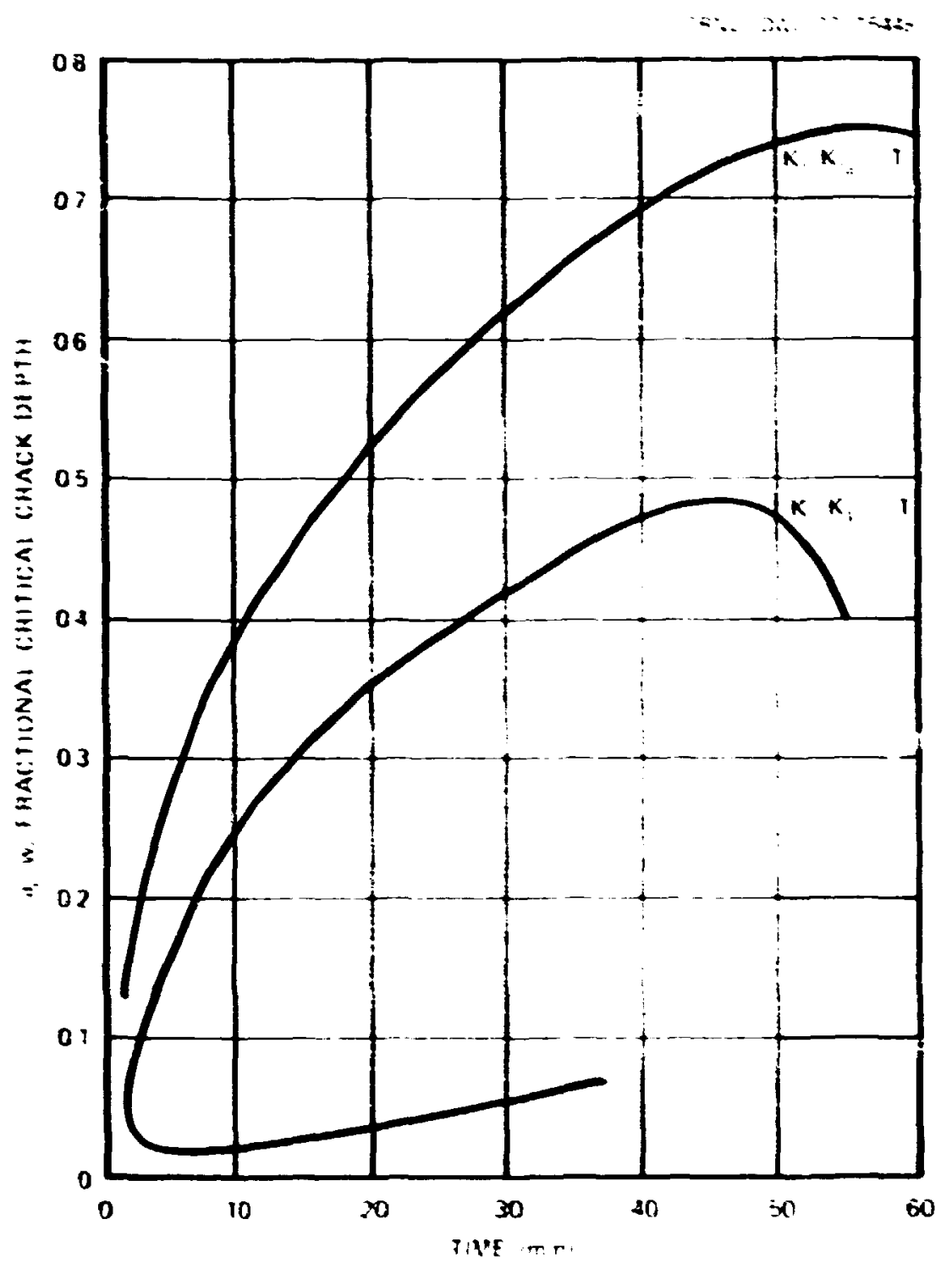

Fib. 12. Fractional critical crack depth $\left(a_{c} / w\right)$ vs tive in transient for continuous circunferential flaus in the high-copper reference calculational nodel, assuning no warm prestressing.

for Irradiated pressure vessel material; and, of course, to verify that linear elastic fracture mechanics (LEF) is applicable under LOCA-ECC thermal shock conditions, considering relatively shallow flaw propagation. The latter cask is the purpose of the present Theral Shock Program. 


\section{SYNOPSIS OF EXPERIRENTAL TECHNIQLES AVD PROCEMURES}

As mentioned in the preceding chapter, details of experimental techniques and procedures are covered in Ref. 1. However, a few changes were made for TSE-3 and TSE-4, which need to be mentioned, and a brief revies of the entire subject will help to orient the reader and will wake this report sore complete.

The thermal shock is applied to the inner surface of the cylintrical test specimens by suddenly puping cold fluid through a narrow annulus formed by the inner surface of the test specimen and a flow baffle, as illustrated schenatically in Fig. 13. Prior to quenching, the test speciwen is gradualiy heated to $288^{\circ} \mathrm{C}\left(\sim 550^{\circ} \mathrm{F}\right)$ with an electric furnace, and the coolant is chilled to the desired sink temperature. Heat removed from the test specinen is stored in the large quantity of circulating coolant. A photograph of the test facility showing the major components is presented in Fig. 14 .

Two types of data must be retrieved from a test specimen during the thermal transient: radial teaperature distributions in the wail and indications of rcack propagation. The temperature distributions are used to cbtain fracture toughness distributions and to calculate the thermal stresses. wich in turn are used to calculate the stress-intensity factors. These temperature distributions are obtained with numernus thermocouples located at different depths in the wail. Thermal-hydraulic experiments were conducted with a special test specimen to ensure that quenching was symetrical and uniform (see Appendix $\lambda$ ).

Indications of crack initiation and arrest were obtained with strain gages placed across the flaw (COD gages) and with acoustic-enission instrumentation. For TSE-1, -2 , and -3 , the COD gages were mounted in such a way that crack initiation could result in gage failure, and thus subsequent events would not be detected. For TSE-4, wodifications were made that prevented gage failu.e and thus not only pernitted measurements subsequent to crack initiation detections but also pernitted estimates of propagation depth. A detailed discussion of the development of the improved COD gages is included in Appendix B. 


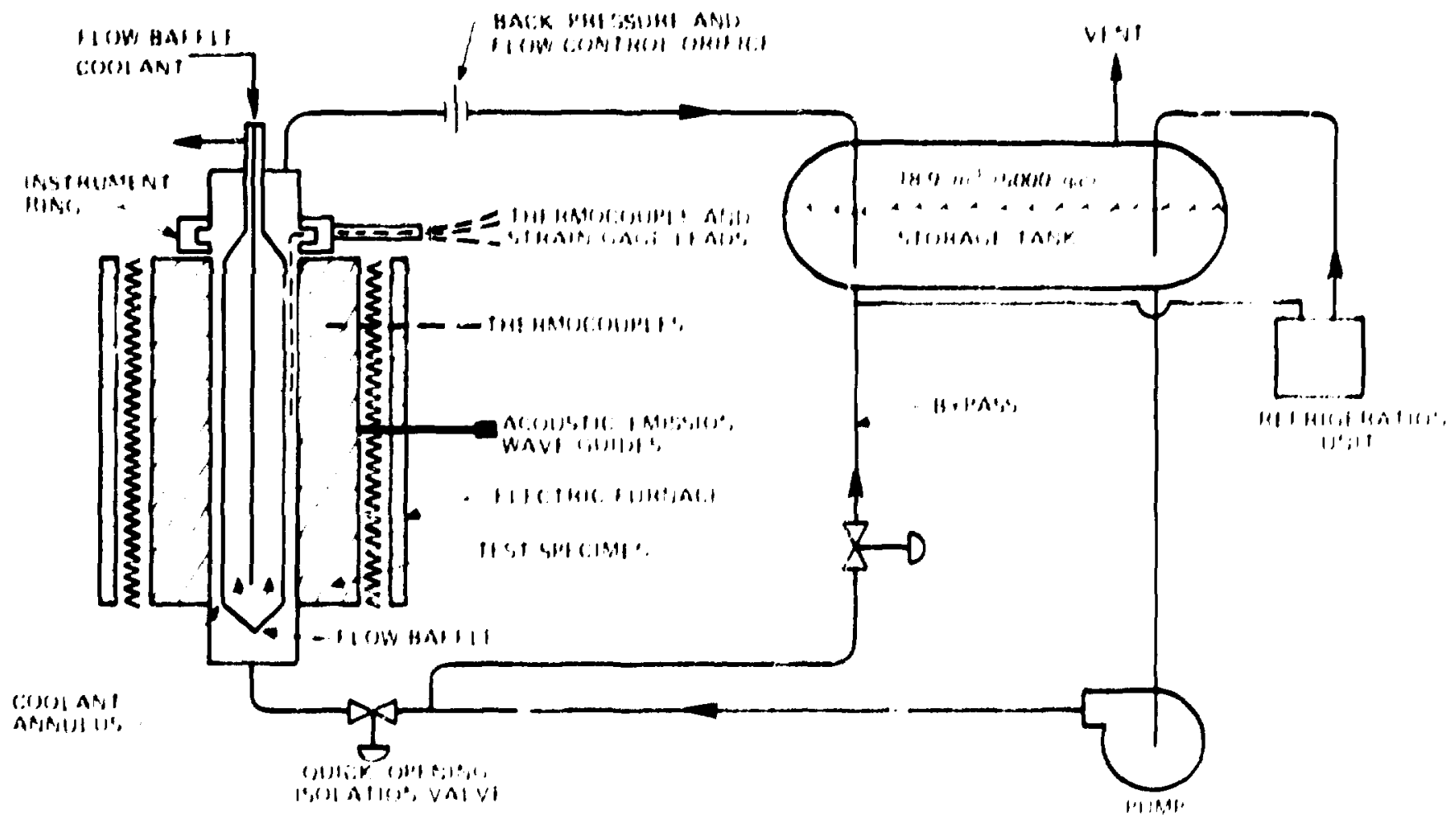

18. 13. Schomatic of thermal shock test facility. 


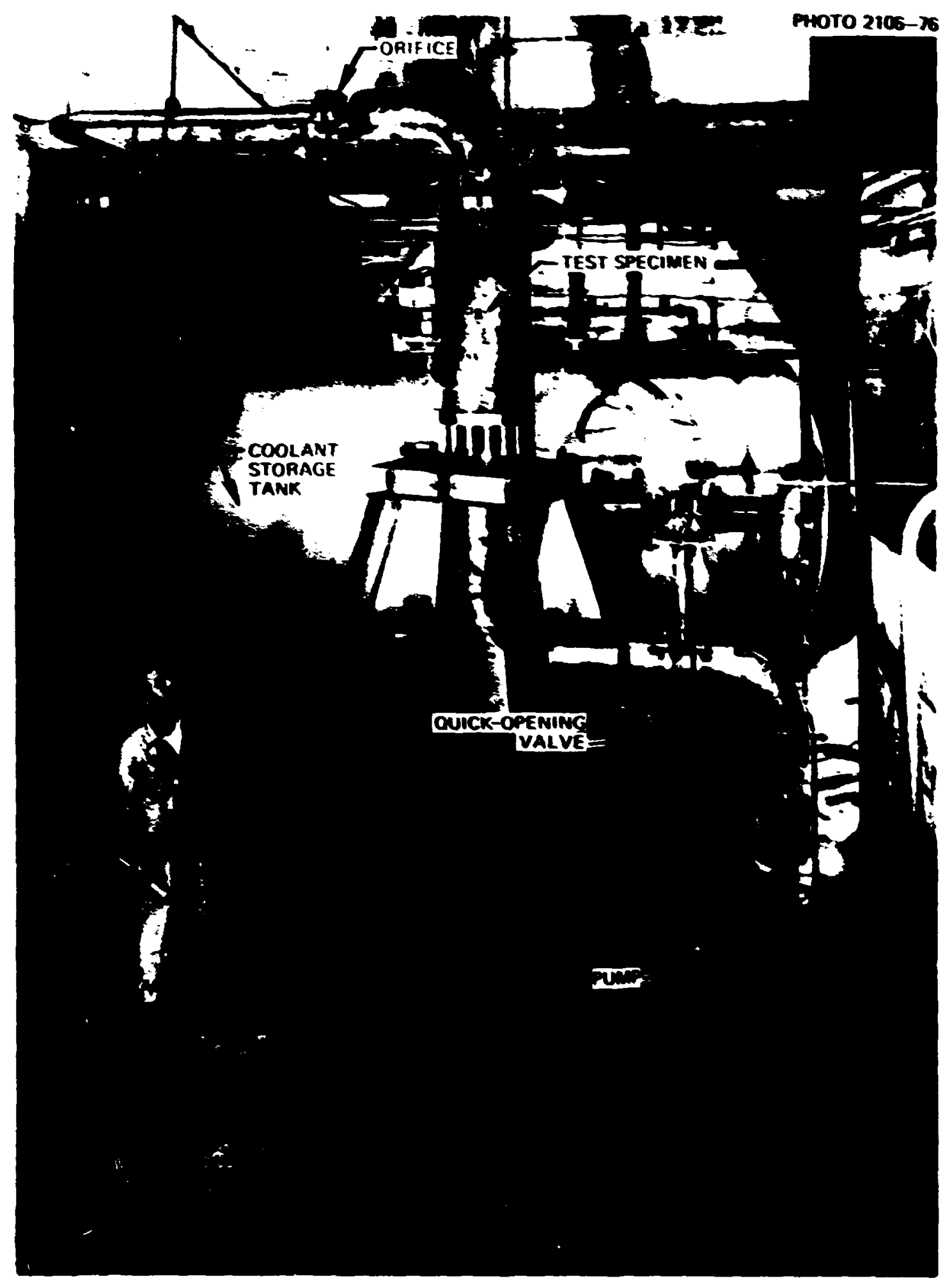

Fig. 14. Photograph of thermal shock test facility during early stages of assembly, showing basic comporients of systen. 
The acoustic-emission work was contracted to Southwest Research Institute (SwRI) for all four tests, and Battelle Pacific Northwest Laboratories (BVW) was invited to participate in TSE-4. SwRI modified their technique for TSE-3 and TSE-4 relative to that used in TSE-1 and TSE-2. Details with regard to wodifications in the AE instrumentation are included in Appendix $B$.

The initial flaus for TSE-1, -2 , and -3 were prepared by first achining a rectangular groove and then placing an electron-bean (EB) weld at the botton. Tr.e velds cracked during the velding operation as the heaced naterial cooled. This initial cracking is the result of very low toughness in the fusion zone (very rapid self-quenching rate) and residual stresses wich develop during the quenching. Although wuch of the residual stress in the fusion zone is relieved when the crack pops in, residual stresses remain in a very narrow region at the crack tip after arrest. However, because of their localized nature, it is believed that these stresses have no significant effect on crack propagation other than to contribute to subcritical crack growth early in the thermal shock transient. Photomicrographs of the flaw prepared for TSE-1 and the subcritical growth that occurred during TSE-1 are shown in Fig. 15 .

The weld groove was used in preparing the flaws for TSE-1, -2 , and -3 because at the time the test specimens were prepared for these tests, the EB wela could not otherwise penetrate to the desired depth. Adjitional EB weld development efforts ${ }^{12}$ resulted in deeper penetration capability, and the long axial flaw for TSE-4 was made without the weld groove. This was an improvement because the veld groove introduced uncertainties with regard to localized temperature and stress distributions. 

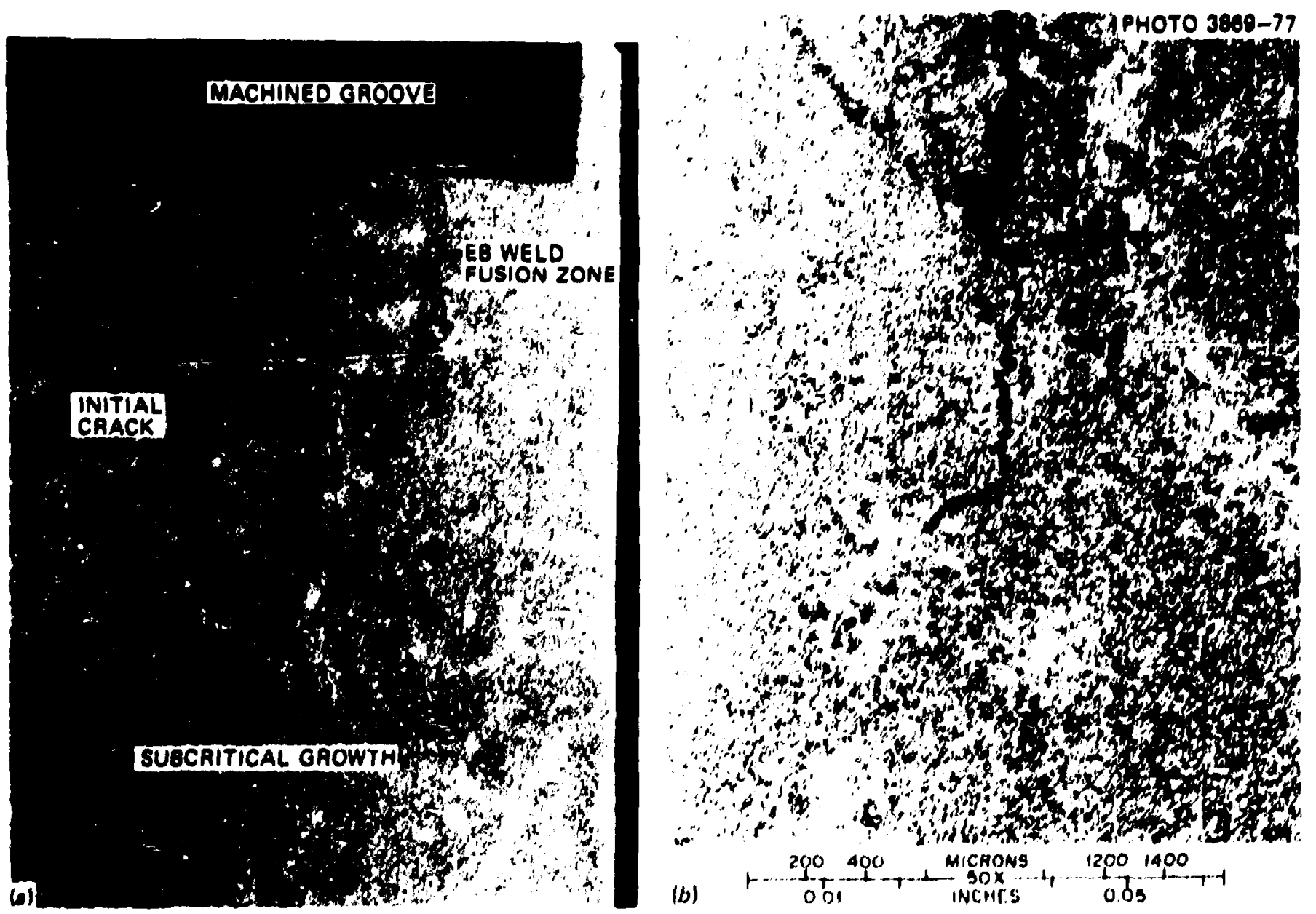

F1g. 15. Postest examination of the electron-beam (F,B) weld from trepanned core TSV-1-1 removed from TSV-1 following TSE-1. (a) EB weld showing crack and extension (tocal effective inltial flaw depth

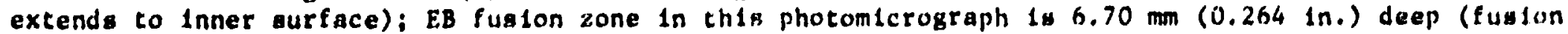
zone only). (b) Region of crack-t 1 p extension $(0.91 \mathrm{~mm}(0.036 \mathrm{in}$.) $)$ at this loeation. 


\section{THERMAL SHOCR EXPERDMENT TSE-1}

The purpose of TSE-1 was to dewonstrate that a long axial flaw with a maximan $\mathrm{K}$ ratio of $\mathbf{} 0.7$ would not experience unstable crack grouth. The AE and COD instrunentation indicated that, if crack extension took place, it was very early in the transient, when teaperatures were too high for brittle fracture. Metallographic exanination of a core renoved from the wall of the test specimen showed a very short extension $[\sim 2=(0.08$ in. $)]$, and it was hypothesized that the comined effect of thermal stress and EB veld residual stress resulted in subcritical crack grouth at upper-shelf tempratures. The combined stress appeared to be adequate, and the depth of penetration was quite shallow because of the very steep gradient in residual stress at the tip of the original flaw. However, an exanination by scanning electron nicroscopy (SEA) of a portion of the resoved core that was split to reveal the fracture surfaces indicated frangible fracture.' The core specimen was not ideal, and it was intended that additional sanples be resoved and exanined following TSE-3, which was conducted on the same test specimen using the same flaw in its slightly extended condition. An SEY examination of the additional sample showed that the portion of the fracture that occurred during TSE-1 was ductile, and the portion that occurred during TSE-3 was brittle. Additional proof regarding the fracture wode for TSE-1 was obtained by examining another core specimen which had been rewoved from TSV-1 following TSE-1 and which was well preserved. The SEM examination of this specinen revealed ductile fracture. Thus, it can now be concluded that unstable crack growth did not take place during TSE-1; this is in agreement with what was expected on the basis of the LEFH analysis.

Detailed information regarding the metallographic examinations is included in Chapter 8. 


\section{THERMAL SAOCK EXPERIYENT TSE-2}

The purpose of TSE-2 was to deteraine whether an axially oriented finite-length flaw with a portion of its crack front having maximen $k$ ratios in excess of unity would propagate axially to become a "long" flaw and then propagate radially. The initial flaw was senicircular with a radius of 19 (0.75 in.), and the thermal shock was severe enough that the flaw initiated. As illustrated in Fig. 7, propagation took place in two events, there vas essentialiy no extension radially beyond the deepest point of the flaw, and the 1 -dal length was $142 \mathrm{~m}$ (5.6 in.). Calculetions that excluded the effects of warm prestressing and assumed semielliptical geometry for the extended flaw indicated that the flaw would becowe long enough to grow radially $\left(\left(_{I} / K_{I c}\right)_{\max }\right.$ for a long axial flaw with a $=19$ was 21.2] and, with the effects of warn prestressing included, there were indications that the flaw would not extend the length of the cylinder and would not propagate radially.

The potential for warn prestressing of the fiasl crack front $(\mathrm{b} / \mathrm{a}=$ 3.7) is illustrated in Fig. 16, which is a plot of $K_{I}$ vs time for several points on the crack front. At the tive that the final crack front first existed $(86 \mathrm{sec}), K_{1}$ for each point on the crack front is close to a minu value. This means that for times greater than $86 \mathrm{sec}$ or thereabout, $K_{1}$ all along the crack front will be decreasing with time, and thus presunably crack initiation cannot take place even though the calculated $K$ ratios eventually ay be equal to or greater than unity.

Since warn prestressing way play a very important role in mitigating the LOCA-ECC theraal shock problea, it is important to understand that TSE-2 should not be classified as an adequate dewonstration of warm prestressing under therwal shock conditions. It may be that warm prestressing dia ifmit propagation; however, there were too many uncertainties associated with $K_{I}$ and $K_{I c}$ to perait a firc conclusion. For instance, the $K_{I}$ calculations are based on a semilliptical crack-front shape for the two extended flaw shapes, and, as Indizated by Fig. 7, the intermediate and final crack shapes are not actually semielliptical. Furthermore, the method for calculating $K_{I}$ has been compared with a three-dimensional finite-element analysis developed by Ayres, ${ }^{13}$ and it was found that, for identical semielliptical geonetries, our method ${ }^{1 /}$ overestimates $k_{1}$ over wost of the crack 


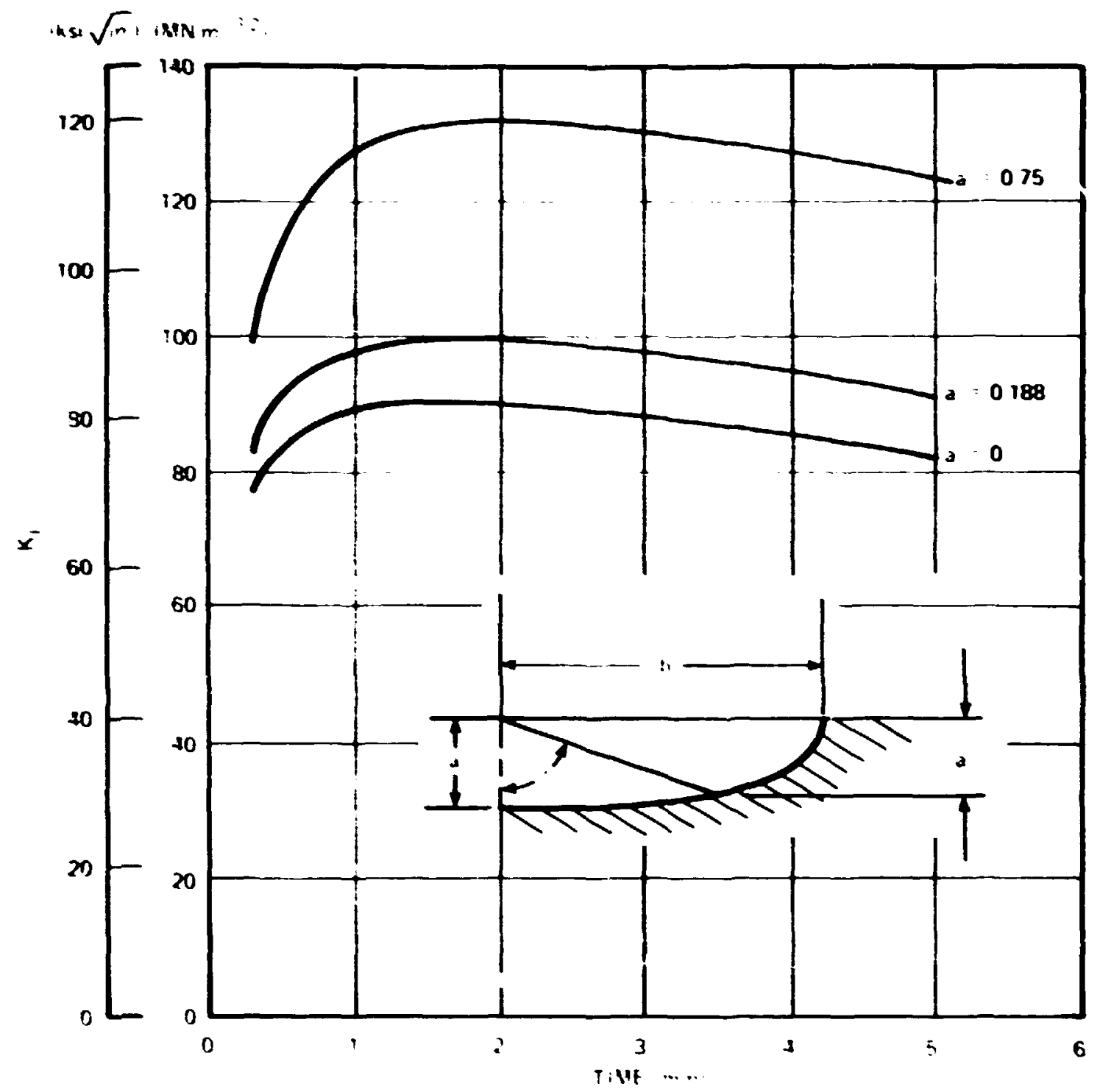

Fig. 16. $K$ vs time for TSE-2; semielliptical flaw with an aspect ratio $(b / a)=3.7$ and a maximum depth (a) of 19 am $(0.75$ in.).

front. It these differences in the two methods of analysis are considered. it is quite possible that the maximum $k$ ratios along the crack front for the final flaw shape were simply less than unity and that warm prestressing did not play a part in limiting crack extension.

As discussed in Ref. 1, the results from TSE-2 indicated that the running-crack dynamic toughness and thus the arrest toughness of the test 
specimen material was considerably less than the static fracture toughness. This appeared to be the case because the flaw propagated through areas where the calculated $R$ ratio based on $R_{I c}$ was considerably less than unity. Arrest toughness values based on results from TSE-2 are presented in Fig. 17 along with the static fracture coughness curve.

Two $K_{I a}$ vs $T$ curves were obtained, one for each of the two arrest events. The $R_{I}$ calculation for the intermediate crack shape was expected to be wre accurate than that for the final crack shape, and thus the lover of the two $\mathrm{K}_{\mathrm{Ia}}$ curves would be more nearly accurate. The results from TSE-3 and TSE-4 provided additional proof that $K_{I a} \ll K_{I c}$ and the single value of $\mathrm{R}_{\mathrm{Ia}}$ deduced fron TSE-4 is also ploted in Fig. 17. This value agrees

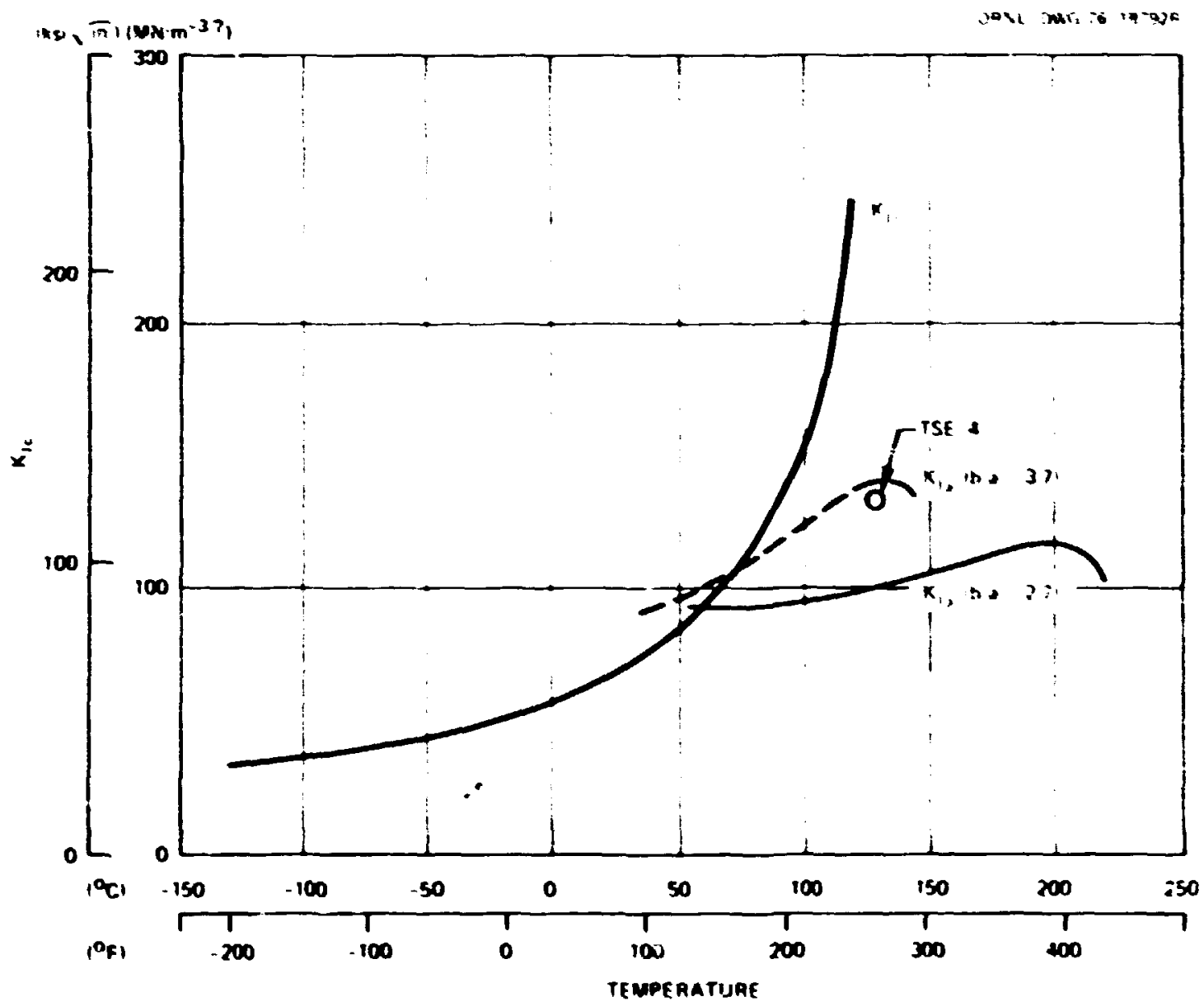

F18. 17. Comparison of $K_{I}$ and $K_{I a}$ for as-quenched A508; $K_{1 a}$ curves are based on data from the dual crack extension in TSE-2, while a single point was obtained from TSE-4. 
betcer with the higher of the two $\mathrm{K}_{\mathrm{Ia}}$ curves. The $\mathrm{K}_{\mathrm{l}}$ calculation for TSE-4 is considered to be much more accurate than that for ISE-2, and thus the $K_{\text {Ia }}$ point derived from TSE-4 should be more accurate. 


\section{TRETAML SHOCK EXPERIMETI TSE-3}

The purpose of TSE-3 was (1) to deternine whether a long axial flaw vill propagate under the specified thermal shock conditions when the maximotio is 21.2 and (2) if the crack does propagate, to deternine what the noninal calculated $K$ ratio was at the time of initiation, and (3) to obtain a masurenent of the arrest coughness.

The third thereal shock experiment (TSE-3) was a companion to TSE-1 i= the sense that the sane test specinen (TSV-1) and flaw were used, and for TSE-1 the aximu $K$ ratio $\left(K_{I} / R_{I c}\right)$ was less than unity, while for TSE-3 it was greater than unity. In other words, unstable crack growth was predicted for TSE-3 but not for TSE-:

Following TSE-1, two 25-m-dian (1-in.) core holes were trepanned from the flaw zone, as shown in Fig. 18, to pernit examination of the fracture. The high stress-concentration factors at these holes were expected to result in localized "premature" crack initiation during a subsequent theral shock (TSE-3). However, at the time TSE-3 was being planned, it was believed that $R_{I a}$ for this quench-only aterial was essentially equal to $K_{I c}$ and thus the core-hole stress concentration would not trigger preature cracking along wuch of the crack front. The holes were plugged with snugfittir: bars that vere seal-velded at the outer surface, and TSE- 3 was conducted as planned.

Shortly before TSE-3 was conducted, it was tentailvely concluded on the basis of data from TSE-2 that $R_{\text {Ia }}$ was substantially less than $R_{I c}$ for the test spscimen material. The tcmperature shift in the region of interest $\left[66\right.$ to $204^{\circ} \mathrm{C}\left(150\right.$ to $\left.\left.400^{\circ} \mathrm{F}\right)\right]$ appears to be in the range of 38 to $149^{\circ} \mathrm{C}$ (100 to $\left.300^{\circ} \mathrm{F}\right)$, and the corresponding calculated crack jum range is $\mathrm{a} / \mathrm{w}=$ 0.2 to 0.4 , aeglecting the effect of the core holes. If the crack juaped deeper than 177, it could not reinitiate because, even in the absence of varm-prestressing effects, the $R$ ratio for cracks deeper than 172 never exceeds unity.

Typical temperature distributions obtained from TSE-3 are shown in Figs. 19 through 21, and tabulaced temperatures and the results of fracture echanics calculations based on these temperatures are included in Appendix C. According to calculations using the measured temperature distributions, 


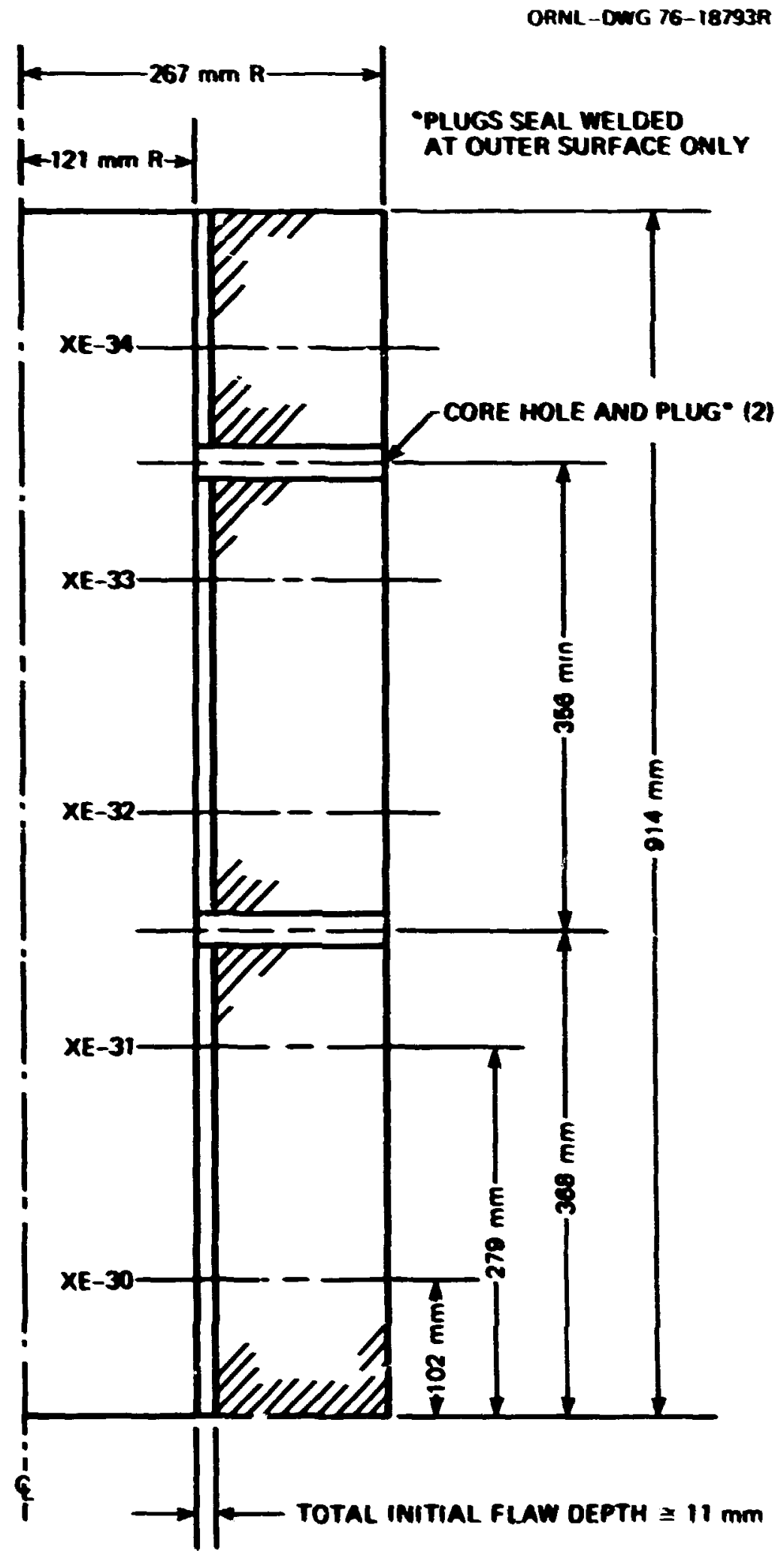

Fig. 18. Cross section of TSV-1 showing location of COD gages and core holes in TSE-3 ( $1=0.039$ in.). 


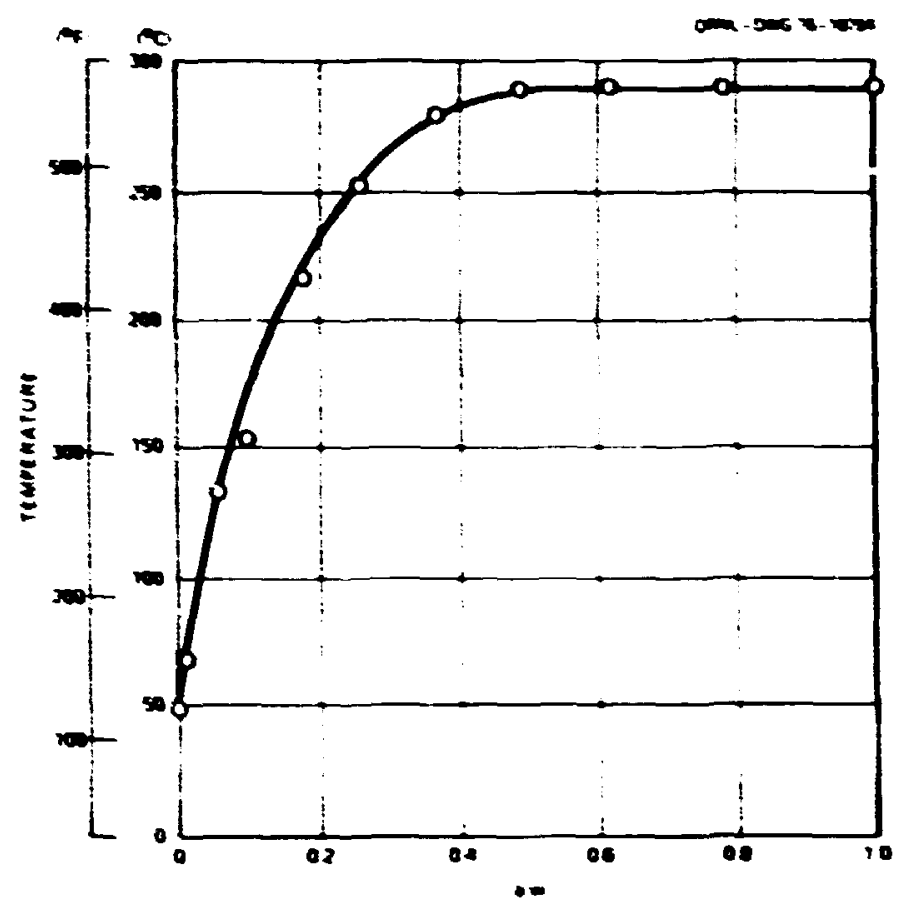

Fig. 19. TSE-3 temperature distribution at $59 \mathrm{sec}$ into transient.

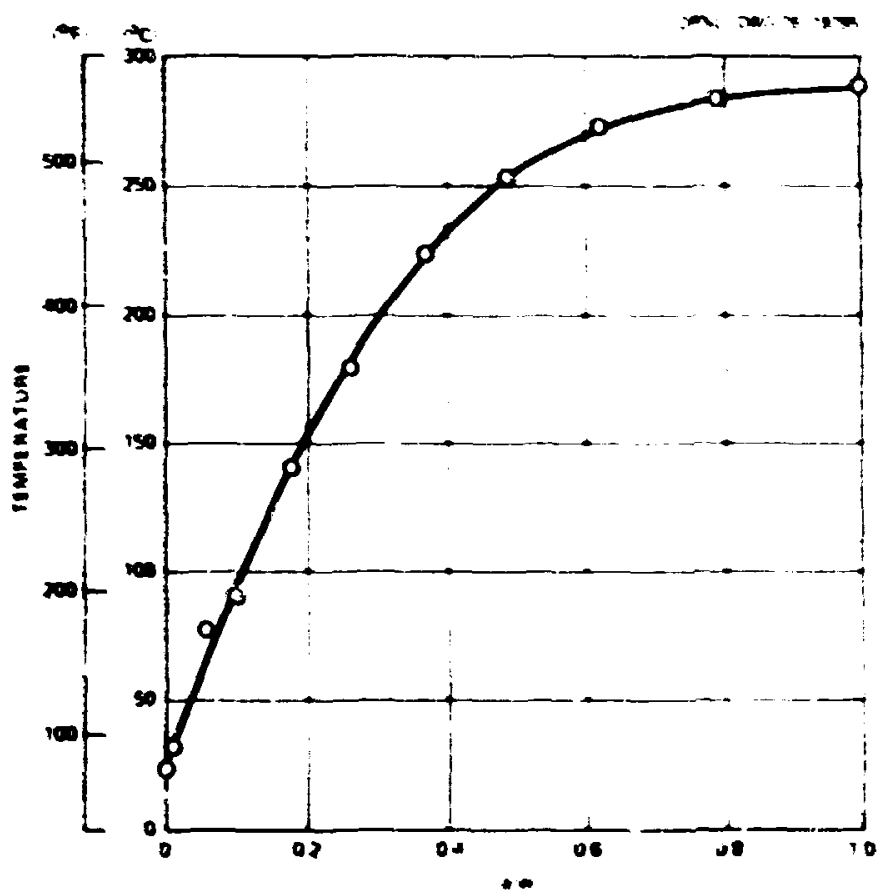

Fig. 20. TSE-3 temperature distribution at 181 sec into transient. 


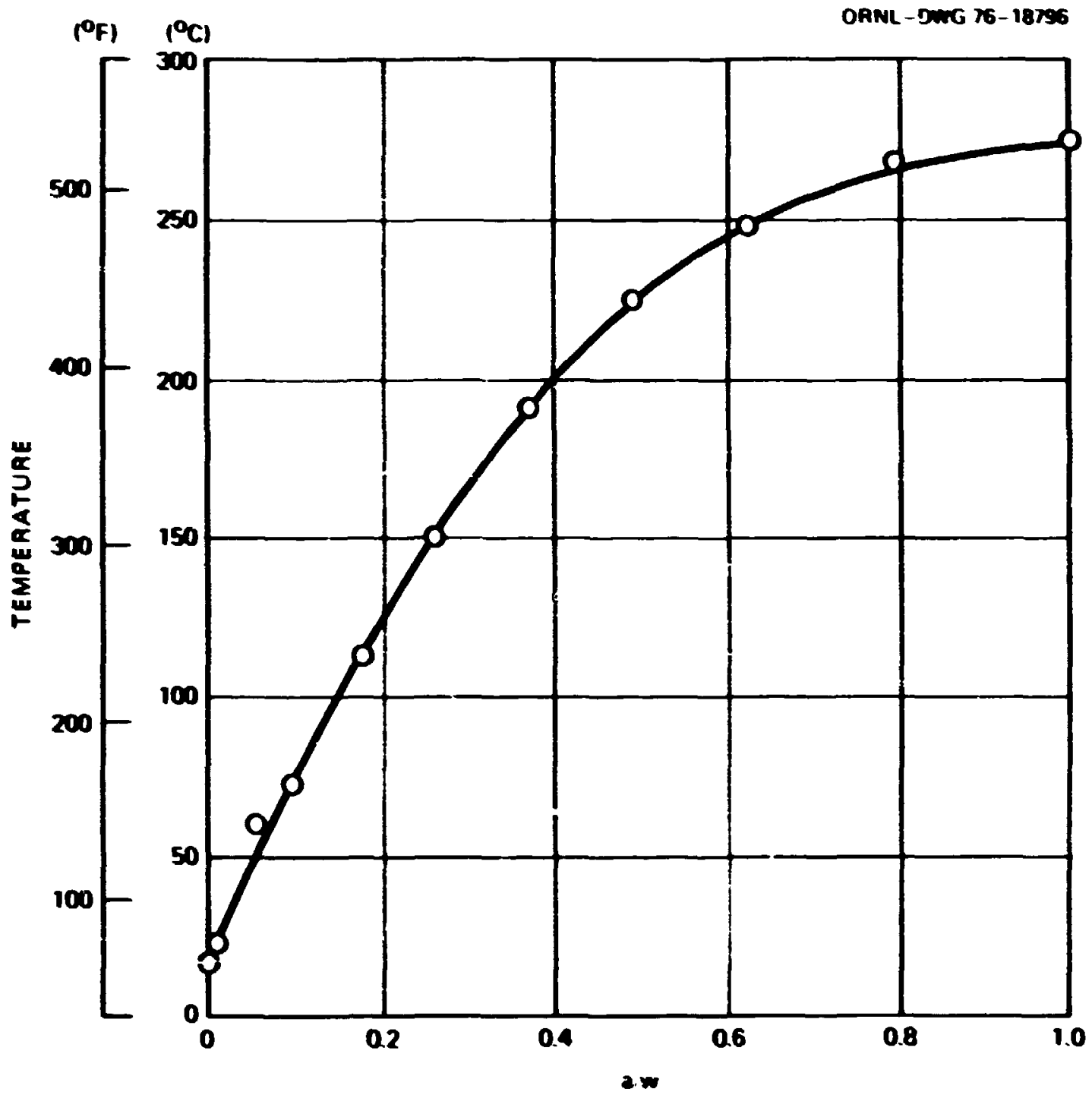

Fig. 21. TSE-3 temperature distribuiion at $300 \mathrm{sec}$ into transient.

a maximum $R$ ratio of 1.13 was obtained, and a $R$ ratio of unity was achieved at 3.0 ain into the transient. The calculated $R_{I}$ values given in Appendix $C$ do not include stress concentrations around the core holes where cores were trepanned following TSE-1. Thus, higher $R$ ratios would be expected in the vicinity of the holes, and a value of unity would occur sooner.

The aximum nominal calculated $R$ ratio achieved during TSE- 3 was less than that intended $\left(\sim_{1} .2\right)$ as a result of problens encountered with operation of the quick-opening valve. The valve opened lors enough for the 
test section to fill with coolant and then closed; about $14 \mathrm{sec}$ later, the valve opened again and remined open. The result was a theral shock that was less severe than intended.

Output fron the 000 gages is showa in Fig. 22 (note that gage XE-33 tas not operable during the test), and the precise location of the gages is indicated in Fig. 18. The two initial COD events shown in Fig. 22 are the

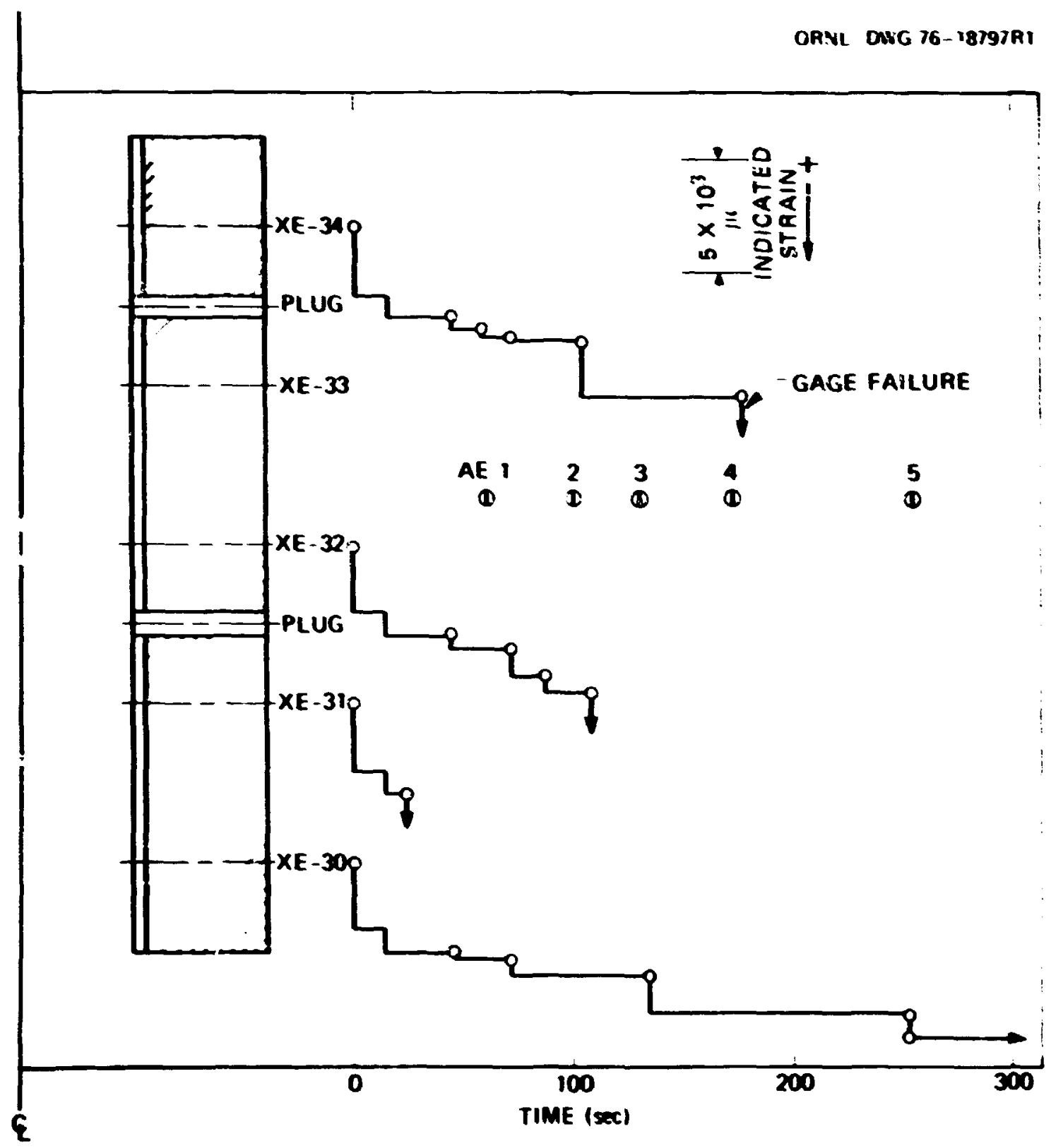

F18. 22. COD output in TSE-3 showing tine of occurrence of ajor cine-integrated bursts of acoustic energy. 
result of thereal effects on the gages, thermal stress, and perhaps subcritical irack growth at the tines the dual thernal shock was applied. A few seconds later (24 sec iato the transient), COD gage $\mathrm{XF}-31$ opened (the gage filament parted), indicating a relatively large anount of crack opening. Shortly thereafter, the other gages began indicating very sall crack-opening and arrest events. Gage XE- 32 opened at 110 sec into the transient, and XE-34 opened at $178 \mathrm{sec}$. Gage XE-30 did not open, but continued to indicate small events up to $2250 \mathrm{sec}$, which indicates substantially less crack propagation near the inlet end thar: elsewhere.

The numerous small events shown in Fig. 22 could be crack-straightening events prompted by locally high values of $K_{I}$, or they could be an indication of initiaticn-arrest events near the core holes. Many of these events took place early in the transient when the nominal $\mathrm{R}$ ratio was too sall for initiation, and in some cases when the temperature corresponded to upper-shelf toughness. As shown in Fig. 6, the upper-shelf cemperature (based on $2 \mathrm{~T} \mathrm{CT}$ specinens) is $120^{\circ} \mathrm{C}\left(250^{\circ} \mathrm{F}\right)$. The temperature at the tif of the initial flas did not fall below $120^{\circ} \mathrm{r}$ until $1.4^{\circ}$ min into the transient. The larger dimensions of the thermal shock cest specimen would probably result in a somewhat higher upper-shelf toughness, but not much increase in the corresponding temperature.

The AE data are presented in Fig- 23, which shows the acoustic energy emitced in a 10-sec pariod, as a function of tirse, divided by the total energy enitted over a 300-sec period, the latter time period starting 32 sec before initiation of the thermal shock. As shown in Fig. 22, the peaks in the $A E$ curve correspond to events or groups of events indicated by the COD instrumentation. A detailed interpretat. on of the AE data is presented in Appendix $B$.

After the test specinen was renoved from the cest facility, the COD gages were inspected before they were rewoved. It was deternined that the 1.6-maD (0.062-in.) sheath portion of the XE-32 gage was buckled longitudinally over a short [ $1.3-6(20.05-i n)$.$] length located directly$ over the crack. Also, the $0.13-2(0.005-i n$.$) flange was broken directly$ over the crack, and the ends were overlapped. This indicates that substantial crack opening took place during the chermal transient, and the extended gage buckled during crack closure. 


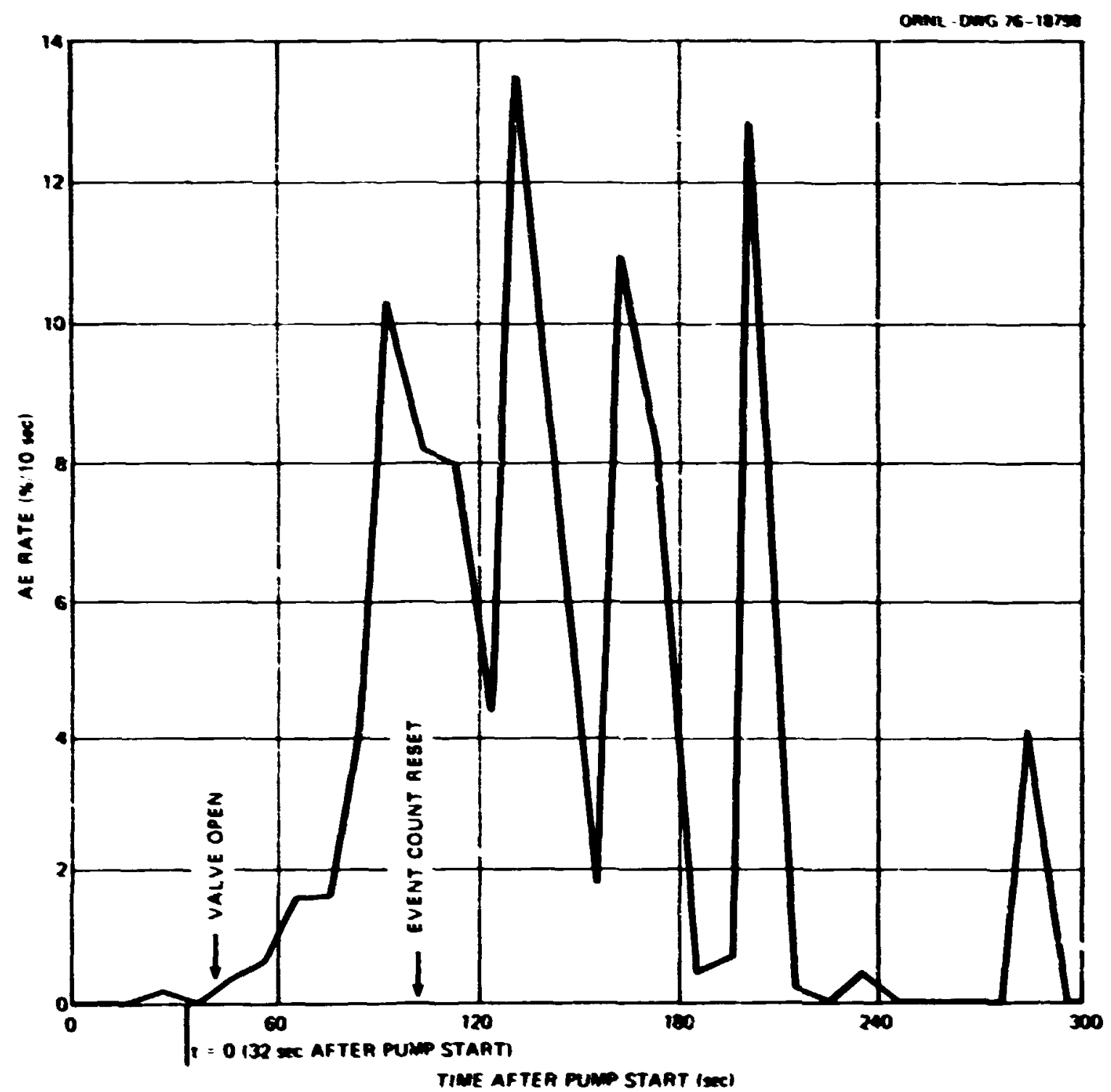

Fig. 23. Acoustic energy emitted in $10 \mathrm{sec}$, as a function of tive, divided by the cotal acoustic energy enitted over a 300-sec period.

The next step was to trepan two 25-a-dian (1-in.) cores from the locations shown in Fig. 24 (cores 3 and 4). Inspection of these cores revealed that the total fractional crack depth was about 251. This was considered excessive from the standpoint of using the test specimen (TSV-1) for another thermal shock test; therefore, three wore cores were removed, and finally a narrow axial section containing the entire crack region was cut from the specimen. The cores and the section were split apart at 


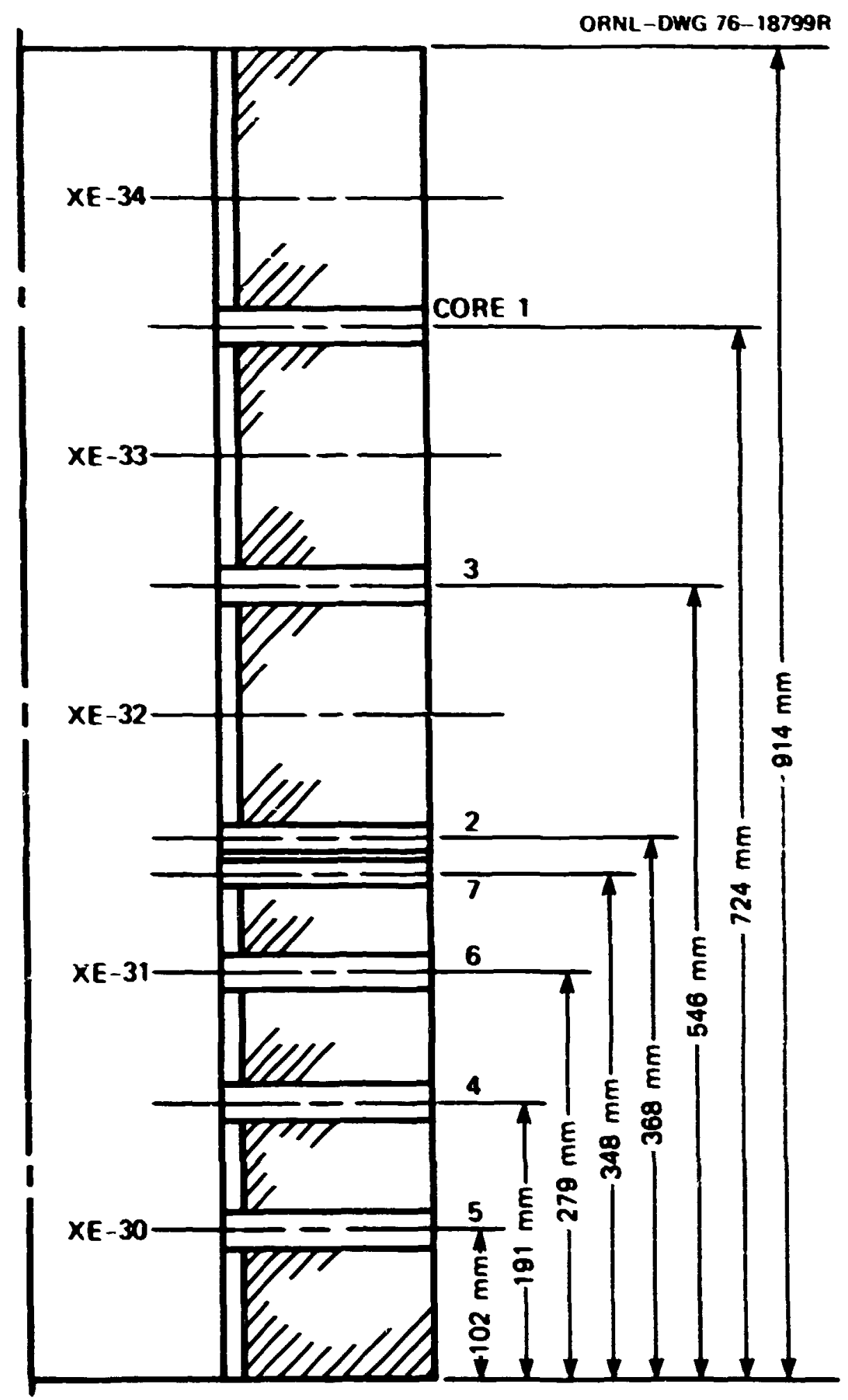

Fig. 24. Location of 25-m-dian (1-in.) cores trepanned from TSV-1 following TSE-1 (cores 1 and 2) and TSE-3 (cores 3 through 7$)$. (1 = 0.039 in.). 
cryogenic temperatures to reveal the iracture surfaces. Locations of the additional cores are showa in Figs. 24 and 25, and photographs of the core fracture surfaces and the section fracture surface are presented in Figs. 26 and 27. Note that the crack depth is reasonably uniform along the length of the test specimen except near the ends of the cylinder and adjacent to the core holes that were achined prior to TSE-3. At these latcer locations, there is essentially no propagation of the initial flaw. The absence of propagation at the edges of the holes presuably is a result of free surface effects that wore than compensate for the stress concentration around the holes. The lack of penetration at the ends of the test specimen probably results from a lack of restraint at the ends of the cylindrical test specimen as well as from free surface effects.

The several "early" initiation events shown in Fig. 22, particularly the one corresponding to $C O D$ gage $X E-31$, indicate that the stress concencration around the holes had an effect on the tine of initiation. COD gage XE- 34 indicated a large crack opening (extension) at about the predicted time (180 sec); however, initiation in this area, even though affected by the presence of the core hole, could have been delayed by the proxinity of the area to the end of the cylinder. COD gage XE-30, which was located the same distance from the end of the cylinder but wuch farther away from a core hole, registered less penetration, assuming that failure of the COD gage (XE-34) implies a considerably larger crack opening than was recorded up to the time of failure. It is also of interest to note in Fig. 27 that there is a substantial length [76-(3 in.)] of flaw at the inlet end that did not initiate, while at the outlet end the penetration tapers off to zero. This difference in behavior at the two ends probably results from the relatively close proxinity of a core hole at the upper end. An SEH exanination of the fracture surfaces showzd that the fractures were of a brittle nacure.

Based on the above observations, it seems reasonable to conclude that the presence of the core holes ( 1 and 2 ) had a significant ef fect on crack propagation, and it is not possible to deteraine whether the flaw would have inftiated in the absence of the core holes. Also, since the COD gages in the central region of the test specimens failed prior to the tine that initiation events ceased, it is not possible to deduce values of $\mathrm{R}_{\mathrm{Ia}}$. 


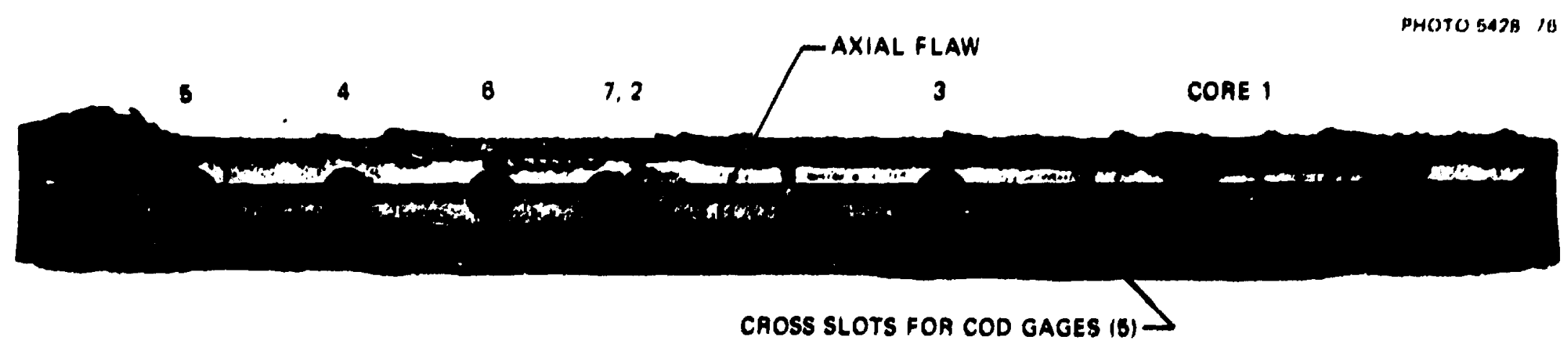

Plg. 25. Section of wall cuncalning the long longltudinal flaw cut from TSV-1 following TSE-3 (1 cm $-0.394 \mathrm{ln}$.). 
PHOTO 5A29 10
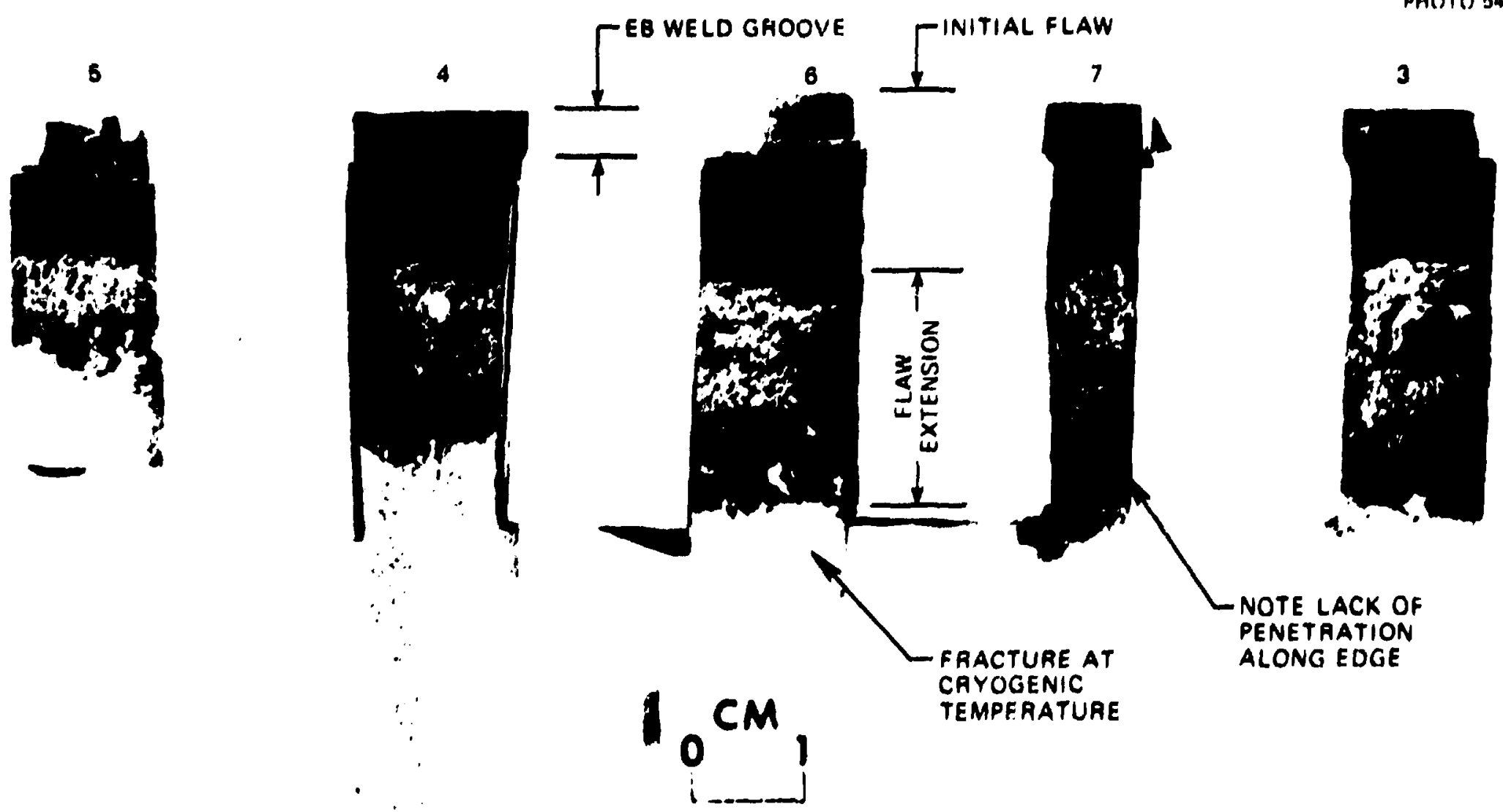

F18. 26. TSE-3 core fracture surfaces $(1 \mathrm{~cm}=0.394 \mathrm{ln}$.$) .$ 
PHOTO 50/B 76

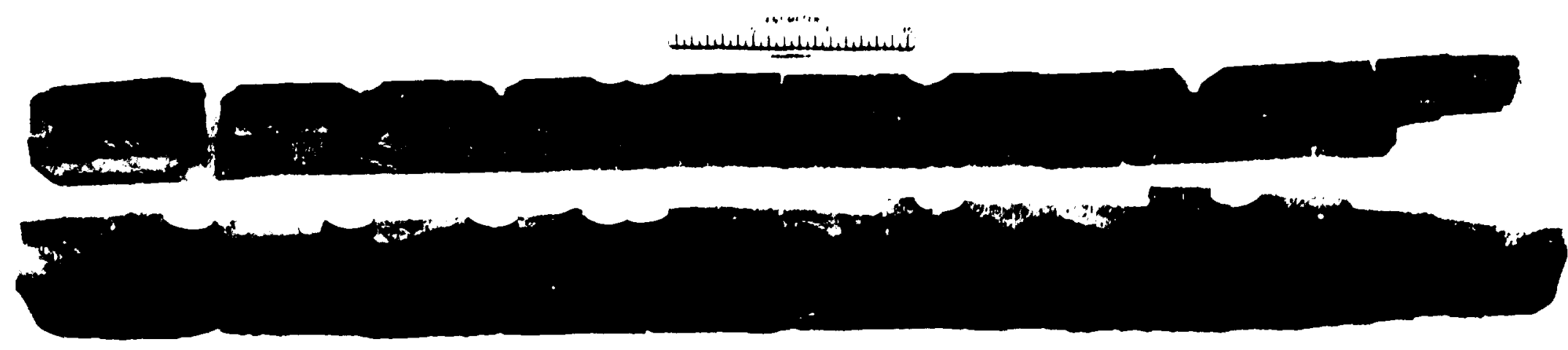

F1g. 27. Fracture surfaces revealed following TSE-3 by splitting long section contalning flaw region. Flow inlet is at 1 eft $(1 \mathrm{~cm}=$ 0.394 (n.). 


\section{THERMAL SHOCR EXPERIYENT TSE-4}

The purpose of TSE-4 was the same as that for TSE-3. The biggest difference in the two experiments was the exclusion in TSE-4 of the two core holes that vere present in the TSE-3 test specinen. The TSE-4 test specinen was TSV-2, which had been used in TSE-2 and at that time contained an axialiy oriented senicircular flaw. Following TSE-2, the 150-am-long (6-in.) flawed region was removed by electrodischarge wachining (EDH) and the hole was plugged (see Fig. 28). The long axial flaw for TSE-4 was pliced $180^{\circ}$ from the plugged core hule. Other differences in TSE-4 vere a core severe thermal shock (the sane as that intended for TSE-3) and a flaw generated without the EB weld groove. Another difference was in the wounting of the COD gages (see Appendix B). In TSE-4, the gages did not fail, and thus all autiple events, if any, could te detected. Furthermore, the potential existed for making rough estimates of crack propagation depths on the basis of COD gage output.

Predictions of crack propagation were ade for TSE-4 based on calculated temperature distributions, an estimated initial flaw depth, and a $K_{I a}$ vs tcmperature curve deduced fron TSE-2 results. These calculations indicated that crack initiation would take place at $102 \mathrm{sec}$ into the transient and that arrest would take place at a fractional wall depth of 0.23 . They also indicated that a single step, exclusive of subcririca; crack growth and possible unstable crack growth associated with EB weld residual stresses, would take place, and reinitiation would not be possible because the maximum $R$ ratio for the arrested rrack depth would be less than unity.

The output from the COD gages is sumarized in Fig. 29 and Table 4, and the location of the gages is shown in Fig. 36. The initial COD event $(0-6 \mathrm{sec})$ is the result of thermal ef fects on the gages, theral stress, and perhaps subcritical crack grouth. In the time range 60-80 sec, there were saall step changes indicated by gages $X E-31,-32$, and -33 , and $X E-32$ indicated a secund step that was considerably larger. At $150 \mathrm{sec}$, all five COD gages indicazed relatively large steps, the three in the midregion being considerably larger than those near the ends.

Acoustic-enission data obtained by SuRI indicated that there were several "high level" emissions in the time period 40-90 sec and then again 

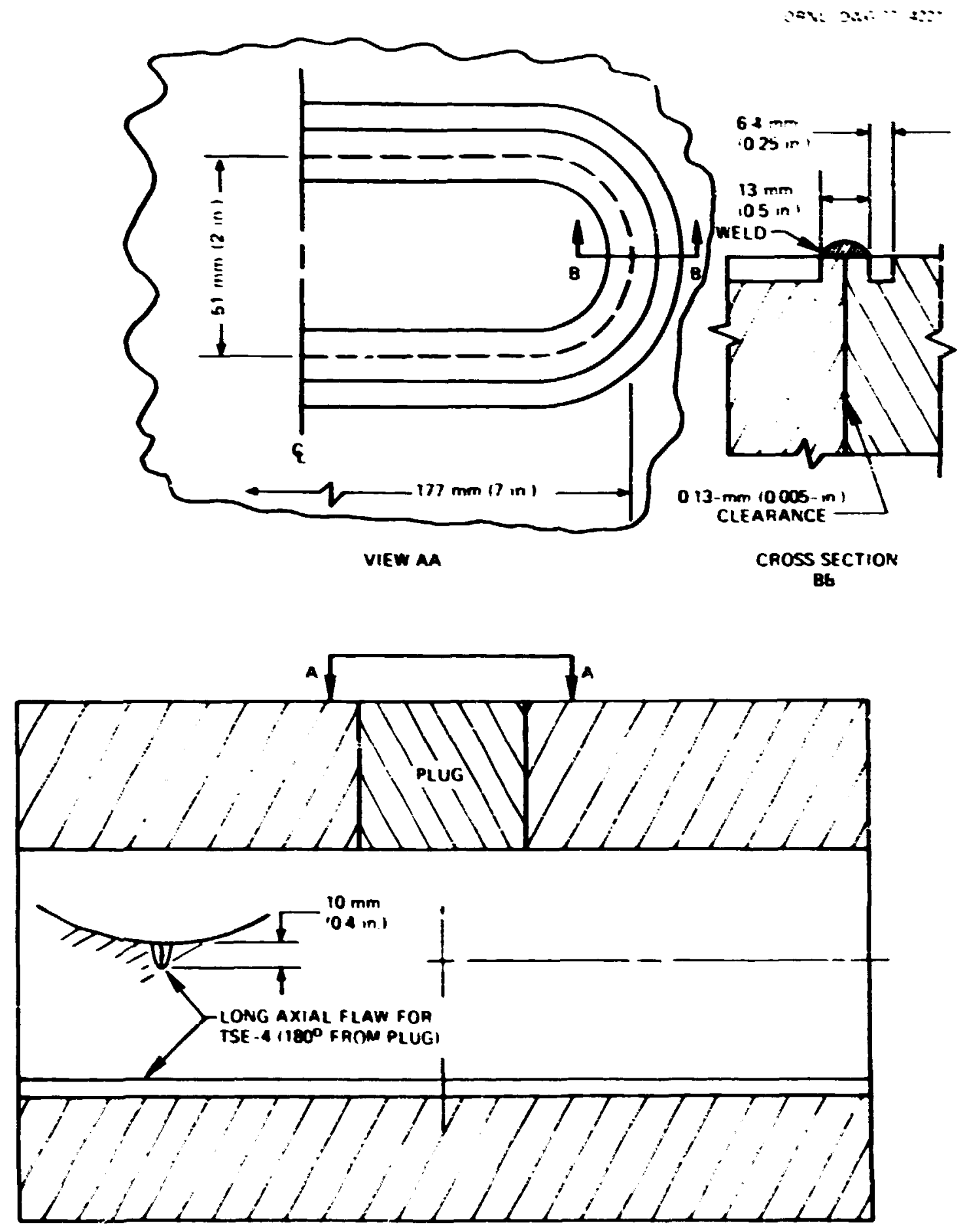

Fig. 28. Plug and flaw details in TSV-? as preparce for TSE-4. 


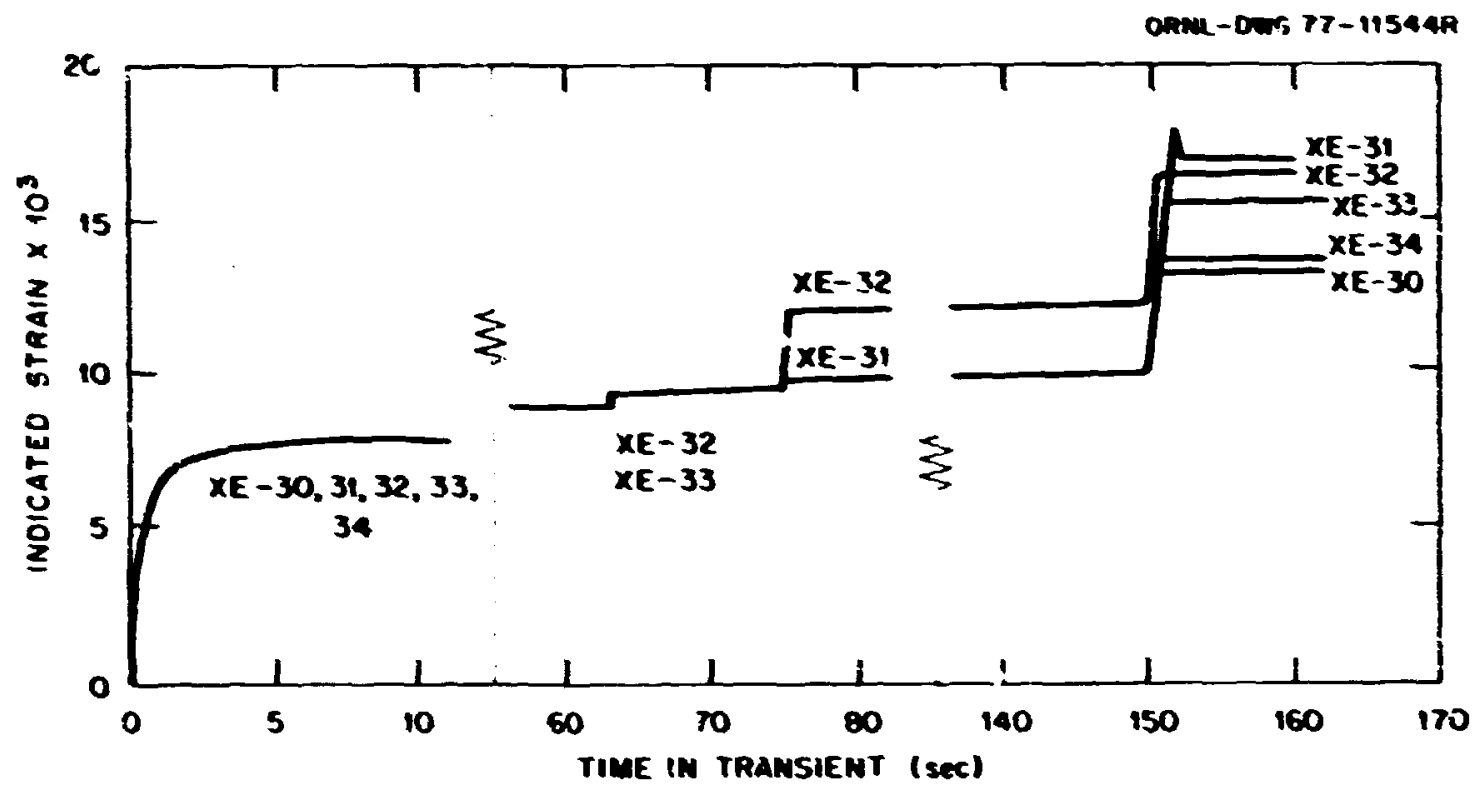

Fig. 29. Illustration of changes in indicated strain froe COD gapes during TSE-4 (not quantitatively precise).

Table 4. Step changes in COD output during TSE-4

\begin{tabular}{|c|c|c|c|c|c|}
\hline \multirow{2}{*}{ COD gage } & \multicolumn{5}{|c|}{ Change in strain (microstrain) } \\
\hline & Time (sec): & $0-6$ & $64-68$ & $74-76$ & $150-152$ \\
\hline$X E-30$ & & 6400 & & & 3700 \\
\hline$x E-31$ & & 7000 & & 280 & 6600 \\
\hline$x E-32$ & & 6700 & 150 & 2000 & 4800 \\
\hline$x F-33$ & & 7000 & & & 5700 \\
\hline$x E-34$ & & 6500 & & & 3700 \\
\hline
\end{tabular}


CANL-DWG 7T-11543R

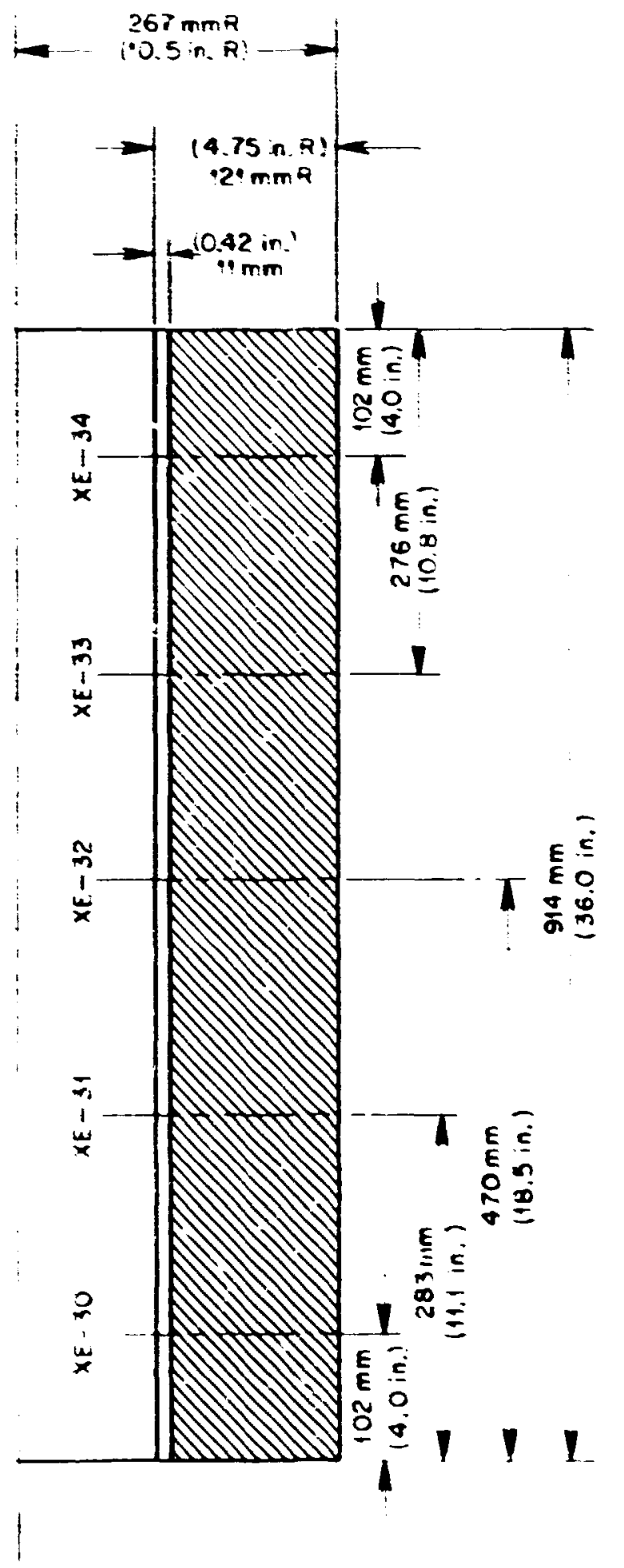

Fig. 30. Location of COD gages on TSV-2 for TSE-4. 
at 2150 sec. Several events occurred froa 160 to $240 \mathrm{sec}$ but vere of lower agnitude. It is possible that sone of the acoustic enissions emanated fron the core-hole plug iocated $180^{\circ}$ from the long axial crack. It was not possible to differentiate between the acousic enissions enanating from these two locations.

Very little AE daca were collected by Battelle Pacific Northest Laboraturies because a necessary last-ainute relocation of vaveguides apparently resulted in one of their two waveguides not seating properly against the test specinen. No AE data were recorded, but visual observations of the scope indicated that events occurred at 2154, 224, and $235 \mathrm{sec}$, the first enission being much greater than the other two. Hore details regarding the AE data are included in Appendix B.

There was one other acoustic enission detected during the thermal transient: at approximately $150 \mathrm{sec}$ into the transient, several nbservers within 5 a (15 ft) of the test specinen heard a single loud ping, which was similar to, but louder than, those heard during TSE-3.

After removal of the test spevinen from the test facility, it was observed that ail COD gages were buckled along their unbonded length (see Figs. 31 and 32). This would be expected because of the large indicated local strain (1.77). This does not imply that the strain measurements during the transient were inaccurate; laboratory tests have shown that, while under tension, the partially bonded gage has good accuracy to 22 strain and is a satisfactory event indicator to 57 strain (see Appendix B).

In order to perait exanination of the fracture surfaces, five 25-indian (1-in.) cores were trepanned from tine flawed area following the thermal shock experiment. As shown in Fig, 33, the cores wire taken fron regions of the test specimen close to each of the COD gages. The core closest to the center of the specimen was located directly under COD gage XE-32 and is shown in Fig. 32. A short section of the core containing the extended crack was separated from the rest of the core and then split at cryogenic teperatures to reveal the fracture surfaces. These surfaces for the three centrally located cores are shown in Fig. 34, and the actual initial and final erack depths that were deterainev from an exanination of the exposed surfaces are listed in Table 5 . As indicated, the initial flaw depth was about as expected $(0.076)$, and the final depth $(0.14-0.17)$ was reasonabiy 


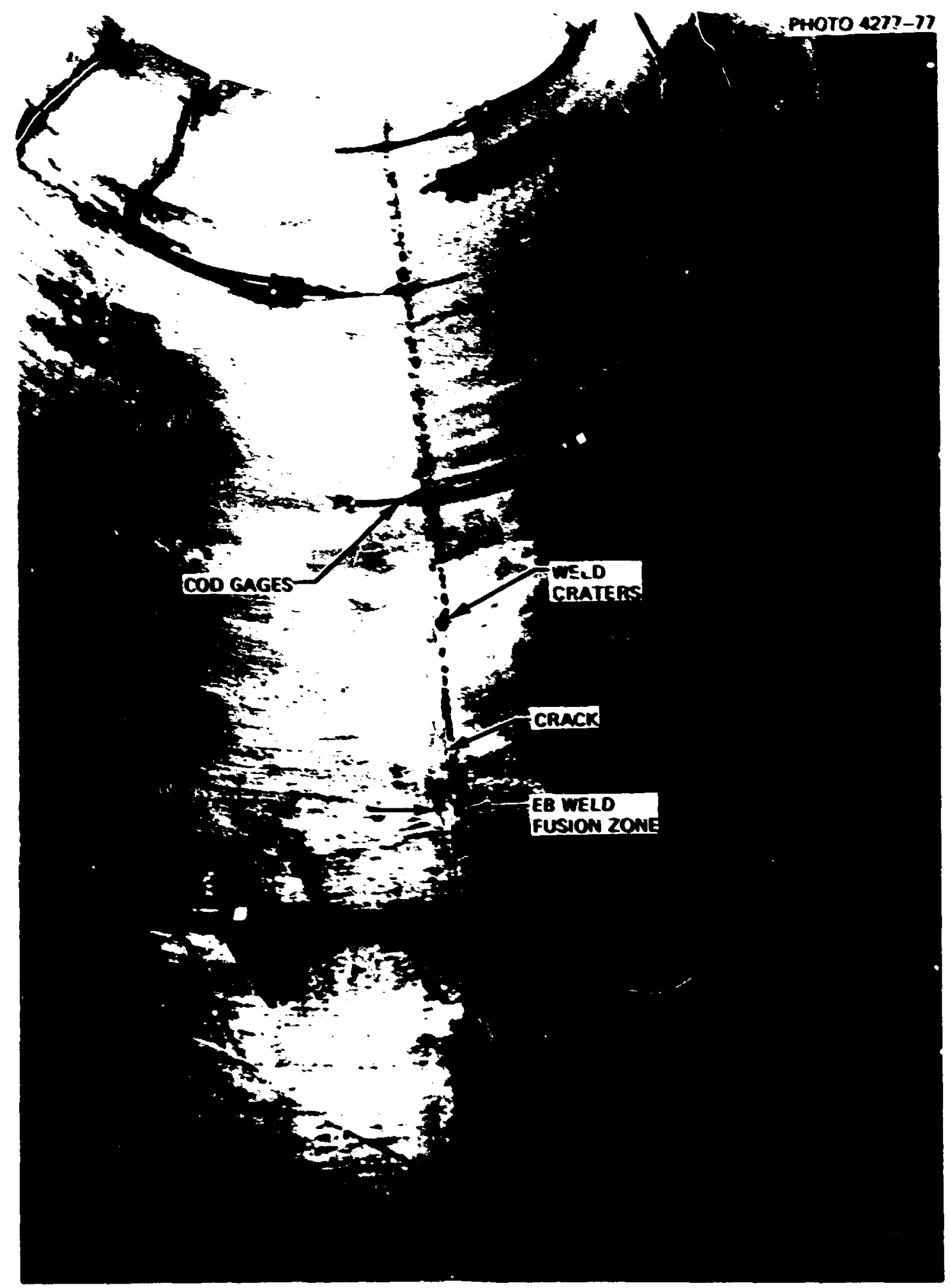

Fig. 31. View of inner surface of TSV-2 following TSE-4 showing electron-beas weld $f l a w$ and $C O D$ gages. Cages buckled during experiment. 
PHOTO 4278-77

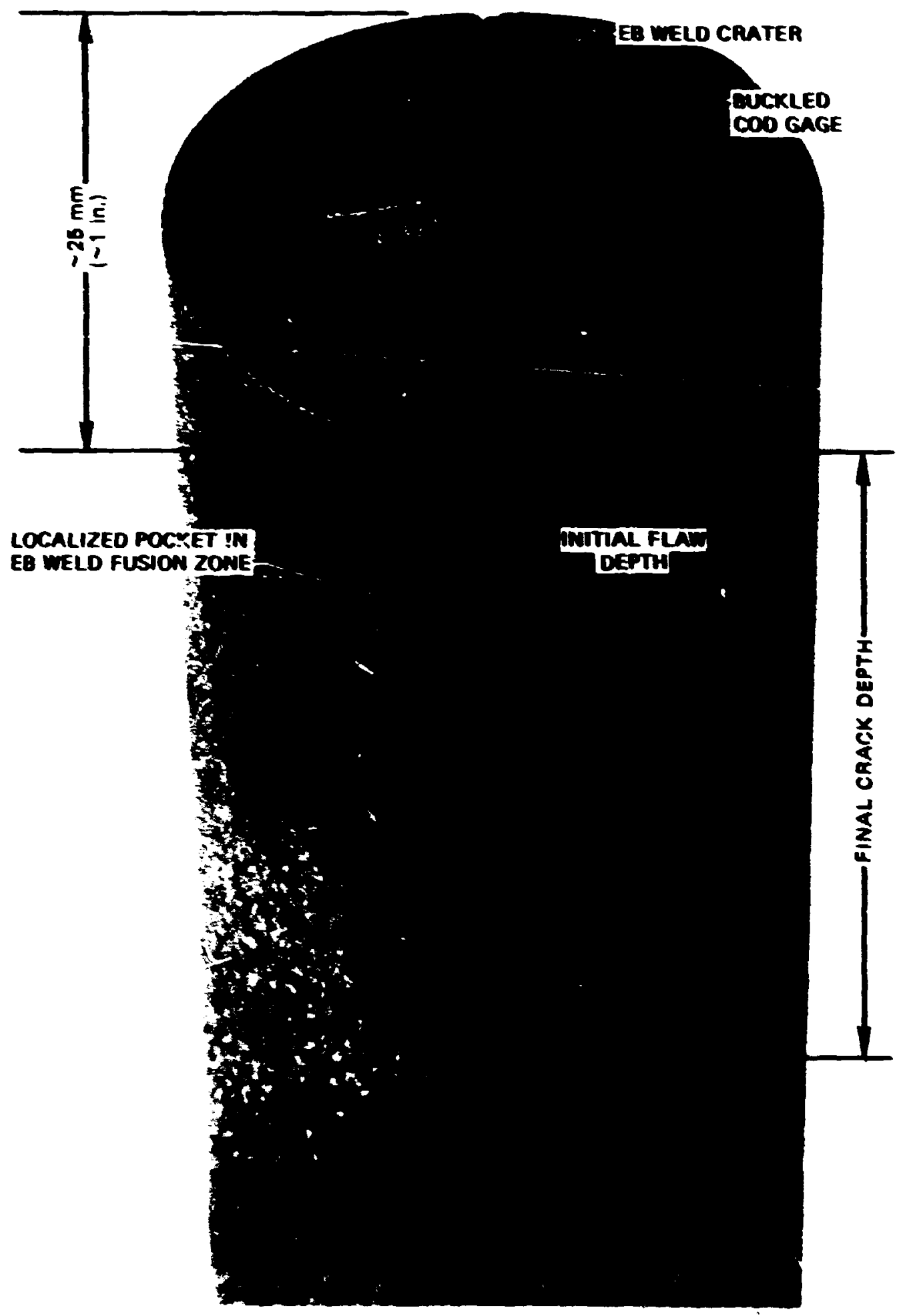

Fig. 32. Core trepanned frcn TSV-2 following TSE-4 showing initial and final crack depth and a buckled COD gage; location at widlengch of cest specinen. 
ivl cang i: itsesa

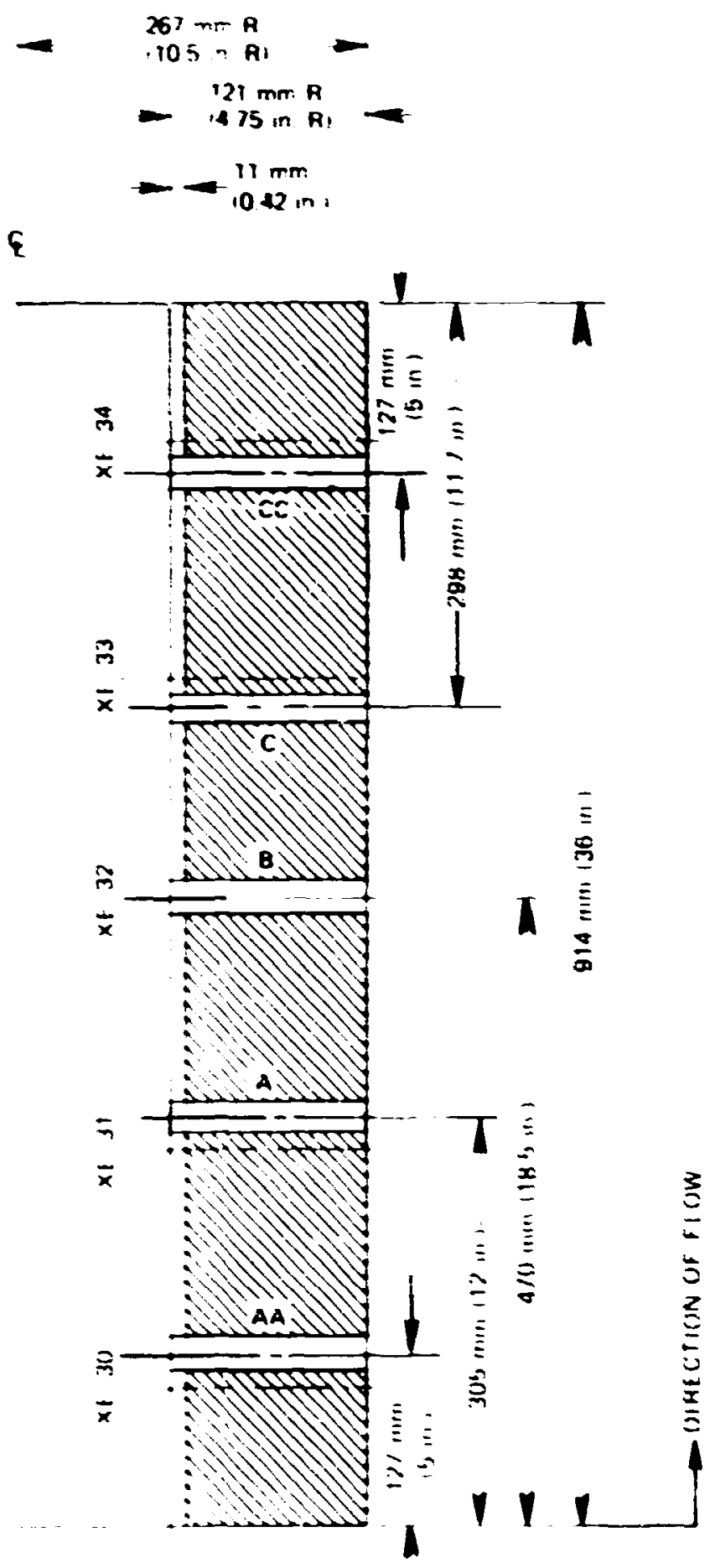

Fig. 33. Location of 25-m-diam (1-in.) cores trepanned from TSV-2 following TSE-4. 


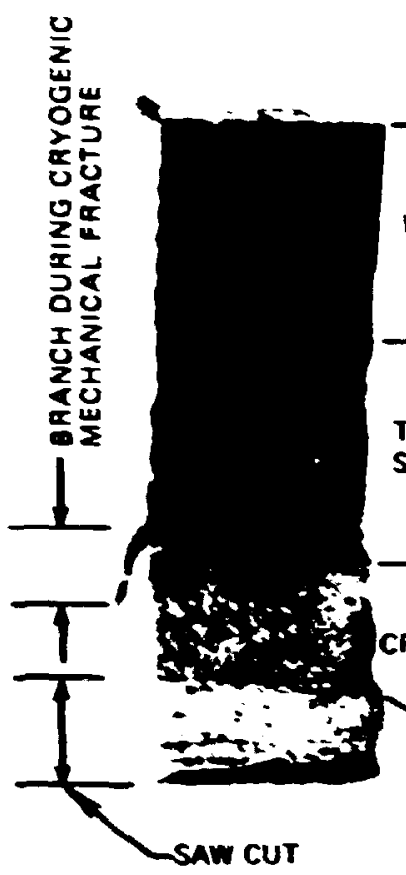

C

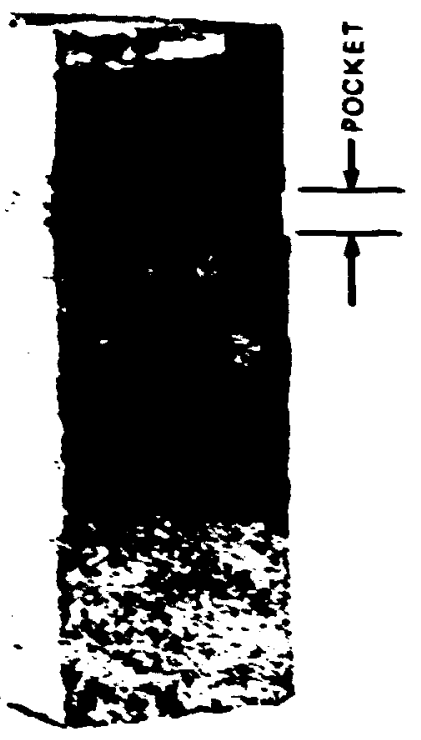

8

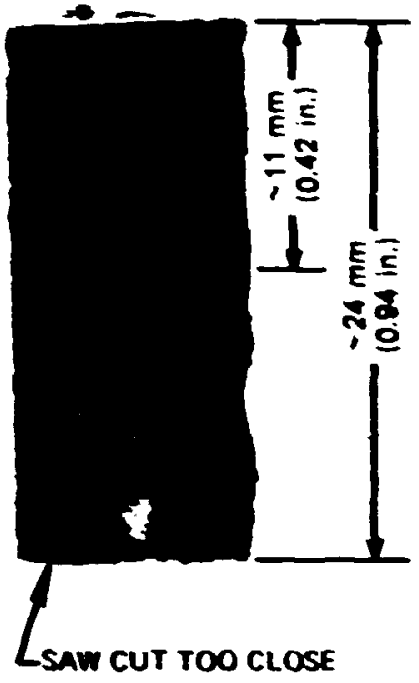

A

Fig. 34. Fracture surfaces revealed by splitting short sactions of 25-m-diam (1-in.) cores at cryogenic temperatures. Cores trepanned from TST-2 following TSE-4. Refer to Fig. 33.

Table 5. Keasured flaw depths at locations of core holes

\begin{tabular}{lll}
\hline & \multicolumn{2}{c}{ Fractional flaw depth } \\
Core & \multicolumn{1}{c}{$(\mathrm{w})$} & \\
\cline { 2 - 3 } & Initial & Final \\
\hline AA & 0.076 & 0.163 \\
A & 0.082 & 0.174 \\
B & 0.071 & 0.158 \\
C & 0.071 & 0.152 \\
CC & 0.071 & 0.141 \\
\hline
\end{tabular}


uniform over the region containing the cores. The shallowest penetration (0.14) was neai one end, as would be expected on the basis of TSE-3 results. of particular interest is the uniformity of final depth over most of the length, wich demonstrates that the cylinder is effectively infinitely long. Calculations made using the measured transient temperature distributions (see Figs. 35,36 , and $3 i$ for typical distributions and Appendix $C$ for detailed results of the calculations) and the nominal $K_{I c}$ vs $T$ curve in Fig. 6 indicate $a k$ ratio of $\imath 1.10$ at $140 \mathrm{sec}$ for $a / w=0.076$. The fractional crack depth corresponding is $2 \mathrm{k}$ ratio of 1.00 at $150 \mathrm{sec}$ is 20.090 , and the calculated + ive at wich $K_{I} / K_{I c}=1$ for $a / x=0.076$ is $2125 \mathrm{sec}$. At $75 \mathrm{sec}$ into the transient, the $k$ ratio for $a / w=0.076$ is 20.6 , and the naxiaur $K$ ratio at that $t$ ine is 20.8 and corresponds to $a / w=0.03$. The maxima $K$ ratio calculated for $a / w=0.076$ was 1.29 and occurred at $25 \mathrm{~min}$.

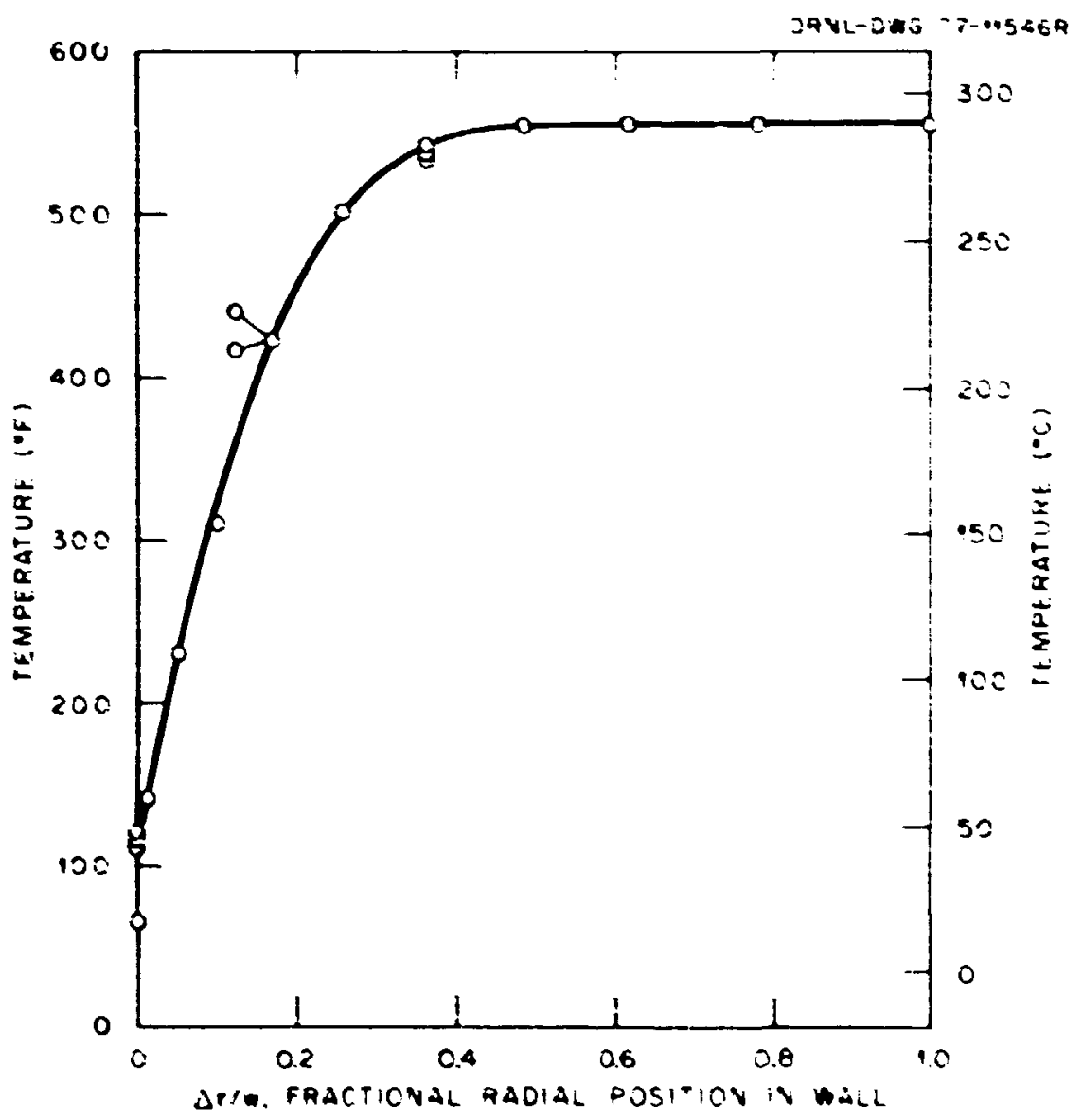

Fig. 35. Radial temperature distribution weasured during TSE-4 at $40 \mathrm{sec}$ into the transient. 


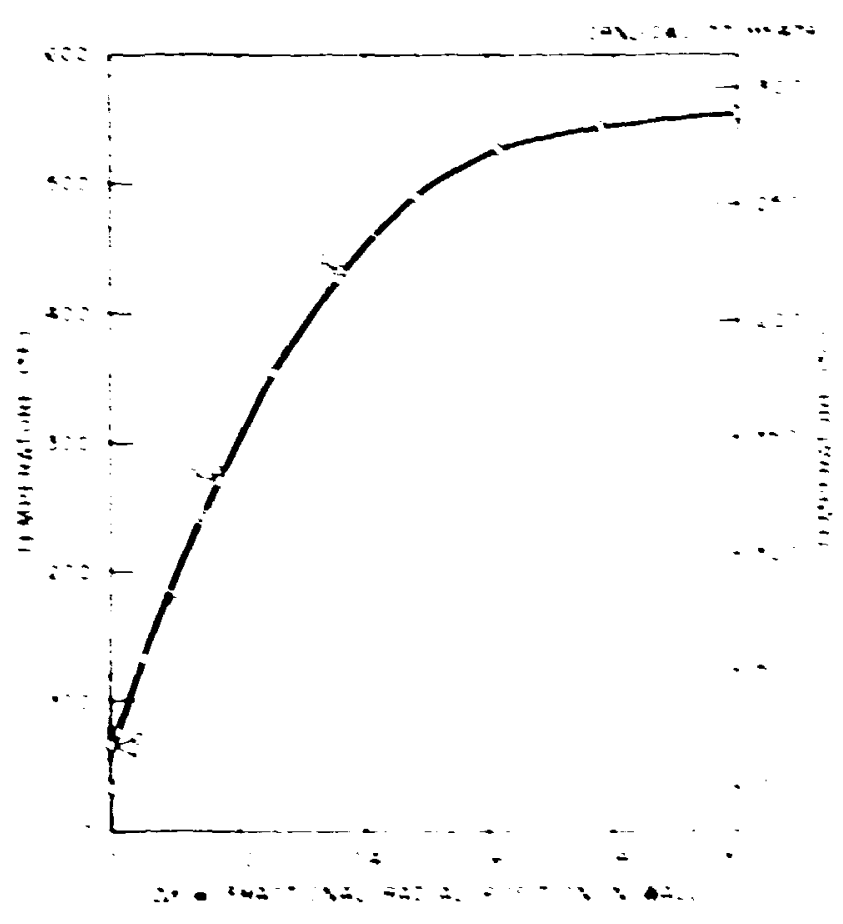

Fig. 36. Radial temperature distribution weasured during TSE-4 at $162 \mathrm{sec}$ into the transient.

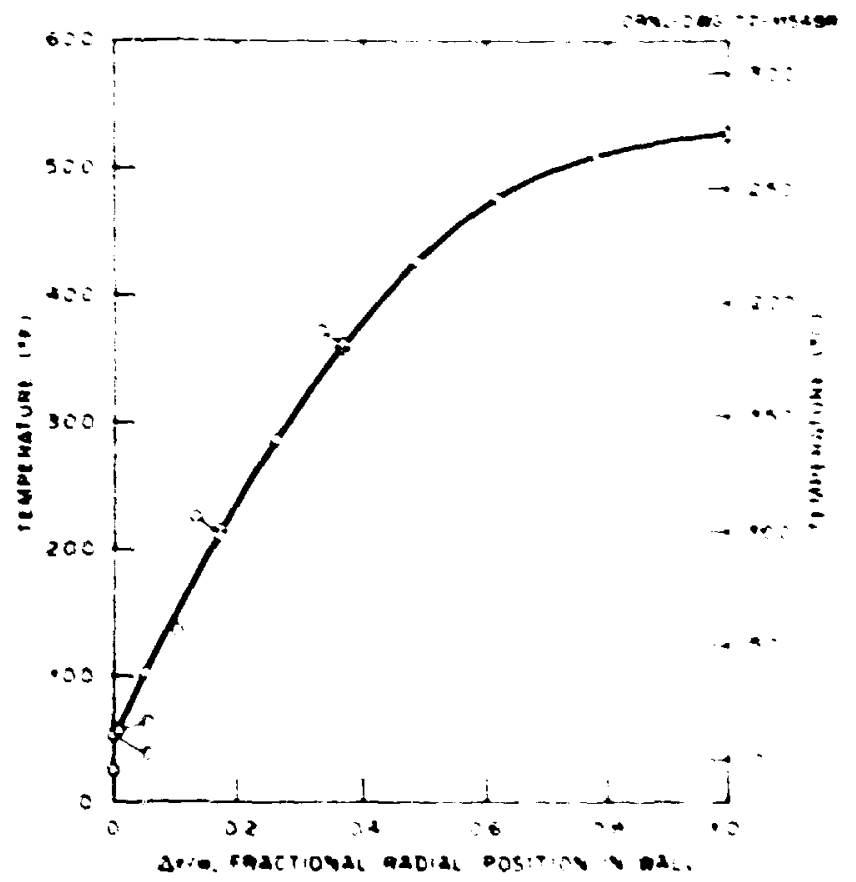

Fig. 37. Radial temperature distribution neasured during TSE-4 at $302 \mathrm{sec}$ into the transient. 
The test specimen temperature corresponding to $a / w=0.076$ and $t=150$ sec was $074^{\circ} \mathrm{C}\left(\sim 165^{\circ} \mathrm{F}\right)$. At this temperature, a $10^{\circ}$ variation in $\mathrm{K}_{\mathrm{IC}}$ corresponds to an $8^{\circ} \mathrm{C}\left(15^{\circ} \mathrm{F}\right)$ change in temperatcre. Al? things considered, the accuracy of the cemperature measurement is not much better than this. Thus, inaccuracies in temperature measurements could account for the apparent 105 "error" in the above calculated $k$ ratio $\left(K_{I} / K_{I c}=1.10\right.$ for $a / k=$ 0.076 and $t=150 \mathrm{sec}$;. However, it is wore likely that most of the error is associated with the scatter in the $K_{I c}$ vs $T$ data.

Before the five cores were removed from the test specimen, an indication of final crack depth was obtained by combining the CUD output wizh the calculated (finite-element) crack openings for various crack depths. By this process, the final fractional crack depth near the central portion of the test specimen was estimated to be 0.15 , assuming an initial fractional crack depth of 0.076 . The total calculated crack opening from initiation of the transient to $t=150 \mathrm{sec}$ for $\mathrm{a} / \mathrm{w}=0.15$ is $0.30 \mathrm{~mm}$ $\left(12 \times 10^{-3} \mathrm{in.}\right)$, and the COD output also indicates a value of $0.30 \mathrm{~mm}$.

Once the actual final crack depth was known, it was possible to obtain an estimate of the arrest toughness for a specific temperature. For $a / w=$ 0.15 and $t=150 \mathrm{sec}$, the cemperature was $126^{\circ} \mathrm{C}\left(258^{\circ} \mathrm{F}\right)$, and $k_{I}=127$ $M N \cdot m^{-3 / 2}\left(116 \mathrm{ksiv} / \overline{n_{0}}\right)=K_{I a}$. This value of $K_{I a}$ is about 25 ; greater than the value deduced from TSE-2, as shown in Fig. 17.

Based upon these results and with only nominal values of the various paraweters considered, it would appear that the predictive merhods of analysis used in connection with TSE-4 are quite accurate. 


\section{FRACTOGRAPHIC EXAMINATION OF THE FRAC ELRE SLRFACES DEVELOPED DURING TSE-1, TSE-3, and TSE-4}

$$
\text { D. A Canonico }{ }^{*} \text { R. S. Crouse }
$$

Two thernal shock test cyinders (TSV-1 and TSV-2) were used for the four theral shock experiments. TSV-l was used for thermal shock experiments 1 and 3 (TSE-1 and TSE-3); TSV-2 was used for thermal shock experiweats 2 and 4 (TSE-2 and TSE-4). A description of the processing history and eechanical properties of these test cylinders was previously provided.' Hetallographic examinations were conducted on specimens removed from the test cylinders after the experiments were completed. The exaninations made after completion of TSE-1 and TSE-2 were previously recorded. 1,15 Since that time, additional studies hare been conducted on the wetallographic specimens from TSE-1.

The intent of this study is to ascertain the mode of fracture that occurred as a consequence of the chermal shock. The wetallographic examinations included scanning electron microscopy (SEM) for samples from TSE-1, -3 , and -4 and light wicroscopy examinations of samples from TSE-4.

Test sylinder TSY-1 contained a long axial flaw. The same flaw was used in both TSE-1 and TSE-3. Following TSE-1, chree 25-m-diam (1-in.) cores were removed from the flawed region of the test cylinder. These cores were netallographically examined, and a slight crack extension was noted. Reference 15 describes the examination of these cores. There was some question regarding the wode of the slight crack extension that was found, and this area has been examined wore thoroughly following TSE-3. Prior to TSE-3, the core holes were plugged. Following TSE-3, in which the test cylinder was subjected to a wore severe thermal shock than in TSE-1, the entire crack region was removed from the cylinder and opened to reveal the fracture surfaces. Samples of the fracture surface were rewoved from near the central region of the vessel and examined by means of Say and light aicroscopy.

The test cyllinder used for TSE-2 and TSE-4 had two different slaws $180^{\circ}$ apart. In TSE-2, the initial flaw was semicircular with a radius of

\footnotetext{
* Mecals and Ceranics Division.
} 
$19 \mathrm{~mm}(0.75 \mathrm{in.})$, and, as a result of the thermal shock, the flaw extended to a length of $2140 \mathrm{~m}$. is core containing the entire flaw was rewoved for metal lographic examination, the results of wich are discussed in Ref. 1 . Prior to TSE- $i$, the oblong core hole was plugged, and a long axial flaw was generated at a position $180^{\circ}$ fron the plug. Fcllowing TSE-4, which was basically the same experiment as TSE-3, three 25-n-dian (1-in.) cores were rewoved from the central portion of the crack zone for exanination.

As an aid in understanding the role of $S E A$ in deteraining the fracture mode during crack propagation, the fracture appearance of Charpy V-notch $\left(C_{v}\right)$ specimens of the same material used in the thermal shock experiments was documented. The $c_{v}$ data from these tests were previously reported. ${ }^{16}$ The specisens were obtained from near the inner wall of the prolongation from one of the thermal shock cylinders. The prolongations had been exposed to exactly the same austenitizing and quench treatwent as the cylinders. Further, they were held at $288^{\circ} \mathrm{C}\left(550^{\circ} \mathrm{F}\right)$ for $24 \mathrm{hr}$ to simulate any "tcoper" that the cylinders would undergo as a consequence of being held at $288^{\circ} \mathrm{C}$ prior to th: rhermal shock.

Three tested $C_{i}$ specimens were selected for this discussion. Specimen identification, test temperatures, and recorded toughnesses are given in Table 6. The specimens represent material behavior that is essentially on the lower shelf (ITS-154), in the transition region (ITS-159), and on the upper shelf (ITS-161). SEM photomicrographs of the fracture surfaces of the $C_{v}$ specimens at a magnification of $300 \times$ are shown in Fig. 38 . The

Table 6. Charpy v-notch test specimens used in scanning electron microscopy study of TSE-3 and TSE-4

\begin{tabular}{ccc}
$\begin{array}{c}\text { Specimen } \\
\text { identification }\end{array}$ & $\begin{array}{c}\text { Test } \\
\text { temperature } \\
{\left[{ }^{\circ} \mathrm{C}\left({ }^{\circ} \mathrm{F}\right)\right]}\end{array}$ & $\begin{array}{c}\text { Charpy V-notch } \\
\text { impact energy } \\
{[\mathrm{J}(\mathrm{ft}-\mathrm{lb})]}\end{array}$ \\
\hline ITS-154 & $-46(-50)$ & $11.5(8.5)$ \\
ITS-159 & $93(200)$ & $22(16)$ \\
ITS-161 & $177(350)$ & $43(31.5)$ \\
\hline
\end{tabular}



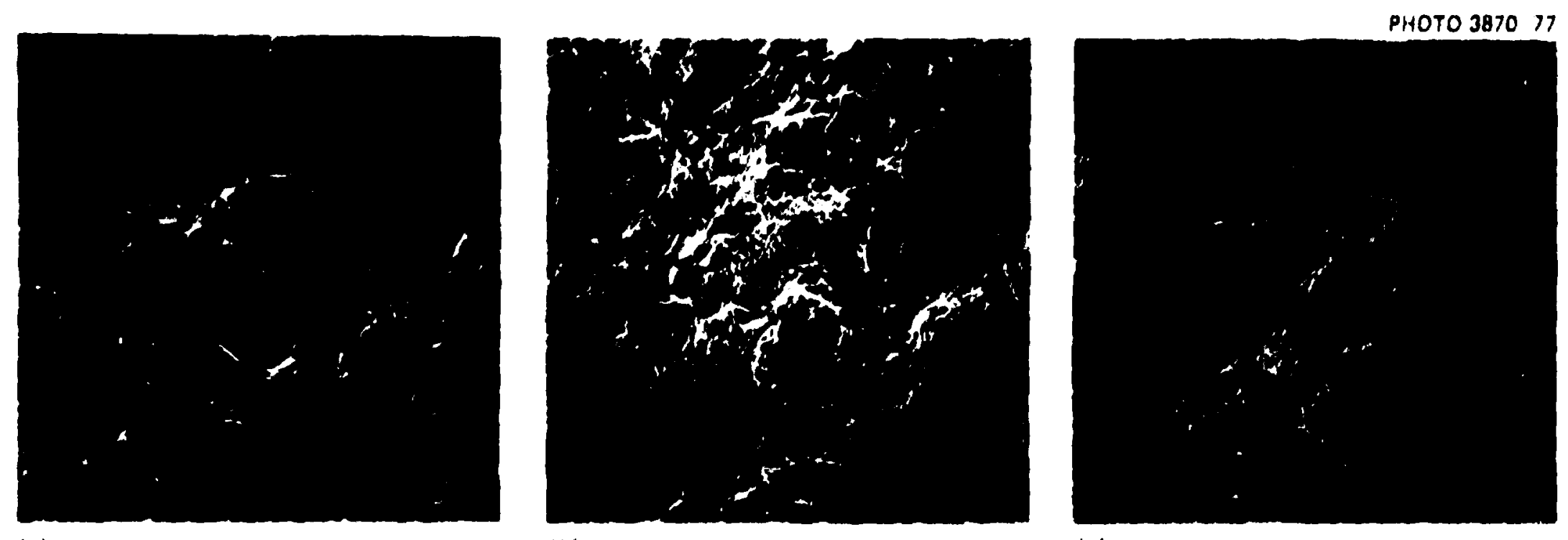

\begin{tabular}{|c|c|c|}
\hline & $\begin{array}{l}\text { TEST TEMPERATURE } \\
{\left[{ }^{\circ} \mathrm{C}\left({ }^{\circ} \mathrm{F}\right)\right]^{\circ}}\end{array}$ & $\begin{array}{c}\text { ENERGY ABSOABED } \\
{[J|f(-\mid b)|}\end{array}$ \\
\hline (a) & $-46(-60)$ & $11(8.6)$ \\
\hline (b) & 83 (200) & $22(16)$ \\
\hline (c) & $177(360)$ & $43(31.5)$ \\
\hline
\end{tabular}

F1g. 38. Scanning electron micrographs of Charpy V-notch specimens tested if the temperatures Indlcated (magniflcation 300x). The Impact energy absorbed at the test temperature is given. (OrIginal roduced 20.5\%) 
specimen tested at the highest temperature (ITS-16I) extibits a dimple fracture mode. This $m$ ie is indicative of a ductile failure and, indeed, was tested at a temperature on the upper shelf for this materiai. The other two specimens are sonewhat similar in appearance; boti contain a predominately cleavage fracture surface with some small regions that failed in a dimple mode. The percent of dimple fracture, although small in both samples, appears to be greater in the specinen tested at $93^{\circ} \mathrm{C}$. These SEy photomicrographs will be used for comparative purposes during the discussion of the fractures that occurred in TSE-3 and TSE-4.

\subsection{Thermal Shock Experinents TSE-1 and TSE-3}

The section of the fracture surface from iSV-l that was removed for examination following TSE-? is shown in Fig. 39. Three specimens vere removed for SEM examination, and the photomacrographs of the surface (magnification $22 x$ ) are shown in Fig. 40 . An extensive SEY examinatiun was made of each surface. This examination identitied the shailos ( $2 \mathrm{~mm}$ ) extension attributed to TSE-1 and revealed that the iracture mode for this narrow region was predcminately durtile (dimple structure).

Additional proof regarding the fracture mode for TSE-1 was obtained by examining a cored specimen that had been removed from the test cylinder following TSE-1 and mounted in epoxy for metallograplic examination of the crack line. This well-preserved specimen was demounte. and the fracture surfaces exposed by completing the iracture mechanicaliy at cryogeni: temperatures. An SEY examination revealed that the extension that took place during TSE-1 was ductile. These recent findings are contrary to SEM observations repcrted earlier for a different specimen.' However, the fracture surfaces examined earlier were partially obscured by a protective filn, and a final conclusion was deferred until the recent examinations could be completed.

Figure 41 shows SEX photomicrographs taken .t a magnification of $300 x$ of representative areas from specimens TSE-3-1 and TSE-3-2 (see Fig. 40 ) that correspond to the TSE- 3 crack extension. The similarity between the areas is evident, and a third specimen (TSE-3-3), which is not shown, had a fracture appearance nearly identical to the two show in fig. 11 . The 


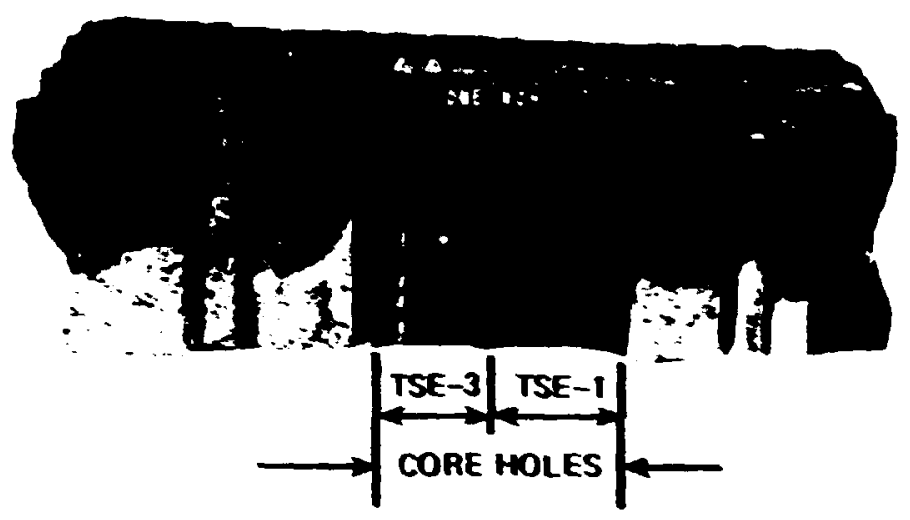

Fig. 39. Photograph of a section of the fracture surface from TSV-1 following TSE-3 (1 in. $=25.4 \mathrm{~m}$ ).

fracture was essentially by the cleavage wode, with a sall. percentage of the area exhibiting a dimple worphology. These SEA photonicrographs can be compared to those shown in Fig. 38. The similarity between the photoaicrographs in Fig. 41 and the $C_{v}$ specinen fractured at $93^{\circ} \mathrm{C}$ (Fig. $38 \mathrm{~b}$ ) is evident .

Specimen TSE-3-1 was selected for a wore extensive study of the fracture surface. Figure 42 contains SEY photonicrographs of the same region of the fracture surface in the TSE-3-1 specimen shown in Fig. 40. The photonicrographs were taken at progressively higher agnification in order to distinguish the character of the fracture. The fracture is predoninately in the cleavage node; however, there are areas that exhibit what appears to be a dimple mode of fracture. These areas were examined at magnifications as high as $3000 x$, and the fact that they do, indeed, contain small regions that exhibit a diple wode of fracture was substantiated.

\subsection{Thermal Shock Experiment TSE-4}

Samples of the fracture resulting from TSE-4 were obtained by trepanning ihree cores from the central region of the fracture (see Fig. 33). The configuration of the core samples is similar to that shown in Fig. 43, wich depicts the cores removed following TSE-I (Refs. 1, 15). The only difference in the appearance of the TSE-4 and TSE-1 cores is the slot 


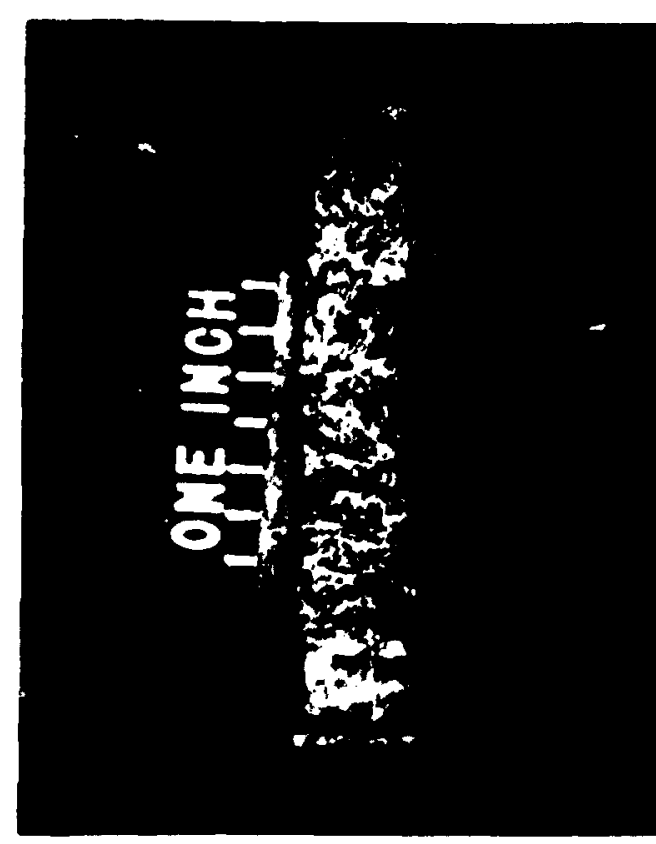

(a) TSE-3-1

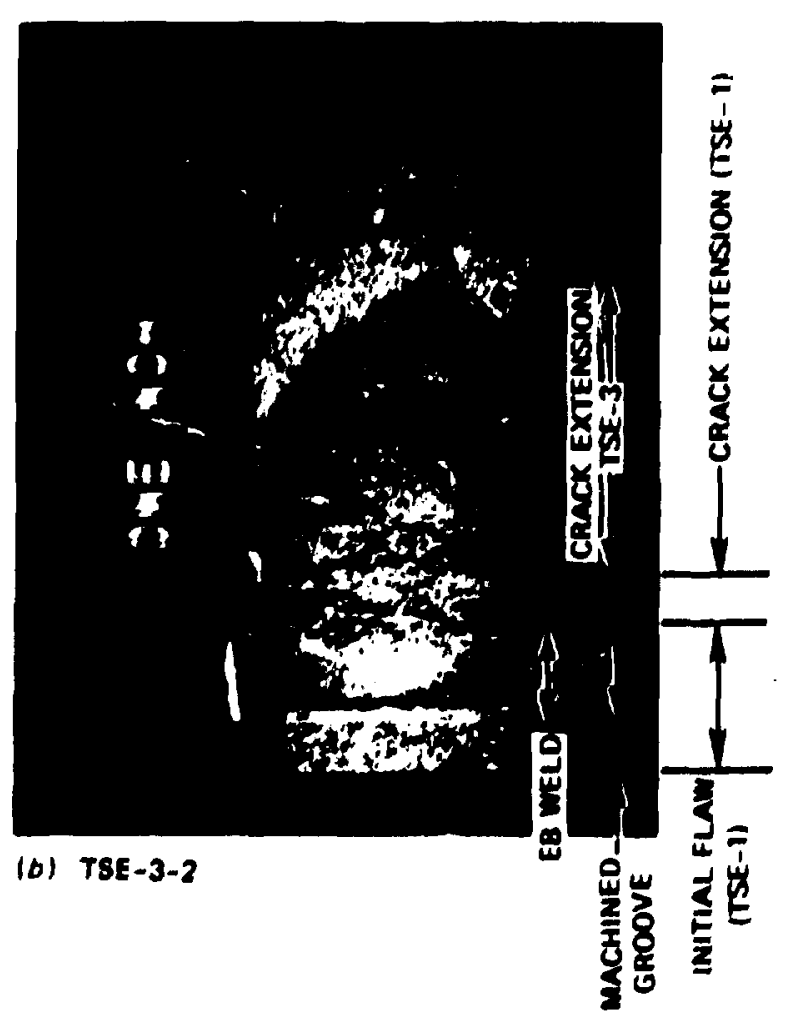

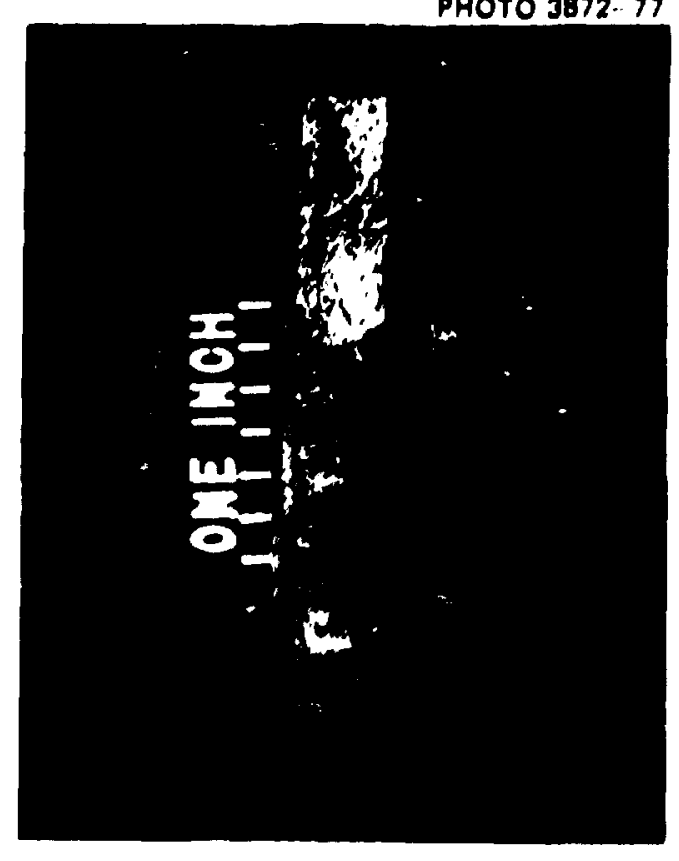

(c) TSE-3-3

F1g. 40. Photomacrographe of the three surfaces examiried by acanning electron mlcroscopy. The pecimens were denlgnated TSE-3-1, TSE-3-2, and TSE-3-3 (1 1n. - $25.4 \mathrm{~mm})$. (Origlnal reduced $22.5 \%$ ). 


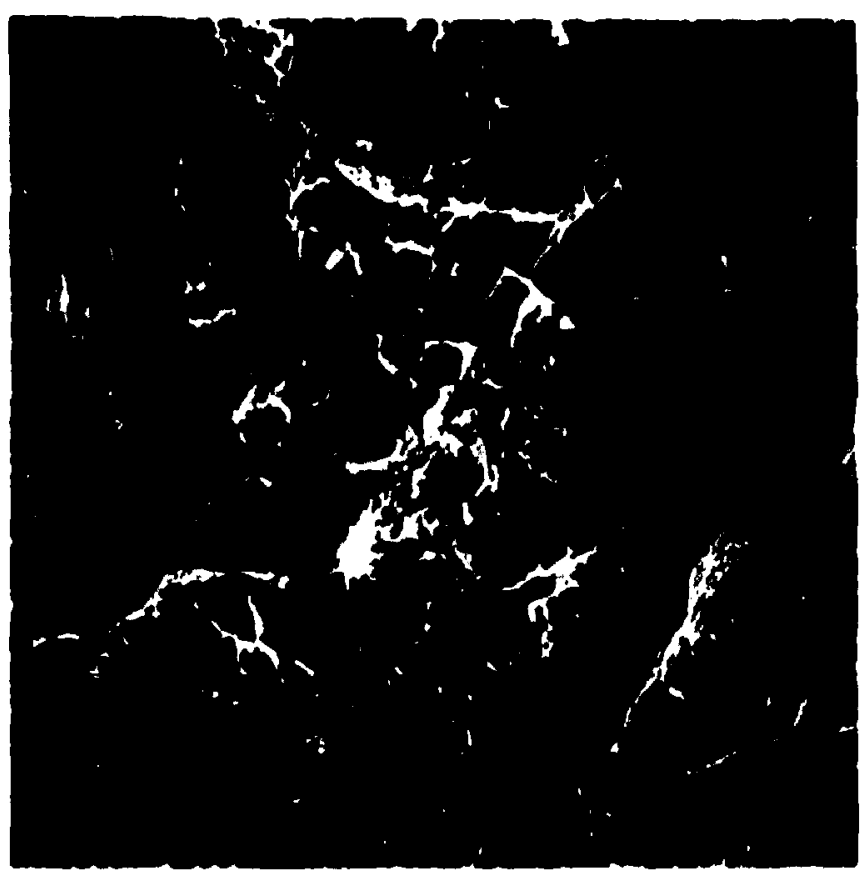

(a) TSE-3-1

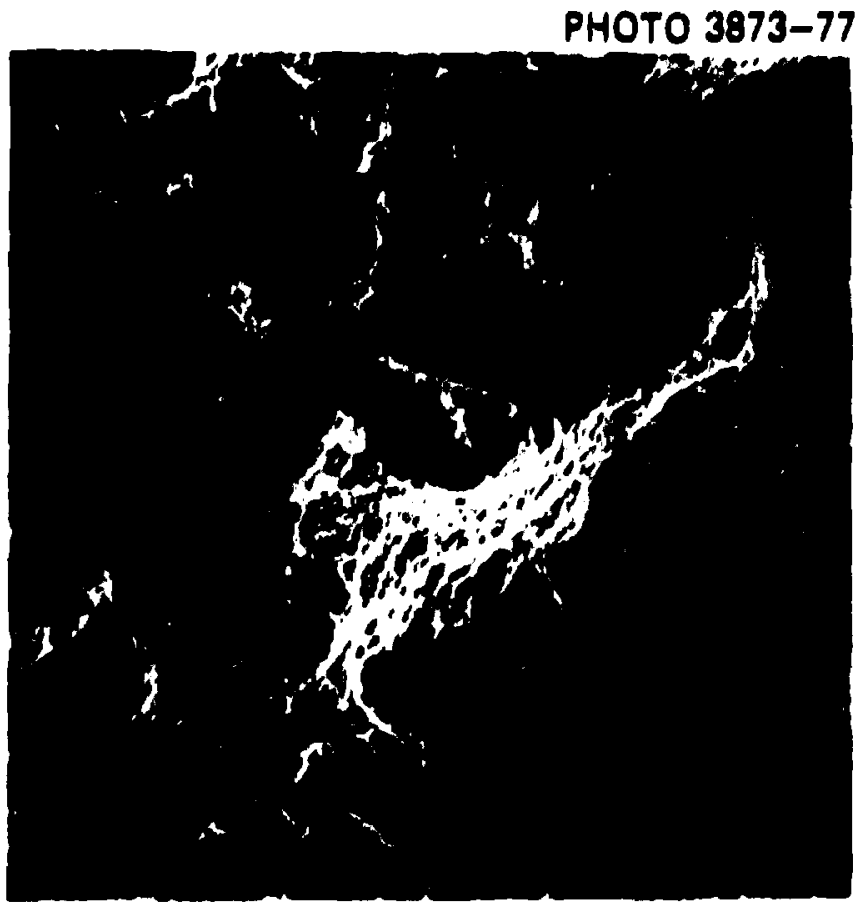

(b) TSE-3-2

818. 41. Scanning electron micrographs of represantative areas of the :racture eurface from TSE-3 (magniflcation 300x). The fracture is predominately by the cleavage mode with amall reglone exhlbiting a dimple mode of eracture. 


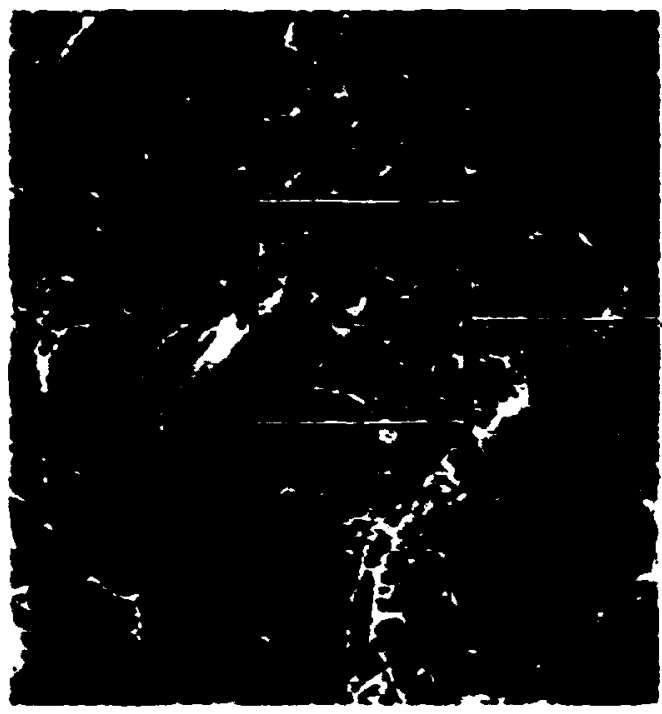

(a) MAGNIFICATION 100X

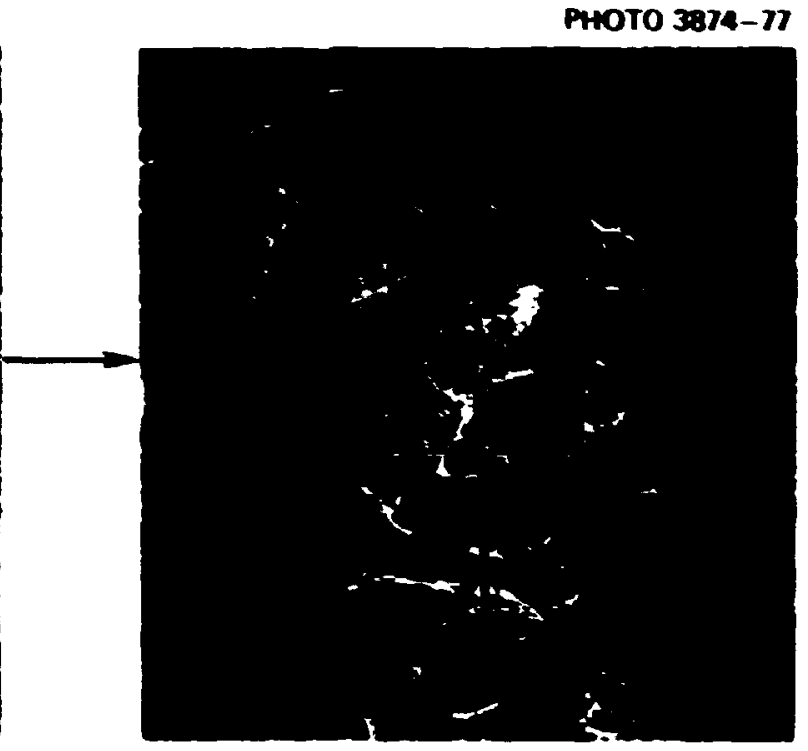

(b) MAGNIFICATION 300X

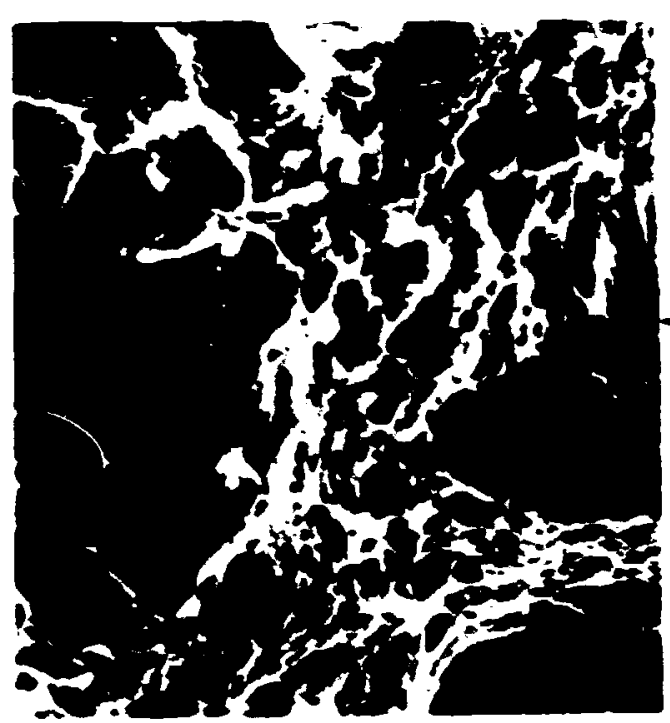

(d) MAGNIFICATION 30000X

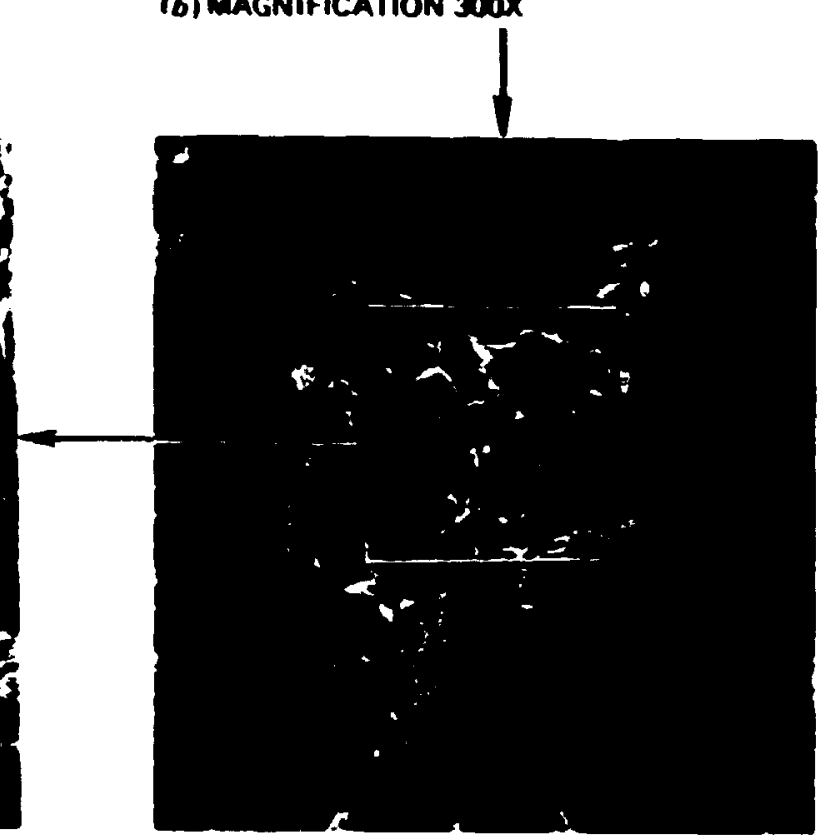

(c) MAGNIFICATION 1000X

Fig. 42. Scanning electron micrographs of a representative region of the fracture surface from TSE-3. The micrographs are all taken in the same area of specimen TSE-3-1. The regions in $42 \mathrm{a}$ that appear to have fractured in a dimple mode do, indeed, exhibit a ductile fracture appearance at higher magnification. (Original reduced $21 \%$ ) 
name ouc is 235

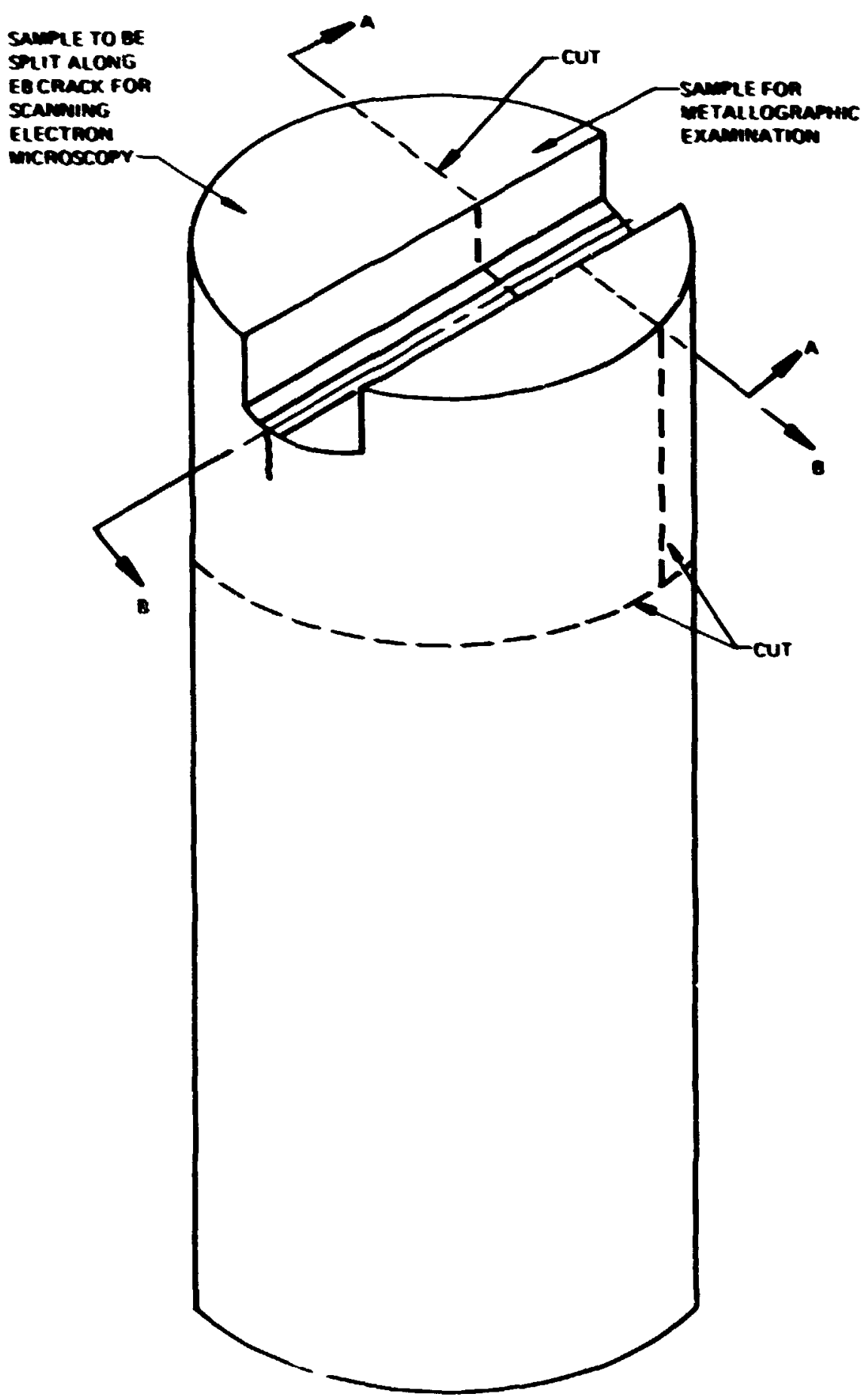

Fig. 43. Trepanned core from TSV-1. The cores removed from TSV-2 following TSE-4 are identical except that the aachined slot was omitted for TSE-4. The section obtained from the cut along $M$ was used for light acroscopy exaninations. Section BB was broken open at $-196^{\circ} \mathrm{C}$ and the surface exanined by scanning electron microscopy. 
across the top. For TSE-4, a slot was not machined alung the length of the inner wall prior to making the EB crack-initiation weld.

One-half of each of the three core specimens was used for light wicroscopy examination of the iracture (cut dlong section $H$ ); the remainder of each core was broken alcng the iracture at $-196^{\circ} \mathrm{C}$. and the surfaces examined by SEY. Photonacrographs showing the crack that was generated during the therral shock are shown in iig. 4 . They were taken at a magnification of $4 x$ with the sample in the unetched and etched $(2 \%$ nital) conditions. The cracks in all three cores propagized in an irregular fashion and in this regard are very similar to chose observed in connection with TSE-2 (Refs. $1,15)$.

Photomacrographs of the fracture surfaces (magnification $2 x$ ) are shown in Fig. 45. An extensive examination of each surface was made with the scanning electron microscope. As show in $\mathrm{Fis.} 45$, the fracture modes for each core are quite similar. The fracture is predominately by the cleavage mode with some small percentage of the surface exhibiting a dimple appearance. Finure io shows a series of SEY photomicrographs at progressively higher magnification. A region that appeared to contain dimple fracture was specifically selected for the higher magnification photomicrographs. The photomicrographs taken at higher magnification $\int 300$ and 1000x (Figs. $i f c$ and $i(f d)]$ conf $i r m$ the presence of some ductile fracture in a surface exhibiting predominately cleavage-mode fracture.

In the course of the SEY investigation of the fracture in ISF-4, we examined the region just below the electron-beam crack-initiation weld. Figure 47 shows a series of SEM photomicrographs taken of this region at progressively higher magnification $(100,300$, and 1000x). These photomicrographs identify a region $20.5 \mathrm{~m}(0.02 \mathrm{in.})$ deep that failed in the dimple mode. This is the region of the fracture that initially propagated as a consequence of the thermal shock. Beyond this 0.5-man region, the crack morphology appears to change to that of predominately cleavage mode. This cleavage morle of fracture is shown in Fig. it. 


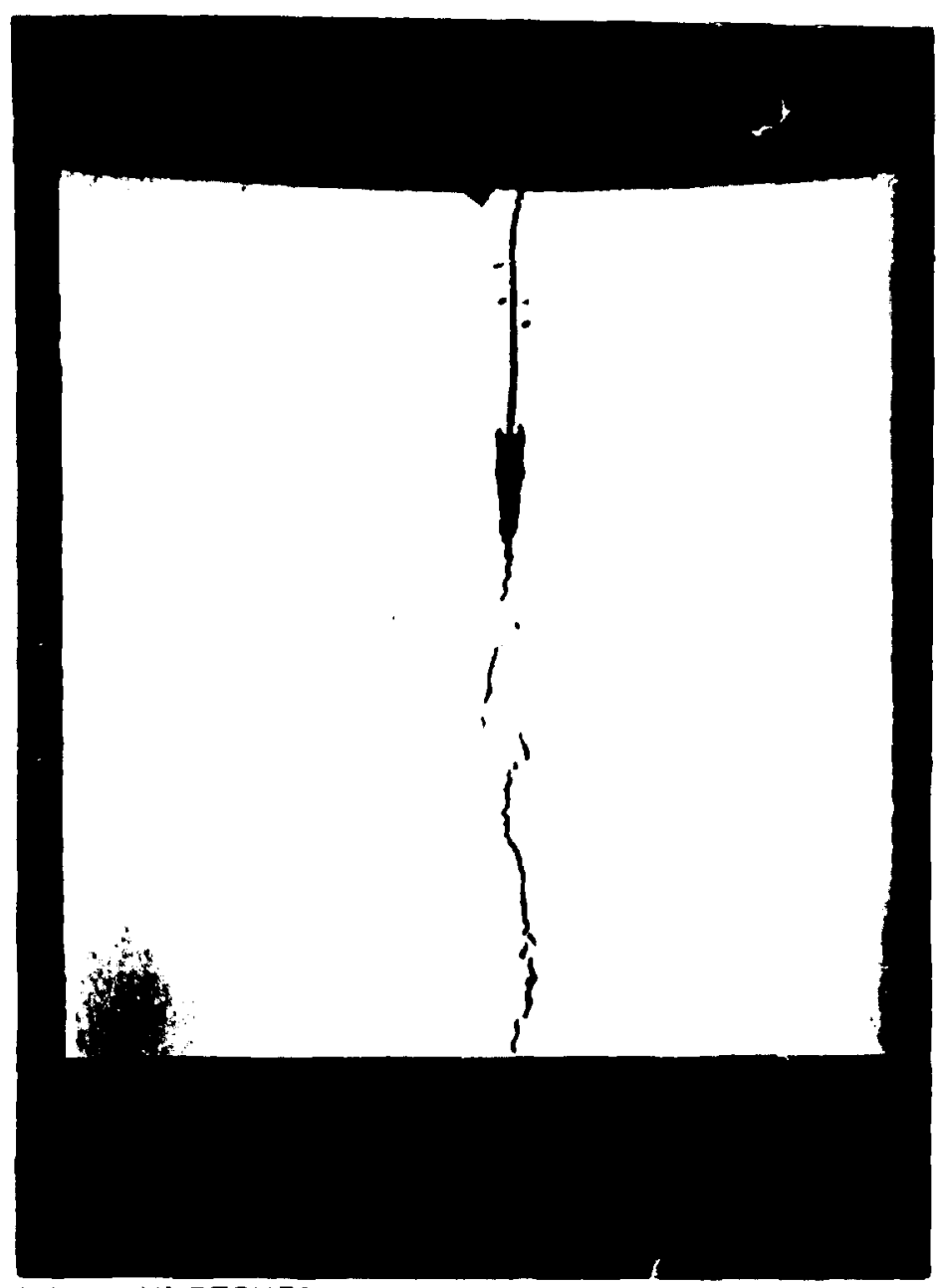

(a) UNETCHED

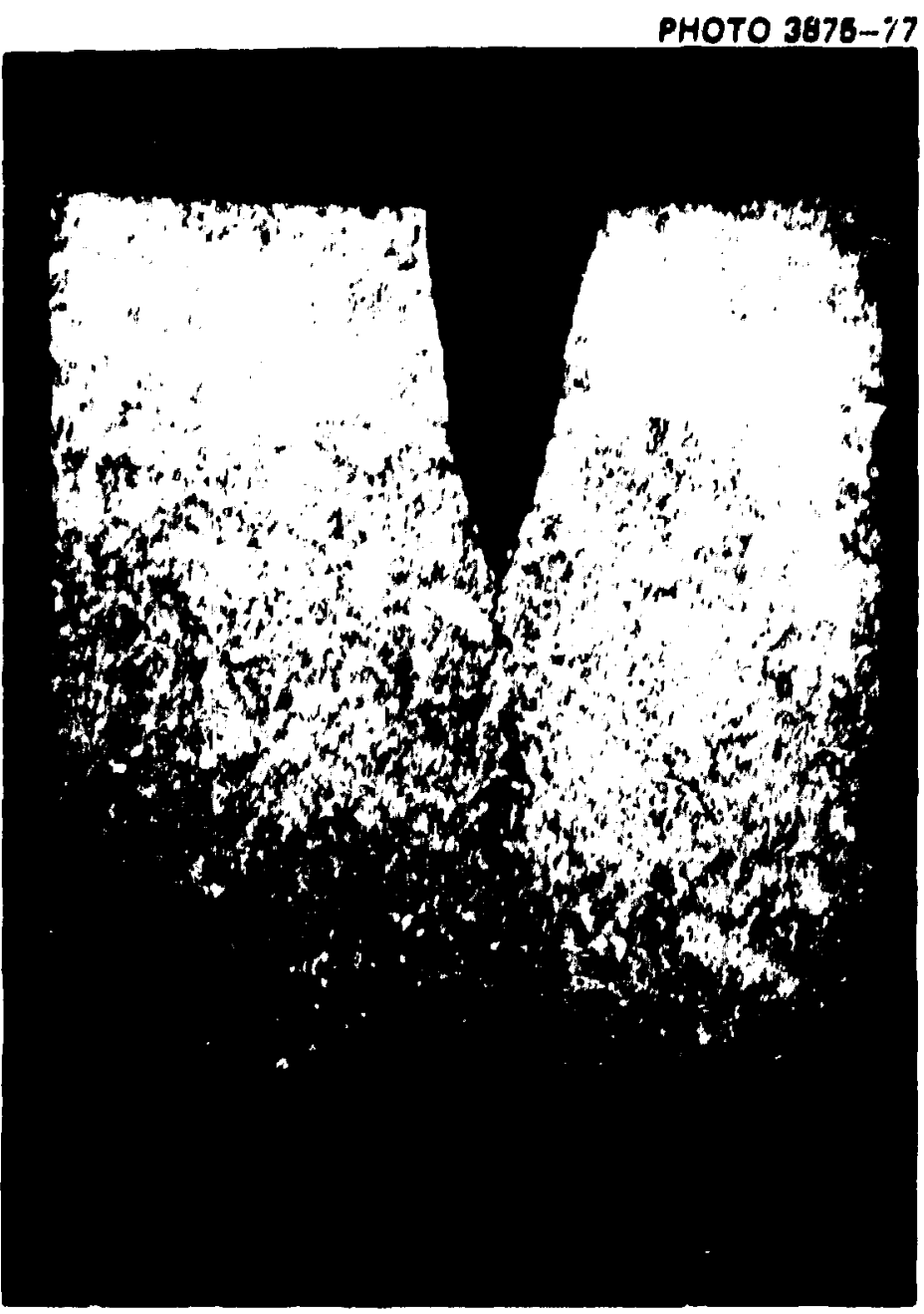

(b) ETCHED (2\% NITAL)

F1g. 44. Fhotomacrographs of core TSE-4a (magniflcation 4x). The crack that resulted from the thermal shock is irregular. 

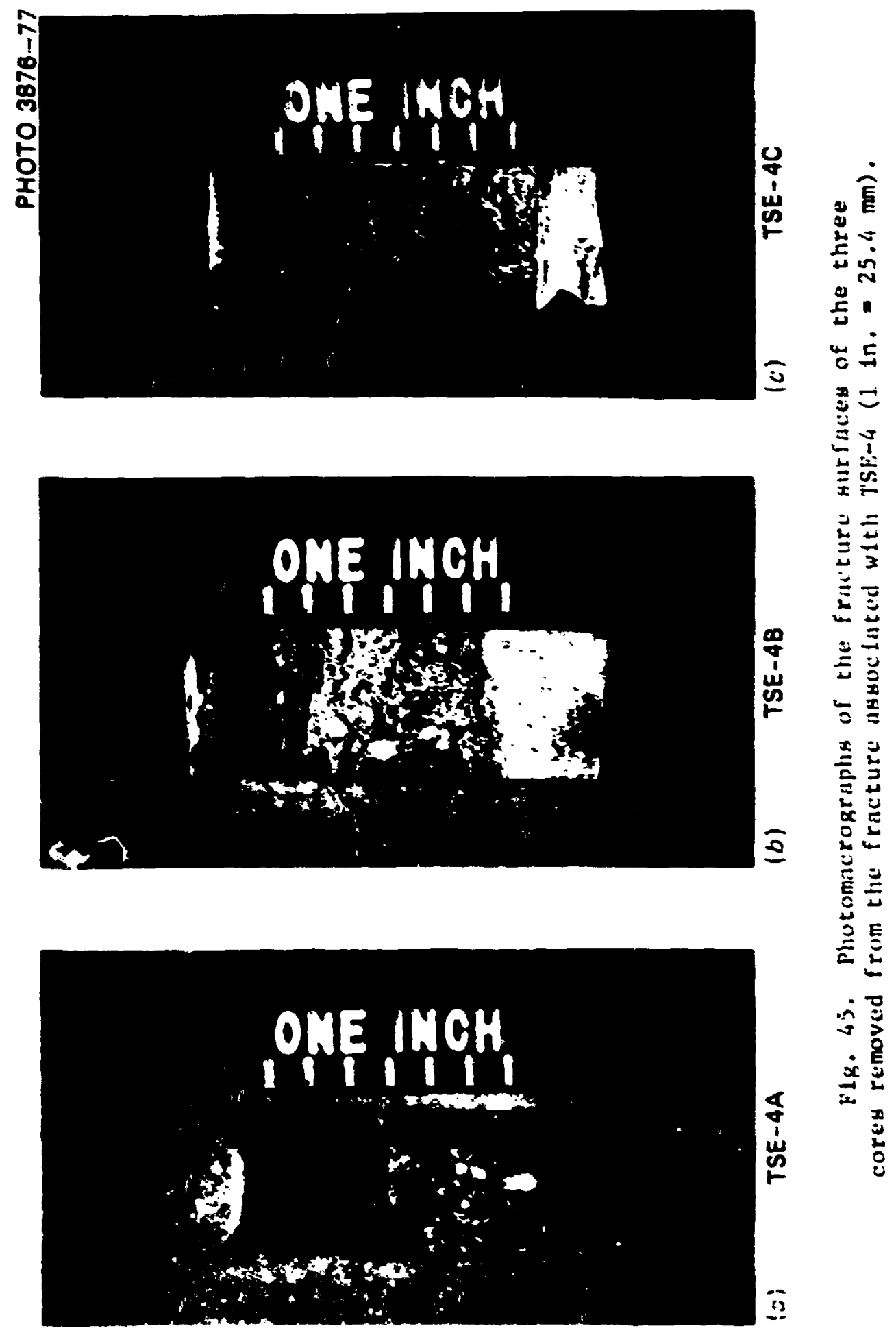


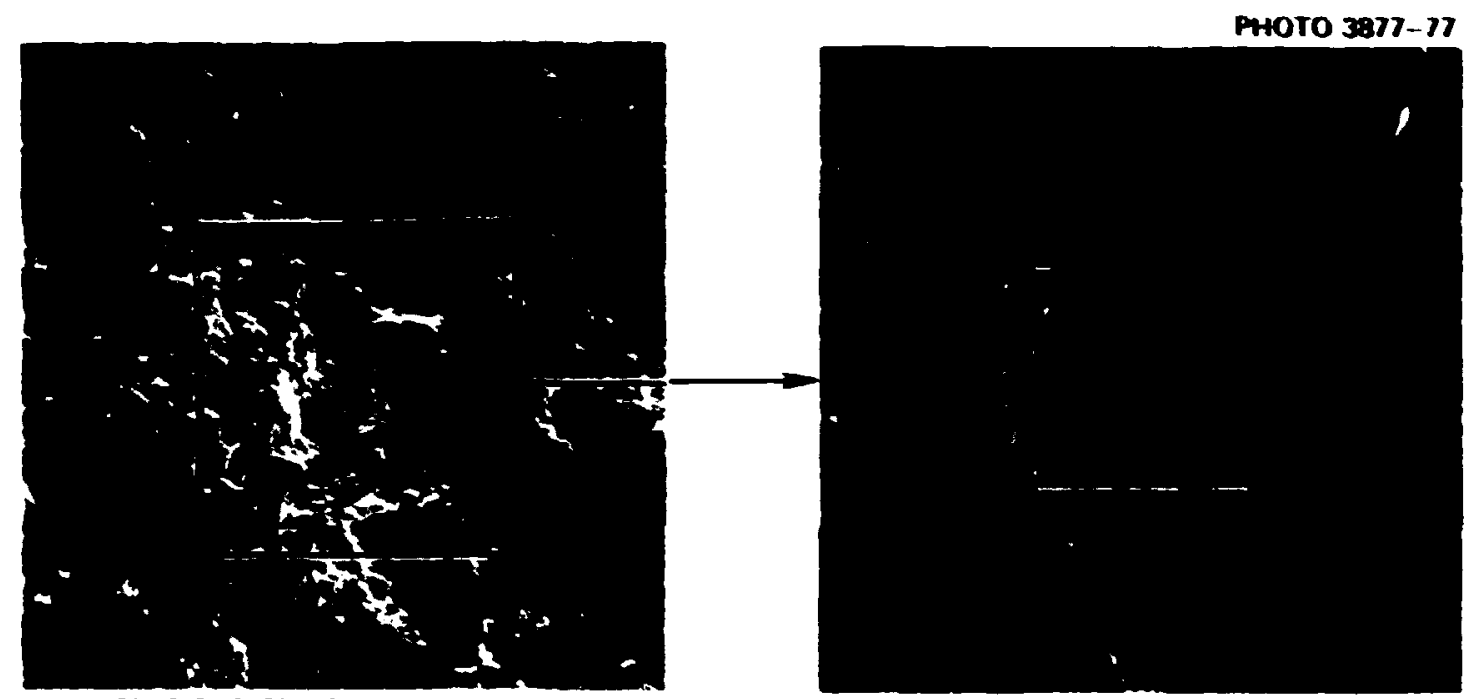

(..) MAGNIFICATION 55X

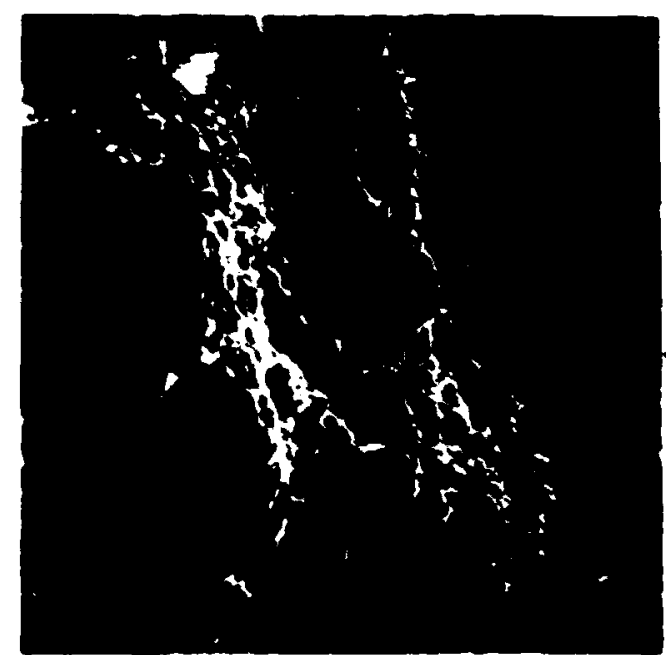

(d) MAGNIFICATION 1000X
(6) MAGNIFICATION 100X

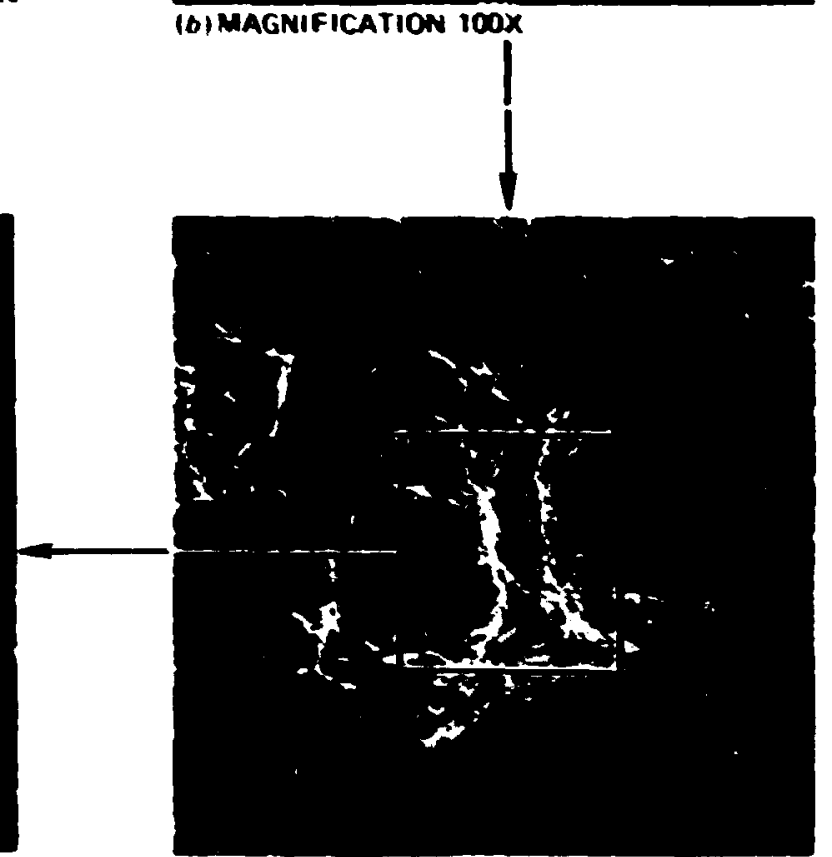

(c) MAGNIFICATION 300X

Fig. 46. Scanning electron micrographs, at progressively higher magnification, of an area representative of the fracture surface in core TSE-4C. The surface appears to show evidence of some dimple-mode fracture, an observation that is confirmed at the higher magnification. Figure 46d is a scanning electron micrograph of the area identified in $46 \mathrm{a}, \mathrm{b}$, and c. (Original reduced 23.5\%) 


\section{PHOTO 3878-77}
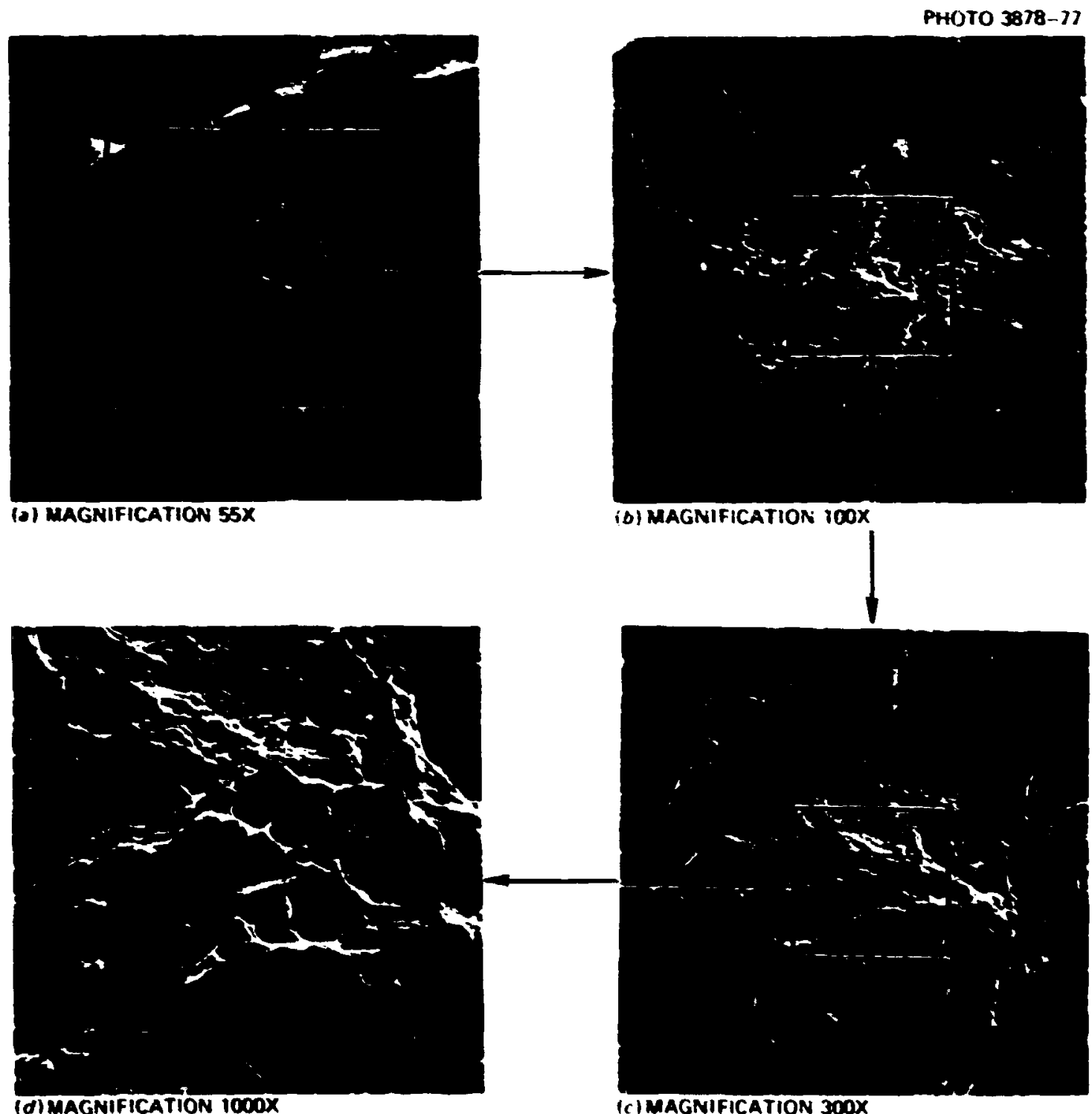

(d) MAGNIFICATION 1000X

(C) MAGNIFICATION 300X

Fig. 47. Scanning electron micrographs of the region just below the electron-bear crack-initiation weld in the TSE-ic core. The electronbeaw weld is apparent in Fig. $47 \mathrm{a}$. The region of interest is about 0.5 (0.02 in.) in depth and is the area of initial cract extension. (Original reduced $25.5 \%$ ) 


\subsection{Discussion and Sumary}

The investigation of the crack surfaces from TSE-1, -3 , and -4 showed the short crack extension in TSE-1 to be by the dimple mode and the fractures in TSE-3 and TSE-4 to be prinarily by the cleavage wode. An extensive SEA exanination of the region just below the EB weld in TSE-4 showed that there is a narrow band of ductile tearing prior to the onset of the main fracture. This feature of the crack extension in TSE-4 is shown in Fig. 47. The TSE-3 and TSE-4 fractures contained areas, perhaps as large as 10 to 157, that exhibited a dimple mode of fracture. This distinction between the ductile and cleavage fracture modes is most easily discerned at a magnification of about $300 x$.

The fractures that occurred as a consequence of the thermal shock are not "brittle" in the glasslike sense of the word. Rather, the thermal shock fracture is best reproduced in a $C_{V}$ specimen of material removed from the prolongation of the heat-treated cylinders used in the thermal shock experiments and tested in the transition temperature region $\left(v 93^{\circ} \mathrm{C}\right)$. A comparison of the SEM photomictographs taken at $300 \times$ of the fracture surface of a $\mathrm{C}$ specimen tested at $93^{\circ} \mathrm{C}$ (Fig. 38) and the fracture surfaces from TSE- 3 and TSE- 4 (Figs. $+2 b$ and $\{b c$, respectively) illustrates this point. Finally, a comparison of the fracture surface that corresponds to the region of the TSE-3-2 specimen that was broken at $-196^{\circ} \mathrm{C}\left(-320^{\circ} \mathrm{F}\right)$ and the fracture surface of the $C_{v}$ specimen tested at $-46^{\circ} \mathrm{C}\left(-50^{\circ} \mathrm{F}\right)$ shows the difference in the amount of dimple-mode fracture. This comparison is made in Fig. 48. A brittle fracture (in the glasslike sense of the word) would ext:ibit a fracture mode similar to that show in Fig. 48 . 

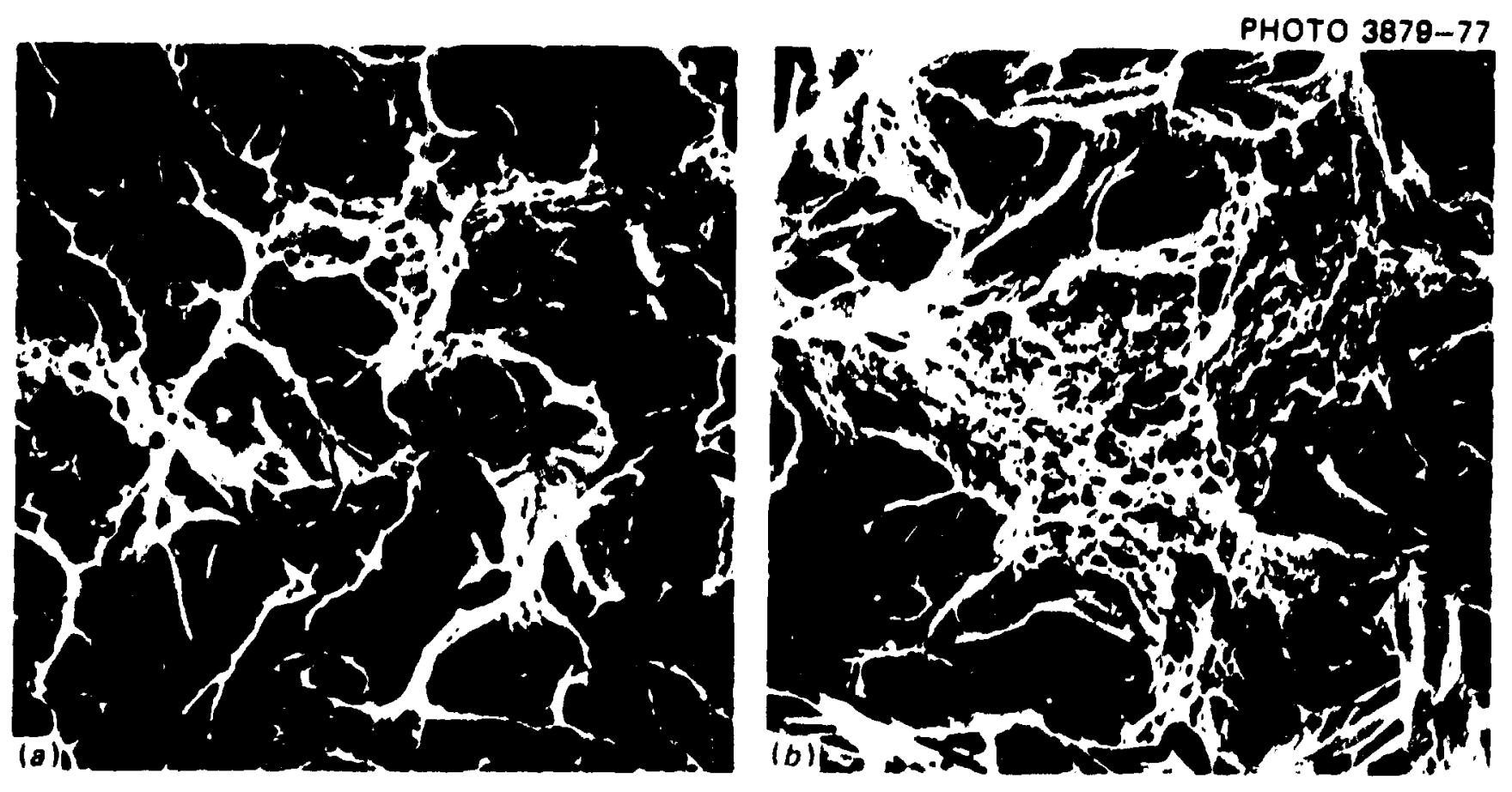

Fig. 48. Compartson between the appearance of fracture surfaces generated at :wo tempuratures: (a) $-46^{\circ} \mathrm{C}\left(-50^{\circ} \mathrm{F}\right)$ and $(\mathrm{b})-196^{\circ} \mathrm{C}\left(\cdots 320^{\circ} \mathrm{F}\right)$.

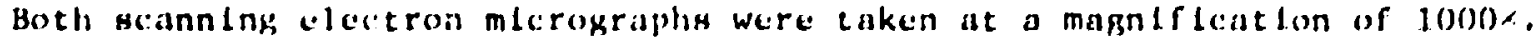
The defference in the amount of dimple fracture in ciach surface is evident. 


\section{DISCLSSION OF RESILTS}

All of the $k$ ratios and other fracture-toughness-dependent numbers reported here for the test specimen material are based on a $k_{I c}$ curye that represents a best average of the available data for the test specimen material and do not reflect the rather wide scatter band i'lat is usually associated with the transition region. The scatcer band for the TSI-I and TSV-2 test specimens has not yet been established, but a statistical analysis performed in connection with a round robin program ${ }^{17}$ irdicates a 20 band width of about $\pm 43 \pi$ corresponding to the transition region.

In each of the four thermal shock experirents, the $k$ ratios of interest (either close to unity or maximum values! were associated with fracture toughness values in the transition region and thus must include a rather large uncertainty. Based on nominal values of fracture tcughness and the results of TSE-4, it appears that the linear elastic fracture mechanics (LEFM) model used to predict the outcome of TSE-4 is quite accurate. In the case of TSE-1, the maximum $K$ ratio was only 0.74 , and thus the aciuracy of the method of analysis cannot be established with an accuracy better chan 26\%. In other words, it is not known what calculated value of the $K$ ratio above 0.74 would be required for unstable crack growth to occur. However, this experiment indicated that, if the $k$ ratio for a long axial crack is $26 \%$ below the critical value as it is for the low-copper RCM (typical PWR), crack extension has a low probability of occurring.

To deduce a degree of accuracy from TSE-2 would require an analytical model that could be used to predict the conditions for initiation when the $K$ ratio varies nver a wide range along the crack front. No such model has been applied thus far. It was belicved that crack initlation would take place during TSE-2 because the raximum $K$ ratio at a point somewhat removed from the surface (one-quarter of the flaw depth) was substantially above unity (1.3). At the time of the first propagation, the calculated $k$ ratio at the surface (making no allowance for lack of restraint at the surface) was 1.4, and that at the bottom of the semicircle was less than 0.5 . Nevertheless, the results of this experimen: indicate that typical finiteJength flaws will not grow to become long cracks in the sense that they 
will not extend axially indeíinitely and will not propagate radiaily bevond the initial mixizur deption.

Aside frot: the fact that only one of the thermal shock experiments (TSE-4) permits a precise verification of the method of analysis (LEFA), it is important to note that sone of the experiments revealed significant anomalies. Furtherwore, since TSE- 4 included the unique conditions associated with a severe thermal shock (nearly equal biaxial strisses and steep gradients in toughness and stress-untensity factor that vary wit! (ime), the validity of LEFY for application to thermal sho:k problems can be established with the one type of experiment (TSE-4).

The studies performed at ORIL using LEFY and neglecting wirm prestressing indicate that a long axial crack will prcpagate nearly through the wall of the high-copper PWR vessel after many years of accumulated radiation damage and that a continuous cir:umferential crack will ceretrate 70 \% of the wall thickness. In the cise of an axial flaw, complete penetration might be tolerated because presurably onl $\because$ mincr ieakage of coolant wocid result, and cooling of the core would not be impaired. It is also quite likely that reducing the conservatisa in the RCy (for instance, b: ...plyin: a three-dimerisional analysis) would resuit in much less calculated peneir.:tion of the flaw, or it might he demonstrated experimentally that the last small amount of relatively tough material (low neutron fluence) could not fracture under any reasonable circumstances.

In the case of a continuous circumferential flaw, deep penerratinn :annot be tolerated berause complete penetration would result in the loss of the bottom portion of the vessel, and thus coolant for the core could not be contained. The RCY for a continuous circumferential flat does not contain the conservatism associated with a long axial flaw, and thus benefits are not to be derived therefrom. Hovever, it might be argued that long flaws in either direction are highly unlikely, and the results of TSE-2 indicate that the much more probable finite-iength flaws will not propagate radially.

The path to acceptance of these concepts and the developement of a more realistic three-dimensional model could be long and wearisome. However, the warm-prestressing phenomenon may provide a solution to the LOCAECC thermal shock problem. All that remains to be done is an adequate 
dewonstration under actual or simlated chermal shock conditions, and that effort is under way. 


\section{REFERENCES}

1. R. D. Cheverton, Pressure Vessel Fracture Studies Pertaining to a PuR LOCA-ECC Thermal Shock: Experiments TSE-1 and TSE-2, ORNL/NUREG/T4-31 (Septenber 1976).

2. F. J. Loss, R. A. Gray. Jr., and J. R. Hawthorne, "Theral ShockRelated Investigations," Stmuctural Integrity of Hater Reactor Pressure Boinding Components, Pranress Report Bnating 14aj 31, 1976, NRC Report 3353, NRL/NUREG-2 (Septenter 1976).

3. F. J. Loss, R. A. Gray, Jr., and J. R. Hawthorne, "Characterization of Warn Prestress Phenomenon in Relation to Crack Initiation During Thermal Shock," paper presented at the Fourth Water Reactor Safety Research Information Heeting, Sept. 27-30, 1976, Gaithersburg, Ad.

4. W. 0. Shabbits et al.. Heavy Section Steel TecionuLagy Pragram Technical Pexcrt 10. 6, Feavs Section Fracture Toughness Properties of i533 Graie $i$ zass ? Steel Flate and Submerged-Are ieldrent, WCAP-7414 (December 1969).

5. "Derivation of $\mathrm{K}_{\mathrm{IR}}$ Curve," Appendix 1 in PVRC Recommendations on Toisiness Reguirements :or Ferritic Hateriais, WRC Bullet in 175, Welding Research Council (August 1972).

6. F. B. Litton, "The Effect of Residual Elements on the Sensitivity of Pressure Vessel Steels to Irradiation Embrittlement," draft memorandum, Materials Engineering Branch, Directorate of Licensing, U.S. Atomic Energy Commission, October 1973.

7. "Effects of Residual Elements on Predicted Radiation Damage to Reactor Vessel Materials," U.S. Nuclear Regulatory Coumission Regulatory Guide 1.99, July 1975.

8. J. G. Merkle, Oak Ridge National Laboratory, personal communication, August 1975.

9. F. J. Loss and J. R. Hawthorne, "Thermal Shock-Related Investigations," Stractirai Integriti of iater Reactor Pressure Boindiar, Comonents, Propress Re:ort Encing Sezruar:, 23, 1976, NRL Report 8006, NRL/NUREG-1 (Aug. 26, 1976).

10. A. J. Brothers and S. Yukawa, "The Effect of Warm Prestressing on Notch

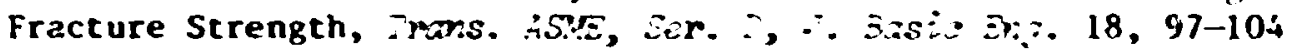
(March 1963).

11. T. C. Harrison and G. P. Fearnehough, "The Influence of Warm Prest ressing on the Brittle Fracture of Structures Containing Sharp Defects," Frins. HSME, Ser. 2, $\therefore$ 3asis Er.: 94, 373-76 (June 1972).

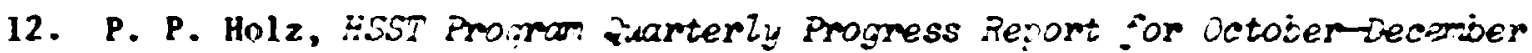
1976, ORNL/NUREG/TH494, PP. 59-63.

13. D. J. Ayres, "Three-Dimensional Elastic Analysis of Semi-Elliptical Surface Cracks Subject to Thermal Shock," PP. 133-43 in Coroutrationai Fracture Mecharics, Second National Congress on Pressure Vessels and Piping, San Francisco, Calif., June 23-27, 1975, American Society of Mechanical Engineers, New York. 
14. J. G. Herkle, quoateriy Progress Reoort on Peactor Sajet Promprs Sponsored by the Division of Reactor Safety Researci :or juis Se: tember 1974, ORM/TI-4729, Vol. II, pp. 3-22.

15. D. A. Canonico, "Posttest Exanination of Flaved Area in Thermal Shock Specinens TSV-1 and -2," Appendir 6 of Pressure Vessel Bracture Studies Pertaining to a FUR LOCA-EC: Themal Shock: Experiments $35 E-i$ and TSE-2, ORM/NUREG/TA-31 (Septemer 1976).

16. U. J. Stel man and D. A. Canonico, Metallurgical Simulation of Irradiation Effects on the Toughness of Pressure Vessel Steels," Rhart. Prog. Rep. on the fiecory Sest. Steel Tech. Praj. for Det.-Bec. 1975, ORNL/ NUREG/TR-3, PP. 115-123.

17. U. Oldfield et al., Eracture Toushess Data for Ferpitic Mulear Pressure Vessei Materials, ETI-TR-75-34R (July 1, 1975). 


\section{$7 i$}

\section{APPENDIX A}

\section{THERYAL-HYDRALIIC EXPERIMENTS FOR INIESTIGATING \\ DEGREE OF SYRETRY IN QLENCHING THE 533-min-OD \\ THERMAL SHOCK TEST SPECIMENS}

Before the thermal shock experiments were conducted with test specimens TSV-1 and -2, thermal-hydraulic experiments were conducted with an identical test specimen, TSF-F. Thermocouples were included to obtain radial and axial temperature gradients, but since there was no reason to believe that significant circunferential variations in cemperature would exist, TSV-F was not adequately instrumented to allow a thorough investigation of the degree of symetry around the rest specimen.

Results from each of the thermal shock and thermal-hydraulic experiments have indicated a significant amount of assmecry in quenching. The indications were believed to be associated with inaccuracies in measuring surface temperatures during a thermal transient and/or perhaps with a poor design of the inlet flow plenum. Eventually, the design of the plenum was modified, but indications of asymetry persisted. Finally. the flow-test specimen (TSY-F) was modified to include a set of thernoccuples at each $45^{\circ}$ position around the test specimen at the horizontal midplane. Each set consisted of three thermocouples located radially $2.5 \operatorname{mm}(0.1$ in.), $5.1 \mathrm{~mm}(0.2 \mathrm{in.})$, and $7.6 \mathrm{~mm}(0.3 \mathrm{in}$ ) from the inner surface. All thermocouples penetraied the wail from the wuter suriace.

The proximity of the theraccouples to the inner surface was such that significant changes in temperature and thus significant degrees of quenching astrumetry would be recorded during times of interest in the transient $(t>10 \mathrm{sec})$. Results from tests conducted with the oodisied flow-test specimen showed no significant signs of quenching asymetry, and thus all previous indications of asymetry are attributed to inaccuracies in measuring transient surface temperatures. Since all measured temperature distributions used in connection with the evaluation of the thermal shock experiments (TSE-1,-2, -3,-4) were based primarily on in-wall thermocnuple positins, those evaluations are considered to be unaffected by the erroneous indications of asymetry. 


\section{APPENDLX B \\ INSTRUAENTATION FOR DETECT ING CRACK PROPAGATION}

\section{B.1 DEVELOPAENT OF IMPROVED COD GAGE INSTALLATION}

Heldable strain gages have been used in the thermal shock experiments as event detectors and, in general, were successful in deteraining the initial onset of crack extension. The gage used is the Ailtech SG-12S. wich is a quarter-bridge, 120- $\Omega$, self-compensated, hermetically sealed strain gage utilizing a nickel-chrome alloy as a strain filament (see fig. B-1). The gages were installed on the inside surface of the cylindrical test specimen (in shallow depressions) directly across the EB weld and transverse to the axis in TSE-1 and TSE-3, and were located directly on the specimen iuner surface transverse to and in the path of the expected extension of the flaw in TSE-2 (see Ref. 1). They were installed in the noraal manner, that is, by an almost continuous spot welding of the wounting flange to the test specinen surface. This technique prevents flutter when the gage is subjected to hydraulic turbulence, but results in a very short effective gage length across the crack itself. Upon crack opening. the local strain in the gage is large enough in some cases to cause failure of the filament, strain tube, and flange, as wight be expected.

Since the crack arrest toughness of the test specimen material appears to be considerably less than the static fracture toughness, contrary to

OAmL-ONG Ts-1000

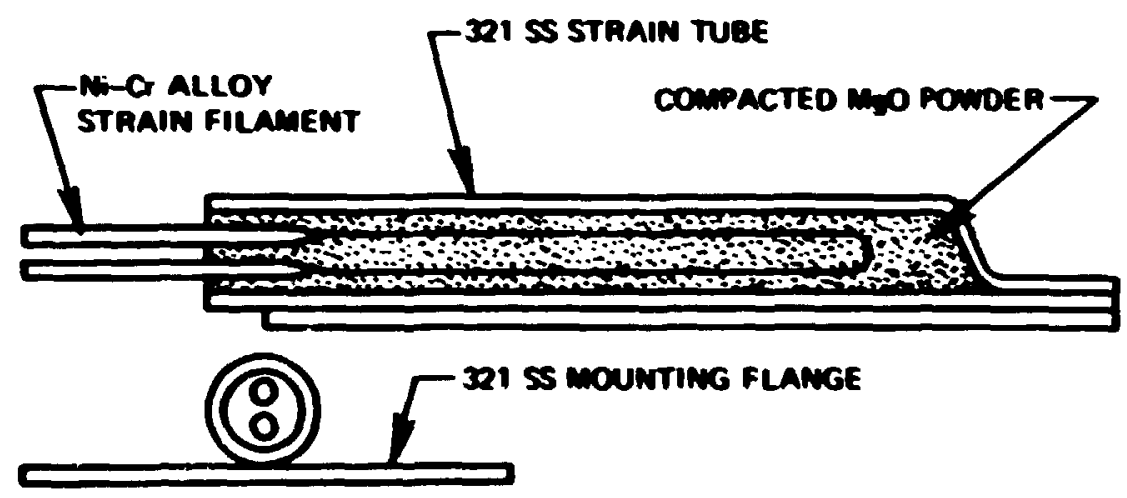

Fig. B-1. Allech SG-125 quarter-bridge gage. 


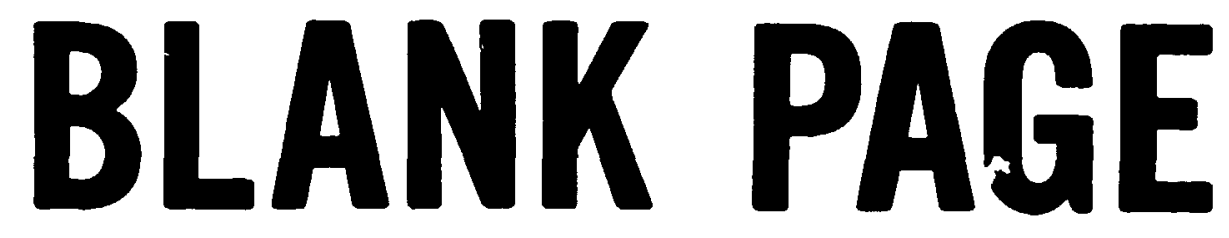


what was expected earlier in the progran, there was a need to detect greater crack opening (drpth) than previously anticipated. Furtherrore, the inclusion of warm-prestressing experiments also required greater COD gage capability. For instance, calculations indicated that fractional flay depths as great as 302 had to be considered, and the corresponding crack opening at the inner surface was $0.51 \mathrm{~m}(0.020 \mathrm{in.})$. It was expected that the gages would withstand 52 local strain before failure. Thus, an effective gage length of $10.2 \mathrm{~m}(0.4 \mathrm{in.})$ was required.

The effective gage length, and thus the displacenent-measuring capability of the gage, can be increased by leaving a central portion of the gage (flange) unbonded to the test specimen surface. Limitations in this regard are associated with the possible flutter problem and the anount of attachwent required to prevent spot-weld failure. Tests were conducted to deternine if the Ailtech SG-125 could be utilized in the above manner. In the first test, four gages were bounted on a "necked-down" tensile specimen. Spot welding of the flange was onitted for a length of $5 \mathrm{~mm}$ (0.2 in.) on two of the gages and for $10=(0.4 \mathrm{in.})$ on two other gages. The unbonded length spanned the necked-down portion of the tensile specimen. (Necking the specimen prevents plastic deformation of the specimen in the spot-weld region.) Under no-load conditions, the specimen was heated slovly by means of an electric furnace to $288^{\circ} \mathrm{C}\left(550^{\circ} \mathrm{F}\right)$ to deternine the effects of differential expansion, which put the rage in coupression. There were no detrimental effects. Then with the specinen still at a tewperature of $288^{\circ} \mathrm{C}$, a tensile load was slowly applied. All four gages failed at an indicated strain of 262 and thus at a local strain in the unbonded region well in excess of 62 . There were no failures of the spot welds.

The potential problew of flutter in the gage as a result of fluid impingenent against the ubonded protion of the flange was investigated in a flow test, using the flow test specimen (TSV-F). Three gages with an unbonded length of $10 \mathrm{~m}(0.4 \mathrm{in.})$ were installed in the flow test specieen, two directly on the inner surface and one in a slight depression. All were placed nornal to the direction of flow. No detrimental effects were encountered in the flow test, and the technique subsequently was used for TSE-4, in which case five gages were mounted directly on the inner surface. 
No failures occurred even though there was considerable crack extension. In a similar experiment (TSE-3), in whith the total-attaciment mounting technique was used, four of the five gages failed.

\section{B. 2 ACOLSTIC EMISSION}

Southwest Research Institute (SwRI) was contracted to install and operate acoustic-emission equipment for TSE-1, -2, -3 , and -4 and to analyze the data obtained from these experiments. At the request of the Nuclear Regulatory Comission (NRC), Battelle Pacific Northwest Laboratories (BNW) made independent acoustic-emission measurements during TSE-4. Final reports subritted by SURI for TSE-3 and TSE-4 and by BNW for TSE-4 are included as a part of this appendix.

In all cases, the acoustic-emission transducer assembly consisted it a cransducer attached to the outboard end of a 3.2-m-diar. (0.13-iñ.) steel waveguide that penetrated the test facility furnace with the inboard end spring loaded against the outer surface of the thermal shock test specimen. For TSE-1 and TSE-2, SWRI used four of these assemblies, located as shown in Fig. B-2 (positions $a, b, c$, and $d$ ), and for TSE- 3 and TSE-4, only positions $a, b$, and $c$ were used. BNh ised positions $d$ and $e$.

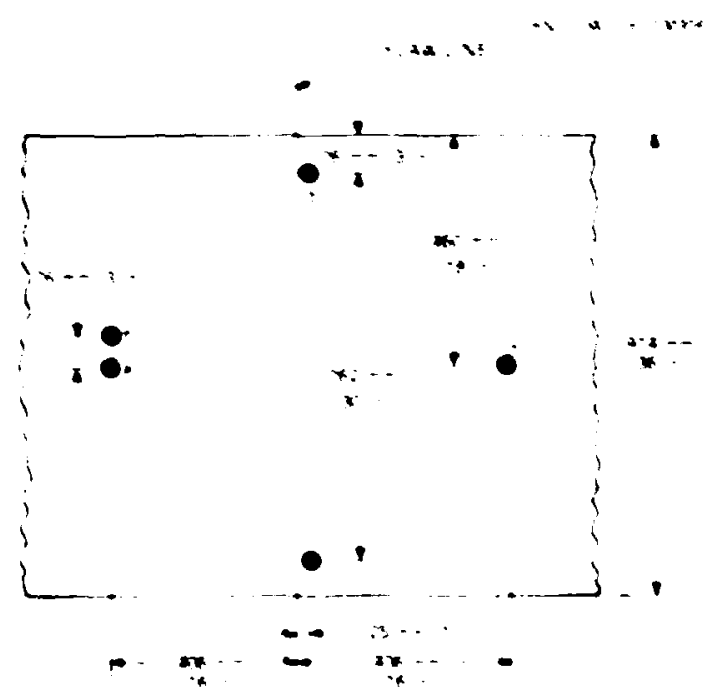

Fig. B-2. Developed view af outer surface of test specimen showing locations of contact points for acoustic-emission waveguides for TSE-1, $-2,-3$, and -4 . 


\section{SOUTHWEST RESEARCH INSTITUTE}

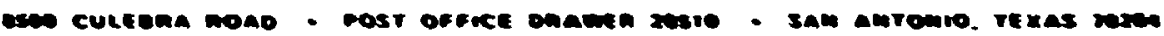

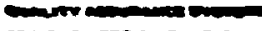

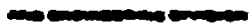

Ampant 24, 1976

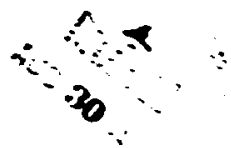

Mr. R. D. Chovertion

Oak Rides National Laboratory

Post Ofince Rar $Y$

Ouk Ridge. Teanesses 37830

Subject: Southweat Research Institute Projects 17-9165-002 and 17-4400-019 Trip Report Nember 1/76

Enclosed is a copy of my prelimimary trip report on the acodintic ceniseica Inte from the Thermal Shock Teat and the Notched Beem Teat coedected at Oak Ridge National Laboratory on Augast 4, 1976. I will make a follow-up report after we receive your dath from these thete.

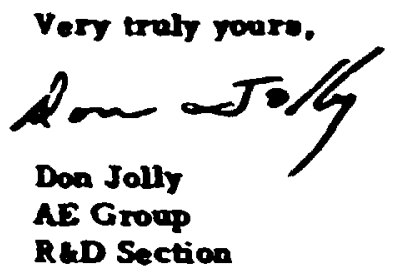

c

Ence.

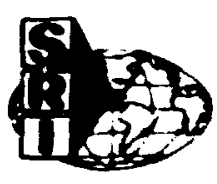


SOLTHWEN . ...: $\quad$ II IXSTITLTE

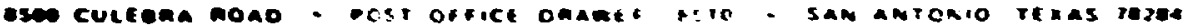

Auguse 23. 1976

TRUP REPORT NUMBER $1 / 76$

Southwest Researcb Institute Projects 17-9165-002 (lebor)

17-4400-019 (1ravel expense)

SPONSOR: $\quad$ Southwest Research Institute and

Union Carbide Con. jointly

TRUP TO: $\quad$ Oak Ridge National Labora:ory

Oak Ridge. Tennessee

DATES:

August 2 - 5, 1976

BY:

Don Jolly

Acoustic Emission Sysiems Specialist

H. L. Jacoby

Senior Technician

PURPOSE

Acoustic Emission Monitoring of * Thermal

OF TRIP:

Shock Test

PERSONNEL

CONTACTED:

Inion Carthide Corp. - Oak Ridge, Temnessee

R. D. Cineverton

SUMMLARY:

This trip :o Oak Ridpe Xiatoral Laboratery (RR.iL) was made for the purpose of collecting acoustic eraissiof. (AE) dat in a Thermal Sioci: Tes: and a Notched Fearr. Tes: it: support of the continus: Feavy Section Tectnolocy Propram.

AE data from the The :-.al Siock Tes: appeared to indicate

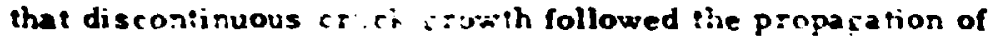
the rmal stresses th. $\therefore$ i ite crlindrical specimer.

AE da:a from the linit ra

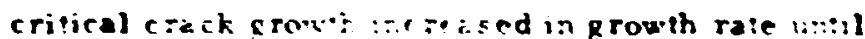
ursiable crack cro $\because$ i oce: 


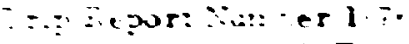

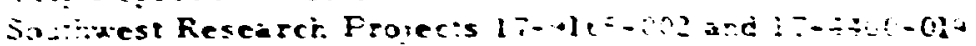

S:ISTAR:

icon:isced)
The AE i eta disclissed in this Irip Report has no: tet: correla: od with o:ter iest para:veiers which were recorted br C.R.X. person-el. The purpose of it:s repor: :s :0 iransi: ite AE da:a :o ORNL.

It is an-icipaied that a prelimirary repor: oi otieg recostec ies: da:a uill he received fror: ORNL it: the reag in:use. The aral, sis of AE da:a will be cor:ple:ed a: tha: :irie and a follow-up report will be isslied. 
Trip Repor: Number 1: T:

Southwest Research. Instiiute Project $17-01 t 5-002$ and $1^{-}-\div \div 00-014$

Page Three

\section{THERMAL SHOCK TEST}

The Thermal Shock Test was performed on a nawed cylundrical specimen of A508 forging steel; $30 \mathrm{in}$ long. 5.75-in wall thickness. and 9. 5-in. inside diameter. The specimen was cooled from 550 deg $F$ by introduction of coolant (-10 deg F) at 500 gal. / mir. The specimen contained a full length naw approximately 0.5 in. deep on the inside diameter.

Acoustic emission (AE) activity was recorded on a two-pen strip char: recorder and real-time source location data were observed on a FLC-3 display.

Because of the coolant now noise, only high-intensity, burst-type AEs resulting from crack growth שere observed. Sheet 1 (AE Rate - F/10 sec-1 of the attached data sheets shows that rapid crack growth started approximatels 50 sec after continuous coolant flow was established. Rapid crack growth proceeded discontinuously in five discrete periods of growth/arrest for approximately 200 sec after iritiation. Sheet 2 (Relative Crack Growth) shows the relative extent of crack growth in each discrete crack step. The crack grow:h rate appears to decrease linearly with time from the initial crack step.

It appears that the initiated crack advanced rapidly beyond the so:e oi maxmum thermal stress and arrested only to be initiated agais as the zore of raximum thermal siress (decreasing in intensity) proc ressed in rough the specimen.

A graph of the cumulative AE activity is shown on Sheet 3 . Where 2 i : s known that the AEs recorded were caused by discontinuous crack growth. The graph of cumulative AE activity is expected so be proportional to the to:al a:ea of crack extension.

The FLIC-3 haw locating and imaging computer was used to record the location of $A E$ events a iong the length of the crack. Due to rapidli chanc: .2 coolant flow noise. the source location computer was saturated during the first two periods of rapid crack growth. Accurate source locations were observed during the subsequent periods of rapid frowth 1105 to 200 sec afic: continuous now was esiablished). A total of 10 to 12 hiph intensity evenis were observed in the central one-third of the crack leng th during this time. An unexpected ancrease in now noise sanirated the display screer acain af:er rapid crack growth had stapped and before a photographic record was made o: the source location display. 
Trip Report Number liT6

Southrest Research Institute Projects 1i-01: $5-002$ and 1 - $-1+00-010$

Page Four

The observed real-time source location data were sufficient, however. to demoastrate that the high-intensity everis o riginated from the longitudiual crack and were not spurious noise.

\section{NOTCHED REAM TEST}

AE data were recorded from a notched beam (30x6x6 in.) loaded in three-point bending. The notched beam contained a starter crack in the root of the notch (approximately $0.5 \mathrm{in}$. depth). The crack was made by an electron beam welding procedure designed so that residual siress remained at the crack tip after cooling.

The shape of the specimen prevented direc: two-dimersional iriangulation of the AE signals, but it was possible to calibrate the FLIC-3 display so that AE sigrals from the crack could be distinguished from the AE sierals oricinating at the center bearing point.

Phoios raphic records of the AE daia are shown on Sheet 4 (AE Loca-jon Da:a). AE signals from the center bearing point a re displayed in a vertical line rear the displar center while AE signals from the crack are displayeo:: ihe encircled areas above and below the display center. The number of triangulaied even:s from the crack increased as the load inrreased. The ra:e of AE activity is plo::ed as a funcrion of load on St.ee: 5 . The recorded activity is composed of birst-tipe AE associated with siepwse crack frowth. The graph of Sheet $j$ illusiraies paiterns of step-arrest associated with sithcritical crack srowth. The rate of growth increased fiscontinuously up to the point of unstable crack growth at ipproximately 77.000 lb. The curnulative AE as a function of loat shown or. Shee: $t$ is expected to be proportioned to :he a rea of sutucritical craik frowth.

\section{CONCLUSIO.IS}

The AE da:a described in this Trip Repor: mis: be correlated wi:t. other iest parame:ers such as therral siress. crack openinf displacerne-:. and sirain hefore definie conclusions can be drawn.

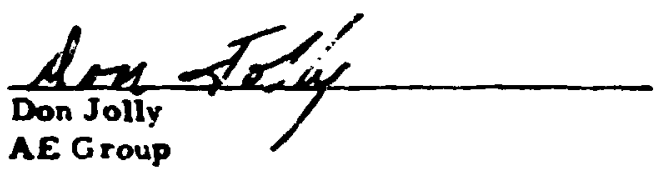

RAD Section

Approved by: $y_{i}-i / l\left(l_{2}\right.$

cl 


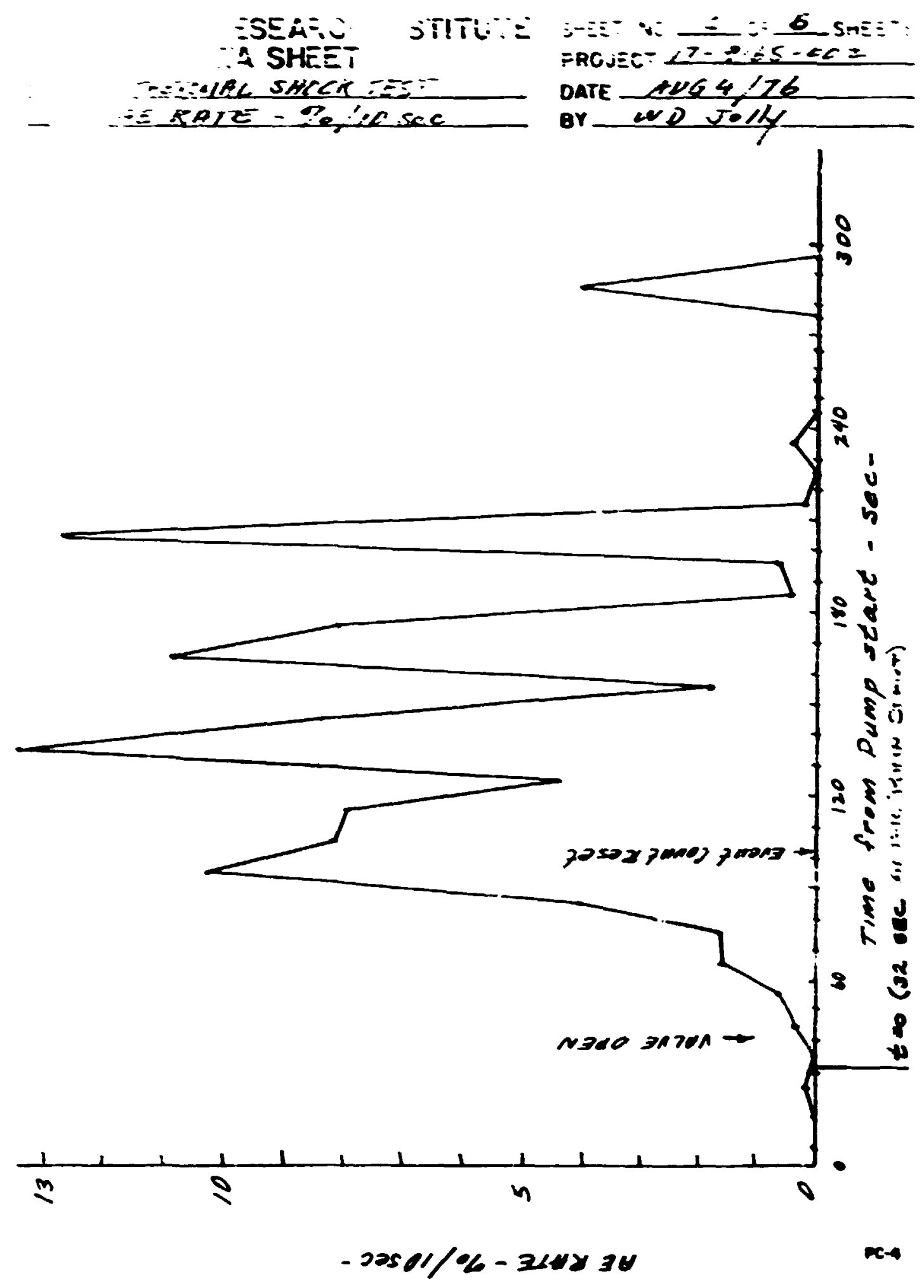


88

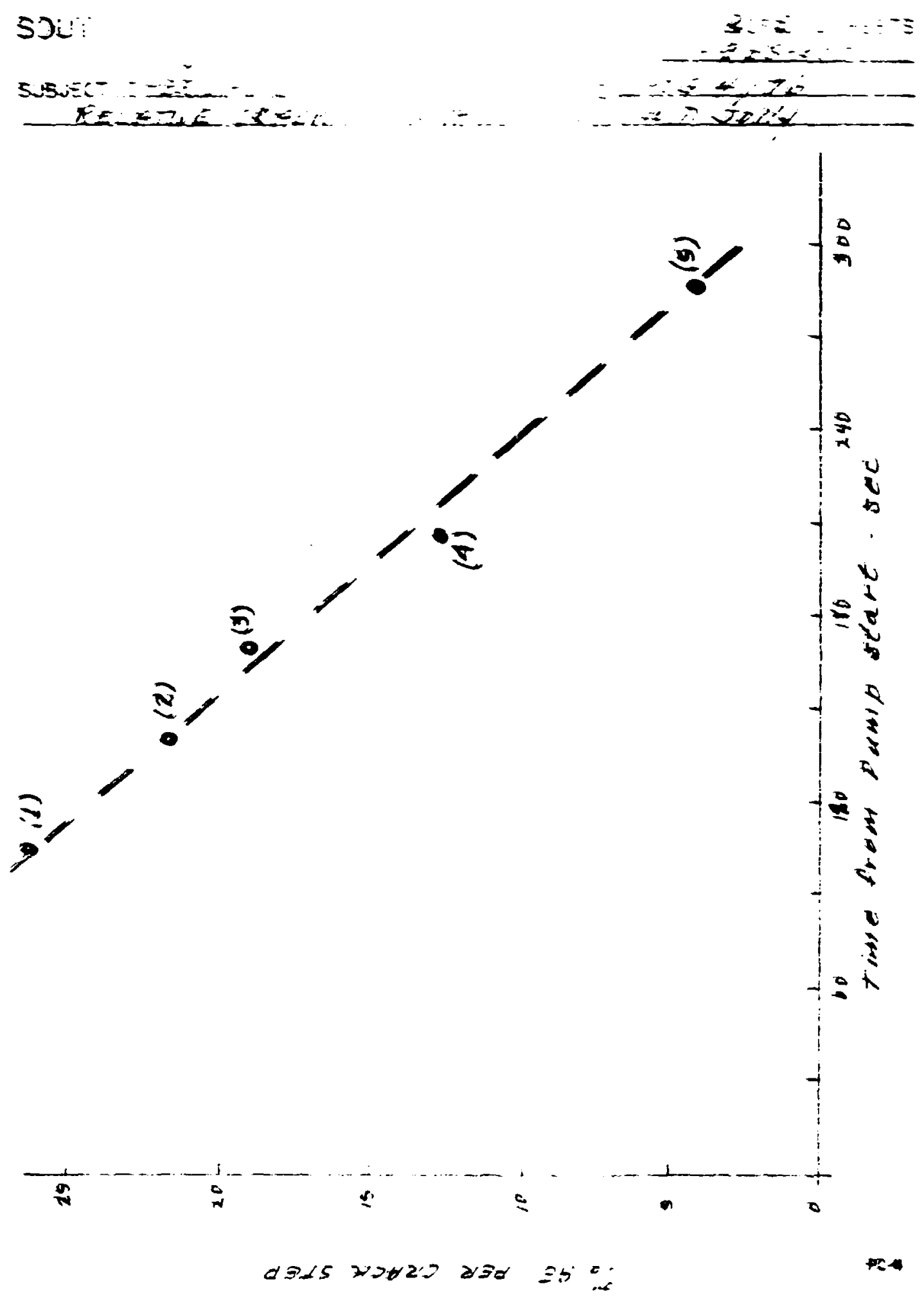


She SST

SUSEE …TZERHEL SHECK TEST

AE-IUNULATUE-

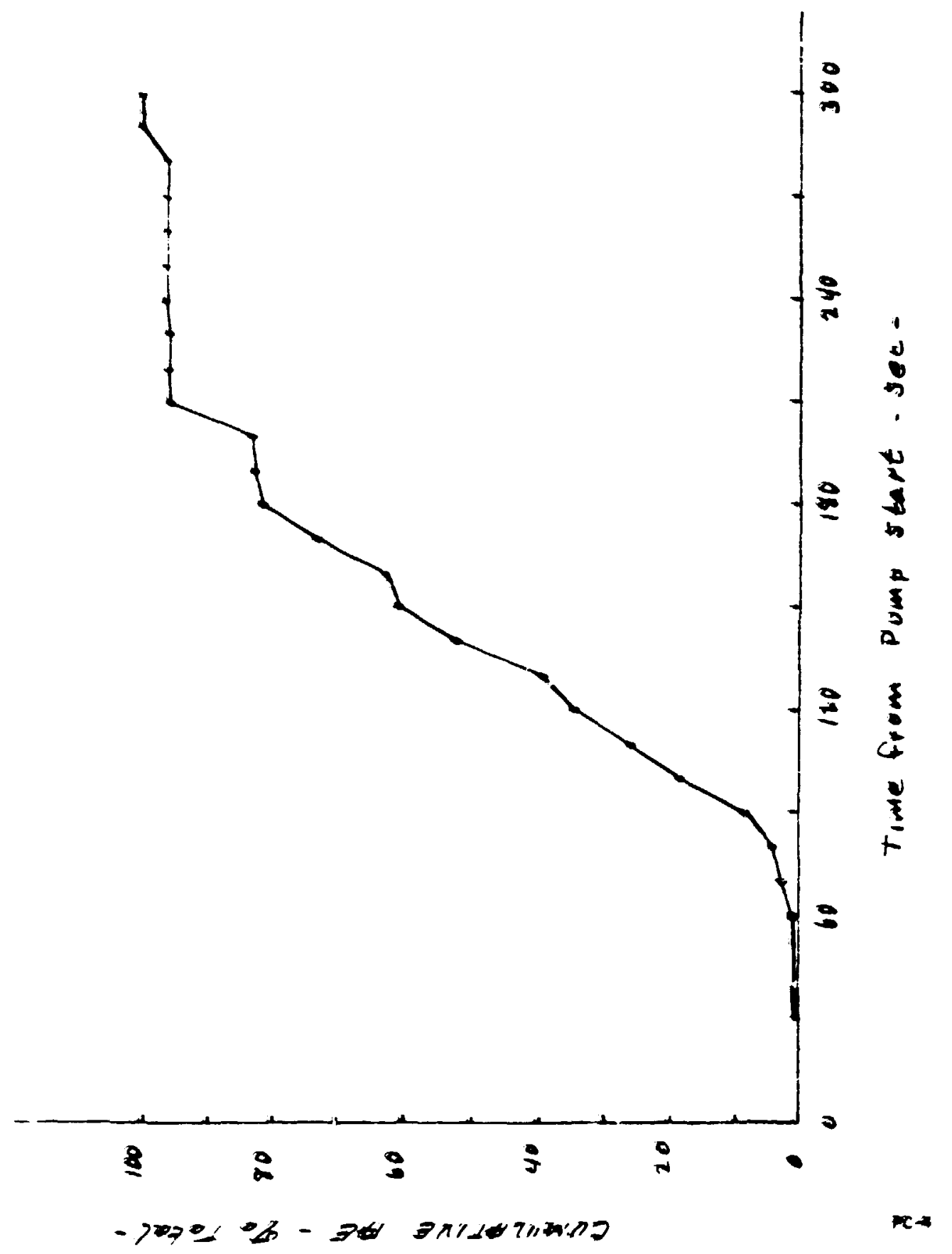


SOUTHWEST RESEARCH ASTITUTE DATA SHEET

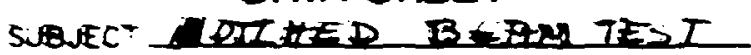
Af

SHET NC $\frac{4}{4}=0$ SHEETS PRO JECT AI- -TIS-DKL

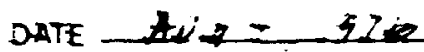

PY (e) Ir Ira

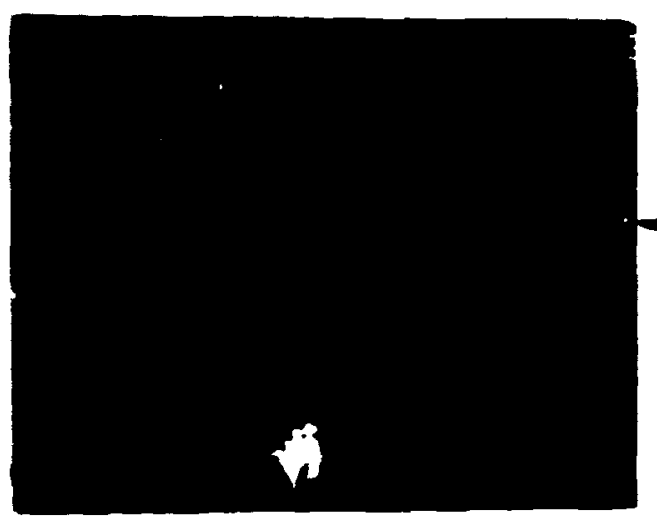

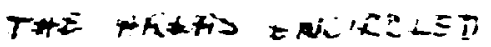

EDPHEDENT

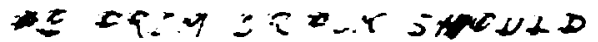

EE DISD-ATED.

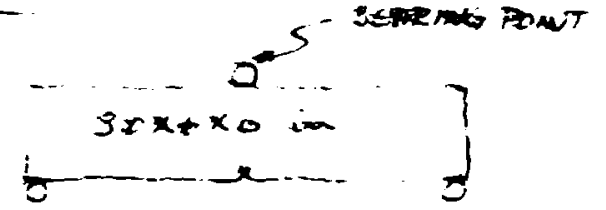

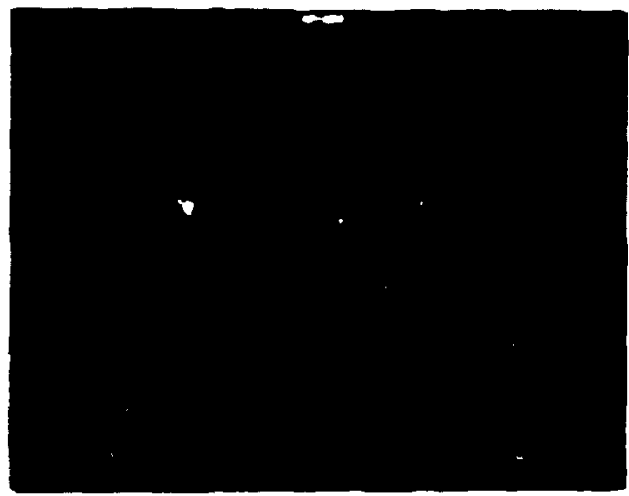

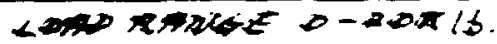

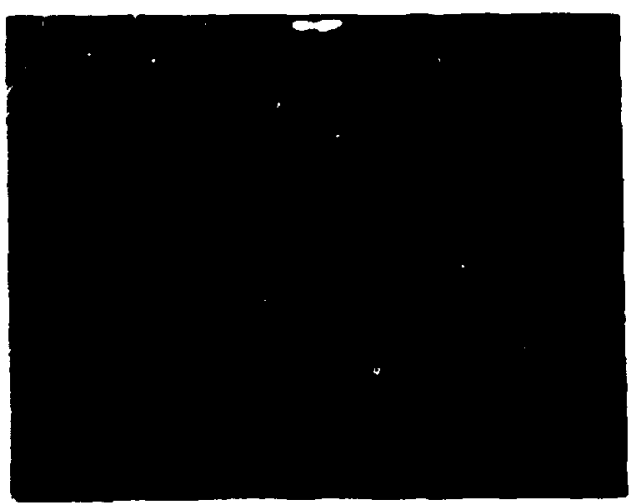

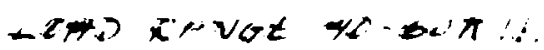

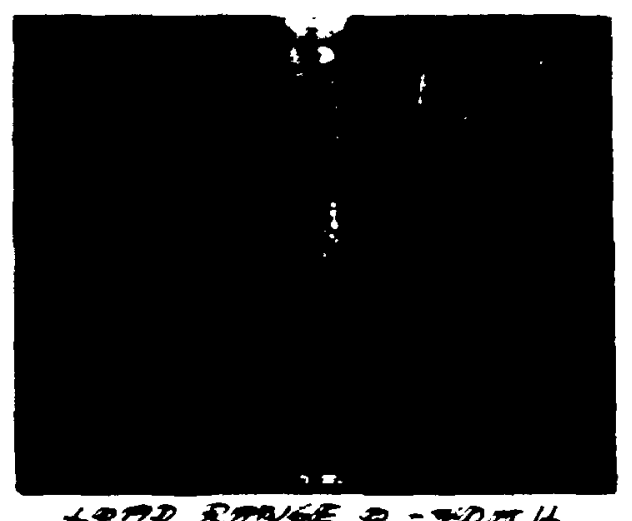

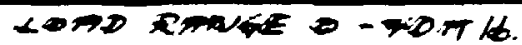

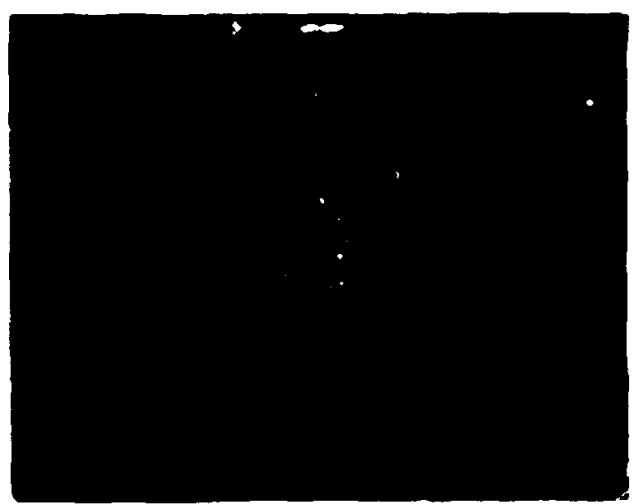

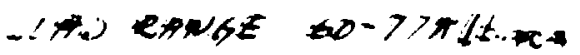
I, $17 \pi \ldots$ ) 


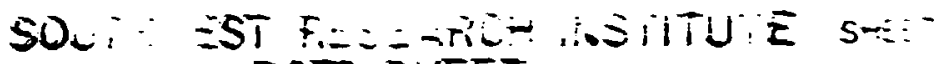

DATA SIEET

SUQUET RESAUIR SIRESS TEST

$P=:=$

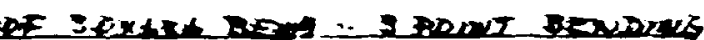

DATE $5 x^{2}=$

BY ID IDLCX

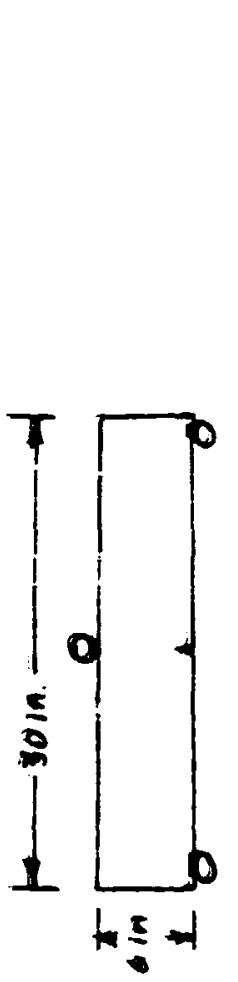

$97000<x-32012000+34 \pi$
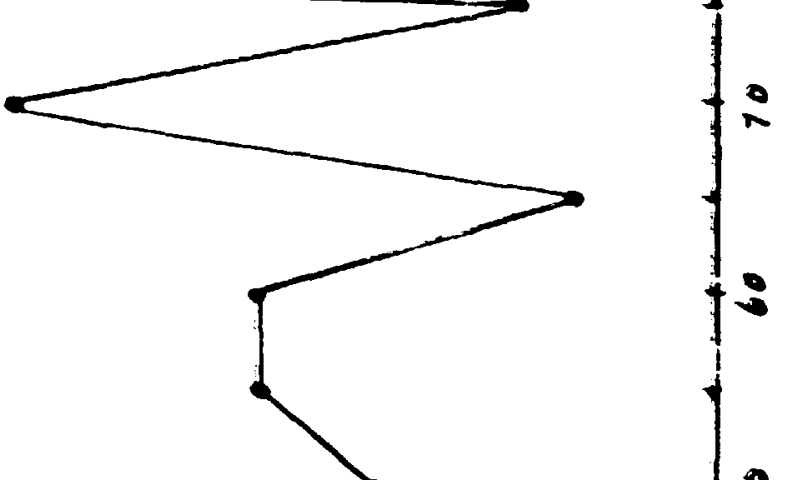

1
0
0
8
1
0
8
2

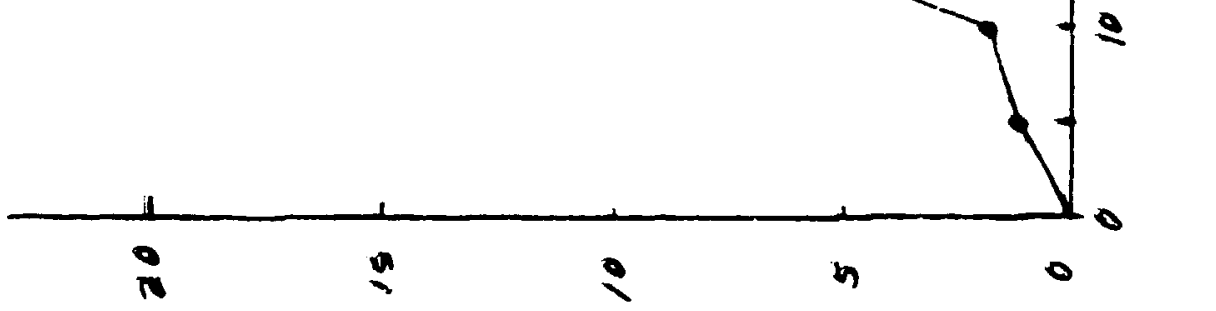

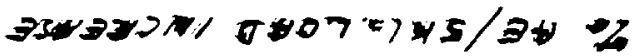

-

(Swh) ? 
SOU itirajT RES

DAT2 $三 \quad \because \div$

I-EETS

DATZ

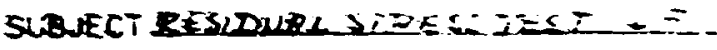

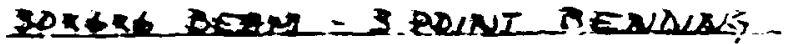

シ

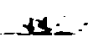
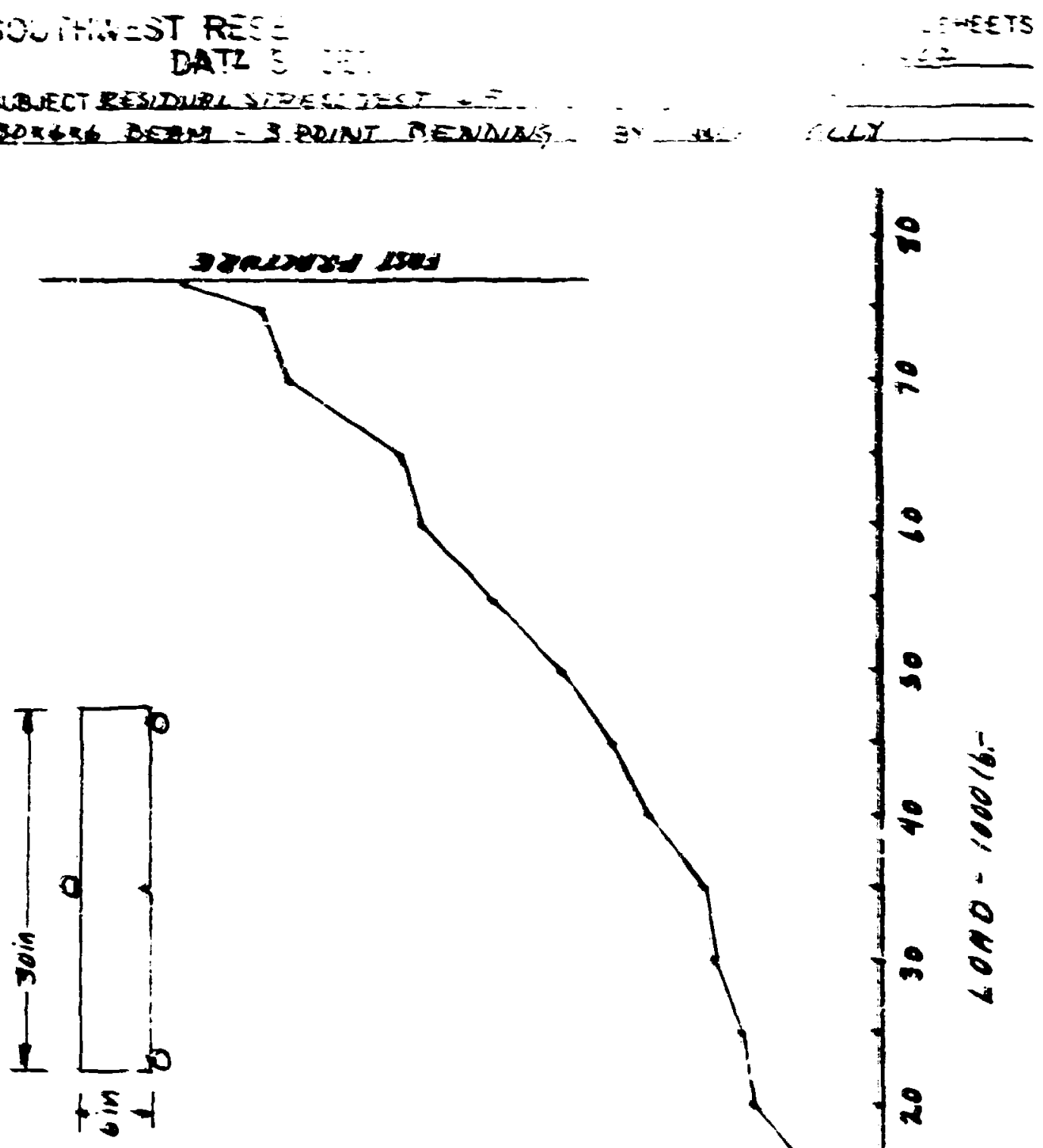

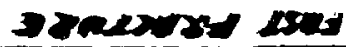

9
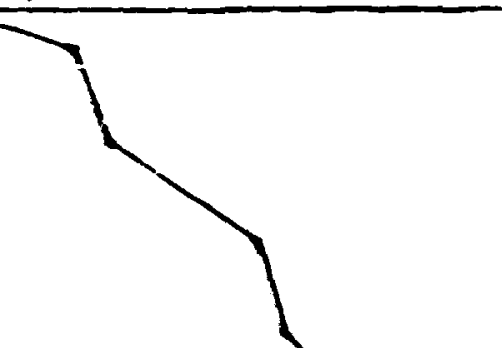
SOLTHWEST RESEARCH INSTITITE

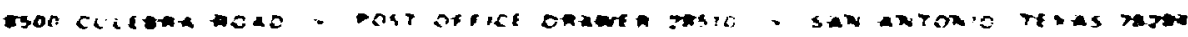

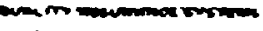

March 1, 1977

TRIP REPORT NONB ER I/77

Sauthest Resentch Institave Projects 17-9165-002 (12bor)

Ji-4400-010 (trave: expenses)

5OOWSOR: $\quad$ Soazhwest Research Instritue and

Juion Cartude corp jointly

TRIX TO:

Oak Ridge National Iabaratory

Oak Ridke. Teronessee

DATES: JanonTy $18=21,1977$

PY:

H. L. Jacoby

Serior Iechnician

PURPOSE

CF TRIP:

Acoostic Emission Monitoring of I he rmal Shack Iest Nomber 4 (TSE-4)

PERSONXEL

CONIACTED:

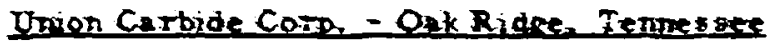

R. D. Chere-ton

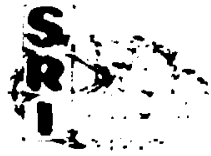


Trip Report Number I/T:

Soutrovest Reseatch lnstitute Proiects 17-9165-002 and J7-4400-016

Pape Two

1.0 SCOPI

1.] A rzip was mide to Oak Ridpe National Laboratoty to collect

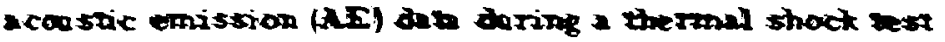
(TSE-4) and a notched-bean west in sepport ax the flown! Section Strel Iechnology Program.

\section{THERMUI SHOCX TESI}

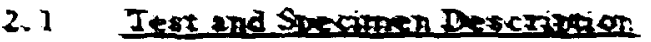

The the rmal shock test was performed on a Inwed, cylim-

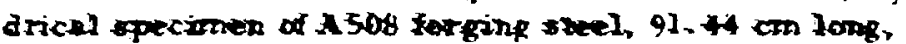
I4. 6-cm wall thicksess, 2411-em insode dismerer. and $167.6 \mathrm{~cm}$ in circumference. The specimen contained a Anw llong its lenpth comsisting of an electron benm (IIB) weld ased as a crack starer. For the west, the specimen was cooled frocn 550 def $F$ by idradoction of coolent at a temperatare of -10 deg $F$ at $500 \mathrm{gal} / \mathrm{min}$.

\subsection{Expionemt Descrimion}

AI sigmels doring the best were coupled to the wexpots by three, 38-cen lom, pointwed steel wrvegrides witrich were pressore coopled to the vespel sortice. The three waver prides were locaved $\$ 0$ as to form a triengle enclosing the Haw area. (See Figare 1.) Arthethed to the ooter exds of the wivepwides were 27-Inw dianele: sensors. As thown in Figare 2 , the ouppots of the wensors were connexved to

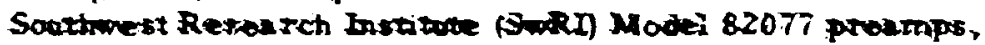
having a pain of approximately 35 at 500 ktiz. The ampli-

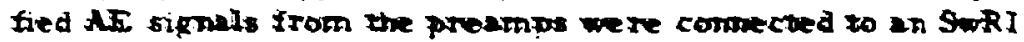

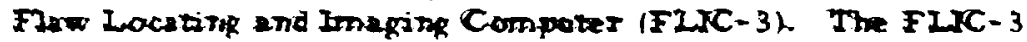
amplifies the AI signals (op to 40 ab), and en envelope devector prevents a video outpat for susp chart recordiag and for thresthold devection in the compoter section. The

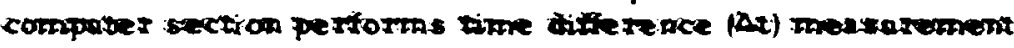

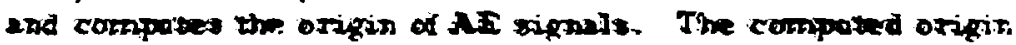

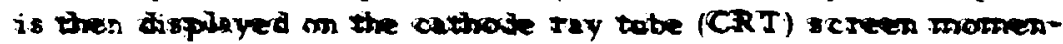
narily, strowng the spatial relationstip to the venos kocations already fisplayed on the CRI scTeem The CRT is a storape type which enables the corrpored locetroms (dots) to be stored for a loog period of time. 
Trip Report Numbet 1: :

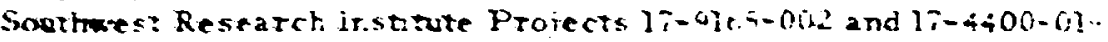

Pace Thres.

in conjunction $x$ ith the stored his on the CRI, a video tape recordinf was made oi the CRT fare so that individeal sicmals could be reviewed later in stop-motion video records. A chronometer was also incloded in the rideo raped display to provide birse of accur rence of inticiciual AE Jocations. As the $\mathrm{A}$ I locations were recorded, they presented brighter dots than sortounding stoted lacations.

The video autput of Channel 8 from the FLIC- 3 was recorded on ore channel of a swo-channel sirip chat: recorder. The other channel of the strip chart recorded the accamulated count of AF events within a spatial window area. The window area of the FICIC- 3 display, 2.s shown in Figare 3. was sized and positioned to accumulate AE locations in an area which. included the expected flaw location. Ihe "wndow count" is an analoi voltage which is proportional to the number of AE exent locations within the window area. In addition, the strip chan record has l-sec interval exent marks for correlation of individual AE locations between the sirip chart and the rideo laped CRI displab.

Prior to tire experiment. an AE system calibration was petformed. A simulated AE pulse was introduced at sevetal points alone the sutface of the ressel, near the naw line. The comnated locations are showr. in Firute i.

\section{3 Iesi DaLa (TSE-4)}

Fur the discussion of the actual test. it will be necessar: to refer to Figores SA through SF, which are copies of the stno chate recordine made durine TSE-4 from. In ivalter onered) in +240 ses.

Duriag the inital pari of the test IFicure $5 \mathrm{~A}$; there was a wery hich backerounci noicc level. At +33 sec the strit chart recording of the viseo output was changed from 2 niv/div to $10 \mathrm{mV} / \mathrm{dir}$ in ordet to see the crests of the nore sicmals. At +41 and +47 sec low-level As bursts were recorded. It was not possible to locatc these signals because the backg roond noise hevel was above the 0 . I V threshole of the FIIC-3c: measurement sectini. It is believed these simals were insigafican: recause of their relatively low amplitude. Ai +10 sec (Ficlite $5 P$ ) the attenuation on the $F L I C=3$ was increased to -46 , di to enathe the $\Delta$ secilom to perform lncainoss. 
Irip Report Normber ]!IT

Southwest Resteatch Institate Provects $17-0165-002$ and $17-4400-016$

Pace Four

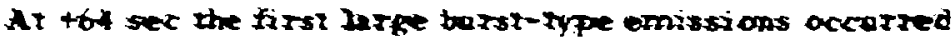
which apporsed to coincide with erack initiacios. This siganl has been labeled at well-derined flue in l. The verm "well defined" devipares AE ewenss that coold be located with absolate cerointy on both the strip chan and the CRT displny, Thertofore, the barst-type AF signals, after Event $\mathrm{l}$, from +64 ro +10 bec, reprewewod is highemplirude spikes on the sirip chart, hive not been aseipmeo locktions becanse they accarted daring period of norive which prevented a precise cortelution of time and powition.

At +88 sec another well-defined event occarsed which

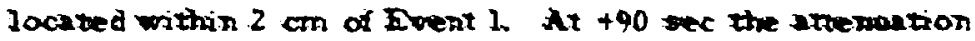
of the FIKC- 3 was incroased to -52 dQ. This sering was foond to be too tow At +100 sec (Fipere $5 C$ ) the ervenoution w2s decreased to $-40 \mathrm{OB}$. By this nime, the backgroond noise had subsided robstamilly;

Ax +150 sec (Figare 5D) there was a high-amplitade burst which lucated a bout i cm below Inent 2. At +351 sec a low- amplitude seties of borsts occatred (Events 3 and 4 ). At +160 sec 2 series of barsts accarred over a period of 18 sec (Events 5 throagh 8). There tiphals ranged from meciom to Jow amplitodes. Some of the sipnals we re not of sofficient amplitade to exceed the threshold and show locations. At +175 sec a mediom amplitade batsi occorred (Fver: 9) in the same area as previous bo-sts in the lowet portion of the central one-thitd of the EB $w$ eld tine.

At -240 sec (see Figare 5F) a mediom amplitude barst (Event 10) occurred adjacent to Events 5,6, and 9, This was the last sipazl of sufficient amplizude to be recorded. Dara recording ceased after a period of 15 min from $\mathrm{I}_{0}$.

\subsection{Itst Sxrmmar:}

The AE instrament data show that large increntent crack growth occarted in the period 5 rom +64 bec to +151 lec. The perjod from +15.2 sec to +240 sec is characterived as intermittent, schall-stop crack erowth. The spatial location, with reference to the waveguide contact points, of the welldefired AE events is pregerited in Figare t. 


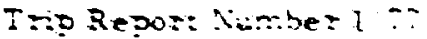

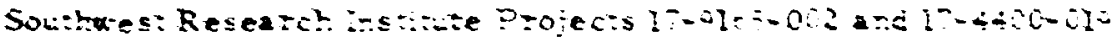

Pace Fine

$2 . \quad$ Corcl as:as

AE daia from the the mal shock test indicated crack growth aloug a portion of the IE welc. The principle sources of AI appeased to te aptoximately lo $\mathrm{cm}$ eithet sicie di a line describits the midpoini of the weld path. Crack iniantion. appeared to occur to sec after thermal ehock sta ried. Recordable AE activity ceased a: $240 \mathrm{sec}$ arter thermal shock staried.

\section{0 TOTCHED-BEAM IEST}

\subsection{Iestand Specime- Descriztion}

AE da:2 were recordec from a notched beam in three-poin: bending. The beam dimensions wete $70.5 \mathrm{~cm}$ long. $10.1 \mathrm{~cm}$ wide, 2 nd $15.2 \mathrm{~cm}$ thick. The notched beam cunta:nes a sizrier crack in the root of the notch as institated in Figure 7. The crack was made by an EE weldiag procecure cesigned so that residual sitess remained 2 : the crack t:p.

\subsection{Equipmen: Desctiptio:}

The AE instrumentazion was the same as ised for the ISE-4 isee Figore 2) with the excepsot of the sensors. The sensors ised wete standard SwRI manuracitire, magnetic mount AE sezsors using point coninct, presstre coupling. See Iigire $i$ for sersor placemerii on the specimet..)

The sinape of the specinen prevsted direc: two-strensionel itiargelation of the AE signals, Jut it was possible to calibrete the FLIC-3 displey, as illusitated in Figute 8, 00 sha: AE signals from the crack could be dissinguistred frors AE signels originating 2: the center beatizg paint.

Prior to the iest, sensijrity and location survers wete made sising a rew source simulator. The simulaton was accomphished by breaking a l. 5-r.i. exters: on of 0.3-mr. percial lead from a mecharical percil. The peticil lead was placed or the

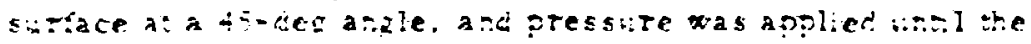

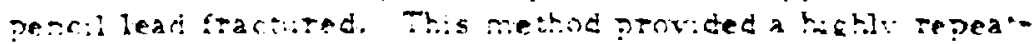
at.le, izsi-t:se, AE siz:al simblation.

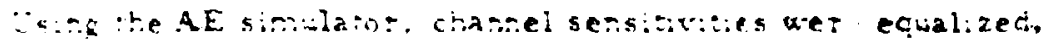

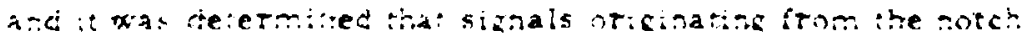


Trip Repot Nimbet 1 :T

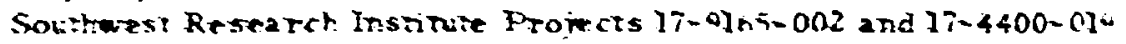

Pape Six

would be displaced from sifnals onfinating from the londing mechanist: ise Fupure 0,1 Daring the entite vest. sichal plins for pach channel were as follows: Chandel $A$. 5t dA: Channel B. 54 dR; and Chanel $C$, 54 dB.

\section{3 Iest Data}

Durital the test, the 1020 was increased smoothly from 0 (2exo) to sit, 000 los. Fast fractire occarred at 80,000 lbs: load.

At the conclusion of the tests a photograph, thown in Figave 10. was made of the FINC-3 CRT display with the stored AE w00xce lacasions. A plot of land versus accomulated Af event cant is presented in Figare 11.

3. $\div$ Ies: Summat:

in summan, the AE event rate increased a: 35,000 lbs and acain at $0,5,000$ ibs'load. A rapid increase in rate after 85.000 lhs load indicated fast fractuse. Au AE events recorded on the CRT display could be cortelated in time with AE evenis recorded on the strip chati. Most of the sicnals carre from one end of the ER weld area as illustrated by Ficate 10 .

3. $=$ Conclusions

AE data from the notched-beam tes" indicated that subcritical crack growth piobably started at 6,5,000 Ibs' laad and incteased in rate antil wistable crack growth occarted a: 80,000 Ibs' load.

\subsection{SCNCLUSTON:}

4. 1 The FIIC-3 ho trangulating and storing AE everts in real time dernonstrated the ability to determine crack initiation and frowth while the tests are in procress. I Te "window" analos लutpoit also futhis hes an immediate indication of AE actirity rate during tesis.

The use of a video cameri., tecorder. and monitot to cortelate data presented on the strip chat recording further enchances the wse of the FLFC- 3 by providint an extensive post-tesi data analysis technigue. 
TTp Repot: Nushe: I -

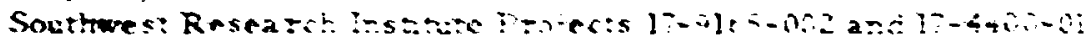

Pare Sere:

\section{S. $\mathrm{RECOMMEXDAIICNS}$}

5.1 Ir sobsequent the rmal shock tesis in he co-dicod. :: :s rerommendec thai initial artenuaior setrines of the FI,IC-3 be a: teas: 52 dF.

It is further recommencied that the riden recording oi the FLIC-3 CRT displas be ised. This provec to be a valuabie aidin pos:-iesi amalysis of data.

For three-do:nt beam loading tests it is recommenced that the FLIC-3 be used because of its abil:n to separate no:se from the center load point / directly opposite the crack siate? notchi and valid Al exents from ine crowite aracs.

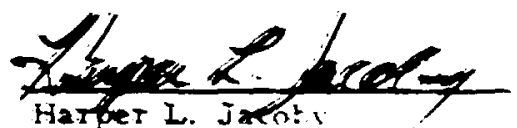

Seriot Techniciat

A. C: Tou

Apntoved t:

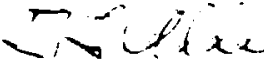

c] 


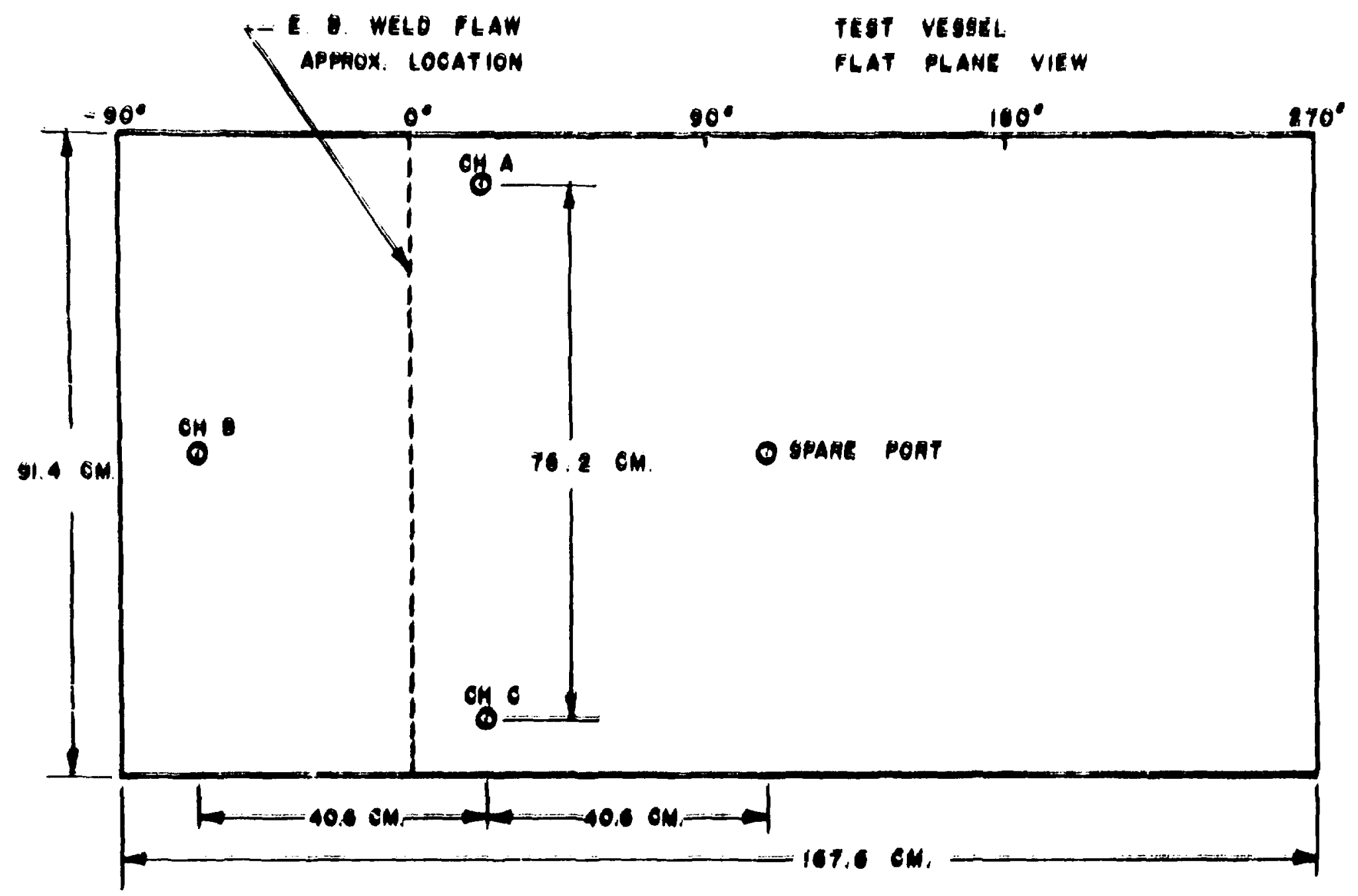

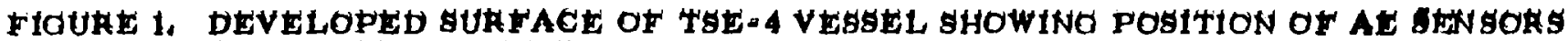
AND EB WELD FLAW. 


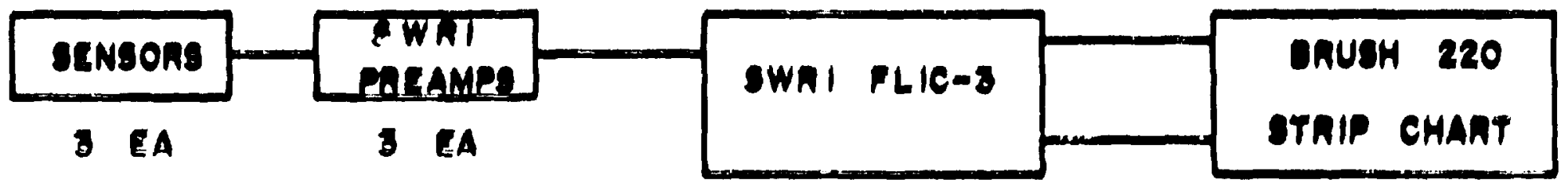

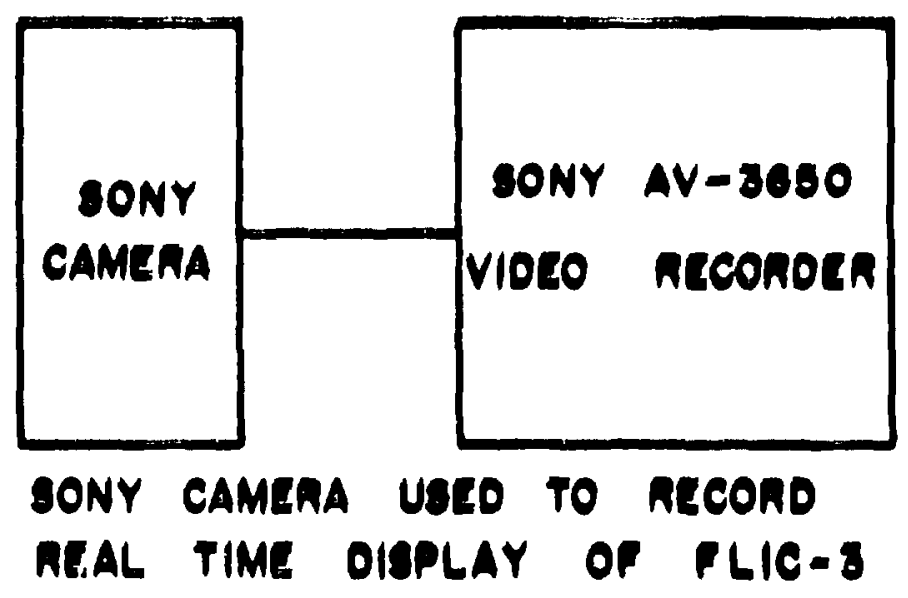

FICURE 2 , BLOCK DIAGHAM OF AE EQUIPMENT USED ON THE-4, 


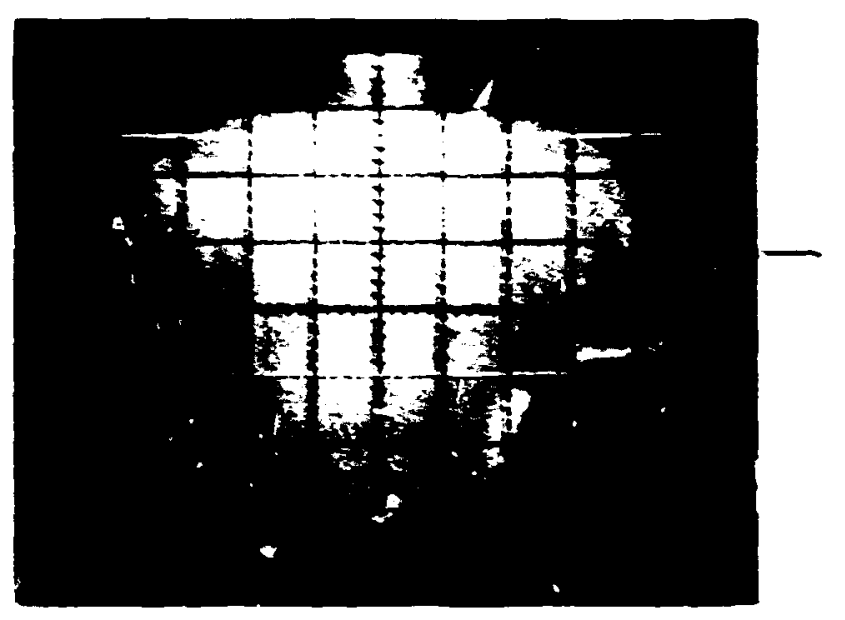

$$
\begin{aligned}
& \therefore \because x
\end{aligned}
$$

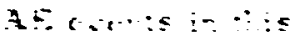

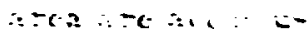

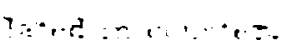
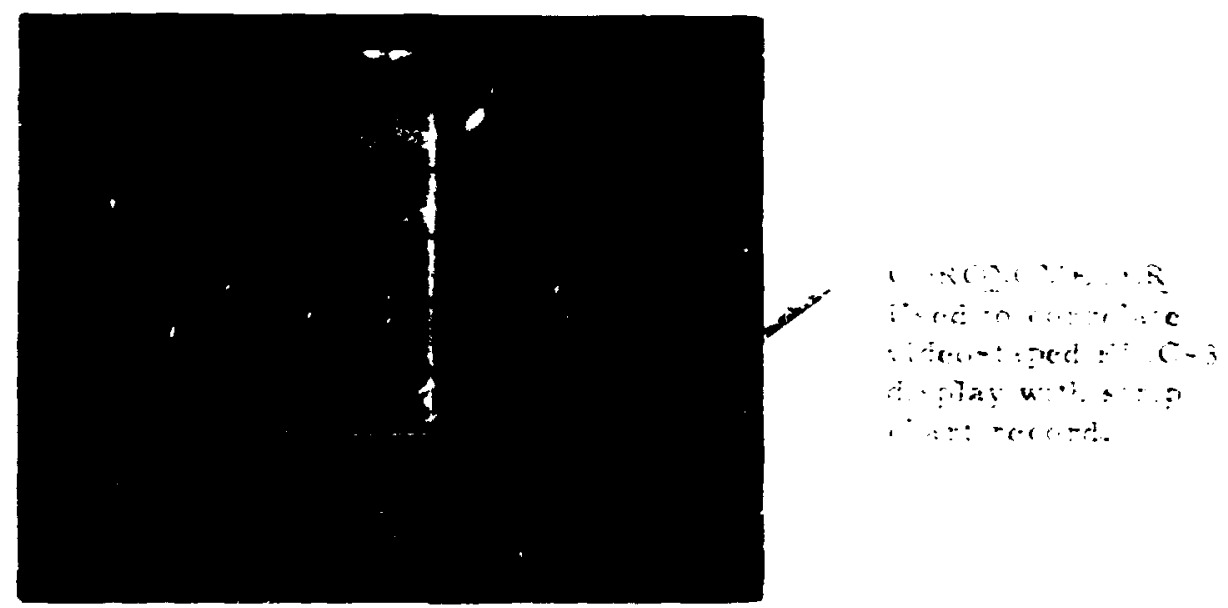

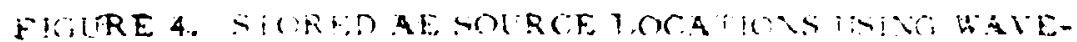

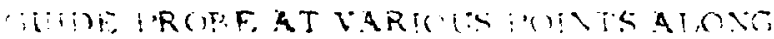

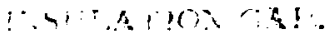




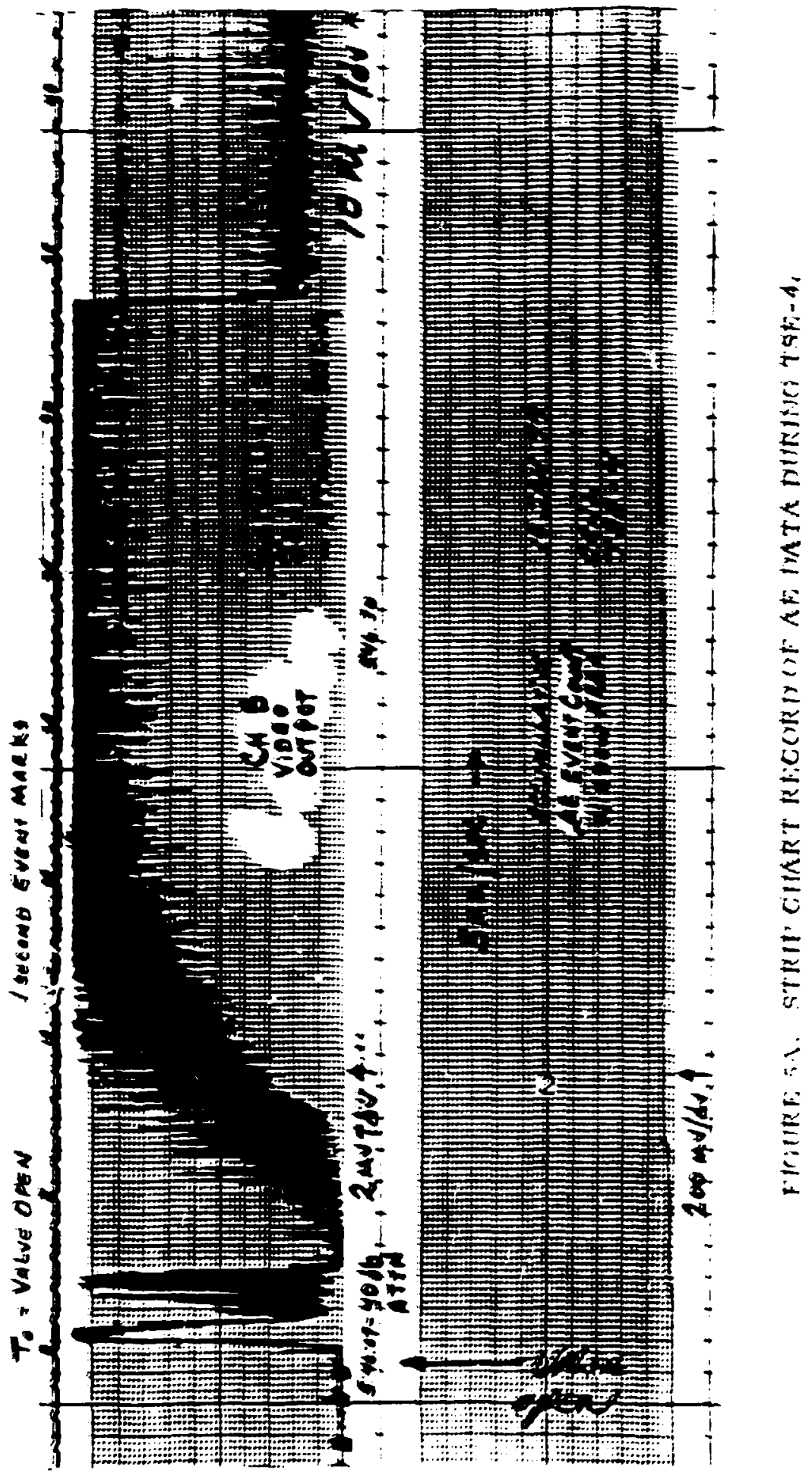




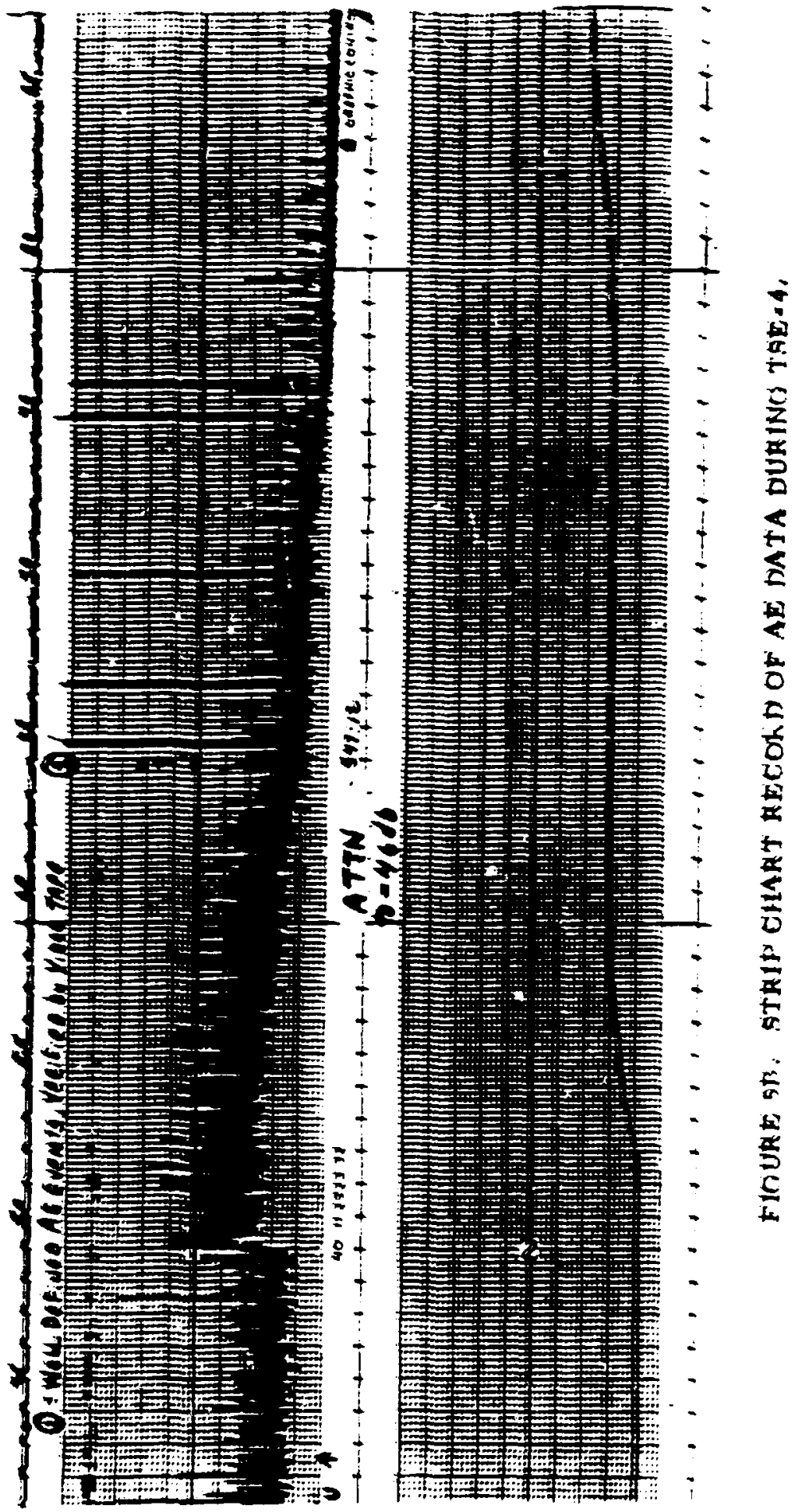




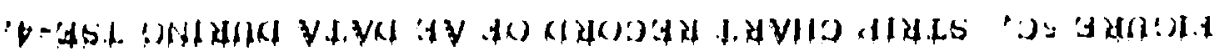

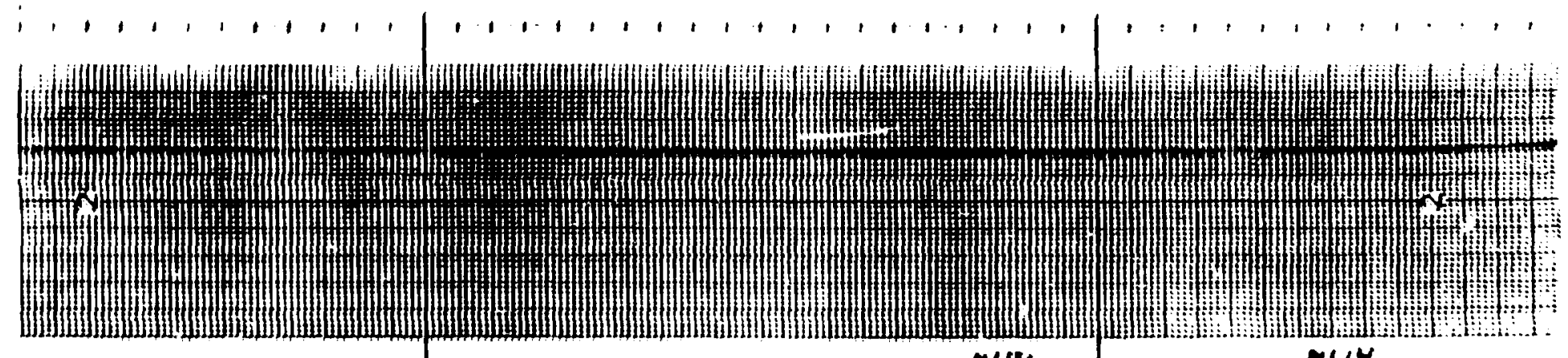

1,1

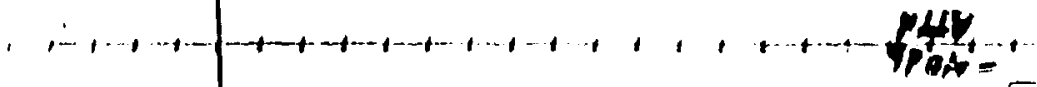
SPY

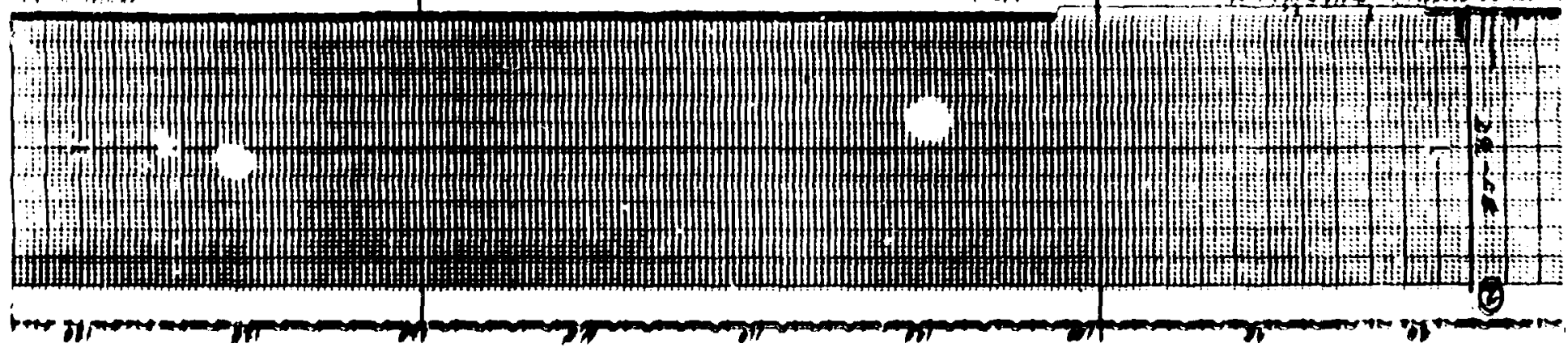




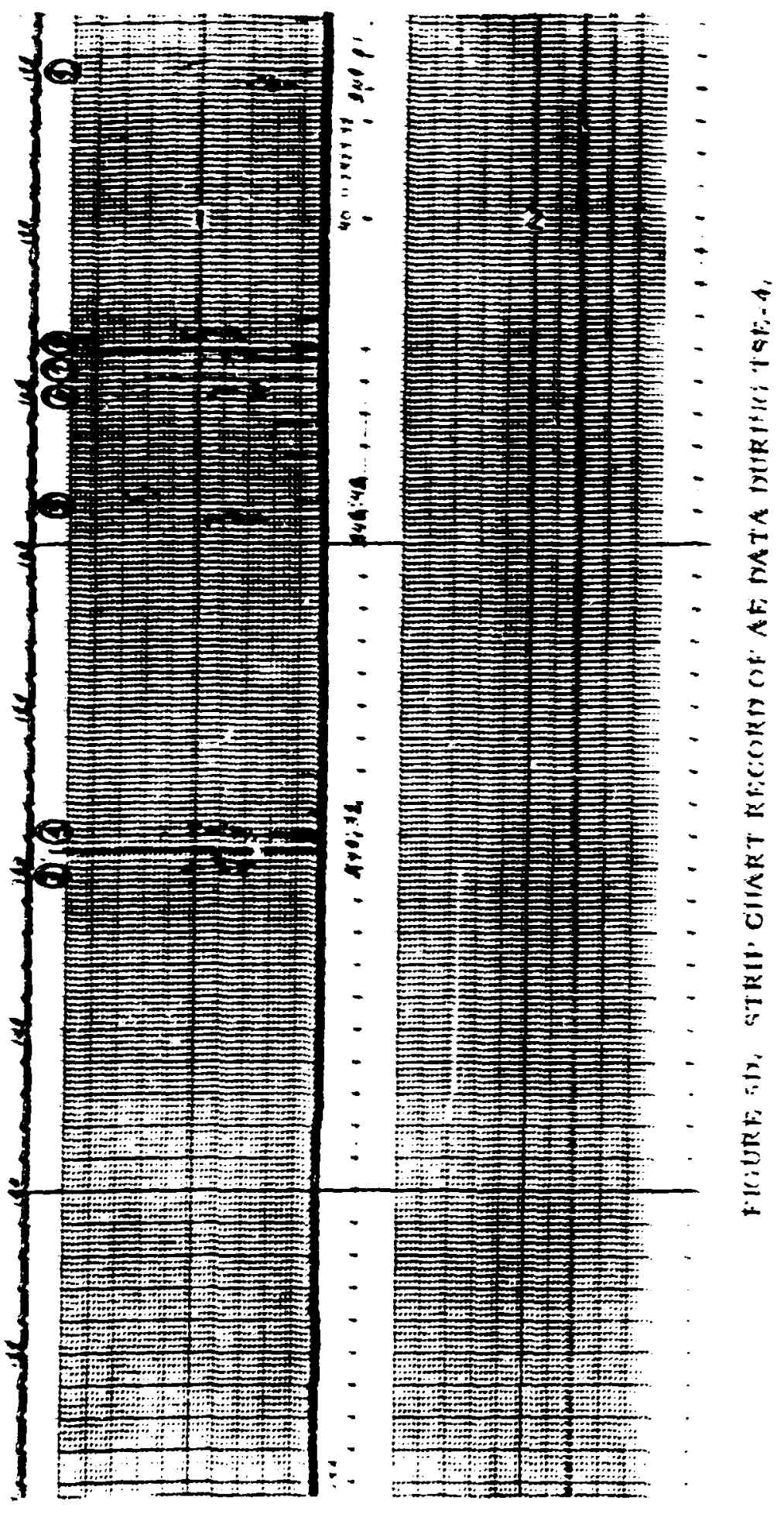




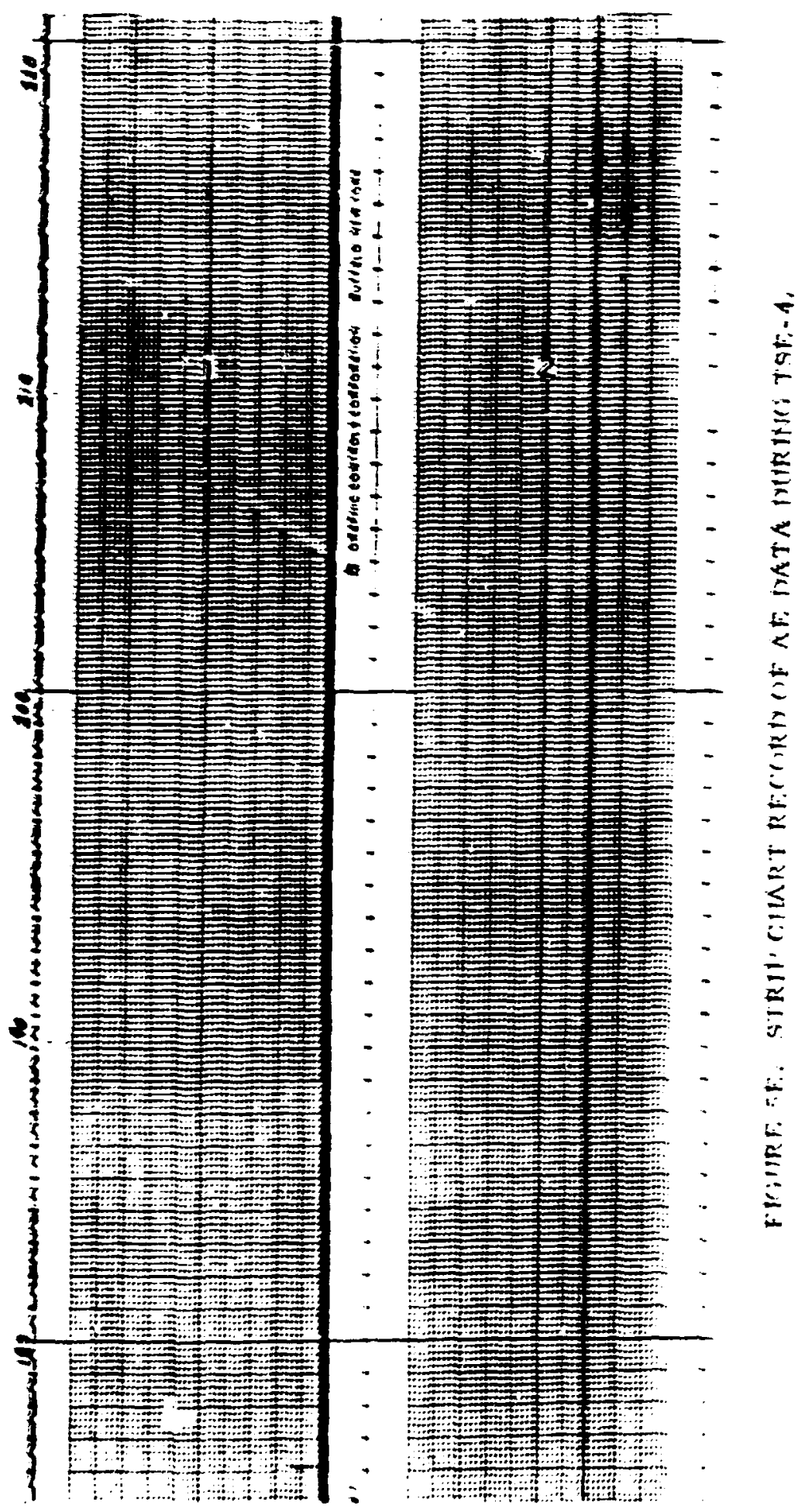




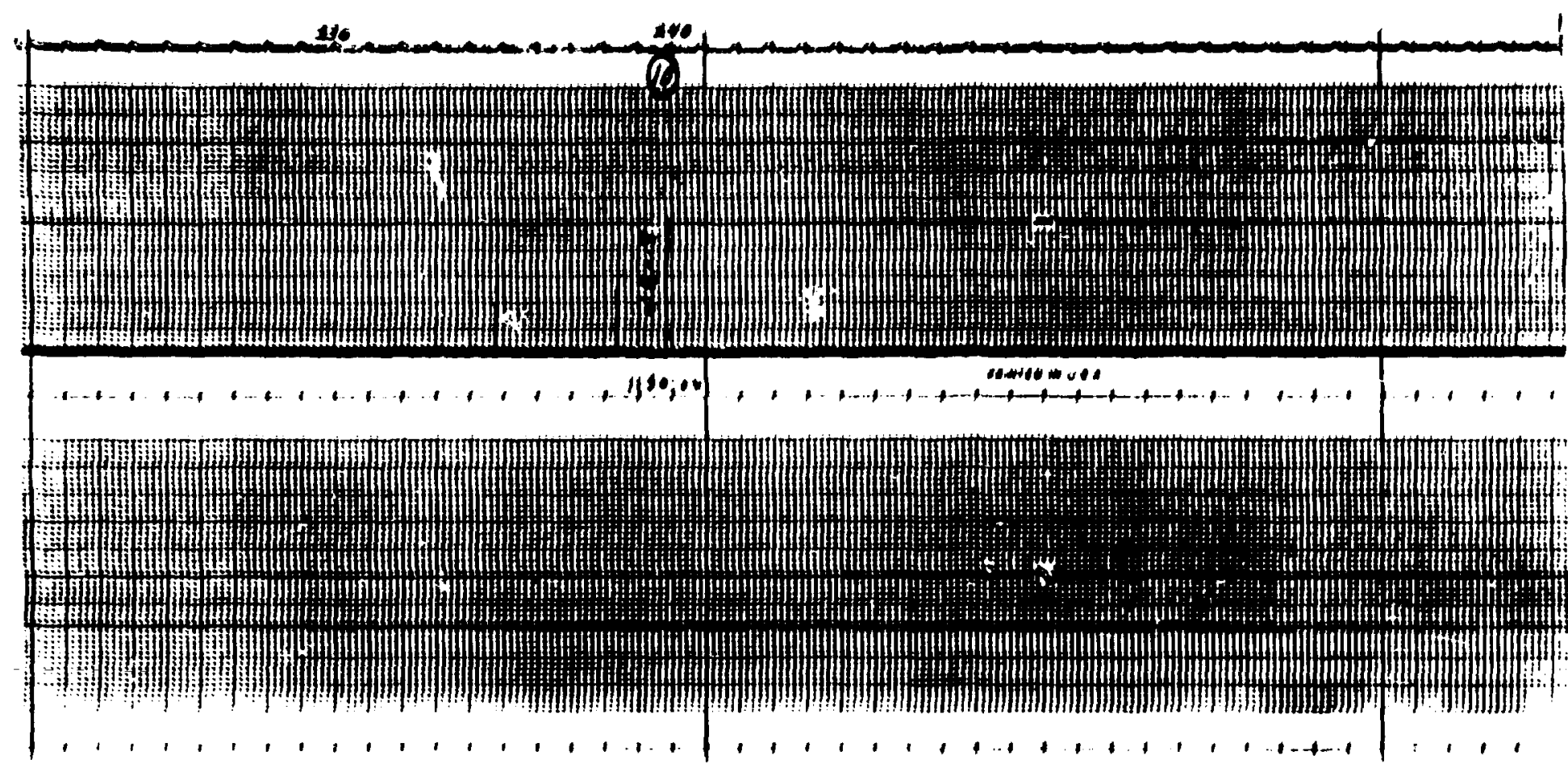

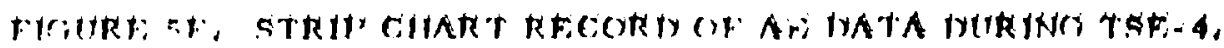




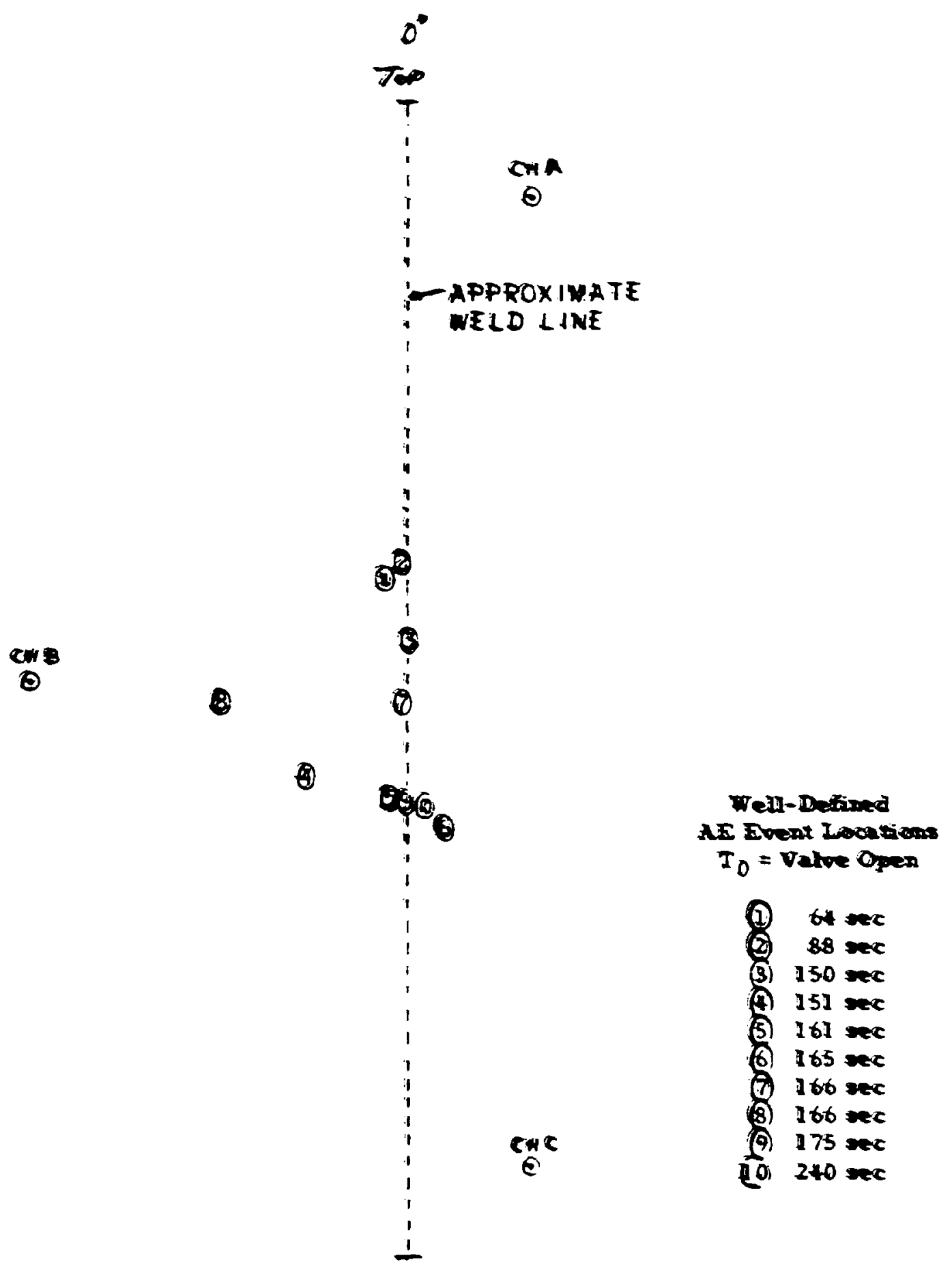

FIGURE 6. LOCATION OF AE EVENTS CORRELUTED WITH STRIP CFIRT RECORD OF TSE-4. 

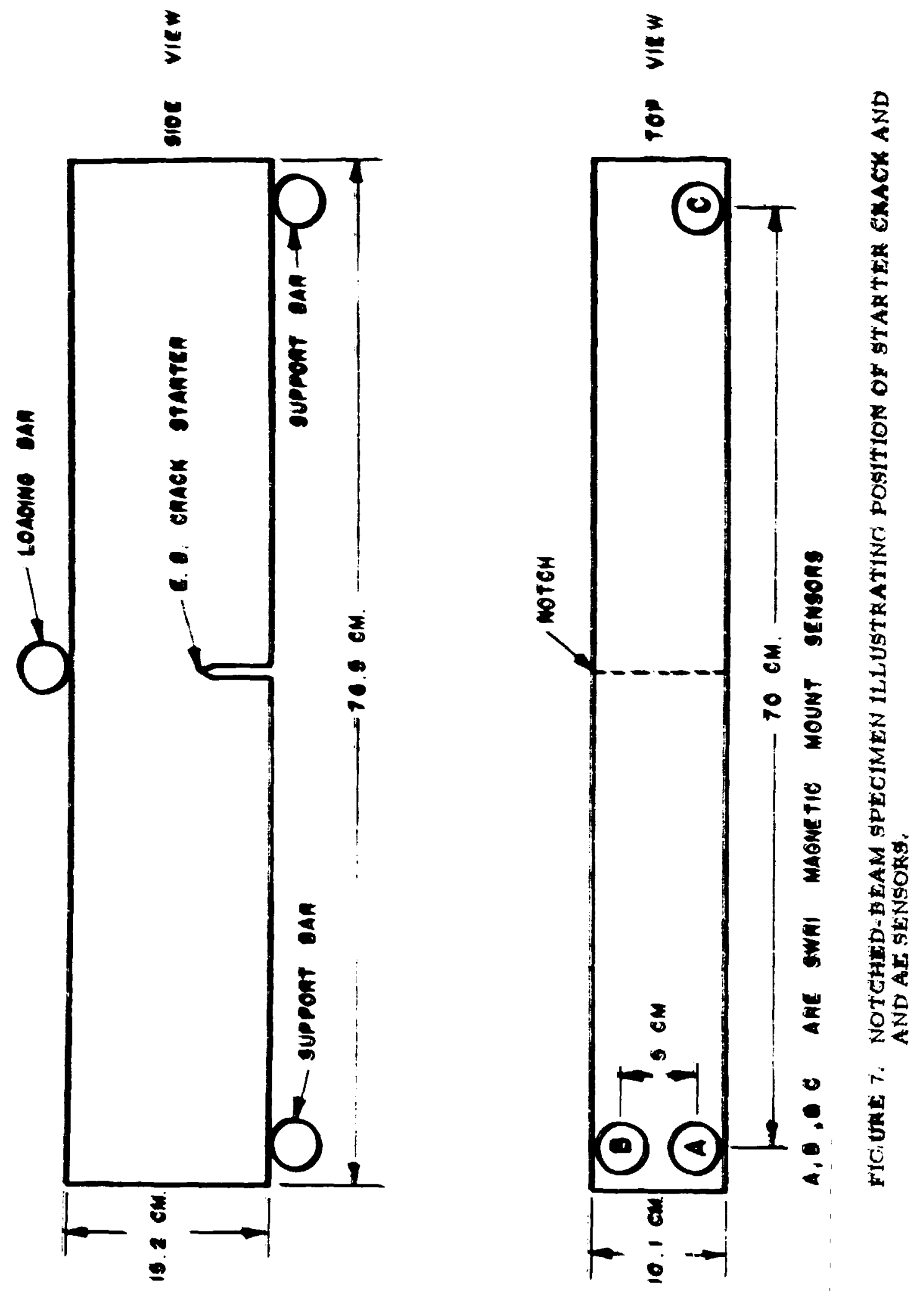


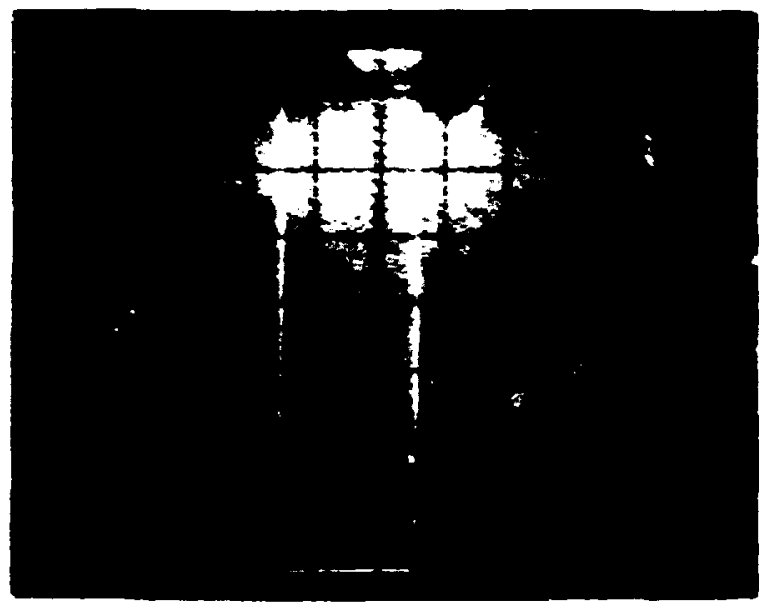

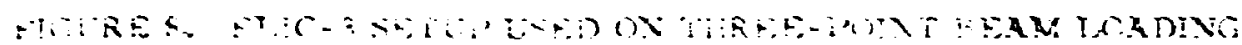

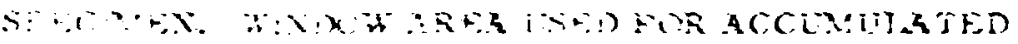

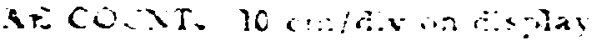

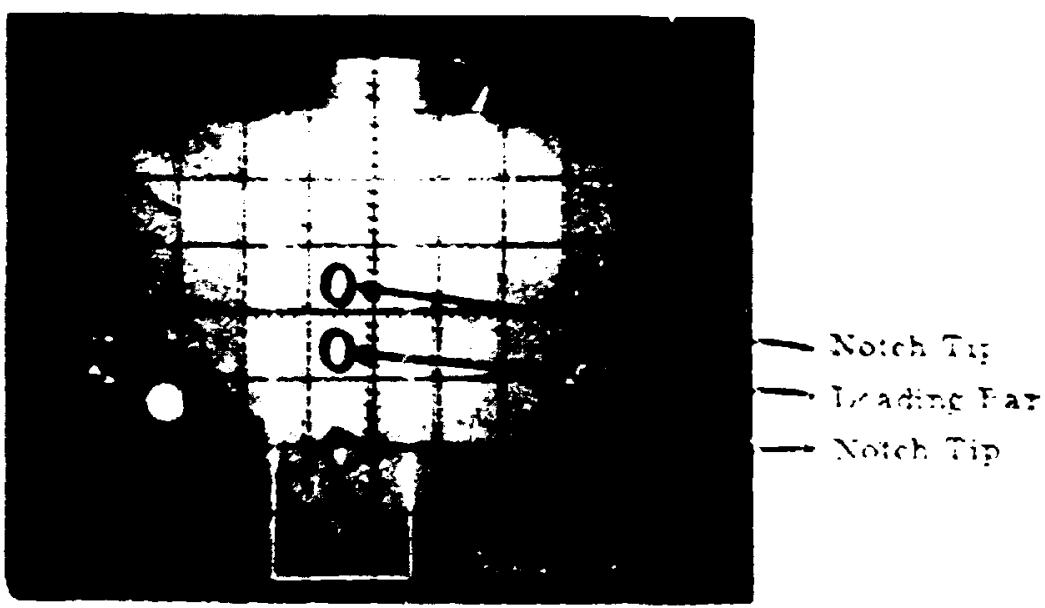

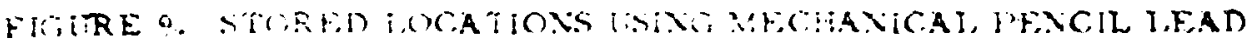
UR FAK AT OUTHR TIR ACF OF NOTCH TIS AND IOIXT

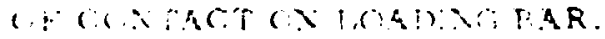




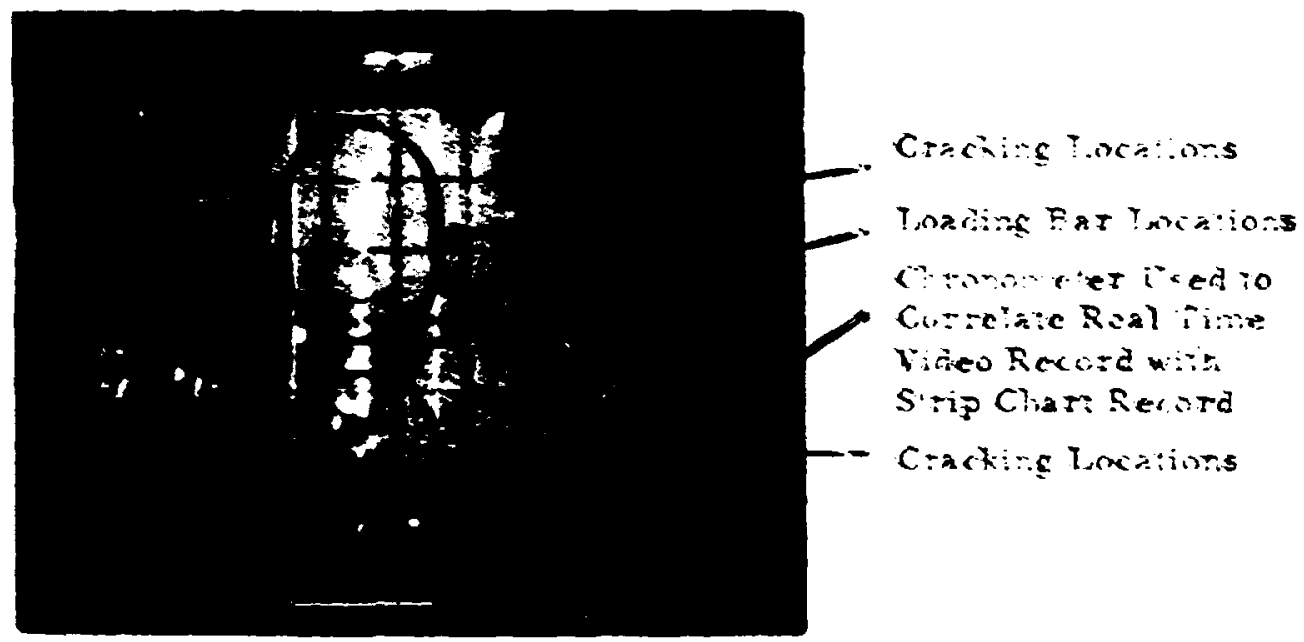

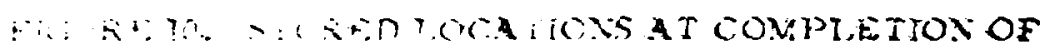
$\because 4.11$ :T.T. 


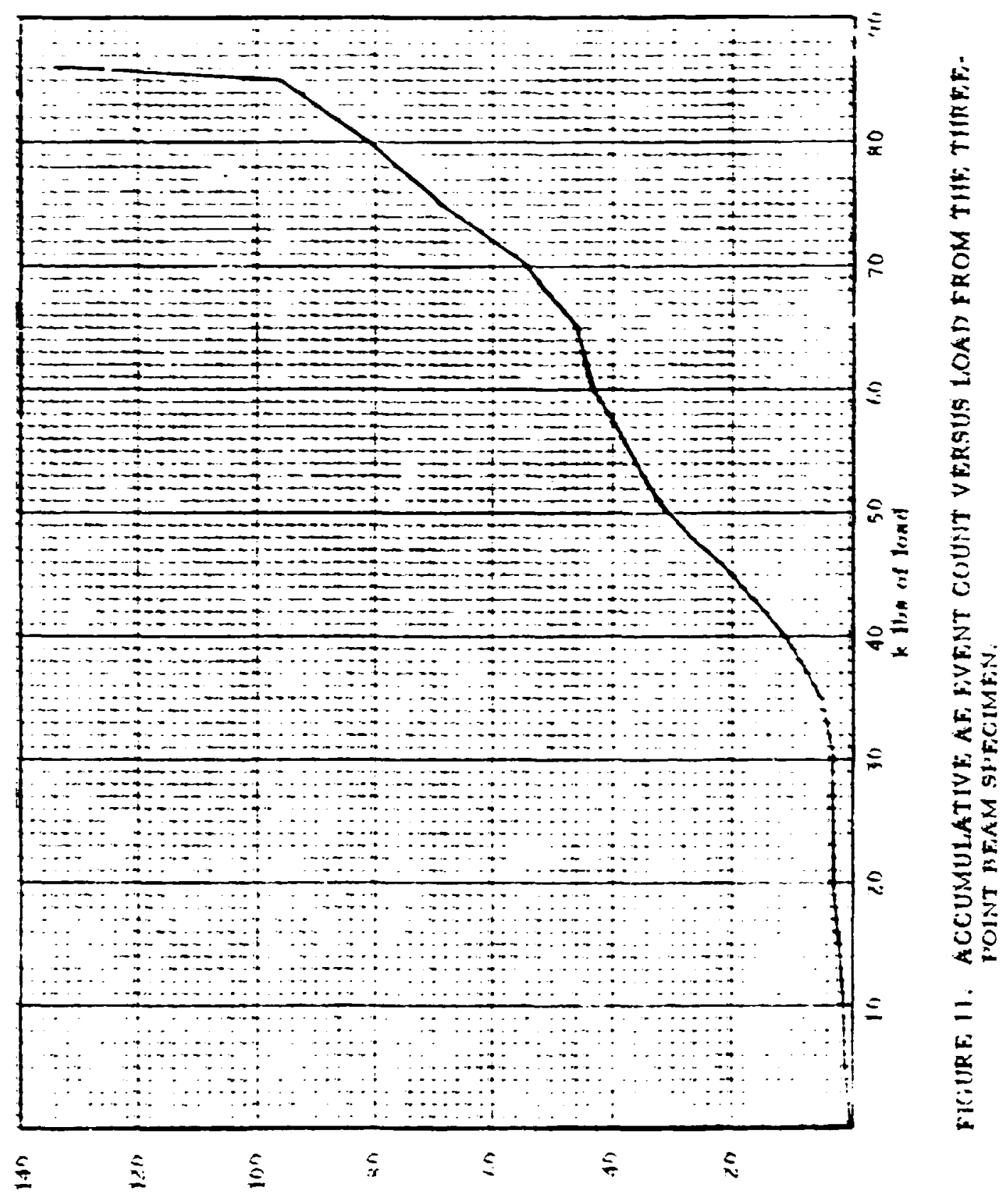




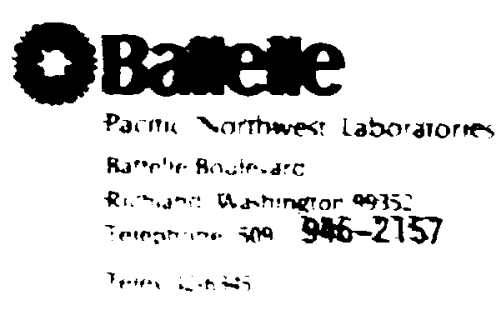

Mr.R. D. Cheverton

Dak Ridge Natiomal Laboratory

P. D. Bax Y

Dak Ridge, Temmessee 37830

Dear Dick:

\section{ACOUSTIC EMISSION-HSST THERMAL SHOCK TEST - OAK RIBGE $1 / 19 / 77$}

As part of acoustic emissiun (AE) characterization research program wich we are performing for the Nuclear Regulatory Comission (XRRC) are required to abtain AE data from HSST texts. The subject test the first of these since initiation of WRC program. The puritose of this letter report is to sulmarize our participation in the subject test.

\section{SUImARY}

AE dat was detected and abserved with the Blw digital momitor system during the thermal 1 shock test, however a record of the data was not obtained due to one faulty sensing point. abserved periods of at acrivity were identified and reported on a time scale relative to start of caolent injection. These appear to correlate with periods of expected crack activity. Output from one COD gauge was satisfactorily recorded. Coolant flow noise not problem to the Brin system.

These efforts were supported by excel lent cooperation from staff members at Dat Ridge.

\section{DISCUSSION}

J. F. Dauson, Test Tecmician, and I visiled Dak Ridge $1 / 17 / 77$ to preview the test arringanient. Subsequently, Mr. Dawson and J. R. Skorplk, Electronic Engineer, returmed to loak Ridge 1/78/77 to install AE instrumentation and monitor the test. Two criterit we inposed were:

- nur participation could not in any way interfere with the basic test.

- Dr instrument system cauld not compramise AE manitoring by Southuest Research institute (SWRI) who were monitoring this test as they had cone on previaus s imilar tests. 
Mr. R. D. Cheverton

January 26, 1977

Page 2

\section{Qbatale}

The BNW AE monitor system consisted of:

- Sensors - two 1/8" dia. x 15" Lng. carbon steel pressure coupled wave guides with 2 MHlat cut PT-5 crystals mounted on the outer end.

- Preamplifiets - $400 \mathrm{kHz}$ nigh pass with $48 \mathrm{~dB}$ amplification.

- Main Amplifier - $400 \mathrm{~K}$ MZ high pass with 76 d8 amplification.

- Analyzer - Buw digital memory monitor with capability to analyze and recoró faur AE parameters (count, energy, rise time and signa? amplitude) plus ore mechanical parameter (COD gauge voltage).

Threshild set to monitor sigmals $>7.5$ volts peak.

- Source Isolator - analyzes difference in time of signal arrival (..t) at the two sensors and limits acceptable data to that falling within a preselected range of $: t$. This effectively restricts accepted data to that originaring within a preselected area of the specimen.

Figure 1 shows a sketch of the test arrangerient relative to Af monitoring. Points A, B, C, D were sleeves installed through the neater jacket to allow mointing meta? wave guide AE sensors. Point $E$ was a supplemental wave guide mounting fixture installed by Oak Pidge persomel. Point E' is the ultimate lucation of the point E fixture as discussed later. Buw was assigned points D E to allow use of AE source isolation to restrict accepted data to that originating from the flaw line.

The BNw AE monitor system was instal7ed on $1 / 18 / 77$ with wave guides inserted at points $D E$. The system chezked out satisfactorily in alt respects. SWRJ installed their $4 E$ monitor in the afternoon of $1 / 79 / 77$ using points $A, B, B$. It was discovered mid-afternoon that they required pcints $A, C, D$ to achieve source location on AE from the flaw. It was thus necessary to move the BNW sensors to points B and $E^{\prime}$. By the time this was completed, start of the thermal shock test was imminent. Sensitivity on point $E^{\prime}$ was poor but there was no time remaining to make adjustments. The net result was that point $B$ showed good response during the test but point $E^{\prime}$ was so insensitive that it did not provide the source isolator with a second input required to validate AE signals from the flaw area. Hence, no AE data was progranmed into the mories. Data from the center coD gauge being monitored was independent of source isolation and it was programmed into memory. The printout of that information is given in Figure $2-A, B, C$. 
w. R. D. Cheverton

January 26, 1977

Page 3

Visual abservations were made of the point $B$ sensor autput on an oscilloscope. These abservations are correlared with the CDD gauge $1 z+a$ in

Figure 2. By $\$ 0$ seconds after apening of the coolant valve, the hydraulic noise had subsided below the 1.5 Volt peak threshold setting on the monitor. Noise signal amplitude was estimated to be about 7.8 to 7.9 volts peak during the first 90 seconds. A tectmique for adjusting sensor system impedance proved to be quite effective in suppressing hycraulic noise below $400 \mathrm{KHZ}$. Three major AE activity areas were abserved on the oscilloscop? monitoring the "B" sensor output. These occurred at 154, 224, and 235 seconds after the coolant valve was opened.

It is still not clear why the $E^{\prime}$ sensing point was so ineffective. Examination of the wave guide showed evidence that it may have slipped past a set screw holding a mounting collat in place. Also, the springs on the mounting fixture that provided coupling force to the wave guide were fully compressed when the wave guide was installed. If the wave guide did slip in the collar, the springs fully compressed in this particular fixture would have been unabie to compensate. POSI test examination confirmed that the wave guide through some cause was not in contact with the vessel wall.

There were several positive results from this test even though recorded AE data was not abtained.

- Obsetved AE appears to agree well with predic ed crack gromth sequence.

- Adjusting the sensing system impedance proved to be effective in overcoming the hydraulic noise interference problem.

- The wave guide configuration used is basically on effective method for sensing AE from a high temperature surface.

- The digital memory syctem recorded information from the COD gauge as expected.

Cooperation and assistance provided by the staff at Oak Ridge was outstanding. te appreciate this very much.

yours very truly,

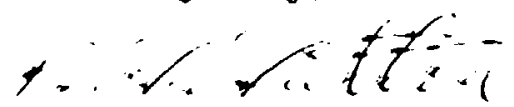

P. H. Hutton

Senior Develapment Engineer

Nondestructive Testing

PHH: jmb

cc: J. Muscara (NRS) 


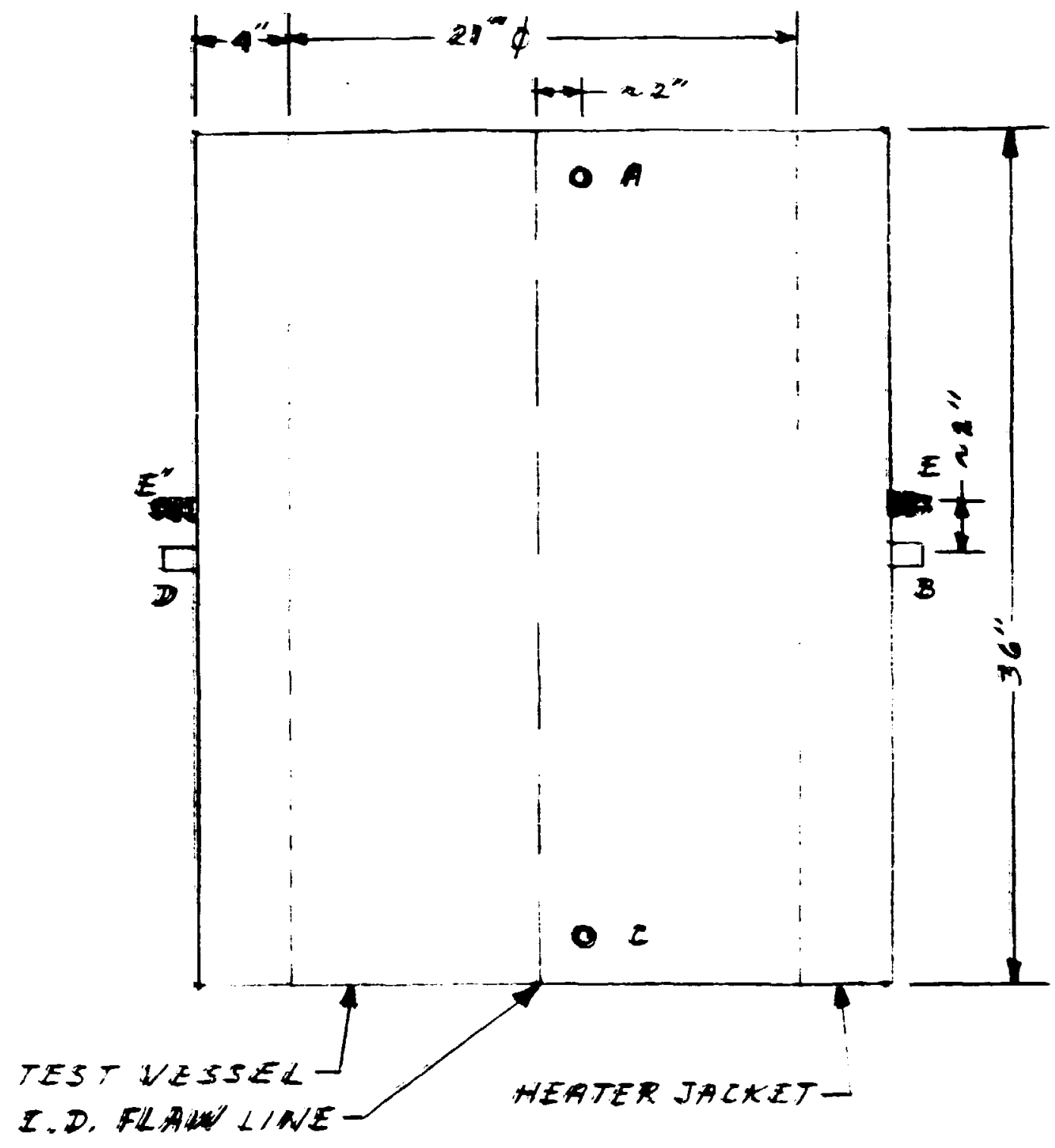

Figure 1 Sketch of AE Monitoring Arranoement for Thermal Shock Test 
W

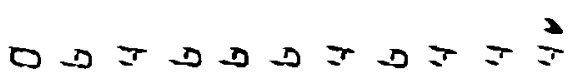

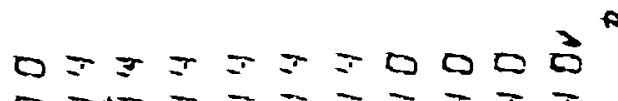

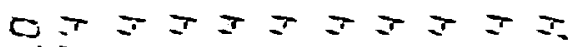

0

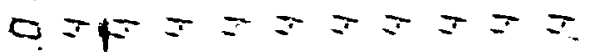

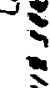

0 a

20

$\therefore$

$\therefore$

A

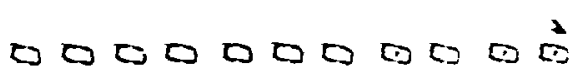

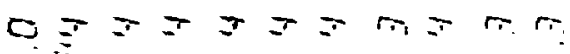

0

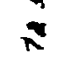

₹."

$\div \quad \leqslant 0$

\author{
A
}

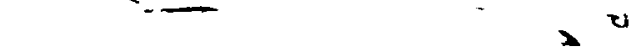

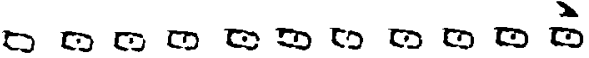

c) $\mathrm{mm} \mathrm{m} \mathrm{mm} \mathrm{mm}$

0

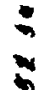

$\therefore$

i $\quad \therefore$

;

$v$

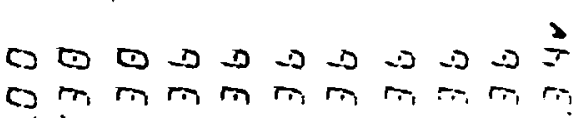

0

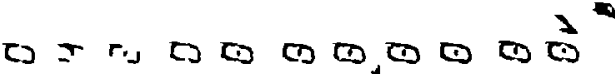

o $m$ m $m-\cdots-1-\cdots$

$\$$
8
8
8
8

$\therefore$

c $\quad \therefore$

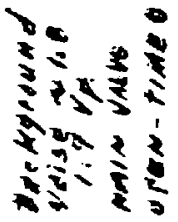

$\rightarrow$

0000000000
0

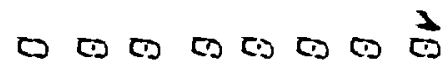

00

0

00

-

$\infty$

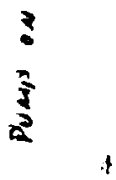

1
050
050
050
050

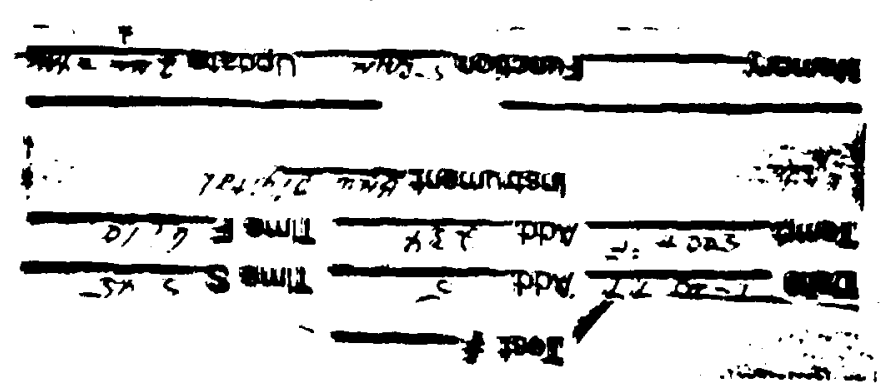




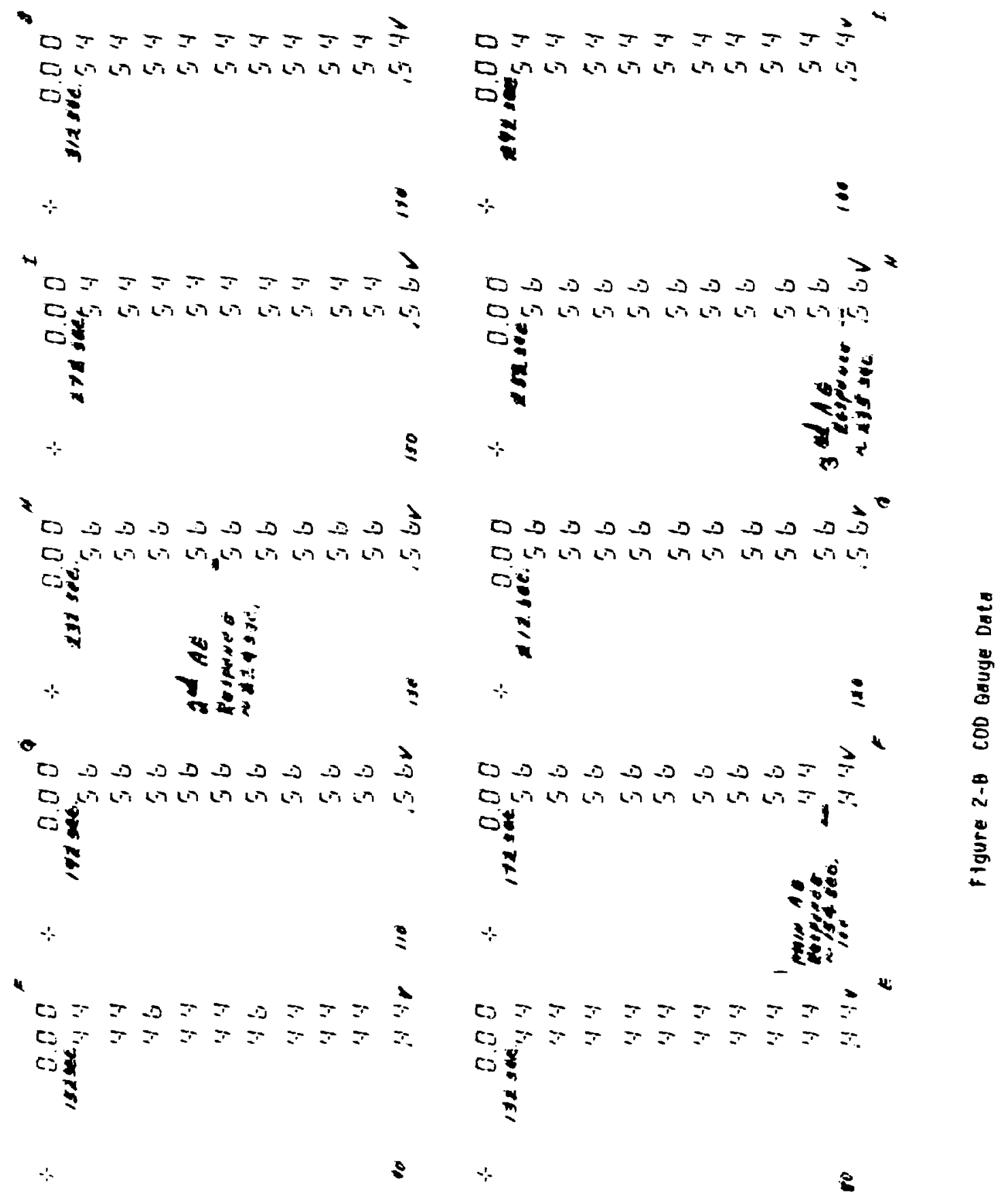




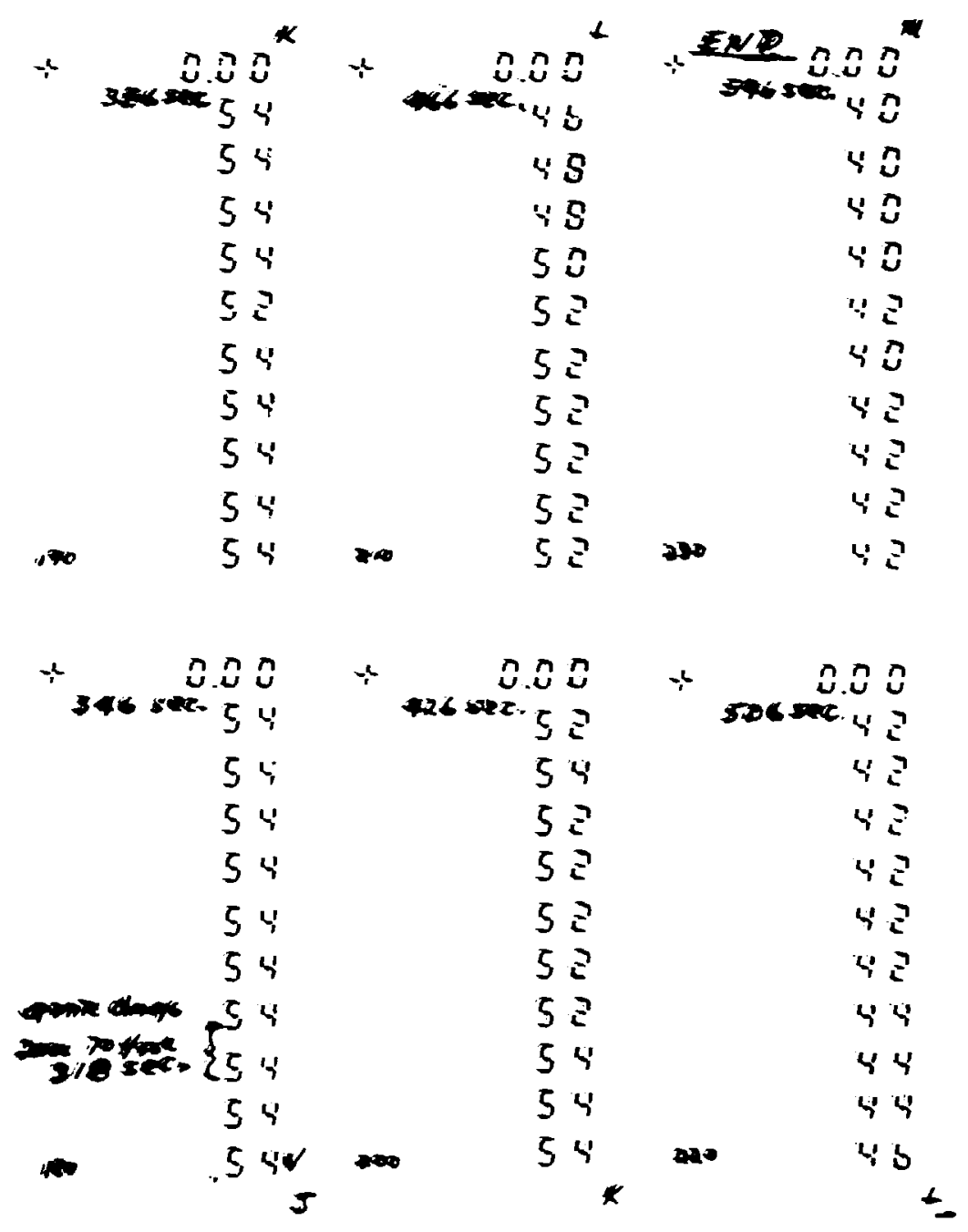

Figure 2-x 200 Dace beta 


\section{THERMAL AWD FRACTLRE MECAATICS DATA}

PERTATING TO TSE-3 AND TSE- 4

Following each thermal shock experiment, fracture mechanics calcuiarions were ande using the remperatures measuted duting the experiment and the static fractare coughness curve in Fig, 5. Tabulated radial tempetarure distributions and all of the fracture mechanics daca ate included in the enclosed sets of computer outpot for TSE-3 and TSE-4. 


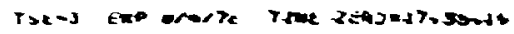

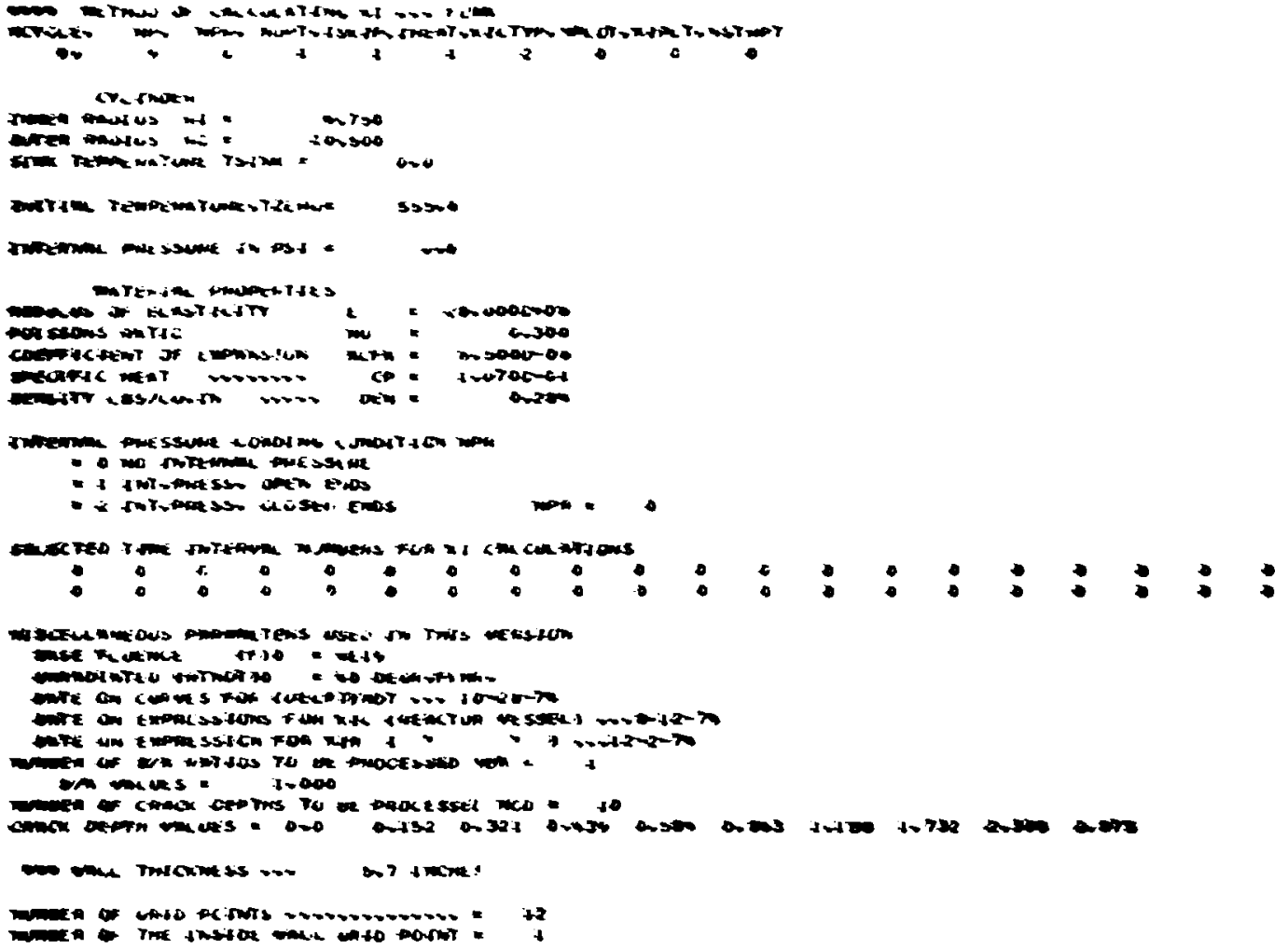

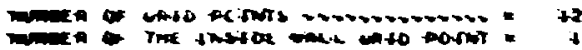

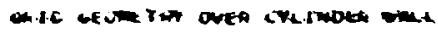

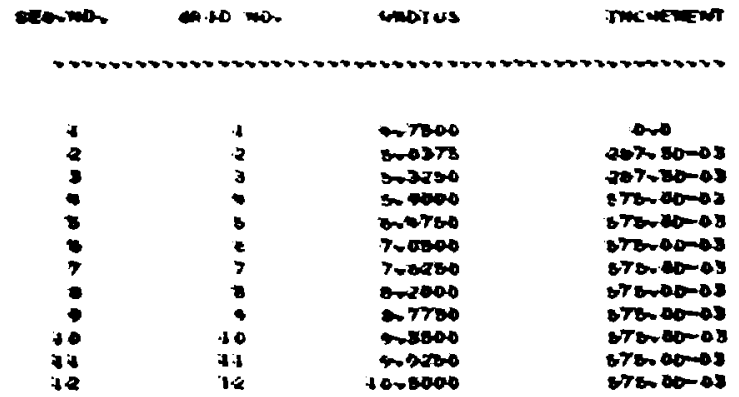

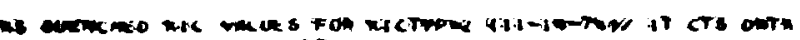

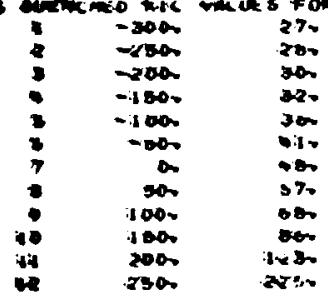




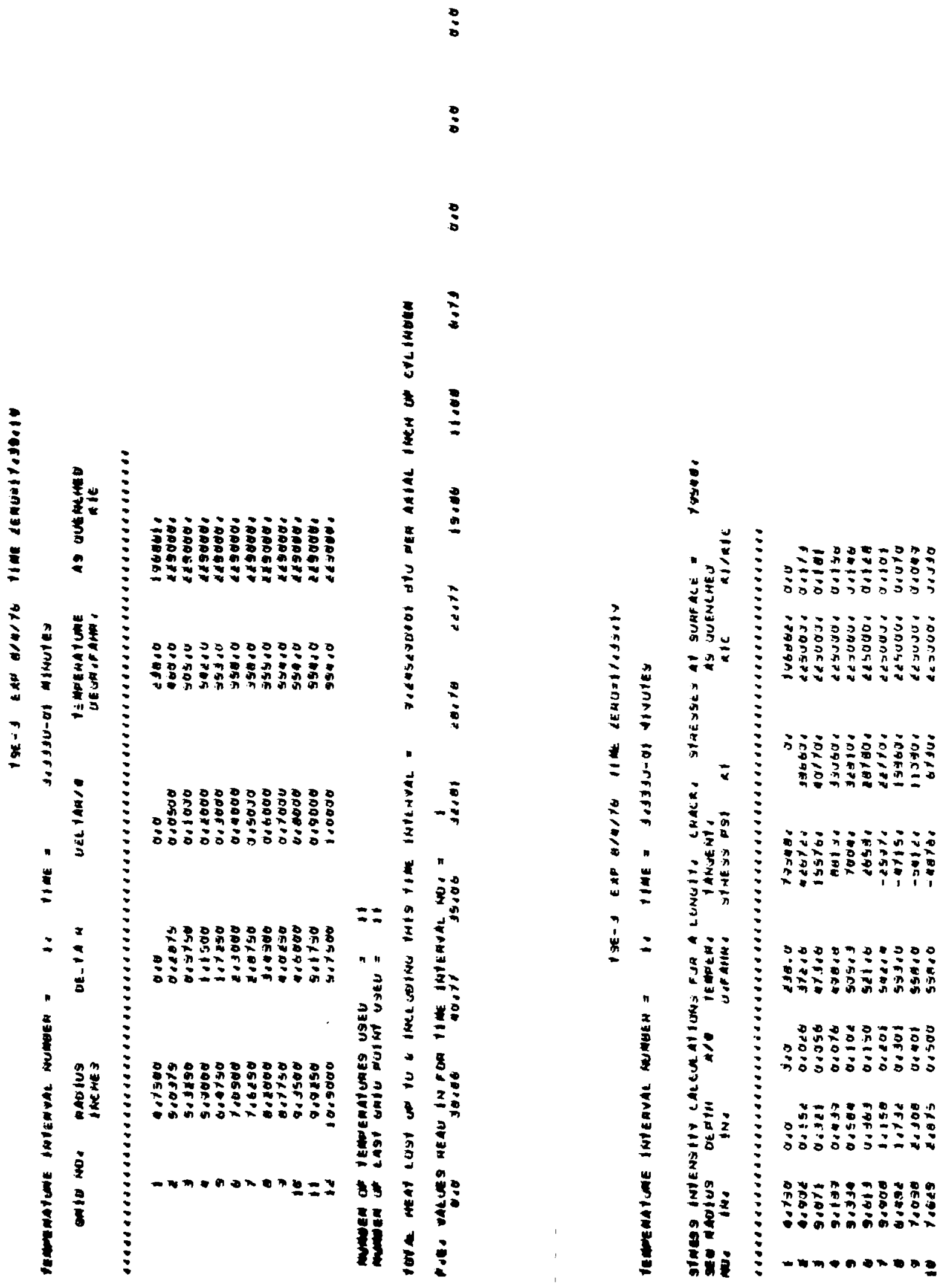



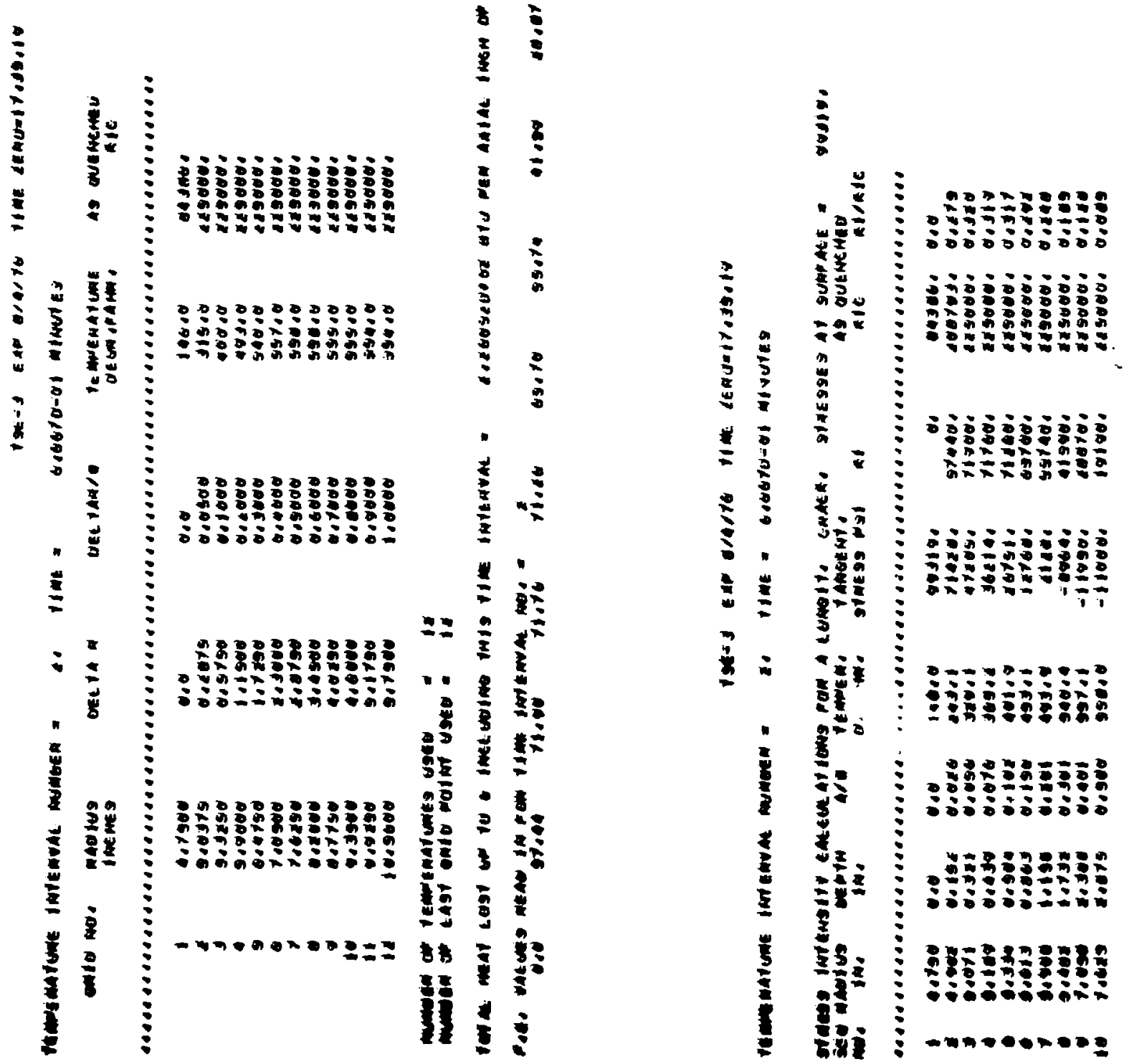

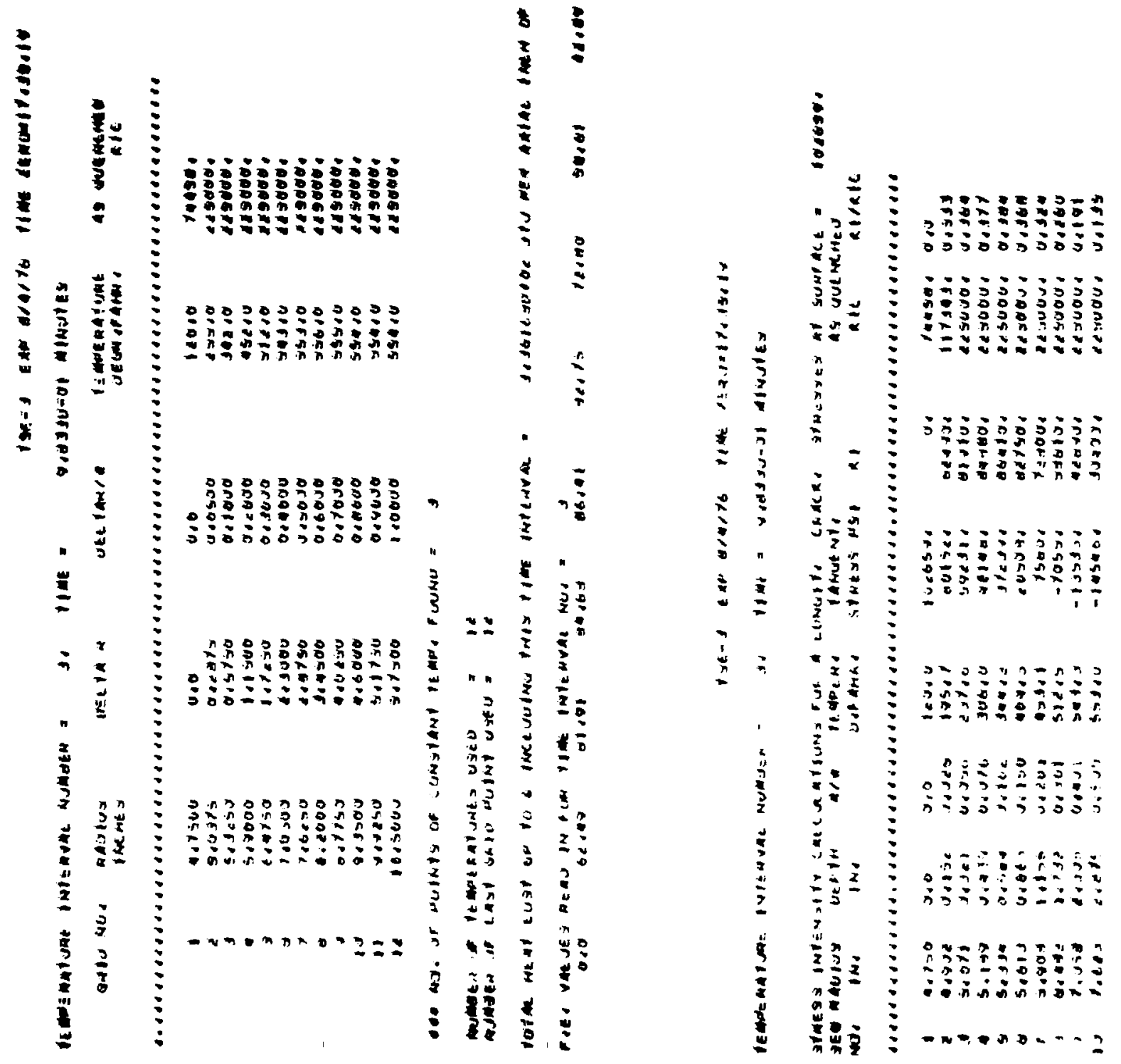


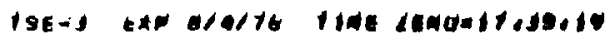

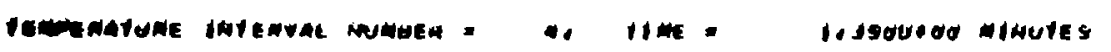

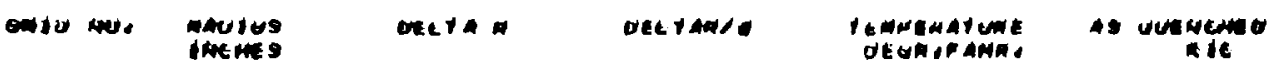

\begin{tabular}{|c|c|c|c|c|c|}
\hline $\begin{array}{c}1 \\
5 \\
5 \\
5 \\
5 \\
10\end{array}$ & 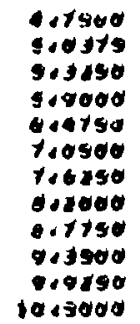 & 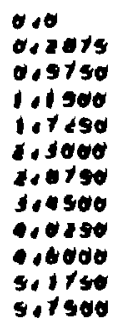 & 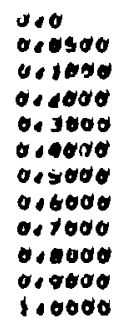 & 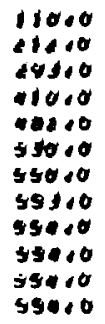 & 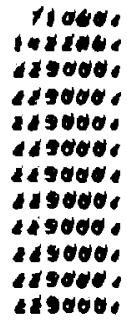 \\
\hline
\end{tabular}

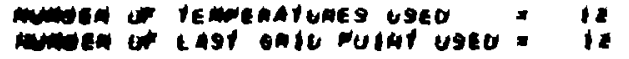

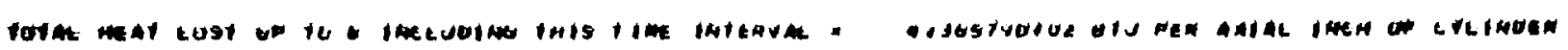

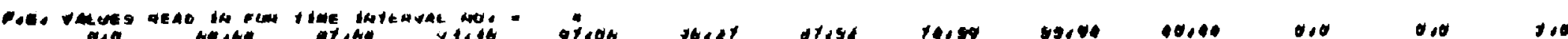

Jugrt

10.000

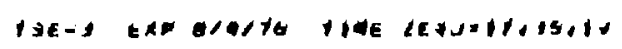

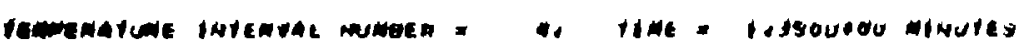

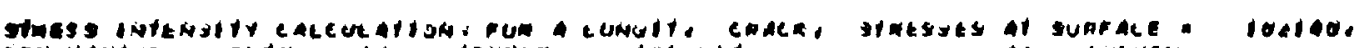

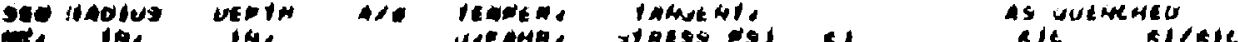

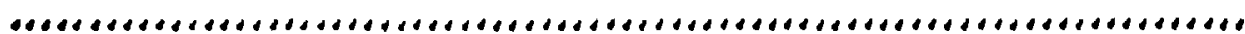

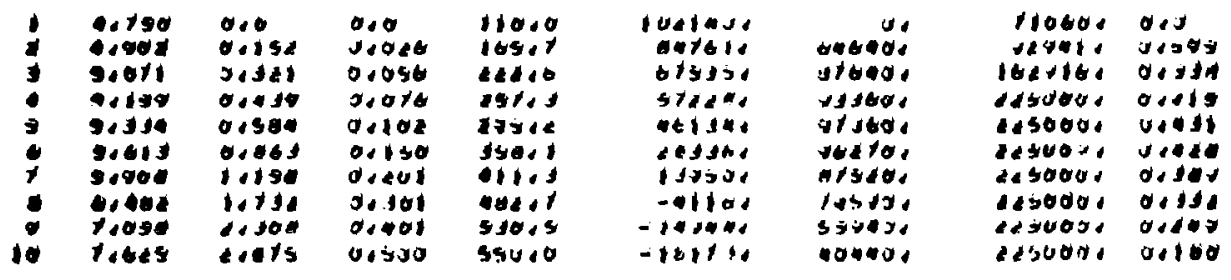



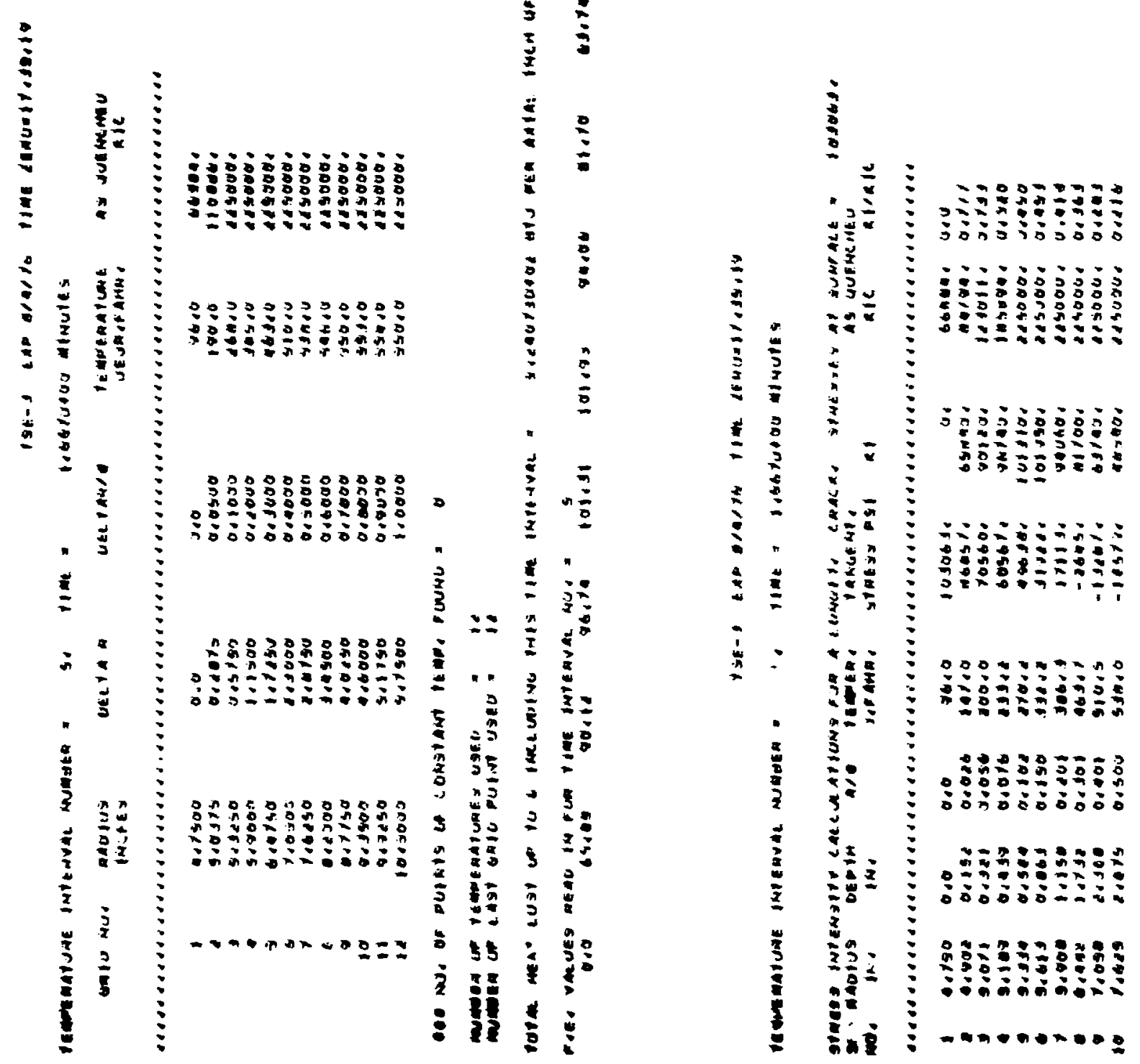
$?$
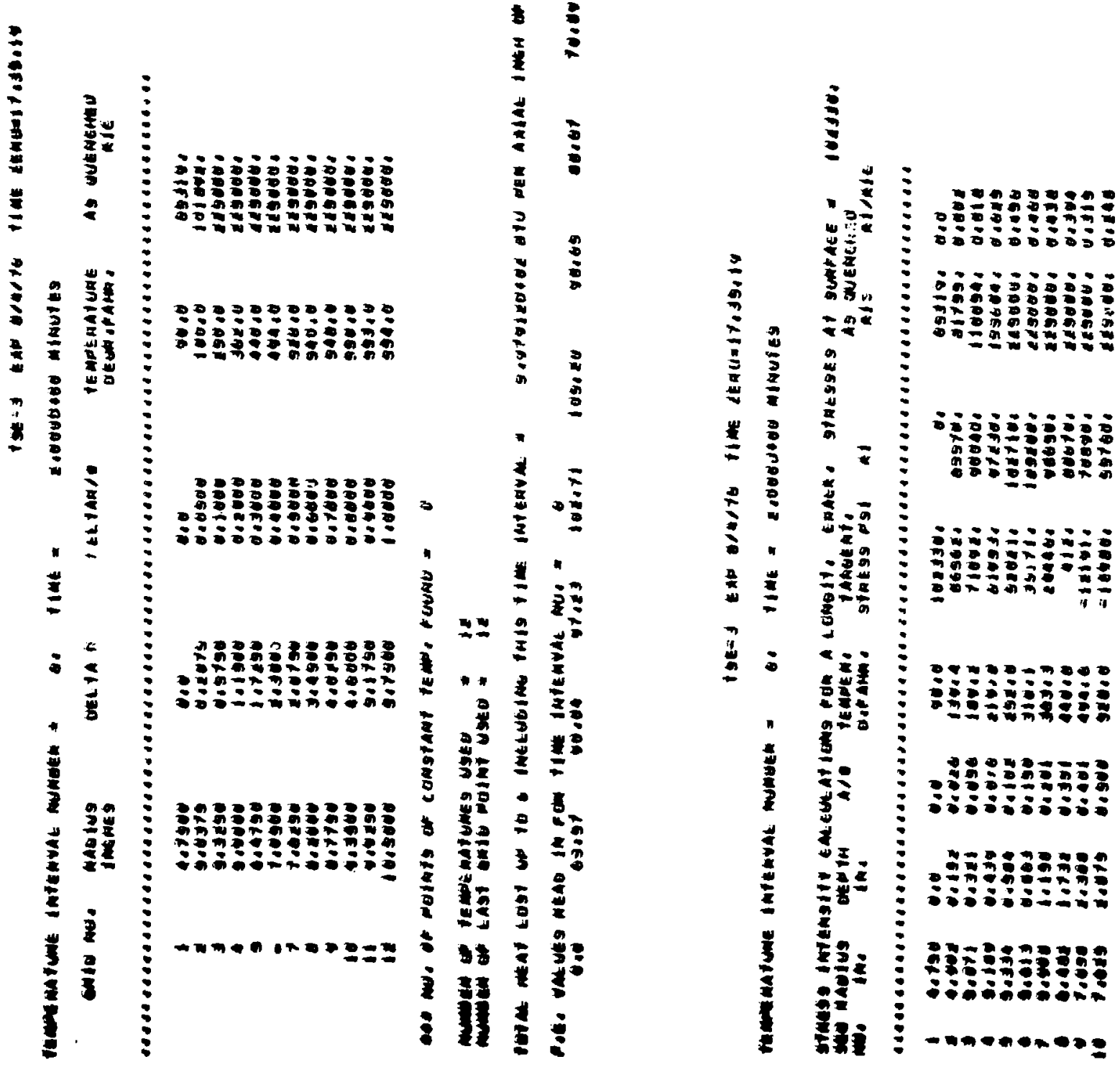
:

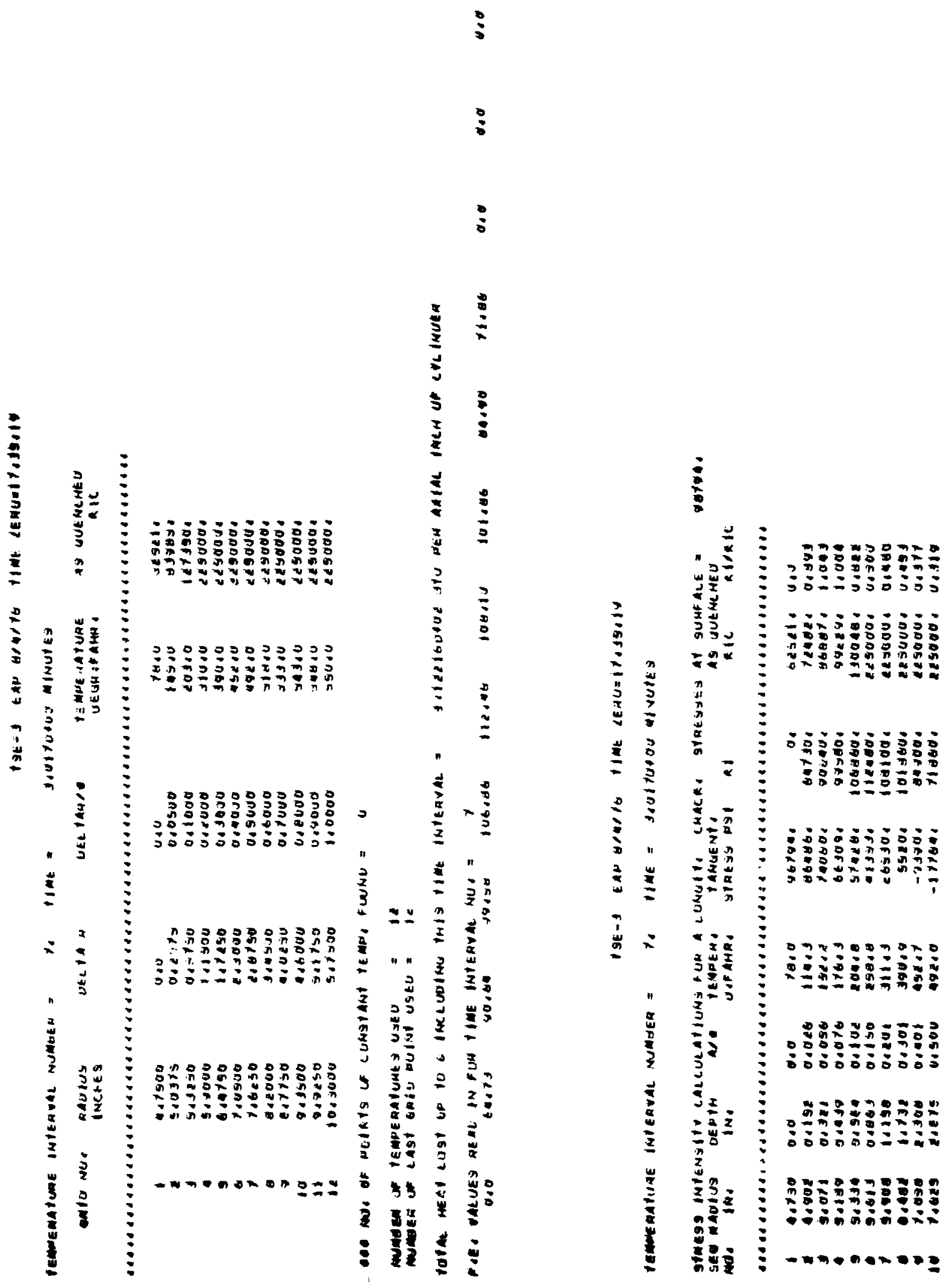




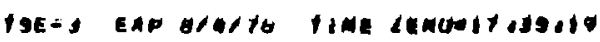

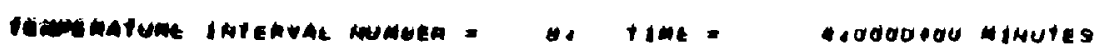

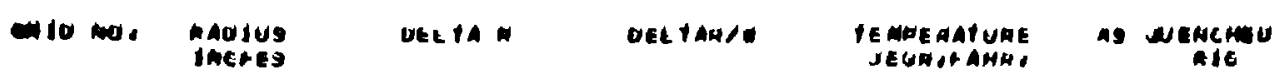

\begin{tabular}{|c|c|c|c|c|c|}
\hline $\begin{array}{l}: \\
: \\
: \\
: \\
:\end{array}$ & 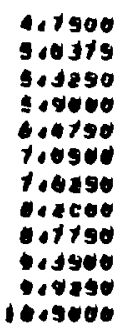 & 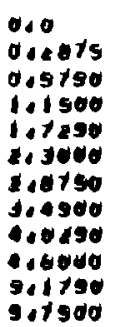 & 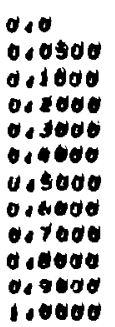 & 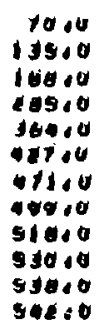 & 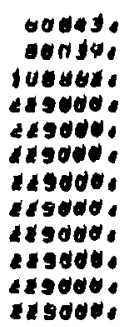 \\
\hline
\end{tabular}

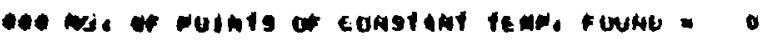

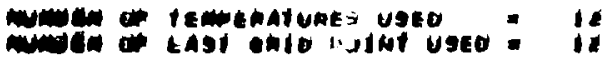

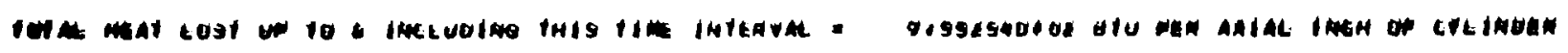

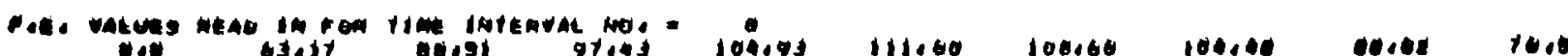

111060100060 100,0

0

0.0

10

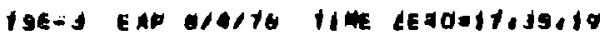

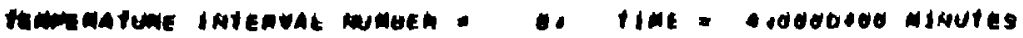

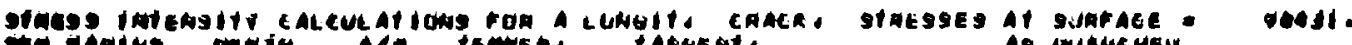

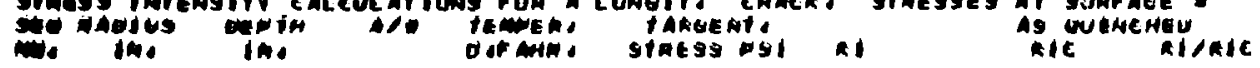

\begin{tabular}{|c|c|c|c|c|c|c|c|c|}
\hline $\begin{array}{l}1 \\
3\end{array}$ & 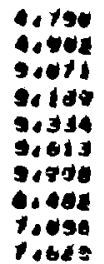 & 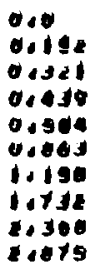 & $\begin{array}{l}0.00 \\
0.080 \\
0.096 \\
00016 \\
0.108 \\
0.190 \\
0.801 \\
0.301 \\
0.001 \\
0.900\end{array}$ & 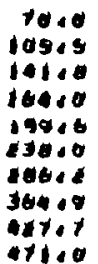 & 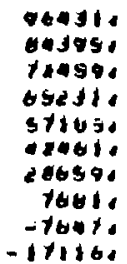 & 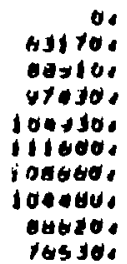 & 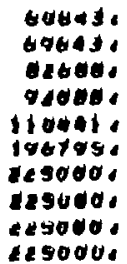 & 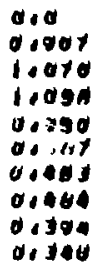 \\
\hline
\end{tabular}



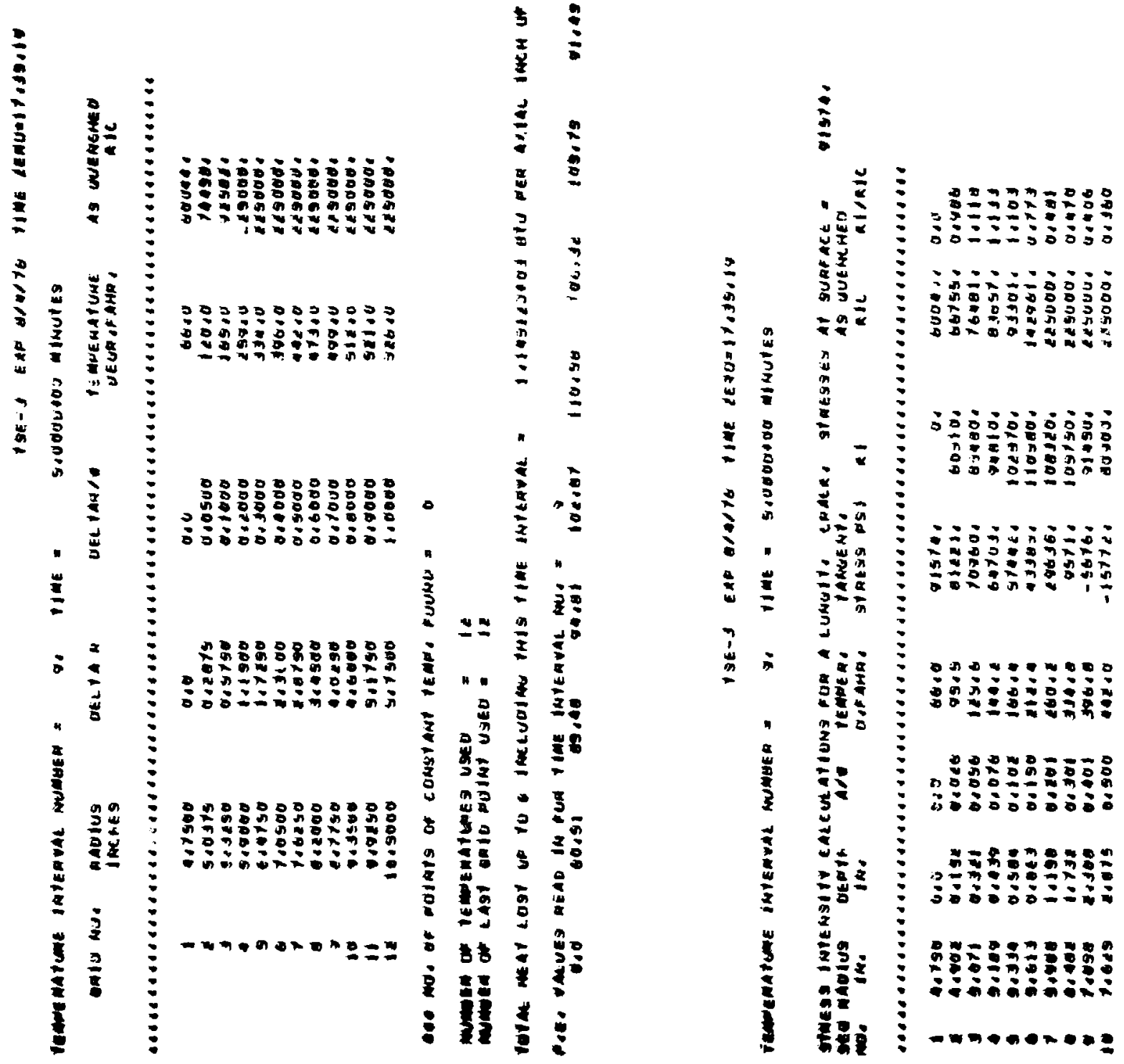

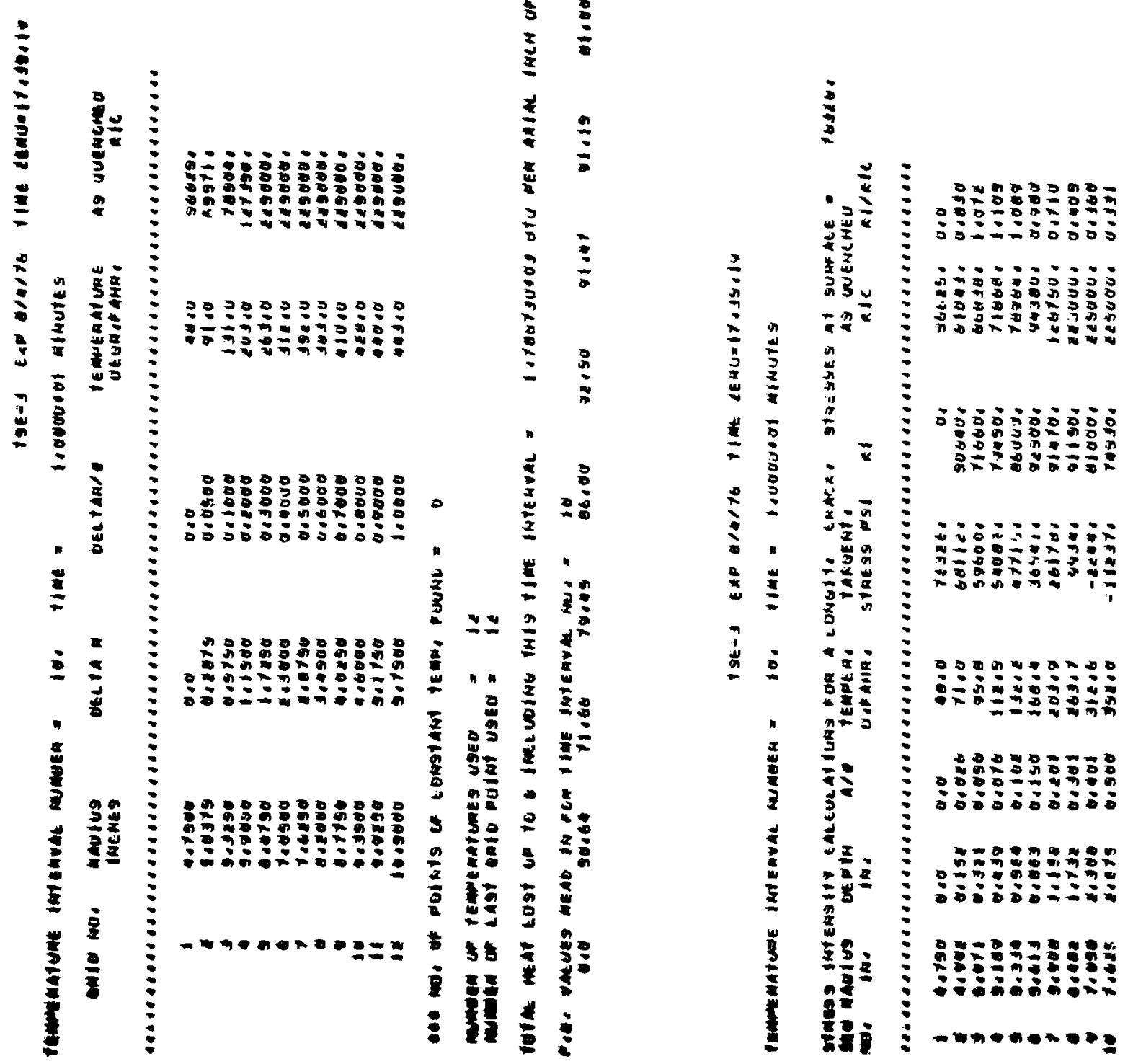


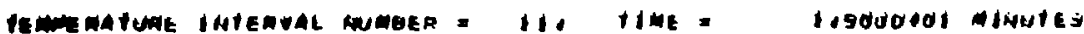

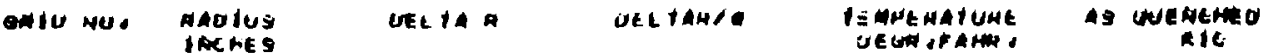

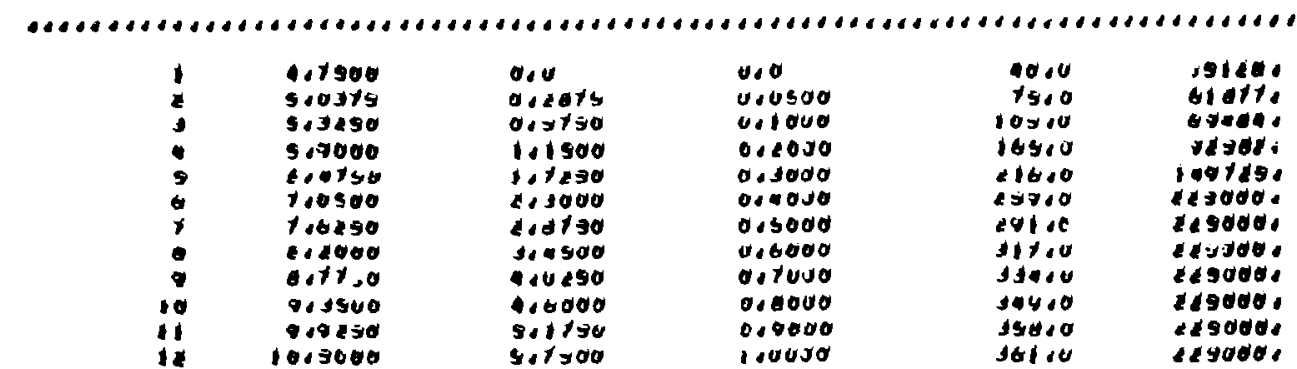

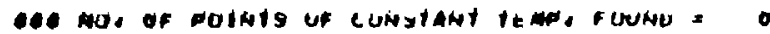

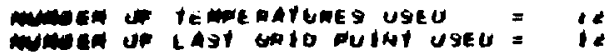

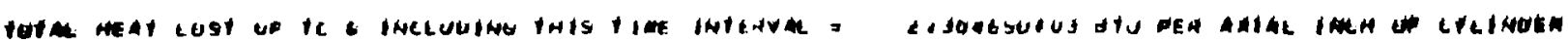

16,34

15,45

19000

49.08

9011

0

00

0,0

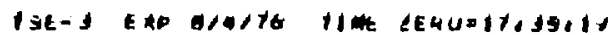

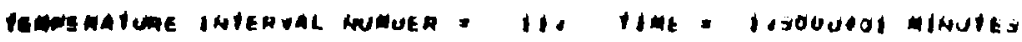

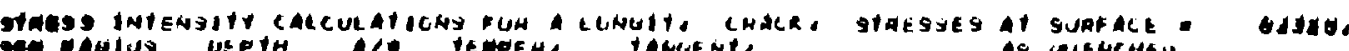

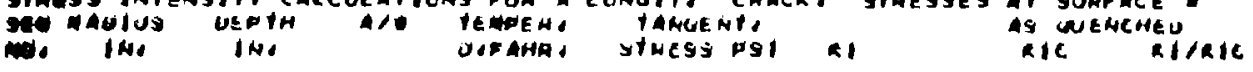

\begin{tabular}{|c|c|c|c|c|c|c|c|c|}
\hline $\begin{array}{l}1 \\
5 \\
5 \\
1\end{array}$ & 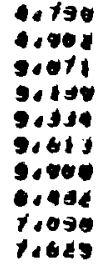 & 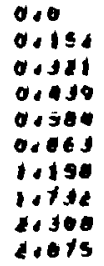 & 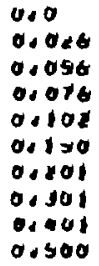 & 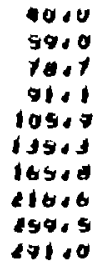 & 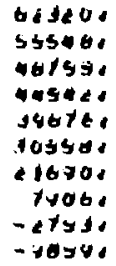 & 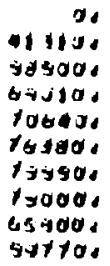 & 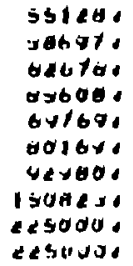 & 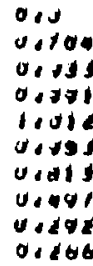 \\
\hline
\end{tabular}

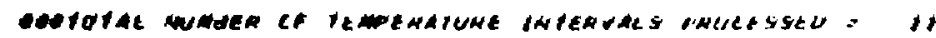




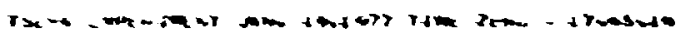

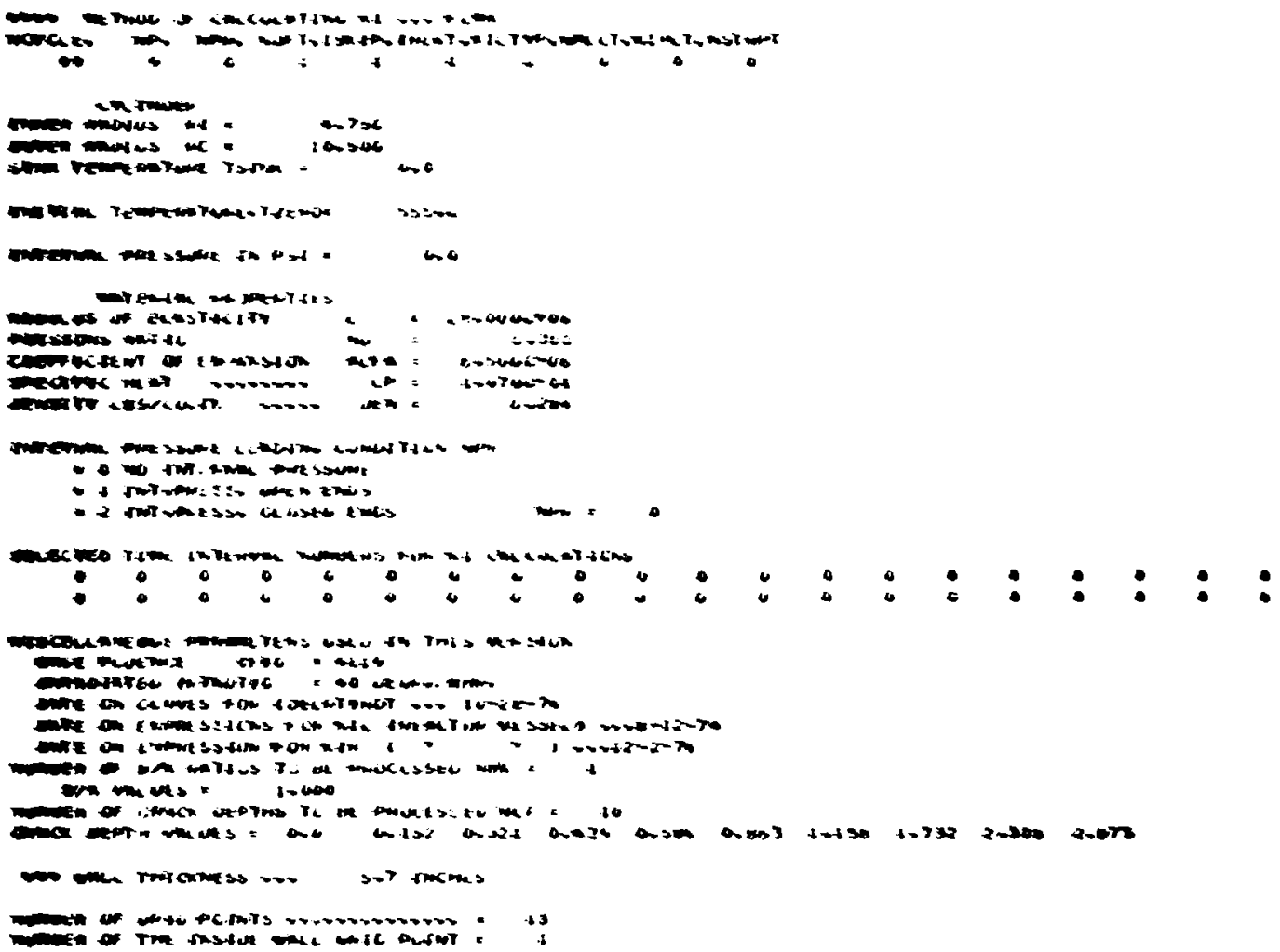

\begin{tabular}{|c|c|c|c|}
\hline 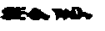 & $\omega+6 \mathrm{mos}$ & malus & 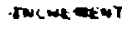 \\
\hline$\star$ & + & $\sim r$ soo & $\infty 0$ \\
\hline$e$ & $\alpha$ & 20,3370 & $\|+7_{\infty}=0,4$, \\
\hline 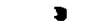 & $=$ & 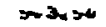 & $\{x=m 03$ \\
\hline 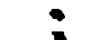 & 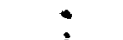 & motes & 207,30063 \\
\hline 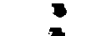 & $:$ & 207000 & $207 \times 30-63$ \\
\hline 7 & 7 & 700 suo & $\$ 7$ inacos \\
\hline$\because$ & $\therefore$ & 700000 & $\begin{array}{l}575-60-08 \\
375-0003\end{array}$ \\
\hline 40 & $\because n$ & orrse & 3rdoons \\
\hline 12 & in & - Wrso & s7g-aond; \\
\hline 4 & +3 & +000000 & arso- co-os \\
\hline
\end{tabular}

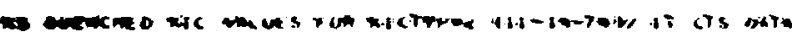

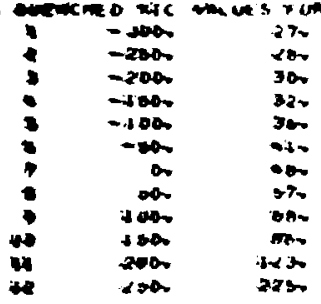



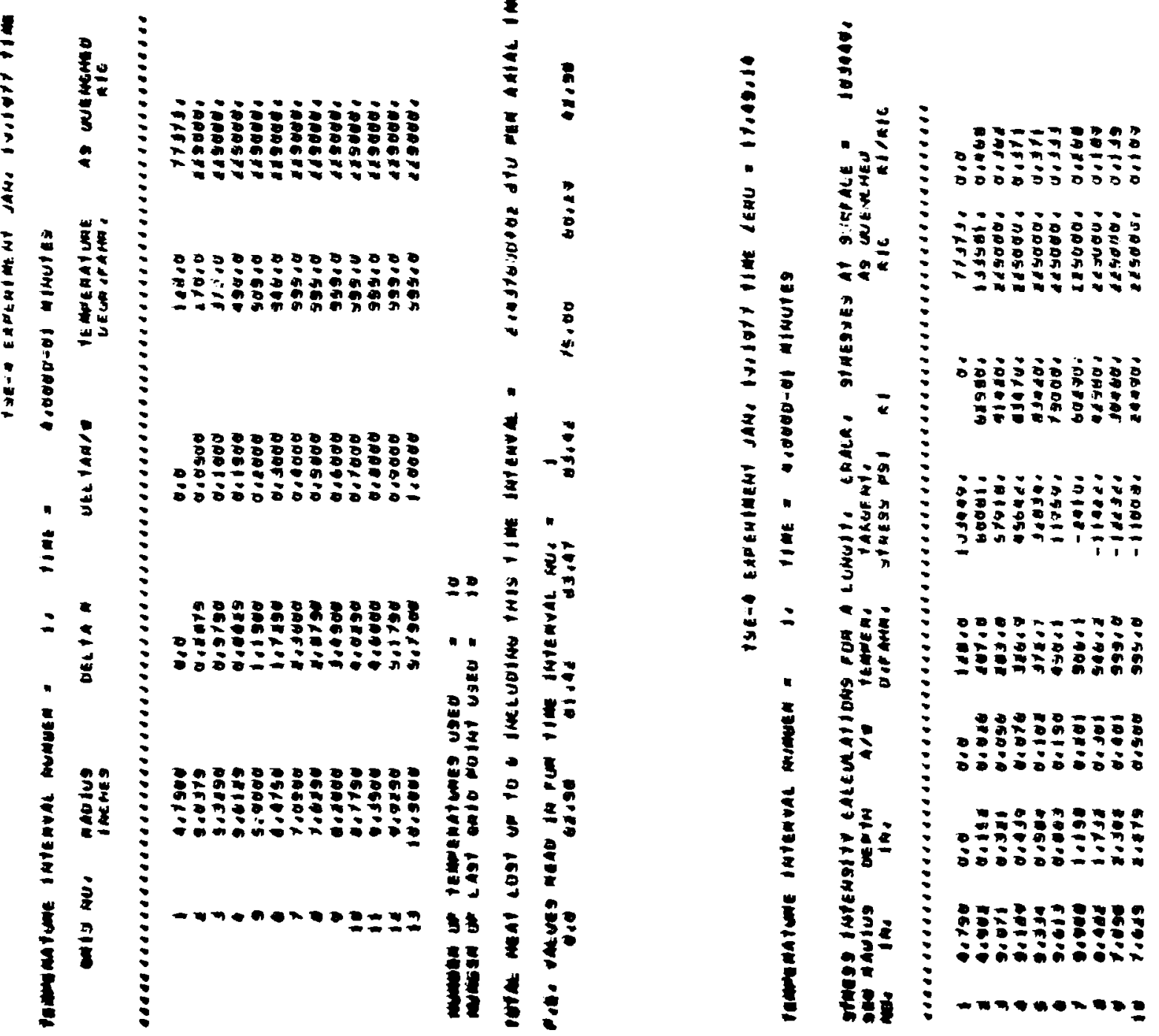

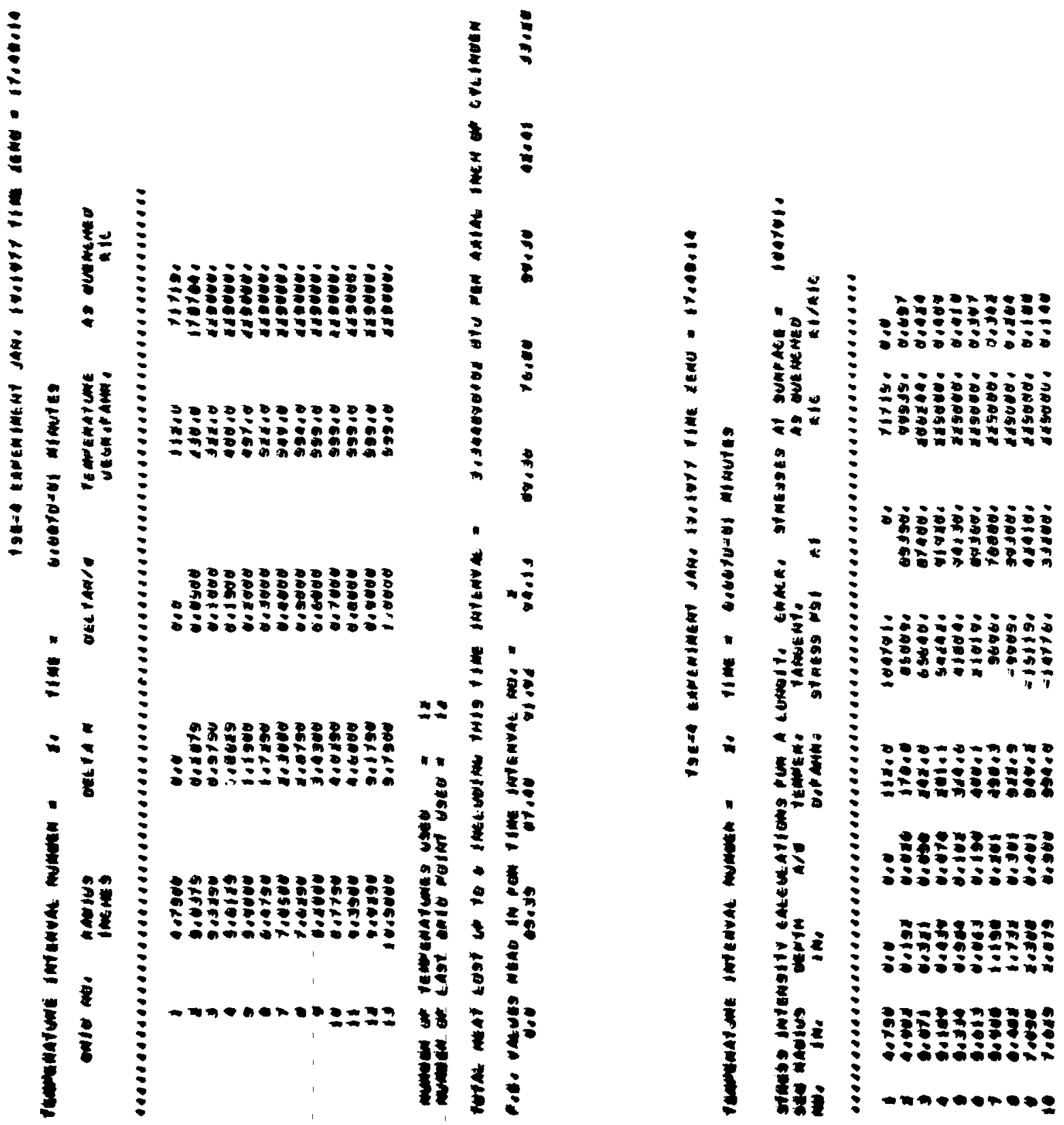

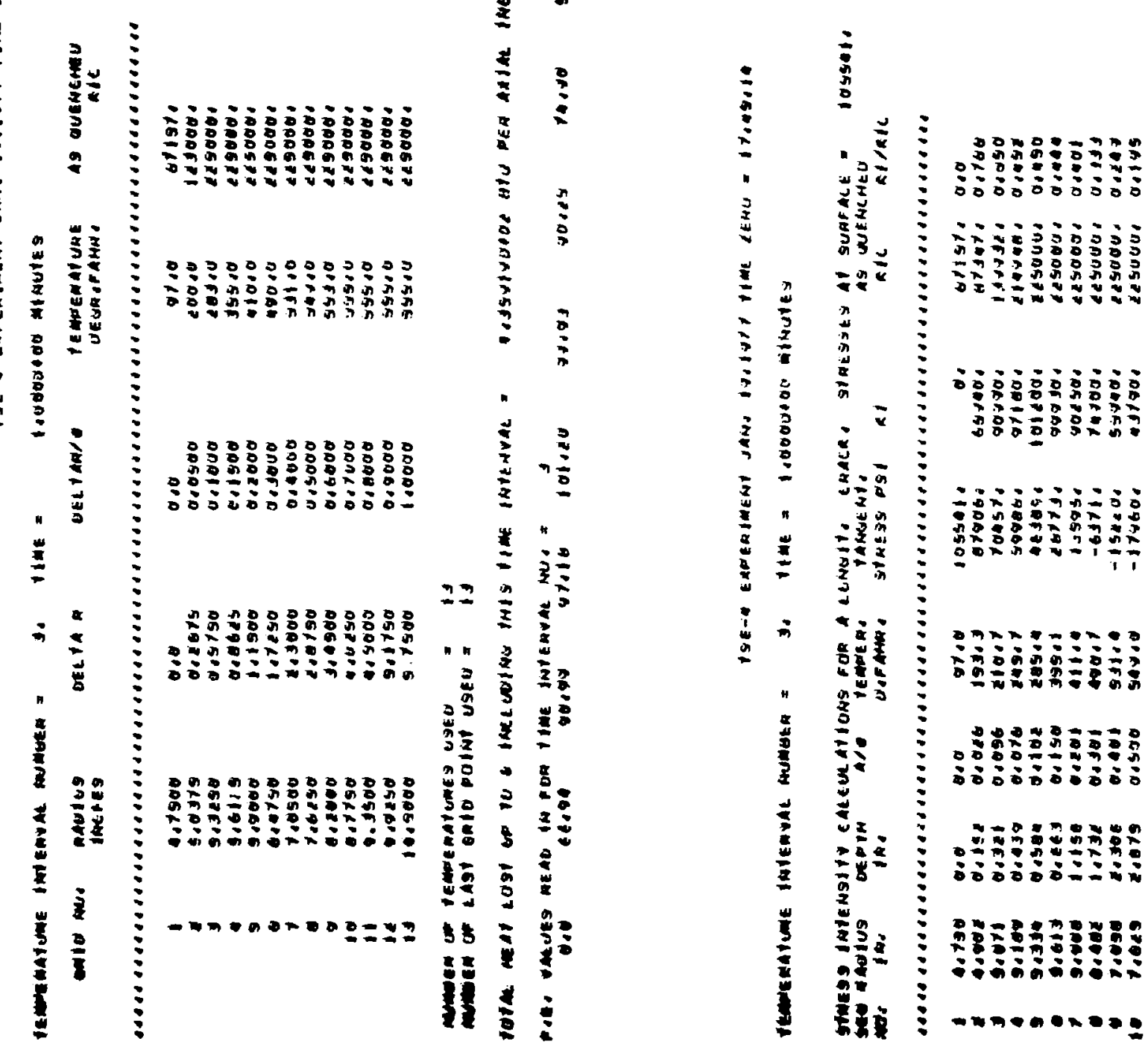


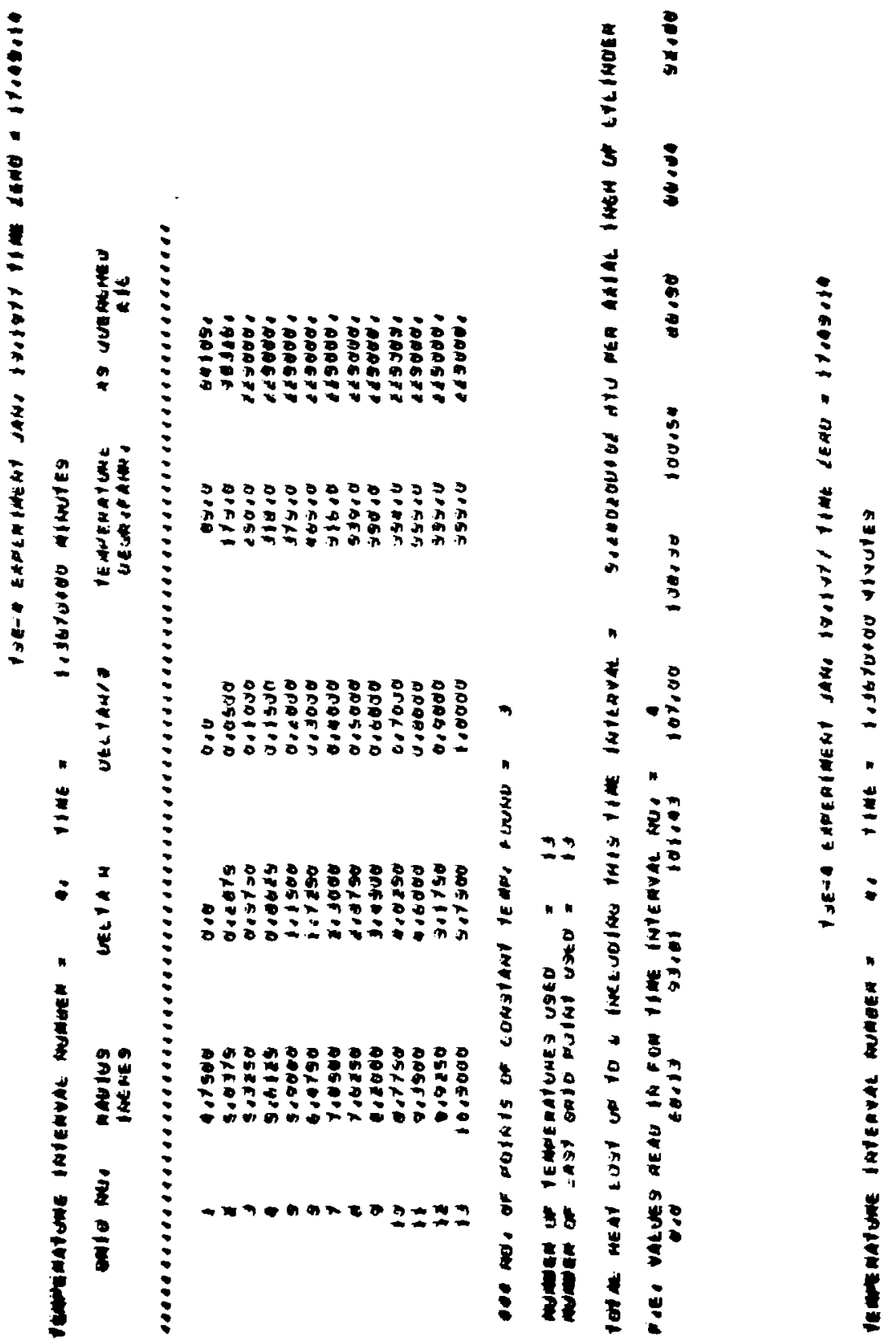

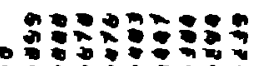

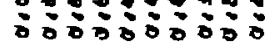

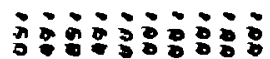

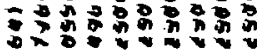

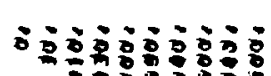

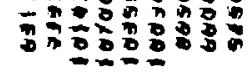

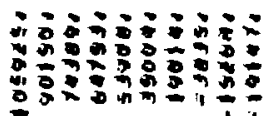

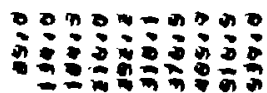

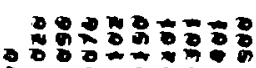

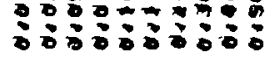

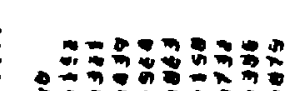

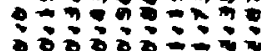

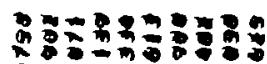

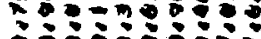
-monomovo 


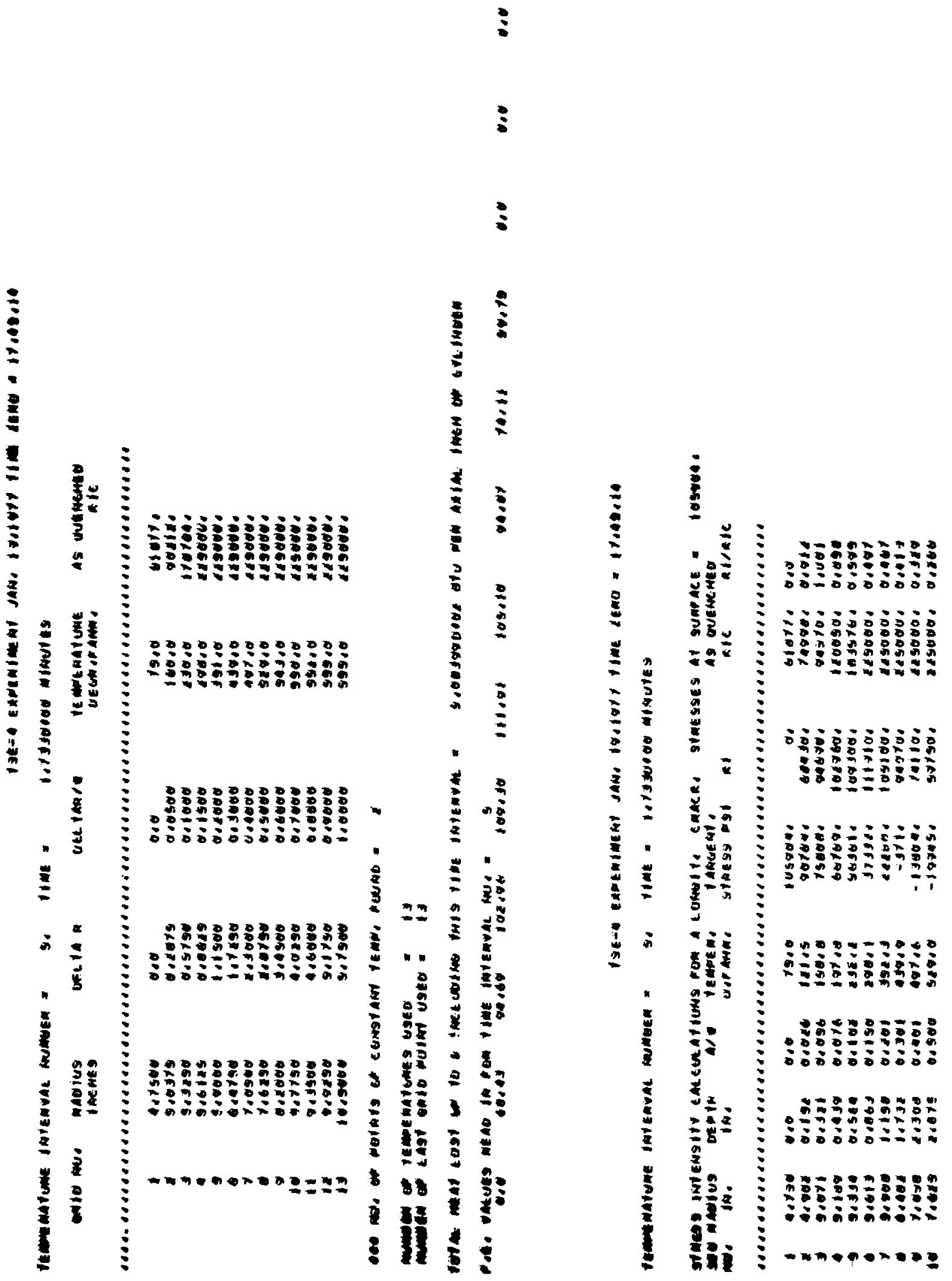




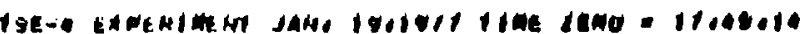

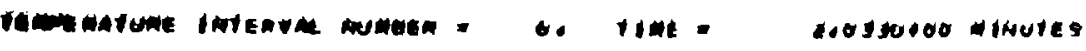

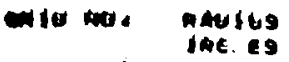
orita.
OEL INATE
TEMEEMATUAE
JEOA IPAHAS
ns winetwo
ilo

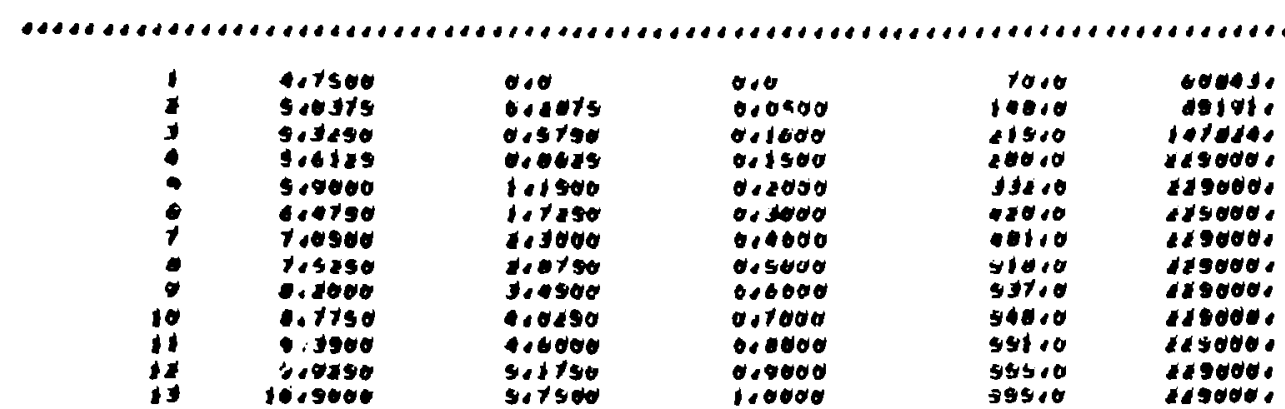

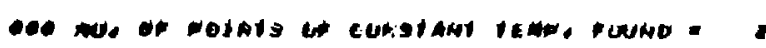

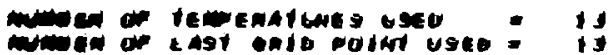

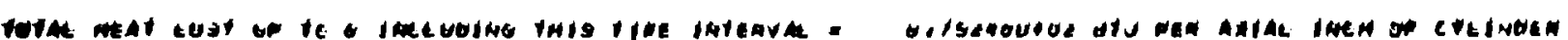

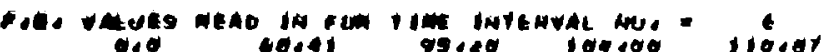

Gio

0014

110.06 10ndos

ovits

$00+14$

4,0

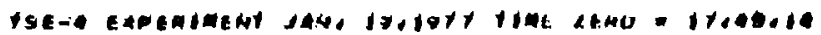

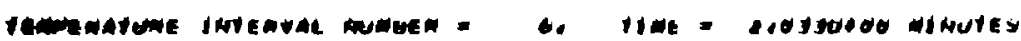

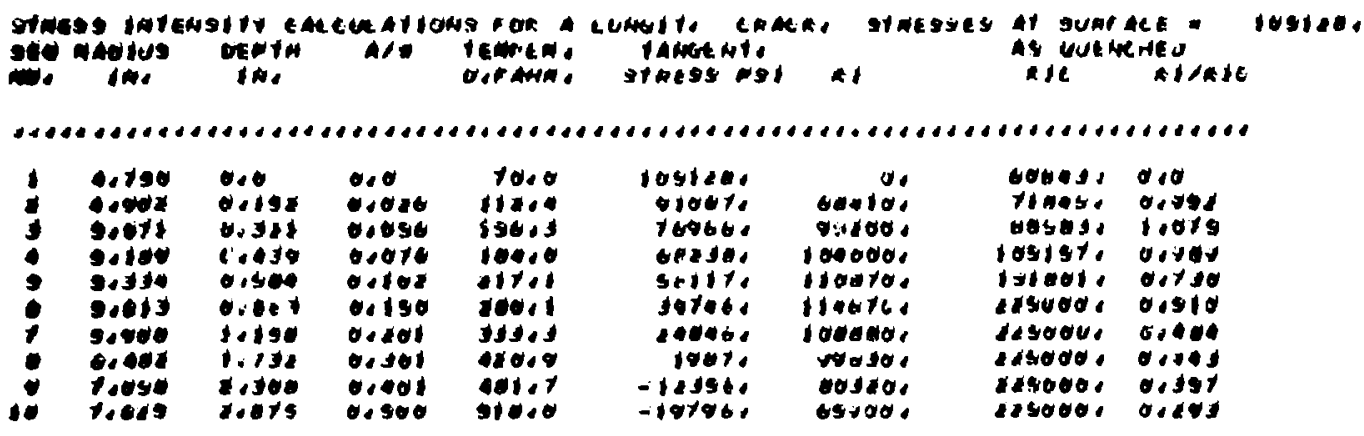




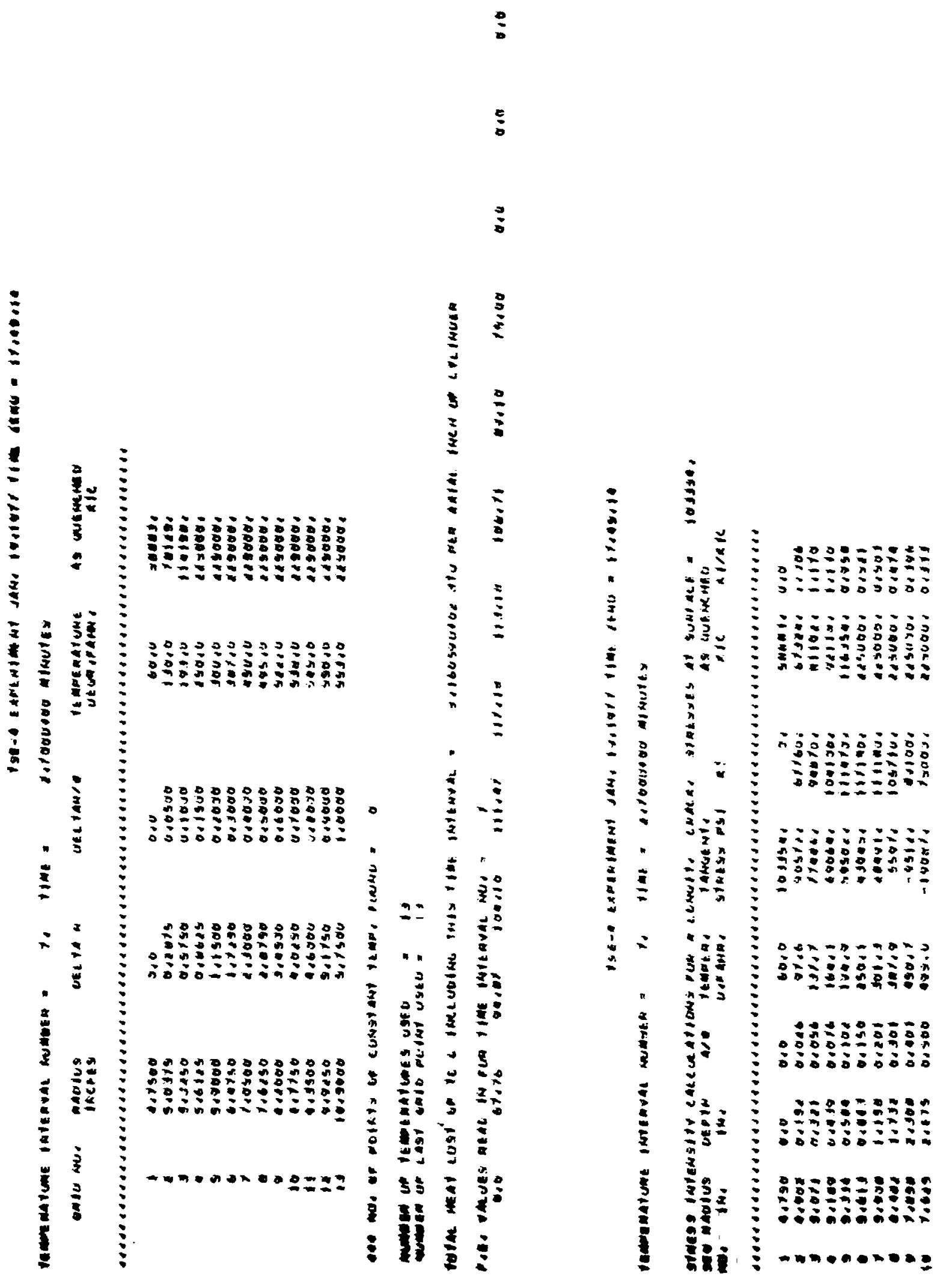




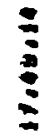

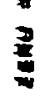$$
\frac{1}{3}
$$$$
=
$$

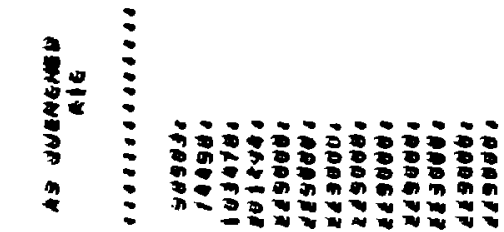

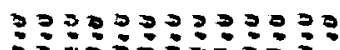

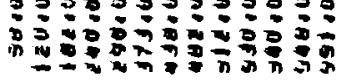

3

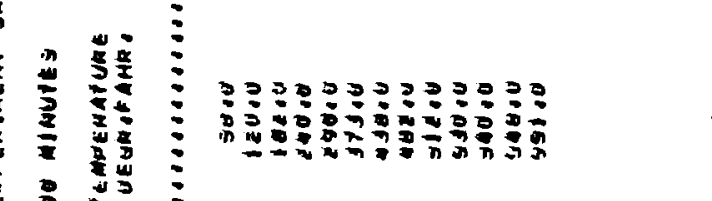

$\rightarrow$

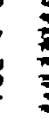

.

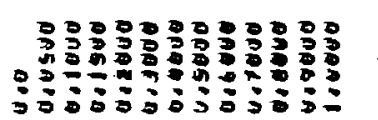

,
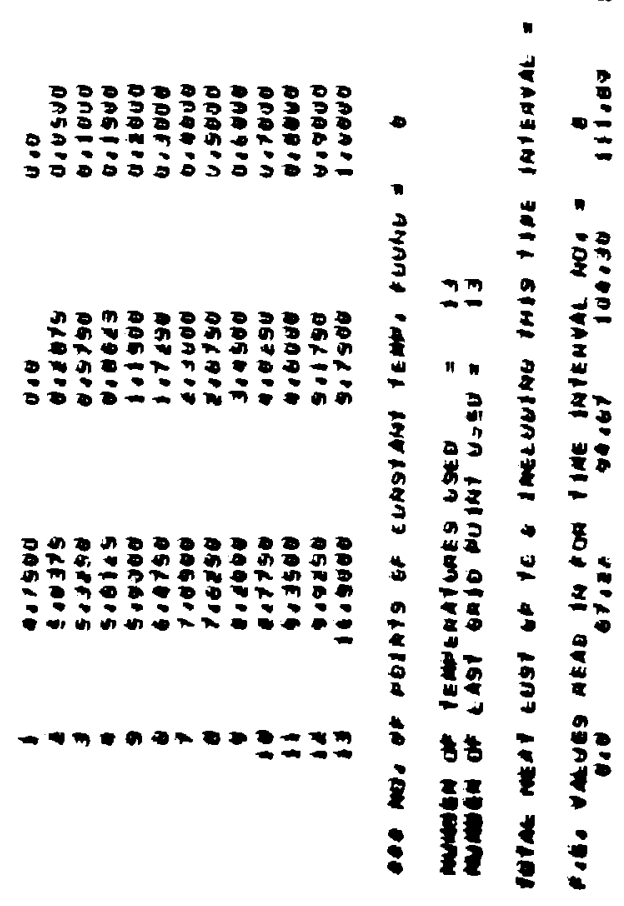

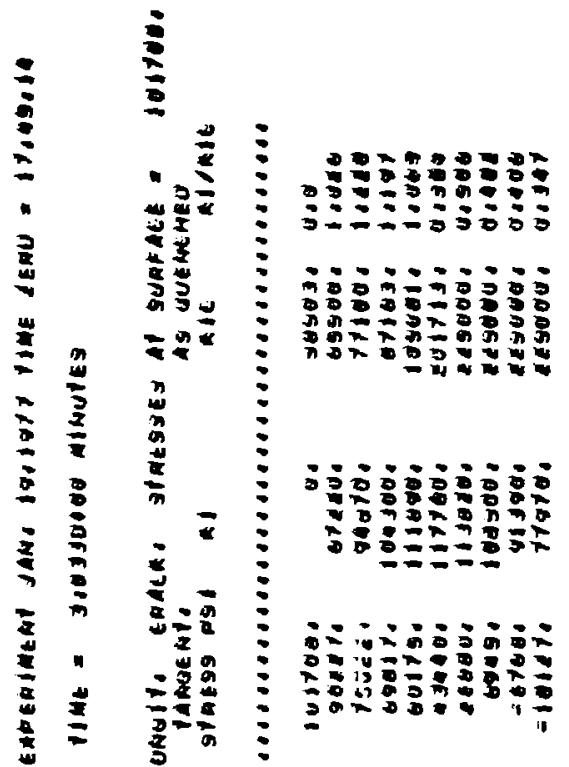

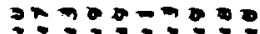

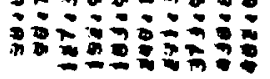

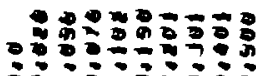

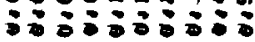

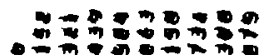

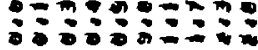




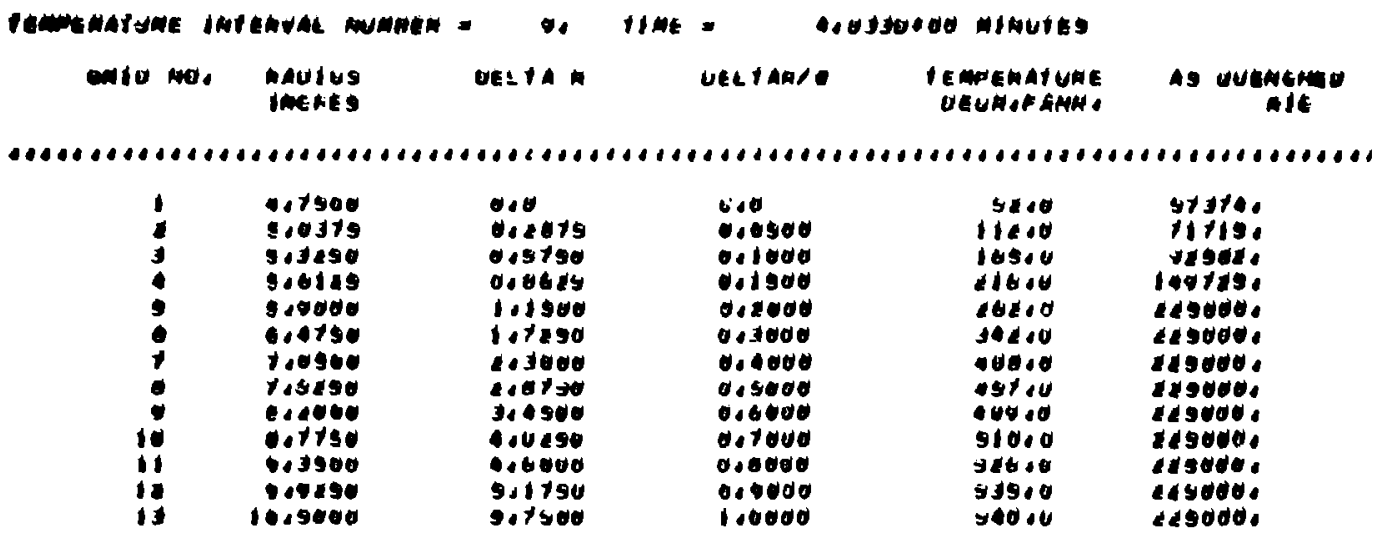

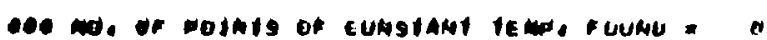

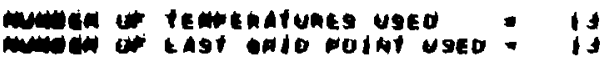

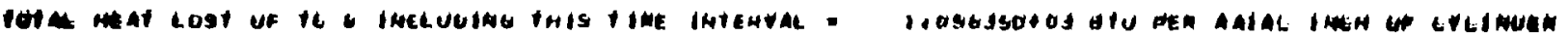

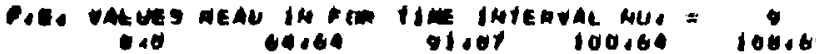

9049014

0.0

010

0,0

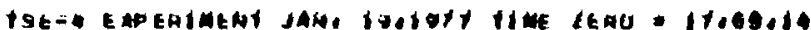

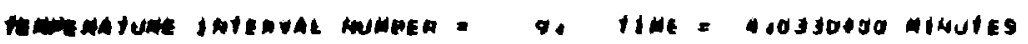

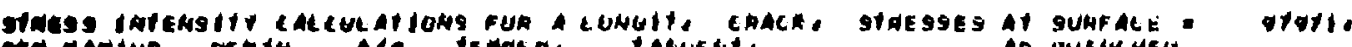

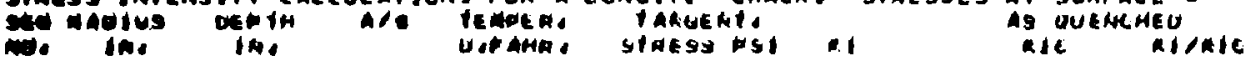

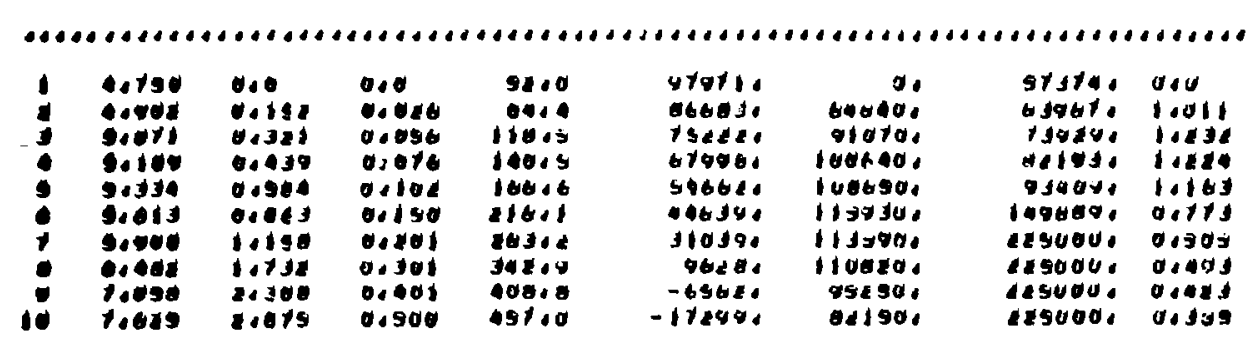




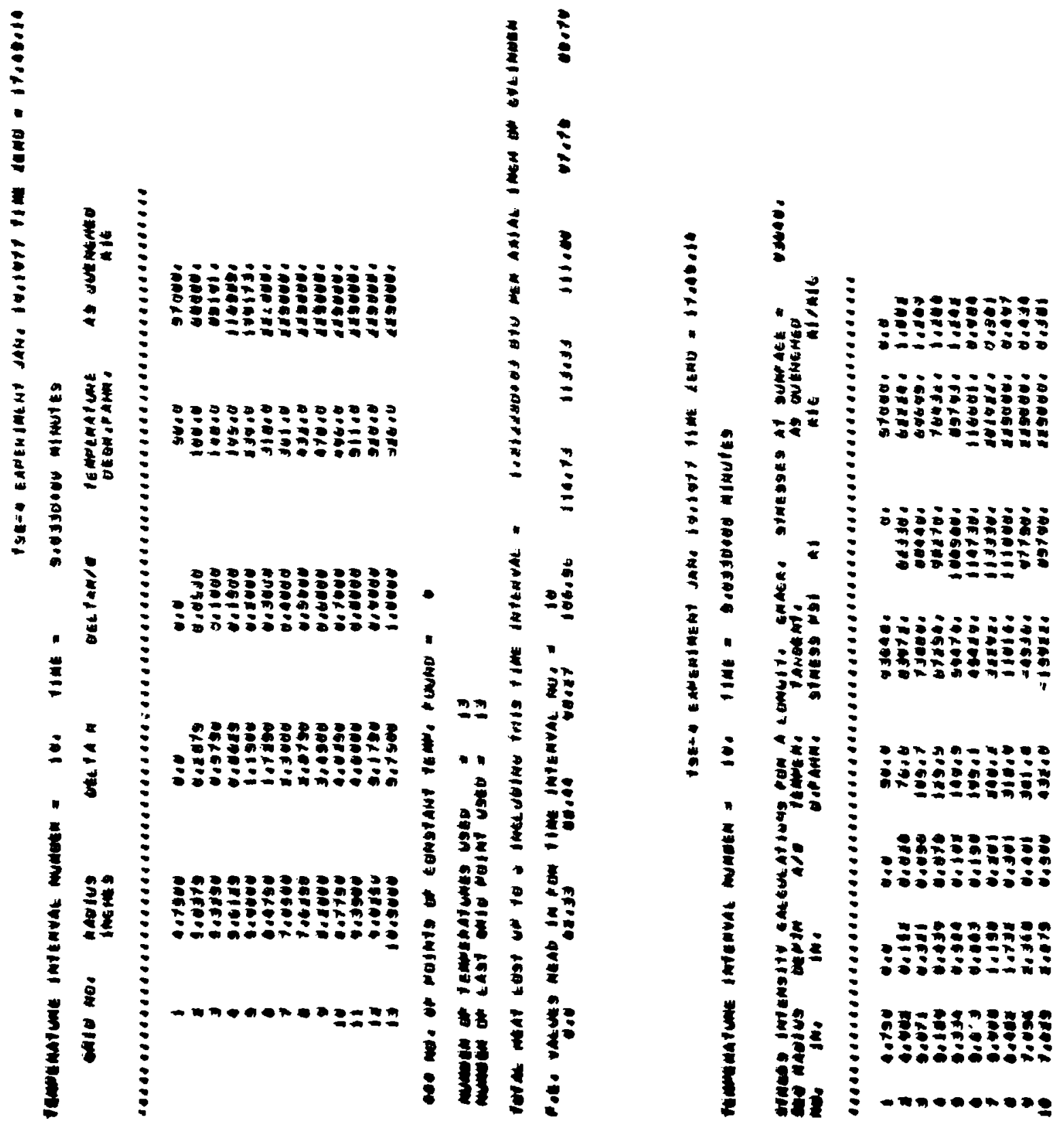



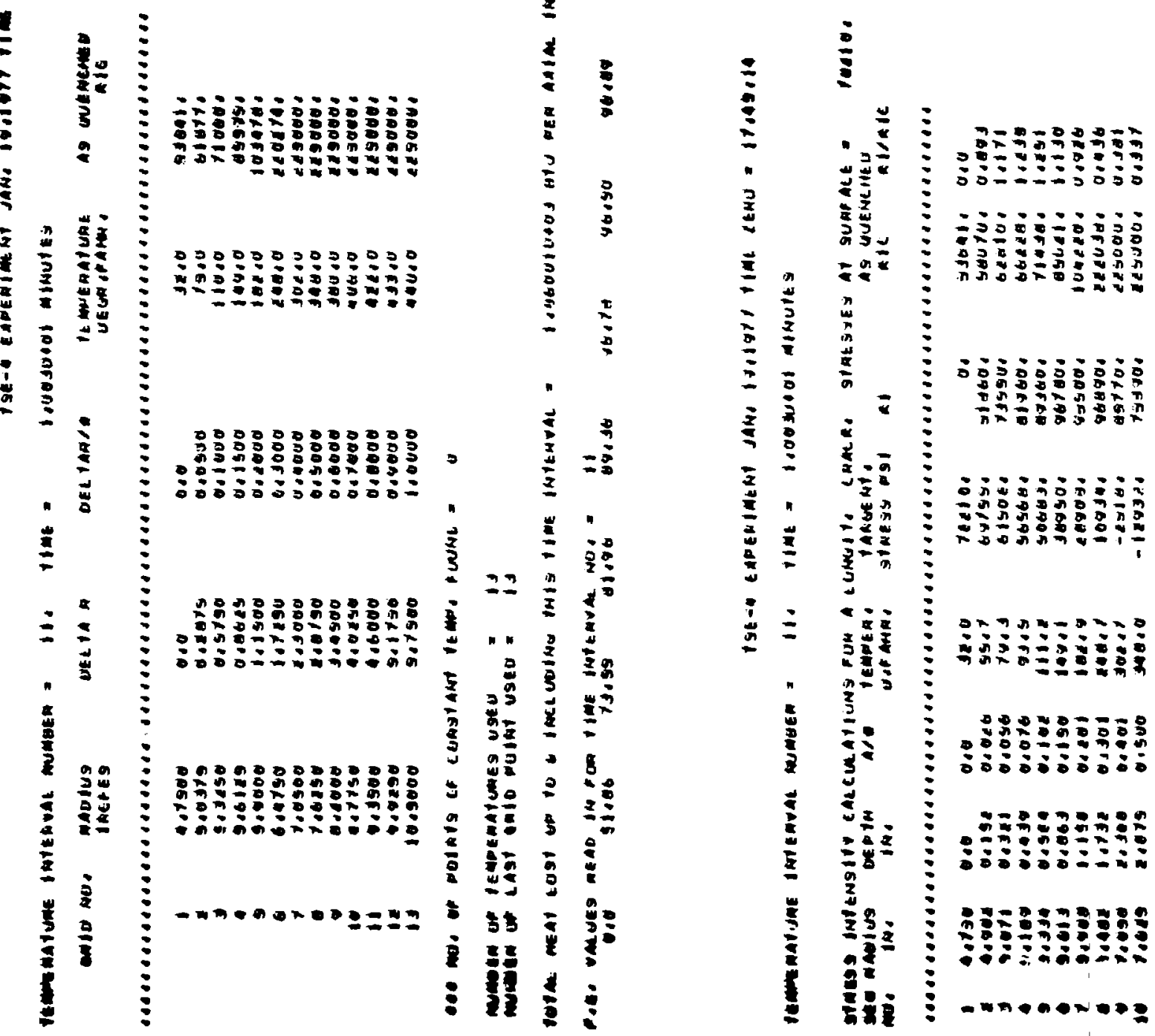


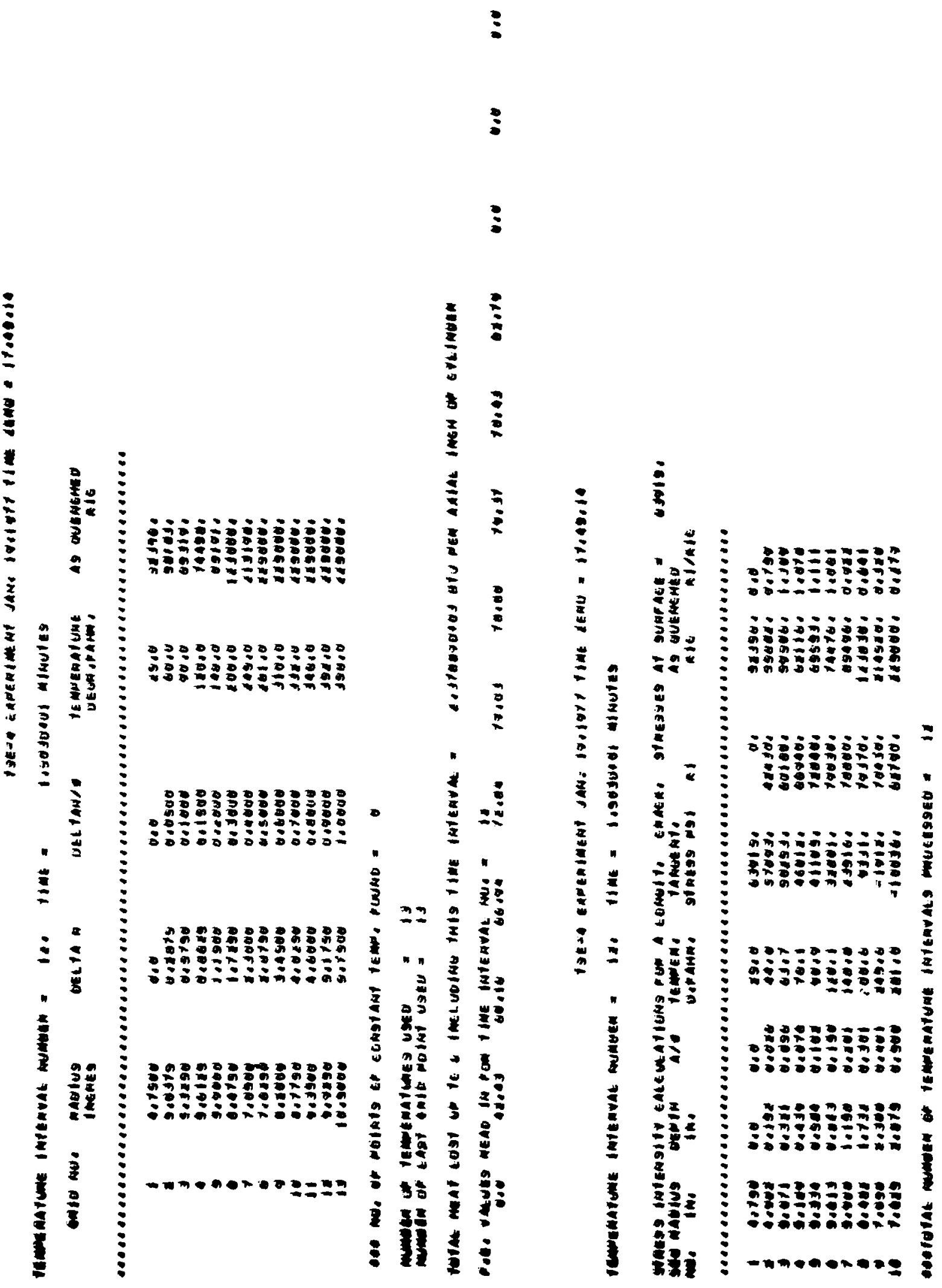


530

$550=2 x=2 x+2$
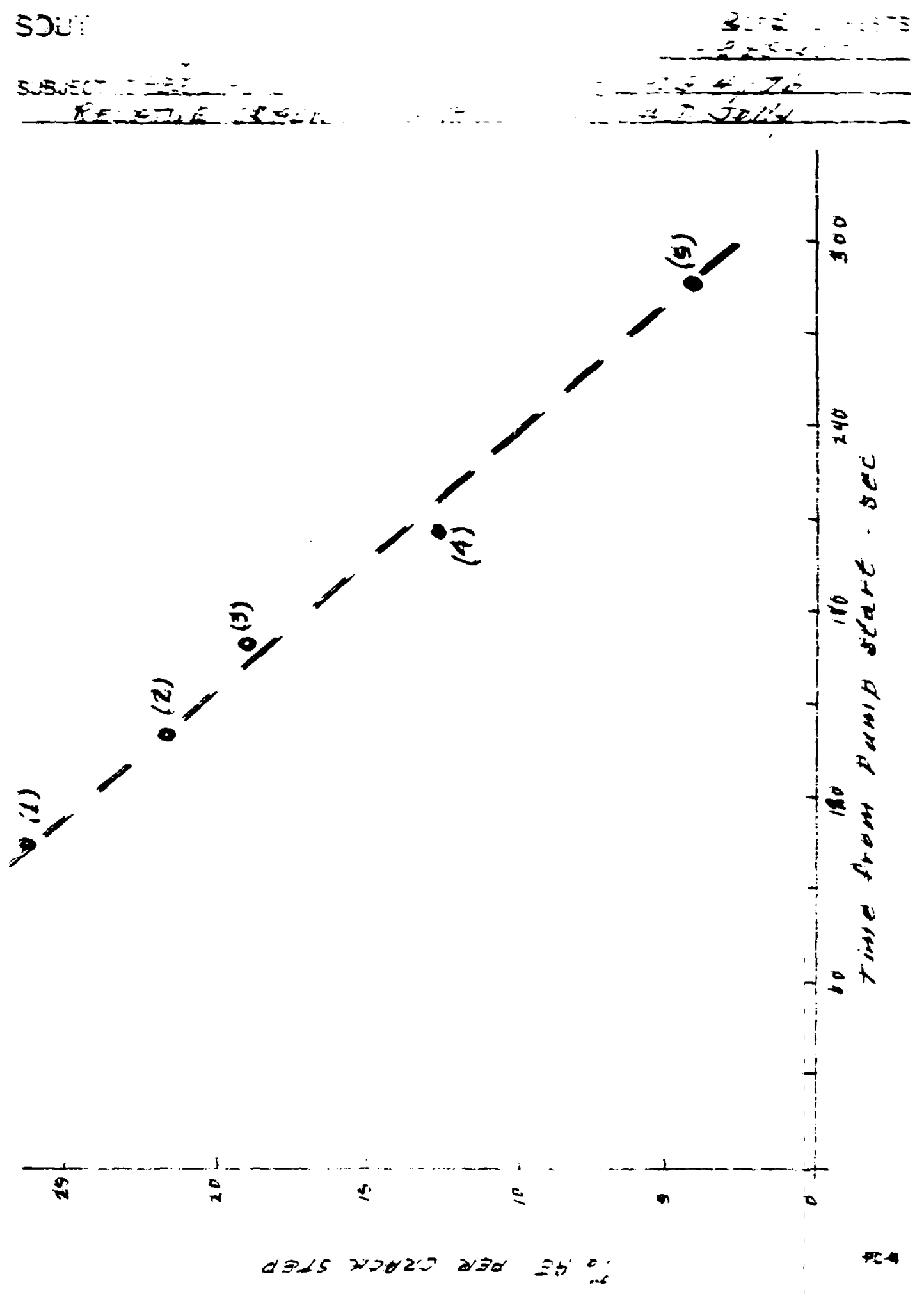